\title{
The Significance of Nuna (the Land) and Urban Place-making for Inuit living in Ottawa, Ontario, Canada
}

By

\begin{abstract}
Anita Kushwaha
A thesis submitted to the Faculty of Graduate Studies and Postdoctoral Affairs in partial fulfilment of the requirements for the degree of
\end{abstract}

Doctor of Philosophy

in

Geography

Carleton University

Ottawa, Ontario

(C) 2013

Anita Kushwaha 
Library and Archives

Canada

Published Heritage

Branch

395 Wellington Street

Ottawa ON K1A ON4

Canada
Bibliothèque et

Archives Canada

Direction du

Patrimoine de l'édition

395 , rue Wellington

Ottawa ON K1A ON4

Canada
Your file Votre référence

ISBN: 978-0-494-94560-5

Our file Notre référence

ISBN: 978-0-494-94560-5
NOTICE:

The author has granted a nonexclusive license allowing Library and Archives Canada to reproduce, publish, archive, preserve, conserve, communicate to the public by telecommunication or on the Internet, loan, distrbute and sell theses worldwide, for commercial or noncommercial purposes, in microform, paper, electronic and/or any other formats.

The author retains copyright ownership and moral rights in this thesis. Neither the thesis nor substantial extracts from it may be printed or otherwise reproduced without the author's permission.
AVIS:

L'auteur a accordé une licence non exclusive permettant à la Bibliothèque et Archives Canada de reproduire, publier, archiver, sauvegarder, conserver, transmettre au public par télécommunication ou par l'Internet, prêter, distribuer et vendre des thèses partout dans le monde, à des fins commerciales ou autres, sur support microforme, papier, électronique et/ou autres formats.

L'auteur conserve la propriété du droit d'auteur et des droits moraux qui protege cette thèse. $\mathrm{Ni}$ la thèse ni des extraits substantiels de celle-ci ne doivent être imprimés ou autrement reproduits sans son autorisation.
In compliance with the Canadian Privacy Act some supporting forms may have been removed from this thesis.

While these forms may be included in the document page count, their removal does not represent any loss of content from the thesis.
Conformément à la loi canadienne sur la protection de la vie privée, quelques formulaires secondaires ont été enlevés de cette thèse.

Bien que ces formulaires aient inclus dans la pagination, il n'y aura aucun contenu manquant. 


\begin{abstract}
This thesis examines the significance of the land for urban Inuit residing in Ottawa (Ottawamiut), the role of urban place-making efforts in fostering meaningful connections to land, and the role of Inuit organizations in facilitating the creation of 'Inuit places' that facilitate connections to land.
\end{abstract}

Based on the rich, insightful and compelling narratives presented in this thesis, I demonstrate that:

(1) The land or nuna plays a significant role in the lives of Ottawamiut participants in this study;

(2) The land continues to be of significance for Ottawamiut between generations (i.e. the inter-generational significance of the land);

(3) Urban place-making efforts are key to fostering meaningful connections to the land within this urban setting; and

(4) Local Inuit organizations, in particular, facilitate connections to the land, thereby transforming abstract urban space into Inuit place-that is, safe places of cultural inclusion-where Ottawamiut are able to engage with land-based knowledge and cultural practices in ways that are both beneficial and relevant to their urban lives.

This thesis demonstrates that part of the common ground which draws this diverse and growing population of individuals together is their deep rooted connections to the land, a connection that is part of the collective, cultural memory and identity of Inuit whether northern or southern-dwelling. Ottawamiut make symbolic connections to the land through the transfer of Inuit knowledge, cultural practices, country food, language, and identity. Critical to all of these is the ability to gather and share. Local Inuit organizations, through the culturally-specific programs and services that they provide, build community and foster connections to the land that extend its meanings into southern, urban space. 
This research adds to the emerging area of urban Inuit research, and contributes novel understandings about how urban Inuit 'make place' for themselves in Ottawa in ways that extend land meanings, thereby transcending supposed geographic boundaries of North and South, and/or urban and rural. In addition, this thesis highlights the needs and concerns of urban Inuit-such as rights and representation by national Inuit organizations-which tend to be poorly understood and underrepresented in urban Indigenous research. 


\section{Acknowledgements}

I'd like to take this opportunity to thank the many people who contributed their time, knowledge and support in order to make this research project possible.

To begin, I'm indebted to the Ottawamiut participants who spent countless hours with me, and so openly shared their knowledge and stories. I hope that the collaborative work we've done together helps to benefit the wider community.

Heartfelt thanks goes out to my thesis supervisors, Fran Klodawsky and Donna Patrick, who have been extremely supportive throughout the course of my doctoral program. Their encouragement, advice and expertise have greatly contributed to my academic progress and to the development of this thesis.

I'd also like to thank my thesis committee members, Gita Ljubicic and Mike Brklacich, for the time, attention and constructive criticism they've provided to help guide this project.

I've had a great deal of support from my student colleagues. In particular, I'd like to thank Pascale Roy-Léveillée and Rae-Lyn Bennett-Blaney for being my personal cheerleaders, always there with friendship, understanding and unwavering encouragement.

Heartfelt thanks goes to my family for their constant support and encouragement. Thanks to my cat, Noodles, for keeping me company during all the late nights spent at the computer. Last but not least, l'd like to thank my husband, Daniel-Ravi Thakorlal, whoin my eyes - has earned himself an honorary doctorate in patience. Thank you for being my best friend. 


\section{Table of Contents}

$\begin{array}{lr}\text { Abstract } & \text { ii } \\ \text { Acknowledgements } & \text { iv } \\ \text { Table of Contents } & \mathrm{v} \\ \text { List of Figures } & \text { viii } \\ \text { List of Appendices } & \text { ix } \\ \text { Chapter } 1 \text { - Introduction } & 1\end{array}$

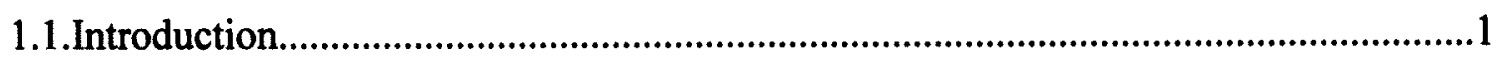

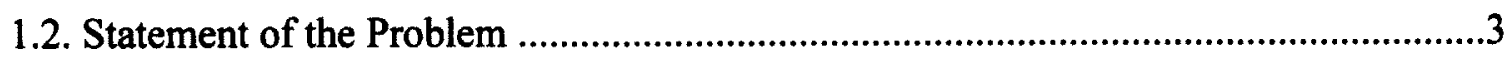

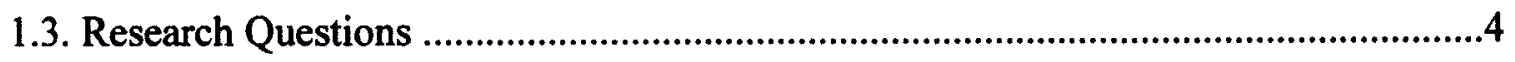

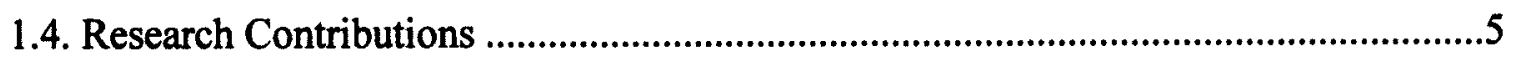

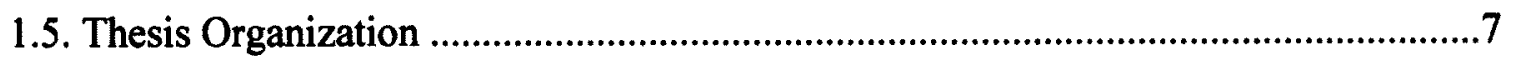

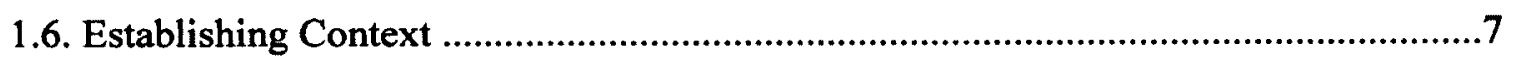

1.6.1. Urban Inuit Associations Across Canada...........................................................24

Chapter 2 - Conceptual Framework and Literature Review 31

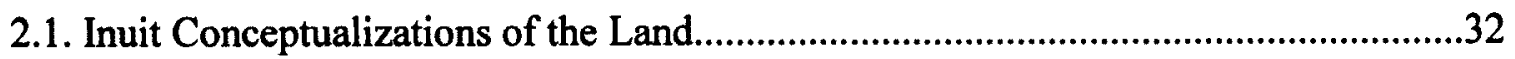

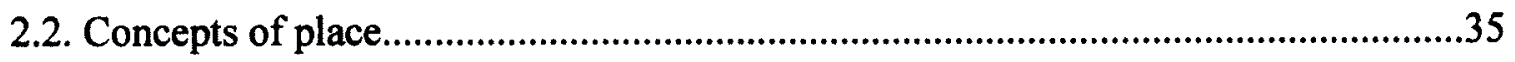

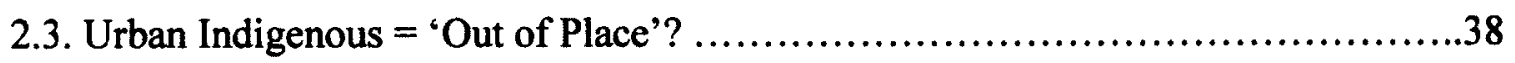

2.4. Contemporary Meanings of the Land for Urban Indigenous people ........................44

2.5. Research on Urban Indigenous Connections to the Land and Place .......................48

2.6. Research on Urban Inuit Connections to the Land and Place ...............................53

Chapter 3 - Research Approach and Methods 58

3.1. Decolonised Approaches Research ......................................................................58

3.2. Critical Reflexivity: Situating Myself within the Research.......................66

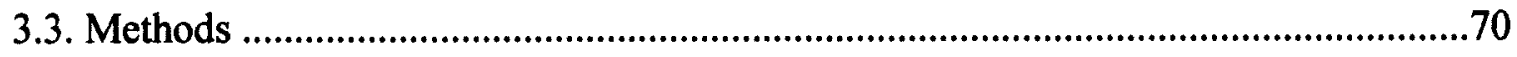

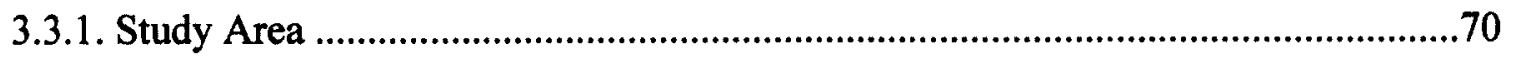

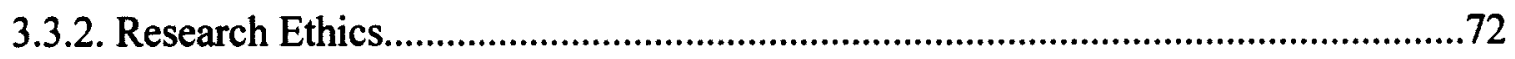


3.3.3. The Research Process: Building Relationships..........................................................73

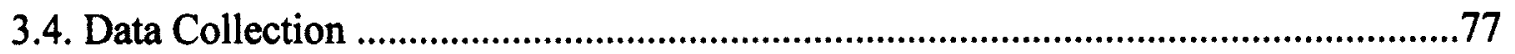

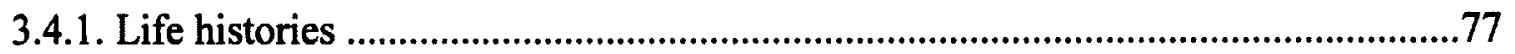

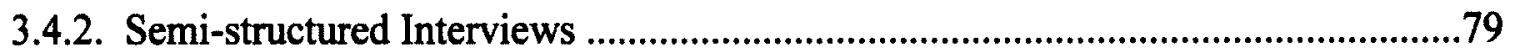

3.4.2.1. Younger Generations of Inuit..............................................................................82

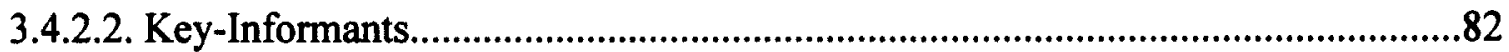

3.4.3 Participant Observation ...........................................................................................83

3.5. Analysis ...........................................................................................................94

3.5.1. Life Histories and Interviews ..............................................................................94

Chapter 4 - Elder Life Histories $\quad 95$

4.1. Life History of Ovilu Goo-Doyle ..............................................................................99

4.2. Life History of Maria Brazeau ................................................................................128

4.3. Life History of Sally Webster ……….....................................................................153

Chapter 5 - Urban Inuit Perspectives on Land, Identity, and Place 206

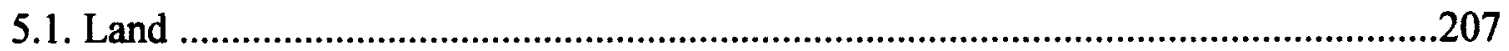

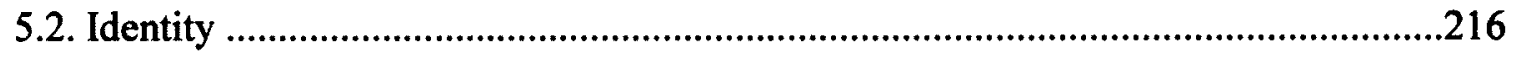

5.2.1. Identity and Urban Inuit Rights ....................................................................229

5.3. Inuit-specific Community-based Service Agencies .................................................232

$\begin{array}{ll}\text { Chapter } 6 \text { - Synthesis: Thematic Analysis } & 238\end{array}$

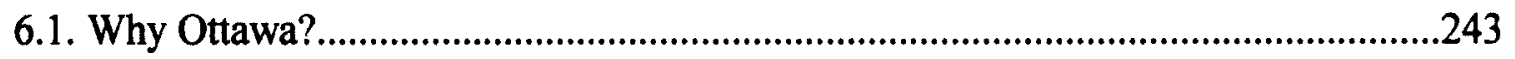

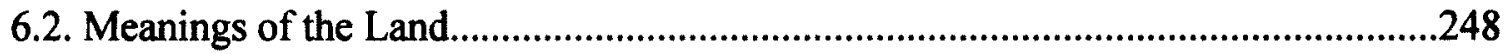

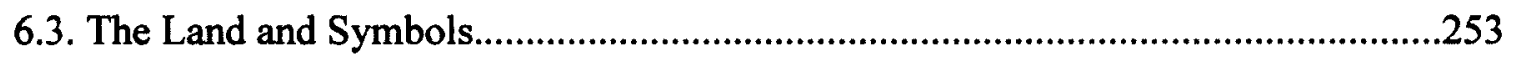

6.4. The Land and History ........................................................................................25

6.5. The Land and Inuit Knowledge...........................................................................256

6.6. The Land and Cultural Practices...........................................................................257

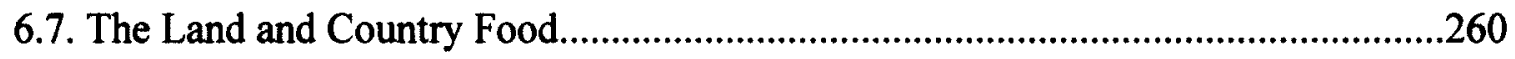




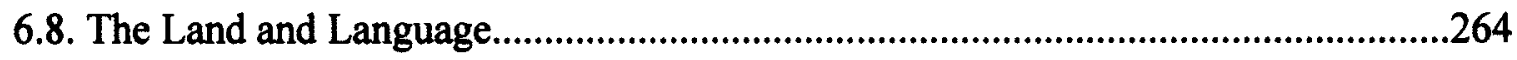

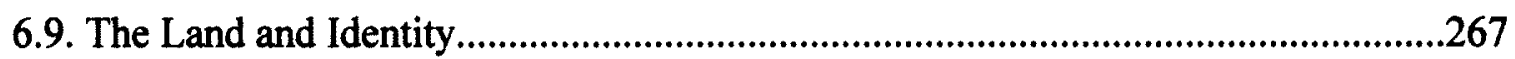

6.10. The Land and Local Inuit Organizations............................................................273

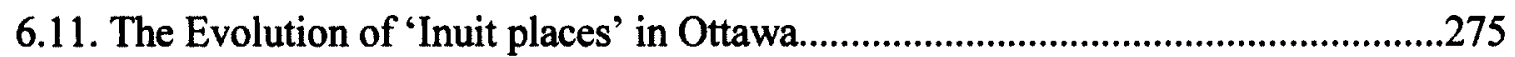

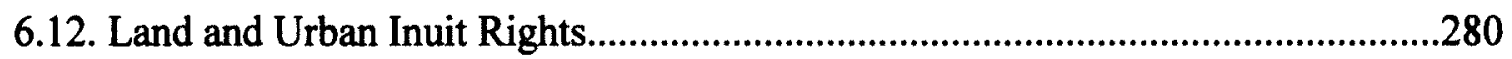

Chapter 7 - Summary and Conclusion $\quad 287$

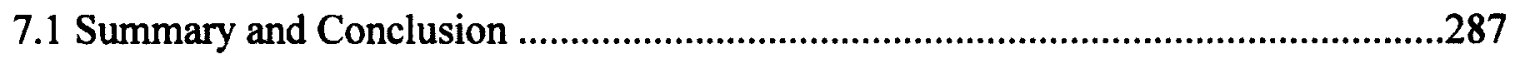

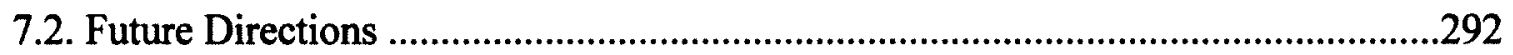

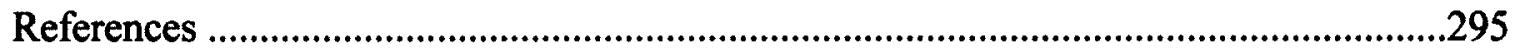




\section{List of Figures}

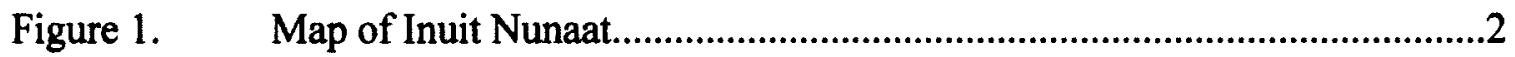

Figure 2. Poster advertising Tungasuvvingat Inuit's $1^{\text {st }}$ Annual Spring Equinox

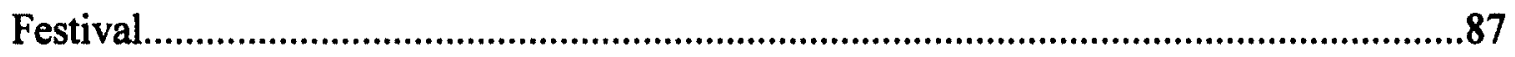

Figure 3. Image of a qulliq, a traditional Inuit seal oil lamp .....................................89

Figure 4. Image of an Inuk woman preparing and distributing seal meat at 'Inuit Day 2011' celebrations held at the Ottawa Inuit Children's Centre ...............................92

Figure 5 - 22. Sally Webster's Stories From Childhood ......................................158 -175

Figure 23 - 56. Sally Webster's Teaching Tools ...................................................184 -202 


\section{List of Appendices}

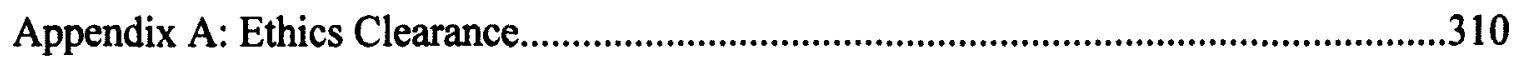

Appendix B: Consent Forms....................................................................................

Appendix C: List of Elder Participants............................................................................315

Appendix D: Guiding Questions for Oral Histories......................................................316

Appendix E: List of Participants from the Ottawa Inuit Community..............................319

Appendix F: List of Key Informants from Government and Inuit Organizations .....................320

Appendix G: Interview Guide for Key Informants.............................................................321 


\section{Chapter 1}

\section{Introduction}

According to the 2006 Canadian Census, the number of people who identify themselves as Aboriginal surpassed the one million mark (Statistics Canada, 2006a). In addition, slightly more than half of Canada's Aboriginal peoples were reported to live in urban areas. While the majority of Inuit live in the four Inuit Nunaat ${ }^{1}$ (see Figure 1 for regional map) regions of Canada, a growing number of Inuit are choosing to migrate to southern urban centres (Statistics Canada, 2006b; ITK, 2007). In 2006, 22\% of Inuit lived outside of Inuit homeland regions, representing an increase of approximately $60 \%$ from a decade earlier (Statistics Canada, 2006c; Patrick et al., 2010). Inuit living in urban areas represent approximately $17 \%$ of the total Inuit population in Canada. The southern cities with the largest Inuit populations are: the Ottawa-Gatineau region, with 725 Inuit residents; Yellowknife, with 640 Inuit residents; Edmonton, with 590 Inuit residents; Montréal, with 590 Inuit residents; and Winnipeg, with 355 Inuit residents (Statistics Canada, 2008). While the Census reports a marked increase in the number of Inuit living in cities, these numbers are still considered an underestimate by local organizations that provide services to urban Inuit. For instance, according to the community organization, Tungasuvvingat Inuit, the population of Inuit living in Ottawa in 2005 exceeded 1000, and has progressively increased year by year (Stellick, 2008, personal communication; Patrick, et al., 2010). More recent anecdotal evidence suggests the population of

\footnotetext{
${ }^{1}$ Inuit Nunaat refers to the Inuit homeland region which stretches from Labrador to the Northwest Territories (NWT). The four regions which comprise Inuit Nunaat are Nunavut, Nunavik, the Inuvialuit region of the NWT, and the Nunatsiavut region of northern Labrador.
} 
Ottawamiut-the Inuktitut term for Inuit living in Ottawa — now exceeds 2000 residents (Ottawa Inuit Children's Centre service provider, personal communication, 2012).

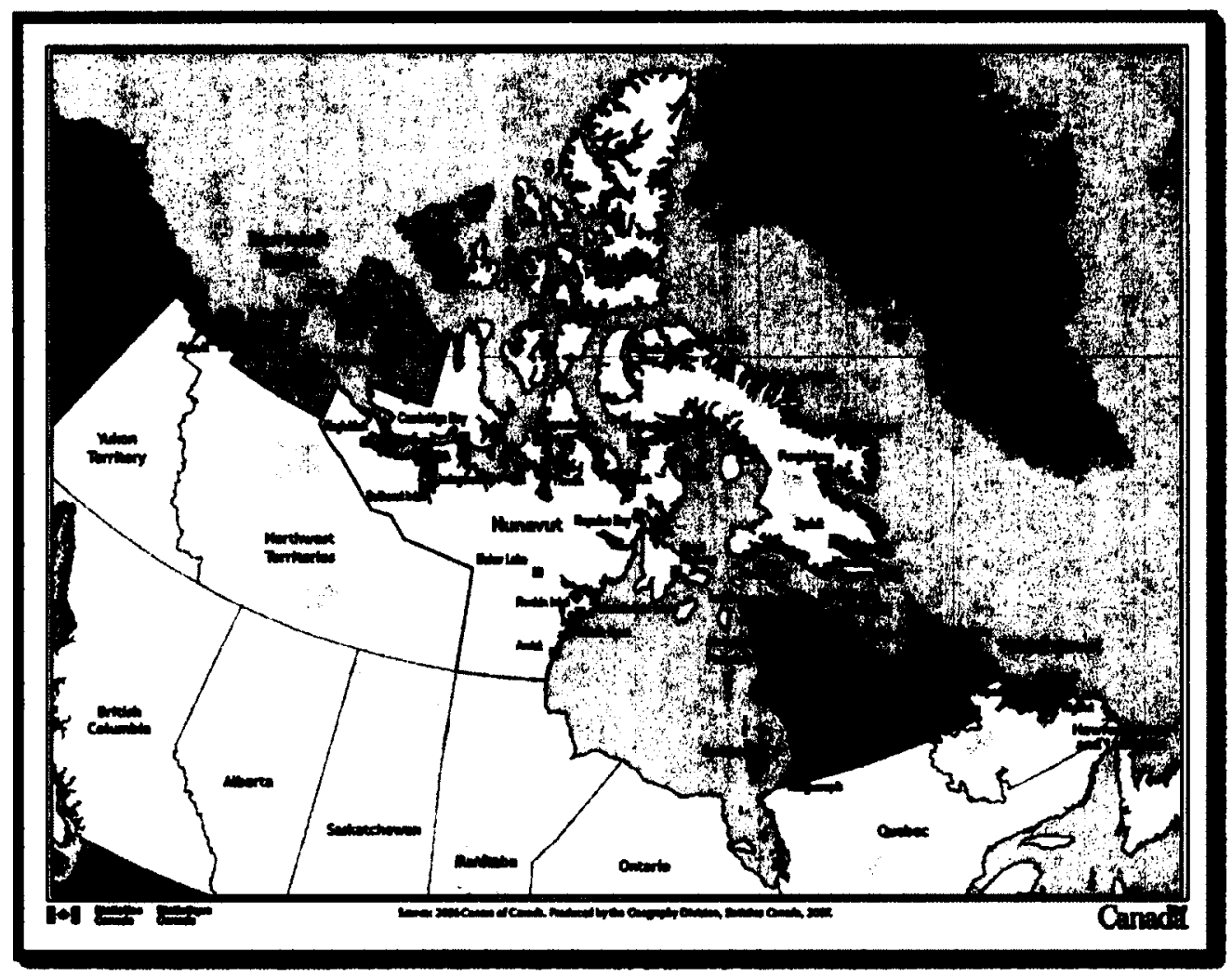

Figure 1. Four regions of Inuit Nunaat ${ }^{2}$.

Inuit have numerous motivations for migrating to southern cities, such as: to find better education and employment opportunities; for medical care and hospitalization; for drug \& alcohol addictions treatment; to escape abusive relationships; to escape from

${ }^{2}$ Statistics Canada: http://www.statcan.gc.ca/pub/89-634-x/2008004/figure/6500054-eng.htm 
gossip and negative environments; and to follow a friend or relative (Kishigami, 1999; 2002). There are also a growing number of Inuit who are born and raised in the southern cities (i.e. the children of migrants), as well as those that have been adopted into southern families (Patrick and Tomiak, 2008).

\subsection{Statement of the Problem}

Whether northern- or urban-dwelling, Inuit possess strong physical, sociocultural, and spiritual connections to the land or nuna (Campbell, 2001). These connections are rooted in the history of Inuit as Arctic peoples who have hunted, travelled, and lived in close relationship with the land for millennia (Bennett and Rowley, 2004; ITK, 2004). The concept of nuna has been a fundamental aspect of Inuit culture and identity for thousands of years. Nuna is an Inuktitut word usually translated as 'land'; however, tends to have meanings which are far more complex than a simple reference to physical land. For Inuit, 'the land' is a holistic and all-encompassing concept that relates living things in a web of interconnections to their environment (Wenzel, 2004). More accurately, nuna relates to "total habitat including the sea, the ice, the mountains, the air, the animals, fish, and even souls and memories of events and the people who live in the past" (Jessen Williamson 2006:19; see also Nuttall 1992; and Patrick, (in press)) (Please see Chapter 2.2 for a detailed description of nuna).

However, unlike the other urban Indigenous people, who are able to move between their rural and urban residences with relative ease (Wilson and Peters, 2005), Inuit living in the south have greater geographic and economic hurdles to overcome in order to visit their northern communities (Patrick and Tomiak, 2008). The expense of 
flying north often restricts the mobility of most Inuit living in cities, thus making visits to their northern communities' infrequent. As a result, urban Inuit face challenges living in cities that are more intensified as compared to other Indigenous groups in Canada, such as: limited access to the land and country foods; reduced opportunity to engage in culturally significant activities which strengthen Inuit identity; fewer occasions to share and generate Inuit knowledge; fewer occasions to learn and speak Inuktitut (Kishigami, 1999, 2002; Patrick and Tomiak, 2008; Tomiak and Patrick, 2010). All of the above geographic and social realities characterize urban Inuit experience in Ottawa, which is the focus of this thesis and which have informed the research questions guiding this research. As we shall see, these processes inform Inuit place-making, and conceptions of nuna that are significant for Ottawamiut.

\subsection{Research questions}

The objective of this doctoral research is to gain a deeper understanding of how changing relationships to the land impact the everyday lives of Inuit living in Ottawa, Ontario. Specifically, this research asks: (1) What is the significance of 'nuna' (the land) to Inuit residents of Ottawa?; and (2) What role does urban place-making play in fostering connections to the land, and the cultural meanings, practices, values associated with the land? Related to question (2), is the embedded question (3): What role have local and national Inuit organizations, including political and community-based institutions, played in fostering Inuit connections to land and cultural identities? 


\subsection{Research Contributions}

While there is a growing area of research which represents the varied experiences of Indigenous people living in North American cities (e.g. Andersen and Denis 2003; Deane et al., 2004; Fixico 2000; Frideres 1998; Gill 1995; Hanselmann 2001; Lawrence, 2004; Lobo 2002; Lobo and Peters 2001; Newhouse and Peters 2003; Peters, 1996, 1998, 2000; Royal Commission on Aboriginal Peoples 1996; Todd 2001), the same cannot be said for Inuit. Despite the increased presence of Inuit living in southern Canadian cities relatively few studies have focused on highlighting the urban experiences or perspectives of Inuit (e.g. Campbell 2001; Carpenter 1993; Chaumel 1993; Fogel-Chance 1993; Kishigami 1999; Lee 2003; Olofsson 2004; Kishigami, 2008; Patrick and Tomiak, 2008; Tomiak and Patrick, 2010), with no research explicitly examining the significance of the land and urban place-making to the everyday lives of Inuit residing in cities.

This doctoral research makes important academic contributions, while also benefitting the Inuit community living in Ottawa, Ontario. This research fills a significant knowledge gap in the urban Indigenous literature by highlighting the experiences and perspectives of urban Inuit, which are currently under-represented. The narratives presented in this research enrich understandings of urban Inuit connections to the land, and the role of urban place-making in fostering dynamic relationships to the land, and the meanings, practices, and values associated with it. More specifically, I argue that the underlying unifying force which draws Inuit residing in Ottawa together is the land, and the meanings, cultural knowledge and practice, and values it represents. For the participants, connections to the land are largely facilitated through urban place making efforts, particularly Inuit 'community centres', which transform abstract, urban space into 
'Inuit place'. Urban Inuit places, that is, places of cultural safety and inclusion, are key to fostering linkages to the land. These linkages extend connections to land and Inuit cultural knowledge and practice which surpass supposed geographic boundaries of North and South. In addition, this thesis demonstrates the inter-generational significance of the land to Ottawamiut who are raising families in the city. Urban place-making efforts are especially significant to youth being raised in Ottawa who have no direct experience or knowledge of the northern communities from which their families originate. For these cases, in particular, having access to Inuit-specific programs and services through local Inuit organizations is instrumental in facilitating the formation of positive cultural identities. Furthermore, this research contributes to theoretical understandings of 'place' by examining: how urban Inuit make place for themselves in urban settings; the characteristics of place; and the significance of the place to urban Inuit. In terms of benefits to the community, this research documents the life histories of three Elders who aspire to share their knowledge and experiences with others. Through the publication of their narratives the Elders transform their life experiences into a resource to educate younger generations of Inuit being raised in Ottawa, recent migrants, as well as nonInuit ${ }^{3}$. Furthermore, the Elder narratives enrich and expand current definitions of what constitutes 'Inuit Knowledge' by documenting information relating to, and within, urban contexts. Lastly, this research gives voice to the interests of urban Inuit which are commonly under-represented and poorly understood, in both research and public policy, as compared to other urban Indigenous groups in Canada.

\footnotetext{
${ }^{3}$ The Elder narratives will be formatted and published in book form. The hope is to make them available at local Inuit service agencies for use by the public.
} 


\subsection{Thesis Organization}

This thesis is organized into seven chapters. This chapter has provided a statement of the research problem, the research questions, and identified the contributions this work can make to the academic literature as well as to the urban Inuit community residing in Ottawa and beyond. This chapter will end with a discussion which situates Inuit migration within the broader historical context of Arctic colonization. Chapter 2 presents the theoretical framework and relevant literature which the thesis draws upon. Chapter 3 details the research approach and methods. Chapters 4 and 5 present the major results of the research. Specifically, Chapter 4 presents the life histories of three urban Inuit Elders. Chapter 5 presents the perspectives of younger generations of Inuit residing in Ottawa. Chapter 6 provides a discussion of the major themes presented in Chapters 4 and 5 . Chapter 7 presents a brief summary of research findings, outlines the major conclusions of the thesis, and identifies future research directions. Chapter 7 is followed by references and the appendices.

\subsection{Establishing Context}

It is useful to situate the various 'push and pull factors' which influence the migration of Inuit from rural northern communities to southern urban centres, within the larger historical context of Arctic colonization, particularly since the end of WWII. As stated by the Royal Commission on Aboriginal Peoples (1996), reconciliation between mainstream Canada and its Indigenous people requires an understanding of the history of European-Indigenous relations, and of contemporary Indigenous cultures. What follows is an abridged account of contact between Inuit and non-Inuit, to illustrate to the reader 
how the contemporary realities faced by Inuit living in northern and southern communities, are in fact part of a longer historical process of colonialism. This account shall focus on the eastern Arctic, as the participants in this study originate from Nunavut and Nunatsiavut (Labrador).

The history of the Arctic over the last century is a microcosm of what happened all over the world in the eras of exploration and colonialism (McElroy, 2008). Inuit first encountered European peoples through Erik the Red's tenth century Icelandic voyages to Newfoundland and Labrador (INAC, 2008). In the late $15^{\text {th }}$ Century, European explorers began to arrive on the northeast coast of North America, searching for gold and a Northwest Passage to Asia. Between the arrival of Martin Frobisher in 1576 and the infamous disappearance of the Franklin expedition in 1848, it is estimated that twentytwo explorers entered the region (ITK, 2004). This period of early contact was followed by contact with whalers in the $18^{\text {th }}$ century, fur traders in the $19^{\text {th }}$ century, missionaries ${ }^{4}$, and during the $20^{\text {th }}$ century the Canadian government and its agents of intervention (e.g. the Royal Canadian Mounted Police, educators, medical workers, social workers, administrators, etc). Contact between Inuit and Qallunaat (i.e. non-Inuit), and the subsequent impacts of contact, appear to vary depending on the nature of the relations between both groups and their level of involvement. For instance, initial contact with non-Inuit whalers and traders was largely economic. Although, contact with these groups did impact Inuit lives and livelihoods through the introduction of exchange economy,

\footnotetext{
${ }^{4}$ The first missionaries entered the Arctic along the Labrador coast when the Moravians established a mission station at Nain in 1771. The Moravian church is still active in this region. However, for most other areas active contact between Inuit and Catholic and Anglican missionaries did not get underway for another 100 years. Missionaries had no direct ties with the government, however, their presence was utilized to carry out rudimentary educational and health services. Medical work and education helped to influence Inuit in their conversion to Christianity. Many saw the missionaries as doing good work as teachers and health care providers, and reasoned that the Christian religion must be good too (ITK, 2004).
} 
goods (e.g. guns, ammunition, food, and other goods), and the introduction of diseases, Inuit maintained a largely independent way of life. Arguably, the most dramatic change in Inuit lives resulted from a shift in attitude by the Canadian Government - that is, from a hands-off approach to one of paternalistic intervention. However, in order to understand what led to this shift, we must look back at the events which preceded it.

As mentioned previously, initially the line of contact between Inuit and non-Inuit in the eastern Arctic was largely economic, centering at different times on whaling and fur trade industries (Oswalt, 1979). Commercial whaling began in the eastern Arctic during the late $18^{\text {th }}$ century (ITK, 2004). During the 1860 s, the whaling industry peaked. During this time year round shore stations were established in areas like Cumberland Sound, thus resulting in the permanent presence of Qallunaat in these areas. The yearround presence of whalers resulted in a new level of impact on trade, on patterns of seasonal land use, and on Inuit health through the introduction of disease. During the latter half of the $19^{\text {th }}$ Century, over-harvesting caused declines in whale stocks. This coincided with a change in the market, which saw less demand for whale oil and other products. As a result of these conditions, many whalers focused their harvesting efforts on smaller marine mammals such as beluga whales, walrus and seal, as well as other important subsistence resources such as caribou, fish, and musk ox (Tester and Kulchyski, 1994). Over time, populations of bowhead whale, caribou and musk ox became severely over-exploited, thus leading to the exploitation of the more profitable white fox fur.

By the late $19^{\text {th }}$ Century, fur traders had begun to move further north, and established trading posts to encourage Inuit to trap arctic foxes (Kulchyski and Tester, 
2007). Inuit participation in the harvesting activities was encouraged by traders because for them it meant greater, more predictable yields. By this point, the Hudson's Bay Company (HBC) had expanded its trade monopoly by establishing posts across the Arctic (INAC, 2008). The transition to the fur economy occurred over a period of roughly twenty-five years, becoming fully developed during the 1920 s in the eastern Arctic.

Despite contact with non-Inuit, Inuit maintained patterns of seasonal migration and subsistence livelihoods well into the $20^{\text {th }}$ century, thereby maintaining a level of independence as well as their relationships to the land (Tester and Kulchyski, 1994). However, even during this period of contact before government interference, self-defined and self-reliant Inuit were drawn into vastly different networks of social relations which started to influence their traditional ways of life (e.g. the introduction of the exchange economy, southern goods, and communicable diseases such as tuberculosis, among others). For instance, historically Inuit were nomadic peoples, that is to say, seasonally mobile within northern Canada (Kulchyski and Tester, 2007). Inuit camps were often determined through economic and subsistence strategies, and kinship ties (Damas, 2002). However, these patterns of social organization and seasonal movement began to shift as Inuit participation in whaling and the fur trade increased. As Inuit became accustomed to the exchange economy and southern goods, traditional camps (typically located in or close to desirable hunting grounds) were increasingly abandoned in lieu of camps located in closer proximity to trading posts ${ }^{5}$. In addition, participation in the fur trade was time consuming and diverted attention away from subsistence-oriented activities to fur-

\footnotetext{
${ }^{5}$ Trading posts operated on a credit system. That is, Inuit hunters harvested animals in order to earn store credit, which they in turn used to acquire southern goods.
} 
producing activities. This shift increased Inuit reliance on the exchange economy and southern foods to supplement their diet.

During the 1920s and 1930s relations between Inuit and non-Inuit remained largely economic, and organized around the demands of the fox fur trade. During this point in time, the bureaucratic stance towards Inuit affairs was a laissez-faire approach which promoted traditional economies because it was thought this strategy would avoid the kind of dependency the government believed was created by the 1876 Indian Act.

However, certain events caused a marked shift in bureaucratic attitude from the hands-off approach to one of state intervention. One event was the collapse of the fox fur trade. When the prices for fur started to fall in the 1930s and the fur trade collapsed, the credit system, which until that point had been viewed as a corporate responsibility, became difficult for companies like the $\mathrm{HBC}$ to carry. The $\mathrm{HBC}$ requested support from the government. Secondly, the collapse of the fur trade also coincided with a historic scarcity of caribou (an important source of subsistence). These factors contributed to the widespread starvation among Inuit across the Canadian Arctic (Tester and Kulchyski, 1994). Thirdly, serious medical problems, including epidemics of tuberculosis and polio among Inuit were increasing and could no longer be ignored by the government.

In 1924, the Minister of the Interior proposed a bill to amend the 1876 Indian Act, specifically recognizing Inuit in Canadian legislation for the first time, and assigning responsibility for Inuit to the Department of Indian Affairs (INAC, 2008). Despite opposition, the bill was passed with the caveat that Inuit were Canadian citizens and would not become wards of the state. In 1928, responsibility for Inuit was transferred 
from the Department of Indian Affairs to the Northwest Territories Council, which operated with the Department of the Interior. In 1930, the Canadian government repealed the 1924 amendment to the Indian Act. Inuit administration, however, continued under the NWT Council in Ottawa and by the North West Mounted Police ${ }^{6}$ in northern Canada (INAC, 2008).

Between 1930 and 1932, the Department of the Interior provided relief to Inuit across Canada. However, the Department expected the Québec government to refund the federal government for their portion of these relief projects. At this time, Québec was the only region inhabited by Inuit with a provincial government ${ }^{7}$. By 1932 , however, the annual cost of relief was so considerable that the Québec government declined making the payments, stating that like First Nations, Inuit should be considered a federal responsibility (INAC, 2008). Thus, a dispute arose between the province of Québec and the government of Canada over responsibility for Inuit residing with the province's borders (Miller, 2004). The issues-which soon ended in the courts-was which level of government had constitutional jurisdiction over and responsibility for Inuit residing in Québec, who were severely affected by the Great Depression, and needed social assistance (ibid.).

Québec brought the question of responsibility for Inuit to the Supreme Court in 1935. The litigation over this case is known as Re Eskimo. The federal government was faced with the matter of Inuit status; the question being whether or not Inuit were the

\footnotetext{
${ }^{6}$ The NWMP were delegated the task of administering relief (i.e. social assistance) to Inuit in the form of food and ammunition.

${ }^{7}$ A council responsible for the federal government administered the Northwest Territories and Yukon Territory from Ottawa, and Newfoundland had not yet joined Confederation.
} 
same as 'Indians'. And if so, were the Inuit to be considered wards of the state or Canadian citizens (Tester and Kulchyski, 1994)? Since the Indian Act no longer applied to Inuit (due to the 1930 repeal), and because it was unclear if Inuit were classified as Indians in the 1763 Royal Proclamation and the Constitution Act of 1876, Québec argued that Inuit were 'Indians' under section 91(24) of the Constitution Act of 1876 and therefore a federal responsibility (Miller, 2004). The federal government's position was that since Inuit were not culturally Indians, there were not embraced by section 91(24) of the BNA Act and therefore not a federal responsibility (ibid.).

In 1939, the Supreme Court of Canada agreed with Québec, pronouncing that constitutionally, Inuit were classified as Indians in Canada (Backhouse, 1999). This distinction made Inuit the legal responsibility of the Canadian Government. However, the Re Eskimo decision did little to alter the delivery of government programs and services. Ultimately, no comprehensive Inuit policy was developed and the departments responsible for northern affairs also managed Inuit affairs. However, despite this ruling, the federal government sought to ensure that Inuit remained distinct from First Nations in legislation and governance. In 1951, the Indian Act was specifically amended to exclude Inuit once again. Although, this amendment specifically excluded Inuit from sharing the status of First Nations, Inuit affairs continued to be administered federally. To this day, the Indian Act continues to outline federal responsibility for First Nations in Canada, however, there is no corresponding legislation or policy for Inuit. Nevertheless, Inuit maintain that the Re Eskimo decision entitles them to specific federal programming for relevant issues, such as healthcare (Backhouse, 1999; Miller, 2004; INAC, 2008). 
Thus, due to the Re Eskimo ruling, federal government implemented relief (i.e. social welfare ${ }^{8}$ ) programs for Inuit throughout the 1930s and 1940s. Tester and Kulchyski (1994) refer to this shift in government policy, as the first and second waves of expansion of state involvement into the lives of Inuit. The first wave of intervention saw the gradual transformation of the credit system, upon which the whaling and fur trade industries were based on, into a relief system. With that, reliance on the exchange economy changed into reliance on state social assistance. As the value of furs declined, relief and family allowances became essential to Inuit survival. However, until 1953, the federal government advocated the maintenance of a traditional way of life for Inuit.

Related to the matter of relief delivery, is that of the E-number system of identification, another form of government intervention into Inuit lives. In 1941, the federal government adopted an identification system to uniquely identify Inuit without having to standardize name spellings ${ }^{9}$ (Smith, 1993; INAC, 2008). This system was similar to the numeric registration used by the Canadian army and navy for their members, and involved issuing disks stamped with unique numbers to Inuit. The adoption of the disks coincided with the date of the federal census, which was completed by missionaries, doctors and nurses, the RCMP and HBC personnel in Arctic communities.

\footnotetext{
${ }^{8}$ Through the Depression of the 1930s and the Second World War, the Canadian Government realized the necessity of providing nationwide social welfare. Resulting programs included old age pensions and family allowance payments for all Canadians, including Inuit, during the late 1940s and 1950s (Tester and Kulchyski, 1994).

${ }^{9}$ Traditionally, Inuit naming was genderless and children were often named after significant or recently deceased family members, regardless of the sex of the name holder or namesake. In the eighteenth century, Catholic missionaries in northern Québec and the eastern Arctic converted and baptized Inuit, and assigned them biblical names. Since certain English language sounds were not familiar to Inuit, they adapted biblical names to facilitate pronunciation. Although Inuit were often known by these names within their communities, they also retained their Inuit names. Variants in names and use of multiple names by individuals did not seem to cause confusion among Inuit, yet whalers and traders, and later members of the Royal Canadian Mounted Police found it difficult to pronounce and spell Inuit names (Smith,1993; INAC, 2008).
} 
Baptismal and Inuit names were recorded, along with the disk number, or E [Eskimo]number, assigned to each Inuk ${ }^{10}$. Between 1945 and 1970, all Inuit interaction with the federal, and provincial or territorial governments required use of E-numbers. Commonly, these interactions included the registration of birth, marriage and death certificates. In the early 1960s, some Inuit and administrators throughout the Arctic raised concerns about the use of E-numbers when this practice was uncommon for other cultural groups in Canada. In 1968, the NWT Council proposed "Project Surname," requesting that all Inuit select and register family names, which, along with their given names, would receive standardized spellings. By 1972, registrations were completed and Inuit within the NWT were no longer required to use E-numbers as identification" (INAC, 2008). Both the Enumber method of identification and "Project Surname" had little or nothing to do with traditional Inuit naming practices. Instead, these systems of identification were put in place for the convenience of government officials and the facilitation of programs and services during this early stage of state intervention into Inuit lives.

The second wave of state intervention was more dramatic and resulted in greater social, cultural and economic change for Inuit. This period was characterized by involuntary relocations ${ }^{12}$, the removal of Inuit from their homes to undergo TB treatment

\footnotetext{
${ }^{10}$ The disks were approximately the size of quarters, and were made from pressed fibre with a hole punched in the top, allowing them to be worn on string around a neck or wrist. With the approval of the Secretary for the Department of State, they were stamped with the Canadian Coat of Arms as well as their unique four-digit number (Smith, 1993; INAC, 2008).

${ }^{11}$ As northern Québec is not within the jurisdiction of the NWT Government, however, their use of Enumbers persisted for several years longer (Smith, 1993).

${ }^{12}$ During the 1950s, 87 Inuit were forced to relocate to the High Arctic. The Inuit originally from Inukjuak (Northern Québec) were moved to Grise fiord and Resolute in 1953 and 1956. Another three families from Pond Inlet, Nunavut, were also moved north to assist the Inukjuaq families adjust to their new environment. The families were promised government support and were promised to be able to return back to their home communities after two years if they wished. These promises were not kept. While the communities of Resolute and Grise Fiord still exist today, many have argued that the government's real
} 
in southern sanatoria ${ }^{13}$, the removal of Inuit children from land-based education to western-style classroom-based education, and the renewed efforts to assimilate Inuit into Canadian society through the government's Arctic 'centralization' policy.

As mentioned earlier, although Inuit had considerable contact with non-Inuit by 1945 , they continued to pursue traditional livelihoods and retained much of their traditional way of life. Part of the reason for the slow progress of the acculturative process was that programs designed to 'incorporate' Inuit into formal systems of education, healthcare, wage labour and permanent housing were not established until the late 1940s and 1950s. However, during WWII, and the Cold War that followed, the Canadian Arctic was host to many American military personnel. These visitors were critical of the Canadian government's perceived neglect of Inuit (INAC, 2008). This negative attention combined with renewed interest in the potential for natural resource exploitation (i.e. mineral and oil extraction), and a desire to demonstrate Canadian Arctic sovereignty, were important catalysts for the development of permanent sedentary Arctic communities (Damas, 2002; Tester, 2006).

intention for the relocation was to assert Canada's sovereignty during the Cold War (See Tester 1994 for a detailed account). In 2010, the Canadian government formally apologized for the forced relocation program.

13 Incidences of respiratory infections were high among Inuit throughout the early part of the 20th century, but became increasingly prevalent during the 1940s (Grygier, 1994). Rather than constructing treatment facilities in northern communities, the government sent large numbers of Inuit to sanatoria and hospitals in southern Canada for treatment. In 1956, approximately $10 \%$ of the Inuit population was receiving medical treatment, mainly for tuberculosis, in southern Canadian hospitals. These prolonged periods of separation caused considerable trauma to the Inuit families involved, as many were separated for years from loved ones who had no knowledge of their location or condition. Although these attempts at eradicating TB were deemed successful, this period of time is considered by many Inuit to be sociocultural disaster. The prolonged separation is seen as responsible for loss of language, change in food habits, and the interruption in the transmission of Inuit knowledge between generations, among other impacts (Moller, 2010). 
Due to the collapse of the fur trade, the government believed Inuit could no longer support themselves by living off the land. Thus, from the state's perspective, Inuit needed to be acculturated and assimilated into southern Canadian culture with the goal of creating wage-earning Canadian citizens (INAC, 2008). Permanent housing was necessary in order to facilitate the adoption of formal systems of education, healthcare and wage labour in the North. Thus, after WWII the federal government pursued a 'centralization' policy which envisioned most Inuit grouped in small, urbanized communities or hamlets (Damas, 2002). Throughout the 1950s the Canadian government encouraged Inuit to settle in communities and established social welfare programs for housing, health care, education and economic development which the state believed would improve their standard of living (INAC, 2008). Inuit were attracted by the promises of improved healthcare, education, and employment opportunities in the settlements (Tester and Kulchyski, 1994). As a result, for the next two decades there was a steady migration of Inuit to the new settlements.

By the mid-60s, many nomadic Inuit family groupings had settled into communities where attempts were being made to organize Inuit life according to Western ideals (Damas, 2002). In large part, settlements were located in areas that were easily accessible to the southerners rather than located in areas traditionally occupied by Inuit (i.e. close to seasonal hunting grounds). Creating communities that were easily accessible from the south allowed for a new generation of northern 'helpers' to settle in the Arctic (i.e. teachers, welfare officers, social workers, service officers) in order to facilitate the assimilation of Inuit into Canadian society (Brody, 1976; Tester and Kulchyski, 1994). 
These colonial agents affectively transformed Arctic communities into models of southern suburbia (ibid).

Instead of reserves, as was the case for First Nations, the federal government envisioned the development of 'northern suburbs' with higher standards of living, but with the challenges of transporting southern architectural models for adequate housing, schools and other institutions, and commercial centres (Tester and Kulchyski, 1994). The government believed that in the settlements, Inuit would enjoy a degree of material security and well-being that they had not previously experienced living on the land. However, in reality life within the settlements was quite the opposite of these early expectations. The housing and sanitary conditions in the settlements at this time were appalling (Tester and Kulchyski, 1994). Traditional Inuit dwellings, such as caribou skin tents and snow houses (i.e. igloos) which were designed to withstand the Arctic climate, were replaced by poorly-constructed, one-room clap-board houses without running water or indoor plumbing. In school, land-based education, Inuit ways of knowing and language were strongly discouraged and Western ways of knowing, social norms and values were promoted. In addition, the sedentarization of Inuit into settlements marked a dramatic change in lifestyle and livelihoods. Inuit living in these settlements discovered that pursuing traditional methods of subsistence was often difficult due to the distance between the settlements and preferred hunting grounds. In addition, within the settlement there was pressure to maintain a steady family income through wage employment which left less time to pursue traditional harvesting activities. This also contributed to an increased dependence on store-bought foods. Clearly, the government's centralization policy resulted in dramatic socio-cultural, economic, and health consequences for Inuit. 
Another thread to be woven into this story is that of Inuit agency and political organization. By the late 1960s Inuit responded to the socio-cultural and economic changes imposed upon them by organizing and becoming engaged in the political process. The impetus was to establish a structure that would enable Inuit to unite with a common voice. The end result was the creation of Inuit Tapirisat of Canada (ITC) in 1971, the national political voice for Inuit in Canada. The ITC was primarily established to lobby the federal government for claims to northern lands from the western Arctic to Labrador, however it also sought to preserve Inuit language and culture; to improve communication to and among Inuit settlements; to ensure that Inuit achieved full participation in Canadian society; to monitor the development of mineral, oil, and gas exploration in the North; and to represent Inuit interests to the federal government in all aspects of northern development (INAC, 2006: 44).

Subsequent to the development of ITC, regional associations were established to provide local representation for Inuit. The efforts of ITC and regional Inuit political organizations resulted in comprehensive land claim settlements ${ }^{14}$ in all four regions of Inuit Nunaat. ITC changed its name to Inuit Tapiriit Kanatami (ITK) in 2001, with the mandate to be:

[...] the national voice of 55,000 Inuit living in 53 communities across the Inuvialuit Settlement Region (Northwest Territories), Nunavut, Nunavik (Northern Québec), and Nunatsiavut (Northern Labrador), land claims regions. [...] ITK represents and promotes the interests of Inuit on a wide variety of

\footnotetext{
14 The James Bay and Northern Québec Agreement and Complementary Agreements (JBNQA), which were reached in 1975 in northern Québec; the Inuvialuit Final Agreement, which was reached in 1984 in the western Arctic; the Nunavut Land Claims Agreement, which was settled in 1993 in the eastern Arctic; and the Labrador Inuit Land Claims Agreement, which was settled in 2003 and ratified in 2005 in northern Labrador.
} 
environmental, social, cultural, and political, issues and challenges facing Inuit on the national level ${ }^{15}$.

Despite the substantial political achievements of Inuit and the successful settlement of comprehensive land claim agreements in all four regions of Inuit Nunaat, the legacies of paternalism and colonialism at the hands of the state persist today. Arguably, the Canadian government, through its interventionist and assimilation policies, created the social problems it claimed 'civilizing' Inuit would prevent. Today, the standard of living in many northern communities is below the national average (Moller, 2010). For instance, according to the International Polar Year Inuit Health Survey (2011) many northern communities continue to struggle with inadequate housing, overcrowding, and hidden homelessness. Food security is a significant issue for many Inuit families across Canada. Many families continue to face challenges in accessing adequate nutritional food, due to: low income; changing dietary habits from traditional foods to store-bought foods; high cost of food in the North; increasing cost of harvesting and hunting (e.g. high cost of gas and ammunition); and a lack of awareness of healthy eating habits. The move away from traditional lifestyle and food sources, and the subsequent reliance on store-bought foods, has resulted in higher rates of chronic diseases such as diabetes and cardiovascular disease among Inuit (Bjerregaard, et al., 2004). Access to adequate health care in the North differs greatly from southern Canada. Most Inuit communities are served by nursing stations. Doctors are available in larger regional centres (e.g. Iqaluit, Yellowknife), and specialized services are often offered in southern centres (like Ottawa and Montréal) requiring patients to travel great distances to access

${ }^{15}$ ITK Website. About ITK. Accessed September $26^{\text {th }}, 2012$. https://www.itk.ca/about-itk 
health services ${ }^{16}$. In terms of education, Inuit experience a high dropout rate from high school, college and university. Educational attainment among Inuit is lower than the rest of Canada with two-thirds of Inuit holding no form of post-secondary education, twice the national average ${ }^{17}$. In addition, accessing post-secondary education and training opportunities remains a challenge for many Inuit. There are colleges located in the regional centres (e.g. Iqaluit, Happy Valley-Goose Bay and Inuvik), however the majority of students must leave their communities to pursue higher levels of education. In terms of employment, the unemployment rate among Inuit is more than three times the national average $e^{18}$.

In addition, resource development and climate change in the North are changing the land physically, and this is changing the relationship Inuit have with the land (Price, 2008; Krupnik and Jolly, 2002; Riewe and Oakes, 2006). Some argue that resource development in the Arctic may improve northern economies and raise the standard of living. For example, mining development in the Northwest Territories (NWT) is increasingly framed as a means of providing economic benefits to Northern Indigenous communities (Hall, 2012). However, rather than benefit local people, Hall (2012) argues that the Northern mining industry is part of Canada's project of internal colonization of Indigenous communities, a project that has intensified and expanded in the neoliberal era. For instance, consider how resource development in the North has been shown to cause environmental degradation of important hunting and fishing grounds (Bielawski, 2003)

\footnotetext{
${ }^{16}$ Inuit Tuttawvingat. Overview of Inuit health: access to health care. Accessed September $26^{\text {th }} 2012$. http://www.naho.ca/inuit/overview-of-inuit-health/access-to-health-care

${ }^{17}$ Inuit Tuttawvingat. Overview of Inuit health: education. Accessed September $26^{\text {th }} 2012$. http://www.naho.ca/inuit/overview-of-inuit-health/education

${ }^{18}$ Inuit Tuttarvingat. Overview of Inuit health: income. Accessed September $26^{\text {th }}, 2012$ http://www.naho.ca/inuit/overview-of-inuit-health/income
} 
resulting in subsequent impacts to traditional livelihoods which are still significant in many northern communities. Other socioeconomic impacts include: reducing the capacity of local communities with regards to traditional activities and knowledge; loss of language; increased economic dependence of women on their partners because industries, like mining, tend to be male dominated (Hall 2012, Bielawski, 2003, Tsetta et al 2005).

In Nunavut political support for resource development flows from the Nunavut Land Claims Agreement (NLCA). Diamond and uranium mining are currently the focus in Nunavut, and Nunavut political organizations assert that the territory is "open for business" (Price, 2008: 128). However, modern resource development efforts are faster and concentrated, with the primary focus of achieving maximum economic benefit through massive extraction (ibid.). Many believe that resource development conducted in such a way fundamentally conflicts with the principles of Inuit subsistence living, which teaches respect for the land. Thus, while resource development may present economic benefits, these benefits are counter-balanced by the overall health and well-being of the land and of Inuit communities. If this argument holds true, it follows that the current situation in northern communities - which are the result of the long history of Arctic colonization - could be exacerbated, rather than be improved. If the social impacts of resource development in the Arctic exacerbate social problems, this may result in creating another push factor, which could contribute to greater numbers of Inuit migrating to southern cities. As resource development in the Arctic is likely to continue, further research to understand the social, cultural, and economic impacts of resource development, and its potential impacts to the southerly migration of Inuit to urban centres, is warranted. 
Another contemporary issue being faced by northern communities is the advent of climate and environmental change. Changes in climate and the surrounding environment have been shown to impact Inuit health both directly (e.g. heat exhaustion, sunburns, inability to accurately predict weather, etc) and indirectly (e.g. limited access to the land, limited access to country food sources) resulting in negative impacts to Inuit health, lifestyles and livelihoods. If climate and environmental changes in the Arctic continues as predicted (Arctic Climate Impact Assessment, 2005) these impacts and others may become exacerbated. If climate and environmental change continue as predicted, it may also contribute to Inuit migration to southern urban centres.

The examples above are not designed to paint a solely negative picture of life in the North, or to make Inuit appear totally vulnerable or without agency. The creation of Nunavut and the settlement of comprehensive land claims across the North clearly demonstrate their collective political power and agency. However, the examples above do serve to illustrate the contemporary realities of many Inuit residing in the North. Understanding these 'push factors' illustrates the lure of southern Canadian cities and provides insights into the motivations Inuit may have for migrating to southern urban centres. As noted earlier in the chapter, research shows these motivations include: to find better education and employment opportunities; to seek medical care and/or hospitalbased care; to seek drug \& alcohol addictions treatment; to escape abusive relationships; to escape from gossip and negative environments; and/or to follow a friend or relative (Kishigami, 1999; 2002). There are also growing numbers of Inuit who are born and raised in the southern cities (i.e. the children of migrants), as well as those that have been adopted into southern families (Patrick and Tomiak, 2008). 
The previous section has provided pertinent background information and established the historical and present-day contexts within which the following research is situated. The next section adds further context by discussing the situation faced by urban Inuit organizations across Canada which contrast to those found in Ottawa.

\subsubsection{Urban Inuit Associations Across Canada}

As this thesis demonstrates, in Ottawa Inuit residents have numerous resources available to them. Specifically, this thesis will show that places which were identified as significant for creating connections to Inuit lands and culture are local Inuit organizations, Tungasuvvingat Inuit and the Ottawa Inuit Children's Centre. Tungasuvvingat Inuit, meaning 'a place where Inuit are welcome', aims:

[...] at empowering and enhancing the lives of Inuit. Since 1987, TI has been operating in Ottawa as a community-based counselling and resource centre. TI offers a supportive environment that attempts to duplicate the community spirit and cultural surrounding of the Inuit homelands. Visitors at the drop-in centre can make tea and bannock; catch up on news from home by reading northern newspapers, and socialize with other Inuit. ${ }^{19}$

Although Tungasuvvingat Inuit started as a small, grassroots organization over the past

25 years it has expanded its presence throughout Ottawa to meet the evolving needs of the community. TI operates and provides a variety of social, cultural, and health services through four separate locations in Ottawa. For instance, Inuit-specific addictions and trauma treatment services operate through the Marmisivik Healing Centre. Family health care services are offered through the Family Health Team Medical Centre. Social and cultural programs, such as community food bank and women's healing circle, are offered

\footnotetext{
${ }^{19} \mathrm{http} / / /$ www.tungasuvvingatinuit.ca
} 
through the Family Resources Centre. Employment services are offered through their building located in downtown Ottawa.

The Ottawa Inuit Children's Centre (OICC) is an organization which aims to fosters strong and proud Inuit children, youth and families. Their mandate is to provide services to:

Inuit children and youth from birth to 13 years of age and their families. The objects of our organizations are: 1) to provide Inuit children and youth with a learning environment that will enhance their overall development; 2) to foster positive parenting through support and education; 3) to promote the retention of the Inuit culture and language.

The OICC runs various cultural and literacy based programs, such as: the Sivummut Head Start Program ${ }^{20}$, Tumiralaat Child Care Centre ${ }^{21}$, Ontario's first Inuit kindergarten program, Family Literacy Program (e.g. Elder storytelling), youth programs (e.g. culture nights, homework club, recreation night), Inuktitut language classes (for children and adults), among others. The OICC differs from TI in that they do not operate a drop-in centre. Their focus in primarily on providing Inuit children in Ottawa with the cultural and educational support they need. However, they also provide services to families and reach out to the wider community in this way.

Urban Inuit organizations have begun establishing themselves in other Canadian cities, such as Winnipeg, Edmonton, Montréal and St. John's. However, at this point in time, none of these urban Inuit organizations have nearly the same capacity as local Inuit

\footnotetext{
${ }^{20}$ The Sivummut Head Start Program is part of the Aboriginal Head Start Initiative administered and funded by the Public Health Agency of Canada (PHAC). The intention behind this program is to assist in creating a beneficial and supportive learning environment for Aboriginal, pre-school aged children and their families that is culturally appropriate, and to give children an educational 'head start'. (http://www.ottawainuitchildrens.com/eng/index.php?option=com_content\&view=article\&id=30\&/temid =35)

${ }^{21}$ The Tumiralaat Child Care Centre program offers spaces for 10 toddlers, between the ages 18 months and 30 months of age. (ibid.)
} 
organizations in Ottawa. The Manitoba Urban Inuit Association (MUIA) was formed in 2008, with the central vision of serving:

[...] the Inuit community of Manitoba through social outreach that promotes and enhances the quality of life through programs and services to help orient Inuit to the southern culture and environment. MUIA is working toward building a supportive environment that attempts to duplicate the community spirit and cultural surrounding of the Inuit homelands.(emphasis added) ${ }^{22}$

At this time, the MUIA does not have a permanent space open to the community, such as a drop-in centre. Through its office and website, the MUIA provides basic support services to Inuit residing in Winnipeg with a focus on creating connections between Inuit, helping Inuit adjust to life in the city, and community outreach. For instance, on the website MUIA newcomers to Winnipeg can orient themselves by consulting the "Welcome Guide", a publication which outlines information regarding: public transit; identification and documentation; accommodations; employment assistance; education and training assistance; health care; and leisure activities. MUIA also organizes community gatherings which it hopes to hold on a regular basis to "help Inuit who are living in and around Winnipeg to connect and share country food, see old friends, and to help keep connected to our Inuit heritage and culture in the city."23

Similarly, the Edmonton Inuit Cultural Society (EICS) has the mission to "build a strong, active Inuit community by providing culturally based support systems to urban Inuit, and representing the Inuit community in the greater Edmonton area"24. Out of their

\footnotetext{
${ }^{22}$ Manitoba Urban Inuit Association website. Accessed april 24, 2012. http://www.manitobainuit.ca/en/

${ }^{23}$ Manitoba Urban Inuit Association website. News and Events. Accessed April 24, 2012. http://www.manitobainuit.ca/en/news-events

24 Edmonton Inuit Cultural Society website. Accessed April 24, 2012. http://www.edmontoninuit.ca/eicscorporatestrategy
} 
office in Edmonton they offer Inuktitut classes and cultural programming (e.g. beading, sewing, drum making, throat signing, etc). EICS also organizes community events such as an annual Christmas feast featuring country food and Inuit games. In Montréal, the Association of Montréal Inuit, which has had organizational and administrative difficulties, primarily focuses its efforts on facilitating community country food feasts.

In the case of Montréal and St. John's, Inuit residing in those cities receive services from local Aboriginal Friendship Centres (i.e. Native Friendship Centre of Montréal and the St. John's Native Friendship Centre, respectively). However, in these cases the services are not necessarily Inuit-specific in nature. Still, Inuit in need are able to access a variety of services through the drop-in centres, which many come to rely on for support.

Although Native Friendship Centres receive core funding under the federal Aboriginal Friendship Centre Program (which was until recently administered by the National Association of Friendship Centres ${ }^{25}$ ), funding is not necessarily secure. Consider the Native Friendship Centre of Montréal (NFCM). They are currently appealing for public financial support after being notified on April $4^{\text {th }}, 2012$ that their core funding had been suspended indefinitely into the future ${ }^{26}$. This is despite having a longstanding record of providing vital services (e.g. day centre access, in-house medical clinic, street patrol services, hot lunch program, food and blanket distribution, weekly socio-cultural events, among others) to the urban Aboriginal population in Montréal for over 38 years. Budget cuts to the NFCM occurred despite the maintenance of funding levels announced in the

\footnotetext{
${ }^{25}$ As of April $1^{\text {st }}$ 2012, the management/administering of the Aboriginal Friendship Centre Program was transferred back to the federal government (Canadian Heritage) from the National Association of Friendship Centres, who had been administering the funds since 1996.

${ }^{26}$ Native Friendship Centre of Montréal website. Accessed April 24 $4^{\text {th }}, 2012$. http://www.nfem.org/
} 
2012 federal budget to the Aboriginal Friendship Centre Program, and a two-year renewal of the Urban Aboriginal Strategy (i.e. $\$ 27 \mathrm{M}$ over the next two years) ${ }^{27}$. As of April $1^{\text {st }}, 2012$ the centre will require $\$ 255,090$ annually to keep its programming running for the 2012-2013 fiscal year and beyond. If adequate sources of funding are not secured the NFCM risks closure, thereby impacting the lives of the hundreds of urban Indigenous people who rely on their programs and services.

Inadequate and unstable funding is among the greatest challenges urban Inuit and Aboriginal organizations face in providing consistent services to their communities (Tomiak, 2009). The level and stability of funding for Aboriginal services, as well as reporting requirements, constrain the ability of Aboriginal agencies to design and implement programming that reflects the needs and priorities of their communities (Tomiak, 2011). Thus, in the absence of core funding, many Inuit community-based service agencies have to rely on project-based funding which is not secure and not reflective of the needs of the community. The issue is further complicated by the current climate of inter-agency competition which is perceived as a major obstacle to building much needed coordination and collaboration among urban Aboriginal agencies. Without the provision of core funding, urban Aboriginal agencies have to apply for program dollars as they become available (Tomiak, 2009; Tomiak, 2011).

Currently, Inuit-specific services are under-funded (Tungasuvvingat Inuit, 2005; Urban Aboriginal Task Force, 2007; Patrick and Tomiak, 2008). Most of the funding is

\footnotetext{
${ }^{27}$ National Association of Friendship Centres website. Accessed April $24^{\text {th }}, 2012$. 'NAFC Federal Budget 2012'. http://nafc.ca/en/news/nafc-federal-budget-2012
} 
allocated to the "Aboriginal" category in which Inuit concerns are largely marginalised (ibid.: 2008): thus:

This "pan-Aboriginal" approach is felt to be simply a short form for First Nations, [...] causing Inuit to continue to be treated as First Nations in program delivery. Inuit, a unique people with their own culture, language, and history, are often forgotten [...] Inuit are frequently not able to obtain funds due, as well, to this pan-Aboriginal approach as funds are often distributed on a per capita basis. Since Inuit are the smallest population of Aboriginal peoples in urban settings, they are frequently given a very small portion of Aboriginal funds. This pan-Aboriginal approach in services and programs is simply not working (Tungasuvvingat Inuit 2005: 7; originally cited in Patrick and Tomiak, 2008).

Furthermore, Inuit programs and services in the North have a greater likelihood of being funded as compared to Inuit programs being operated in cities (Patrick and Tomiak, 2008: 8), thereby adding to the marginalization of urban Inuit.

In October 2005, Tungasuvvingat Inuit and the Inuit Relations Secretariat of INAC co-hosted a two-day workshop on Urban Inuit, entitled "One Voice". The workshop was held in Ottawa and included representatives from St. John's, HappyValley Goose Bay, Montréal, Ottawa, Winnipeg, Edmonton and Yellowknife, as well as the federal government and Inuit organizations. The three themes consistently raised by workshop participants were:

1) The need for an organization representing Inuit in urban areas;

2) More Inuit-specific community centres in urban areas; and

3) The need for additional support from a variety of sources, including the federal government. 
The workshop also focused on issues of concern to many Inuit, including the undercounting that results from methods used by Statistics Canada to collect data on Inuit; the ineffectiveness of the federal government's "pan-Aboriginal" approach to programming, which does not meet the needs of Inuit; the feelings of isolation experienced by Inuit living in southern Canada; and the need to provide urban Inuitspecific support services in areas including education, daycare, business development, job training, policing and the justice system, and social work. Tungasuvvingat Inuit has the vision to establish a network of urban Inuit organizations across Canada. However, this appears to be in the beginning stages (personal communication, 2012).

This section has provided insights into the situations faced by urban Inuit organizations in other Canadian cities. The establishment of urban Inuit organizations in cities like Edmonton and Winnipeg suggest Inuit residing in these cities are also in need of culturally-specific programs and services. As this thesis argues, given the important role local Inuit organizations play in creating 'Inuit place' within urban settings-in particular, for the social networks and programs and services that they provide which facilitate links to land-support for these organizations is not only warranted, it is directly related to the health and well-being of Inuit living in those urban areas.

In the next chapter, I will review the relevant literature as it relates to the research questions this thesis asks. Specifically, literature which addresses geographic notions of place as these relate to urban Indigeneity and Inuit conceptions of 'land'. Other literature to be addressed relates to how urban Indigenous peoples create connections to the land within urban settings, and the role of urban place-making in fostering connections and cultural identities related to the land. 


\section{Chapter 2}

\section{Conceptual Framework and Literature Review}

This research seeks to understand the significance of nuna ('the land') to Inuit residents of Ottawa, and the role of urban place-making in fostering connections to the land; that is, the cultural meanings, practices, and values associated with the land. In order to frame these questions, I begin by presenting the concept of nuna as it is conceptualized by Inuit. This discussion provides the reader with a deeper understanding of the meanings of the land to Inuit. The relevance of the land will become evident later in the thesis (particularly in Chapter 4 and Chapter 5), when we are introduced to urban Inuit who demonstrate that the significance of the land, and the various meanings associated with the land, surpass geographic boundaries (e.g. North versus South; urban versus rural).

Related to the idea of geographic boundaries is that of 'place'. The notion of place has long been part of the colonial and post-colonial discourse in Canada as it relates to Indigenous people and their lands. This is particularly the case when considering the construction of colonial cities, which were defined as settler spaces (Jacobs, 1996). From the colonial perspective, Indigenous presence was restricted to reserve or rural space (Tobias, 1983, as cited in Wilson and Peters, 2005: 397). This apparent dichotomy has important implications for urban Indigenous people, their lives in cities, and their efforts to foster connections to the land within urban environments. Thus, $\mathrm{I}$ begin by presenting Inuit concepts of nuna. This is followed by a discussion on the concept of place as it is 
theorised in Human Geography. I then present a discussion surrounding discourses of the land and city, as they relate to the notion of Indigenous people' 'place' in cities, and the place of Indigeneity in cities. The chapter ends with a discussion of the relevant literature examining urban Indigenous peoples' connections to the land and place within urban environments.

\subsection{Inuit Conceptualizations of the Land}

This thesis examines the significance of the land to urban Inuit, and the role of urban place-making in fostering dynamic connections to Inuit lands and culture within urban settings. To begin, I present a discussion of Inuit conceptualizations of the land, the significance of the land, and the meanings, practices, and values associated with the land.

Indigenous ontologies and epistemologies recognize the land as the source of all existence (Simpson, 2008). For Inuit, nuna is the Inuktitut word which translates to mean 'land'. However, nuna tends to encompass meanings that are far more complex than a simple reference to physical land (Wenzel, 2004). For Inuit, nuna or 'the land' (which shall be used interchangeably) is a holistic, all-encompassing concept that relates living things in a web of interconnections to their environment (ibid.). More accurately, nuna relates to "total habitat including the sea, the ice, the mountains, the air, the animals, fish, and even souls and memories of events and the people who live in the past" (Jessen Williamson 2006:19; Nuttall 1992). Thus, connections to the land extend far beyond the mere physical. Inuit knowledge (i.e. Inuit Qaujimajatuqangit ${ }^{28}$ ), ethics (e.g. respect for

\footnotetext{
${ }^{28}$ Inuit Qaujimajatuqangit is defined as "encompassing all aspects of traditional Inuit culture including values, world view, language, social organization, knowledge, life skills, perceptions and expectations (Wenzel, 2004:204). IQ is thought to be such an important concept to Inuit society that the Government of Nunavut has made it a guiding principle in the making of policy and procedures affecting Nunavutmiut
} 
land), values (e.g. sharing), mythology (e.g. the legend of Sedna ${ }^{29}$ ) and cultural identity are generated, negotiated and shared between generations in relation to activities that take place on the land, from berry picking to seal hunting (Freeman, 1993).

The concept of nuna has been a fundamental aspect of Inuit culture and identity for thousands of years. These deep connections stem from Inuit being Arctic peoples that have lived in close relationship with the land for generations (Krupnik and Jolly, 2002). The depth of the interdependent relationship that exists between Inuit and the land is demonstrated in the following quote by Elder Marino Aupilaarjuk: "The living person and the land are actually tied up together, because without one the other doesn't survive and vice versa" (originally quoted in Price, 2008: 131). Before European contact, everything the people needed to survive came directly from the land. However, the land not only offered a source of food, shelter, and clothing; through their close relationship with the land Inuit develop their own rich forms of knowledge, practices, skills and values:

Every part of the land offers a key to surviving and thriving. The land itself offered shelter as shelters were built from snow and ice. The stones from the earth were carved into tools, the Qulliq (lamp) and offer a variety of stones from which to build navigational, communication and hunting aids (i.e. Inuksuit) The ground vegetation in the summer months offer berries, herbs for tea and medicinal aids. Animals offer more than the obvious sources of food. Animals offered clothing, blankets and padding for sleeping, bones for tools and games, and so forth. All of the tools for hunting and survival even the tools for building transportation all came from the surrounding land. Inuit are indeed ingenious masters of the land.

(Tester and Irniq, 2008), thus also highlighting the significant role the land plays in Inuit lives and the various ways it is expressed.

${ }^{29}$ The legend of Sedna is a well-known Inuit story which describes the creation of sea mammals. 
The skills for life on the land are still taught to children from birth. Young children accompany their parents as they go out on the land to learn everything from traditional hunting and tracking methods to berry picking and clam digging. Sewing skills are also taught early as it is still a root part of Inuit culture born out of surviving on the land.

When out on the land many stories were taught to children in order to pass on knowledge. Many were in the form of Inuit legends designed to keep children away from the many possible dangers that accompanied living on the land ${ }^{30}$.

Inuit had (and continue to have) great respect for the land as their source of survival, place of dwelling, and culture (Bennett and Rowley, 2004). The land and the people were seen as interconnected and interdependent on one another for their mutual well-being:

The living person and the land are actually tied up together because without one the other doesn't survive and vice versa. You have to protect the land in order to receive from the land. If you start mistreating the land, then it won't support you [...] In order to survive from the land, you have to protect it. The land is so important for us to survive and live on; that's why we treat it as part of ourselves. (Mariano Aupilaarjuk, as quoted in Bennett and Rowley, 2004: 118)

This deep connection, stewardship, and sense of belonging on the land is further exemplified in group naming (Bennett and Rowley, 2004). People felt that they belonged to the land and named themselves accordingly. Each regional group referred to themselves as the "-miut' (i.e. people) of the place. For example, Inuit living in Baker Lake (Qamani'tuaq in Inuktitut) would be called Qamani'tuarmiut. Similarly, Inuit residents living in Ottawa often refer to themselves as Ottawamiut (i.e. Inuit of Ottawa).

In modern times, the land continues to be vitally important in the mixed economy of northern communities (Berkes, 2005). Furthermore, for Inuit the land holds deep

\footnotetext{
${ }^{30}$ Ottawa Inuit Children's Centre Cultural website, 'Life on the land'. http://icor.ottawainuitchildrens.com
} 
meaning that is closely linked to health and well-being (Borre, 1994). Country foods harvested from the land are viewed as "real food" imbued with the power to maintain health through the nourishment of the body and the soul (Borré, 1994), and are therefore perceived as healthier than store bought foods which are viewed as nutritionally deficient, and laden with chemicals and preservatives. Furthermore, country foods are the product of a social system and spiritual relations connected with being on the land and hunting/gathering, representing far more than a meal, but rather a healthy culture (Usher et al., 1995). Recent studies have shown maintaining connections to the land is vital to Inuit identity, and is associated with maintaining good health and wellbeing, in both northern communities (Donaldson, 2007; Kushwaha, 2007) and urban settings (this thesis).

This thesis aims to gain a deeper understanding of the significance of the land to Inuit residents of Ottawa. This section has provided insights into Inuit conceptualizations of the land and its varied significance (e.g. as a source of history, knowledge, practice, values, identity, etc). As this thesis is also concerned with urban place-making, the following section shall provide a brief discussion of the relevant concepts of place as they are theorized in Human Geography, with particular emphasis on how the association of Indigenous people with the land has been used to justify their exclusion from urban spaces.

\subsection{Concepts of Place}

Place is defined in various and competing ways in Human Geography based on the particular philosophical perspective of the theorist. Generally, place is defined as a 
meaningful location with the following fundamental characteristics: 1) Location; 2) Locale; and 3) Sense of place (Agnew, 1987). Location refers to the located nature of place. Locale refers to the material setting of social relations. Sense of place refers to the subjective emotional attachment people have to place. Conceptualised in this way place is understood as not only physical, but also partially created through our own emotional experiences.

Place, according to Tuan, is fundamentally defined by a sense of attachment and the affective bond between people and place (Tuan, 1974: 4). One of Tuan's key argument is the distinction between the abstract realm of space, and a felt experience of place. Relph's (1976) 'identity with place' expands Tuan's argument by describing how places may be thoroughly understood in terms of the meaning and intensity they inspire in people identified with those places. He defines identity with place through the concept of insideness, which is the degree of attachment, involvement, and concern a person or group has with a particular place. In contrast, he conceptualizes the notion of outsideness - a sense of strangeness and alienation, such as often felt for newcomers to a place (Relph, 1976).

While such humanistic notions of place are no doubt useful and provide insights into how human beings interact with place, they can also be limiting and exclusive. For instance, Tuan's view is that mobility is adverse to place-making and place attachment, and yet we live in an increasingly mobile world (1977). Critical cultural geographers with backgrounds in Marxism, feminism, post-structuralism have all developed in-depth critiques of Tuan and Relph's theorizations of place in particular (Rose, 1993; Massey, 1994, 2005; Harvey, 1993). Place as it is understood by humanistic geographers and 
philosophers, they argue, is far too vague a notion. It ignores power relations and forces of exclusion that work through a contested association with location, meaning and practice. Rather, they view place as a social construction. This view of place as a social construction, with inherently complex power relations and as contested space/place, is central to this thesis, as it relates to Inuit place-making in Ottawa.

Particularly influential to this notion of socially constructed place is Massey's development of a 'progressive sense of place', which has been widely cited as a plea for a new conceptualization of place as open and hybrid - a product of interconnecting flows or routes rather than roots (Massey, 1994; Anderson, 2008). For Massey, places are the product of multiple intersecting mobilities, and are open to change associated with multiple identities and histories. They are defined by outside forces as much as by internal processes. Places, as such, do not have clearly defined boundaries. Places viewed this way are always porous. Thus, place is characterized as: 1) process; 2) defined by outside forces; 3) the site of multiple identities and histories; and 4) uniqueness defined by its interactions (Massey, 1994). This conceptualization of place is particularly useful when talking about the place of Indigenous people within urban environments, from which they have been historically excluded and deemed 'out of place'. This is the framework that I adopt in this thesis. As we shall see, Inuit places and place-making efforts in Ottawa are dynamic processes. They are sites of multiple Inuit identities and histories-since Inuit living in Ottawa come from all across the Arctic-and yet, Inuit themselves are unified and recognized as a unique collective Indigenous group in 
Canada. This thesis will demonstrate that the power of that collectivity relates to the social, cultural, spiritual and linguistic relationships associated with the land.

\subsection{Urban Indigenous $=$ 'Out of Place’?}

The question of how space and place are implicated in the construction and reproduction of minority groups has become an important focus for cultural geographers and others (Peters, 1996; Razack, 2007). Groups that are socially constructed as 'other' are assigned to spaces and places which express their marginalization and these spatial arrangements contribute to the reproduction of racial and minority group categories (ibid).

Consider the case of Indigenous people in Canada. Common ideas about Indigenous people have emerged out of a colonial history that has created a presence which shapes any attempts to analyse the situation of contemporary Indigenous people (Peters, 1996; Warry, 2007). How Indigenous people are defined in Western thought sets up a fundamental tension between the idea of Indigenous culture and the idea of modern 'civilization' (Das Gupta, 2007). With respect to Indigeneity, discourses of the land and the city have often been defined in marked contrast to one another (Todd, 2001).

Historically, Indigenous people were characterised as the power of nature in human form (Goldie, 1989, as cited in Wilson and Peters: 400). Thus, Indigenous people were understood in relation to the uncivilised "natural world" and through their associations with the land; the separate space where they belonged (ibid.). The image of Indigene in European thought required separation in both space and time, as a prerequisite for the authenticity of Indigenous cultures (Peters, 1998). This spatial and 
temporal separation was formally realized through the construction of colonial cities (Jacobs, 1996).

In Edge of Empire: Postcolonialism and the City (1996), Jacobs describes how the successful exploitation of colonial resources required cities to be built in the colonies. Cities functioned as centres of colonial administration, sites of local production and consumption, and conduits for the flow of goods and services. Cities were important sites in the transfer of modern capitalist culture to new worlds, and were important sites in the deployment of the technologies of power through which Indigenous people were categorised and controlled (Jacobs, 1996).

European social constructions of indigeneity maintained that the authentic Indigenous person was historic, natural, pre-modern, uncivilised, oral, land-based, and thus, non-urban (McClintock, 1995: 40 as cited in Peters, 1998) describes these cultures as existing in "anachronistic space...pre-historic, atavistic and irrational, inherently out of place in the historical time of modernity" (emphasis added; originally cited in Wilson and Peters, 2005: 398). Authentic Indigenous places were associated with places distant from the metropolitan centres of society (Wilson and Peters, 2005). These mappings of space and identity began to increasingly mean that urban places were seen as places where Indigenous people were 'out of place' (Peters, 2002). For example, in Canada, the protection, civilization, and assimilation of Aboriginal peoples was accomplished primarily through the Indian Act of 1876, which established reserves as physical and legal entities separate from urban centres (Peters, 2000 as cited in Tobias, 1983). Reserve and rural locations were spaces where Aboriginal peoples "belonged". In contrast, urban areas were defined as settler spaces (Newhouse and Peters, 2003). In other words, to be 
Indigenous and living in an urban setting was perceived as incompatible (ibid.). These colonial ideas remain prevalent even today. For example, with respect to Inuit they are a familiar part of Canadian identity (e.g. consider the cultural appropriation of the Inuksuk as a national symbol to promote the 2010 Winter Olympics in Vancouver); however, these artifacts largely exist in the popular imagination of the dominant society as 'exotic' and residing in remote, northern communities (Steckley, 2008).

Colonial policies of exclusion contributed to the geographic, economic, and political marginalization of Aboriginal peoples (Helin, 2006). For example, the federal government asserted that its obligations were limited to reserve borders. In other words, the government took no responsibility for Aboriginal peoples living off-reserve. Indigenous people who chose to live in cities were seen as an anomaly or as people who had turned their backs on their culture (Newhouse and Peters, 2003). Until 1999, they could not participate in band politics or programs, or benefit from the expenditure of band capital or revenue monies (Peters, 1997; Peters, 1998). Instead, they were expected to assimilate into the non-Indigenous world, and break ties with their communities (ibid.).

The social construction of the 'authentic' Indigenous person as historic and nonurban, has serious implications for how Indigenous people have been (and continue to be) depicted in relation to cities. In Peters' (1996) analysis of four non-fiction books (written by non-Indigenous people) which attempt to present and analyse the nature of the urban experience for Indigenous people living in Canadian cities, the author found that city life was typified as a source of social problems (i.e. alienation, poverty, homelessness, substance abuse) for Indigenous people. The emphasis upon the struggles of Indigenous people living in cities was taken as evidence to reinforce popular beliefs that Indigenous 
cultures and urban life were incompatible. Indigenous people suffered while living in urban environments because they were deemed to be out of place.

Due to the often difficult socio-cultural and economic circumstances on reserves, during the mid- $20^{\text {th }}$ century, growing numbers of Aboriginal peoples migrated to cities in search of better lives and opportunities (Wilson and Peters, 2005). Indigenous urbanization was framed as a matter of 'cultural adaptation' (i.e. assimilation/integration into mainstream, non-Indigenous society). Parallels can be drawn between this example, and the government's centralization policy implemented in the North (detailed description provided in Chapter 1), which led to the sedentarization of Inuit into settlements in order to facilitate their assimilation into Canadian society. In both cases, Indigenous people were expected to shift their lives in alignment with the ideals, norms and values of the dominant society. In the case of First Nations, Federal and provincial government programs attempted to address the economic and educational needs of Indigenous people in urban areas while giving little or no thought to addressing their cultural needs ${ }^{31}$.

\footnotetext{
${ }^{31}$ Instead, in an effort to address the needs expressed by their communities, concerned individuals began to organize and develop culturally-specific and appropriate programs and services to community members, while also providing safe spaces for the inclusion of Indigenous cultures within cities (Warry, 2007). In Canada, this push for the establishment of specialised agencies to provide culturally appropriate services and programs to urban Indigenous people residing in cities lead to the Friendship Centres concept. The concept of Friendship Centres originated in the mid-1950s as more Indigenous people were moving to urban areas. It was not until 1972 that the Canadian government formally recognized the National Association of Friendship Centres to represent the growing numbers centres and the national level. And not until 1988 did the federal government implement permanent funding for the centres through the formation of the Aboriginal Friendship Centres Program, thus demonstrating a resistance to change long held ideologies (ibid.). While there is no similar program specifically for Inuit, many Inuit residing in urban centres take advantage of services offered by Friendship Centres. This is especially the case in urban centres lacking Inuit-specific community-based service agencies.
} 
During this period of time, Inuit began to migrate to cities as well, although, at first, for different reasons and not always by their own volition. Some of the first Inuit to travel south did so in order to receive treatment for respiratory infections, such as tuberculosis (INAC, 2008). Incidences of respiratory infections were high among Inuit throughout the early part of the 20th century, but became increasingly prevalent during the 1940s (Grygier, 1994). Rather than constructing treatment facilities in northern communities, the government sent large numbers of Inuit to sanatoria and hospitals in southern Canada for treatment. In 1956, approximately $10 \%$ of the Inuit population was receiving medical treatment, mainly for tuberculosis, in southern Canadian hospitals (ibid). Later, during the 1960s and early 1970s, because few northern communities had facilities for secondary and vocational education, young Inuit seeking further education were required to leave their communities to live in school residences in larger northern communities like Iqaluit and Yellowknife, and in urban centres like Montréal and Churchill. Post-secondary studies required even greater relocations, often to communities like Montréal and Ottawa where colleges and universities were available (INAC, 2008). Government reports documenting the experiences of Inuit during this period of time reflect a "between two worlds" sentiment which suggests a framing of Inuit being out of place in urban environments:

Inuit who relocated for academic purposes often found it difficult to live isolated from their families, and to make the transition from living in northern, rural communities to urban cities in Southern Canada. Accessing traditional food resources, and participating in traditional subsistence and cultural activities was difficult in urban centres. Some Inuit experience problem reintegrating themselves to their home communities after they had lived in urban cities and had obtained post-secondary degrees (INAC, 2008: 121). 
During the early 1970 s, small numbers of Inuit migrated to southern urban centres in search of better employment opportunities. In the 1980s, as an alternative to formal education and to improve Inuit employment rates, the Department of Indian Affairs' Indian and Inuit Recruitment and Development Program sponsored on-the-job training in community and business administration for Inuit through several government agencies and organizations located in urban centres (INAC, 2008). Sponsors included Inuit Tapiriit Kanatami (ITK), Makivik Corporation, and the Vocation Training Section of INAC, among others. By 1980, approximately 60 Inuit were working in urban centres, with the majority living in either Montréal or Ottawa. Most worked at Inuit organizations like ITK or Makivik Corporation, at INAC, or at the CBC Northern Service. These early Inuit migrants were also characterised as experiencing difficulty integrating into southern, urban life: "Inuit living in southern cities often experienced culture shock, homesickness, lack of access to country foods, isolation, difficulty understanding cultural rules, and difficulty conversing in English" (INAC, 2008: 124), suggesting they were 'out of place'.

This section discussed colonial notions of place and Indigeneity that relate to this thesis. Specifically, we examined how such conceptualizations of Indigenous peoples as rooted to land and place outside of cities have been used to exclude Indigenous presence from cities (i.e. the notion that urban and Indigenous are mutually exclusive concepts). The following sections examine how urban Indigenous people maintain their connections to the land and actively 'make place' for themselves in urban centres. 


\subsection{Contemporary Meanings of the Land for Urban Indigenous people}

As explored above, the tendency of dominant societies to equate Indigeneity with concepts of 'wilderness', the hinterland and natures (McClintock, 1995; Jacobs, 1996 ; Peters, 1996; 1998, 2000, 2002; Todd, 2001; Newhouse and Peters, 2003; Das Gupta, 2007). This binding of Indigenous people to remote lands, has had serious implications for these groups by fixing them to tradition, the past, and as non-modern peoples frozen in time (ibid.). As a consequence, the powerful 'othering' of Indigenous people has often separated them from contemporary life in the minds of the dominant society.

Others criticize that it has become something of a cliché to state how attached Indigenous people are to the land, even as settler societies deny their access to and ownership of it (Usher, 2003). The tendency to overemphasize Indigenous relationships to the land as 'natural' and taken for granted, also risks de-emphasizing their agency. The success of Indigenous people living in close relationships with the land has been the result of a sophisticated and in-depth set of skills and knowledge acquired and refined over long periods of time:

[...] emphasis upon the land tends to maintain a silence on the agency of Aboriginal people, treating Aboriginal people as holding a position on the land, as if, merely of residence. Yet the significance of the land is a consequence of the success of Aboriginal people in developing and using their technology and cultural and social resources to adapt to their natural surroundings and to use it effectively to sustain survival and reproduce their cultural and social organisation. (Todd, 2001)

This denial of the agency of Indigenous people and the emphasis upon Indigenous people' place being on the land, further complicates the perception of their agency and involvement in urban life: 
With this emphasis upon the land, it seems that by implication, the culture, identity and governance of Aboriginal people is not associated with urban living, with participation in the life of cities or the governance of cities. Yet, despite the continuing symbolic assertion of the importance of the land by Aboriginal elders and leaders, there has been a progressive migration of Aboriginal people away from the land, off reserves and to urban areas, including large metropolitan areas. This migration is leading to changes in the relation between the land and the city and the emergence of new discourses (emphasis added; Todd, 2001: 52).

While Todd's arguments help to problematize discourses of the land and city as they relate to Indigenous people, clearly, there needs to be deeper understanding of what the land signifies for urban Indigenous people. Only then will Indigenous and nonIndigenous people alike be able to move beyond the dominant narrative of 'rural = Indigenous' and 'urban = non-Indigenous'. Gaining a deeper understanding of what the land means to urban Indigenous people, not only challenges dichotomous conceptualizations of indigeneity and place, but also contributes to "the emergence of new discourses" (Todd, 2001: 52). This sentiment is echoed by Dirlik (1996) who argues that:

The insistence on a special relationship to the land as the basis for Indigenous identity is not merely spiritual, an affirmation of an ecological sensibility, but also calls for a transformation of the spatial arrangements of colonialism or postcolonialism (1996: 21 as cited in Wilson and Peters, 2005: 400).

In this way, urban Indigenous people are able to draw on their historic relationships to the land in order to construct 'alternative futures' for themselves which are relevant to their present-day lives (ibid). Since many urban Indigenous peoples live far-removed from their rural or ancestral homelands, many anchor themselves to a largely symbolic sense of the land (Todd, 2001; Howard and Proulx, 2010). The active memory of land and efforts to revive and sustain it, therefore grounds Indigenous peoples in cities 
differently, yet actively, despite lived dislocations and disjunctures (Clifford, 2001: 481). Although definitions of memory, collective memory and cultural memory are widely debated, for the purposes of this thesis, I adopt a definition which highlights the relationship between memory and culture:

Cultural memory is a form of collective memory, in the sense that it is shared by a number of people and that it conveys to these people a collective, that is, cultural, identity. [...] Cultural memory is a kind of institution. It is exteriorized, objectified and stored away in symbolic forms that [...] are stable and situation-transcendent: they may be transferred from one situation to another and transmitted from one generation to another. (Assmann, 2010: 110-111)

In terms of identity construction, cultural memory preserves the store of knowledge from which a group derives an awareness of its unity and peculiarity (Assmann, 2011). The objective manifestations of cultural memory are defined through a kind of identificatory determination in a positive ("We are this") or in a negative ("That is our opposite") sense (ibid.).

The desire of urban Indigenous people to construct alternative futures for themselves in cities was strongly voiced in the Royal Commission on Aboriginal Peoples (1996). The report brought to the forefront the issues of urban Indigenous people in Canada, emphasizing their desires to live good lives within cities, to maintain and develop distinctive Indigenous cultures which are more than heritage, and to exercise significant governance over their daily lives, both as individuals and as communities. The Commission made an important first step in changing the popular view that Indigenous cultures and urban environments were mutually exclusive. The report emphasized the importance of culture to the well-being of urban Indigenous people: 
Aboriginal people stressed the fundamental importance of retaining and enhancing their cultural identity while living in urban centres $[. .$.$] maintaining$ that identity is an essential and self-validating pursuit for Aboriginal peoples in cities (RCAP, 1996, as cited in Newhouse and Peters: 8).

The report stated that in order for Indigenous people to live successfully in cities there is a need to support the elements which they consider to be an integral part of their cultural identity, such as: spirituality, language, a land base, elders, values and traditions, family and ceremonial life (RCAP, 1996). Connections to the land, together with the rituals, ceremonies, traditions, values and meanings associated with these connections are particularly significant to the reinforcement and development of dynamic urban Indigenous communities and identities. This is to say, that these forms of identity-making while 'traditional' are contemporary manifestations and not fixed temporally in the past-they draw upon tradition in ways that work and are relevant to contemporary urban Indigenous peoples and their urban realities (Howard and Proulx, 2010).

By honouring their cultural identities in cities, urban Indigenous people actively create place for themselves in what has historically been a hostile and exclusive environment for the expression of indigeneity. As elaborated by Watson (2010: 273), the increase in urban Indigenous populations does not signify an end in Indigenous communities, but rather draws greater attention to what he calls "diasporic Indigeneity", which is the fluid negotiation and extension of modern Indigenous identities and histories in nonlocal settings (emphasis added). When viewed this way, in terms of place:

Indigenous out-migration is not about the loss of place but about refiguring and redefining the reality of Indigenous places and communities in the contemporary world in and through the lived experiences of its people. (Watson, 2010: 273) 
Learning about the ways in which urban Indigenous people make place for themselves within urban environments not only challenges long-held assumptions about the rightful place of Indigenous people, but also serves to develop more accurate and informed understandings of modern, urban Indigenous communities. Furthermore, in exploring the issue of land, it is possible to gain a deeper understanding of how land meanings extend themselves into urban environments, and influence the construction of urban Indigenous identities; thereby challenging the notion that when one is removed from the land, one is divorced from the meanings, practices, and values associated with the land (Dirlik, 1996; Peters, 1998; Wilson and Peters, 2005; Watson, 2010).

Until this point, we have explored Inuit conceptualizations of nuna ('the land'), discussed colonial notions of indigeneity and the place of Indigenous people with cities, and problematized discourses of the land and city as they relate to Indigenous people.

This research is interested in gaining a deeper understanding of the significance of the land for Inuit residents of Ottawa, and the role of urban place-making in fostering connections to the land. In the following section, I situate this research within an emerging body of literature which examines the how Indigenous people actively 'make place' for themselves within urban space, thereby fostering links to land, culture, and identity.

\subsection{Research on Urban Indigenous Connections to the Land and Place}

Emerging research demonstrates that creating connections to the land continues to be important to many urban Indigenous people, for various reasons including the formation of positive personal and cultural identities, the revival of cultural practices, the 
symbolic reclamation of contested urban lands, the transfer of Indigenous knowledge to urban Indigenous youth, as well as the maintenance of overall health and wellbeing (Lobo, 1998; 2002; Anderson, 2000; Wilson and Peters, 2005; Greenop, 2009; Howard and Proulx, 2010; Watson, 2010). Urban Indigenous people express their connections to land and culture through place-making efforts which occur at many scales and in various ways, thereby demonstrating both creativity and agency in fostering new and dynamic relationships to land which fit their contemporary lives. The creation of small-scale cultural spaces, the revival of ceremonial practices, and the creation of larger-scale cultural spaces are some of the ways urban Indigenous people are extending their connections to the land to urban settings.

Maintaining connections to the land within urban environments becomes significant for urban Indigenous people that live at great geographical distances from their 'home' communities. These individuals, which include Inuit, do not always have the ability to travel back and forth between their rural and urban homes to re-establish and reaffirm their connections to the land, as is often the case for many Indigenous people living in cities whose homelands are more geographically accessible. Wilson and Peters (2005) found that maintaining strong relationships to the land was vital to the cultural identity, and health and wellbeing of urban Anishinabek peoples living in the Toronto area, who lived far away from their home communities. Although urban Anishinabek peoples had less access to the land than their reserve counterparts, rather than losing their connection to land, they 'made place' for cultural practices within urban space. This was accomplished through the creation of small-scale cultural spaces within the city, such as in backyards, secluded areas of public parks, or even within their private residences. 
Connections to the land were created by offering tobacco to Mother Earth, burning sweetgrass in smudging ceremonies, planting and tending gardens, spending time with elders, and also holding onto beliefs in the Creator and Mother Earth. Such strong cultural beliefs surpass geographic boundaries and remind urban Anishinabek peoples of their connection to Mother Earth no matter where they are, whether it be on reserve, or in the city. This connection to land which surpasses the boundaries between urban and rural, or between urban and Indigenous homeland, was echoed in the work of Lobo (1998) who found that urban American Indian people residing in the San Francisco Bay area considered the city to all be part of their 'urban territory'. That is, individuals recognize and reclaim their connection to ancestral lands from which they were displaced during the settling of the United States.

Similarly, Anderson (2000) found that the revival of certain ceremonies served to strengthen urban Aboriginal women's connections to the land. For instance, Aboriginal women are reclaiming their relationship to the moon through ceremony as a means of recapturing a sense of their femininity, as Grandmother Moon is associated with female energy. The revival of ceremonies has also served to pass knowledge onto urban Aboriginal youth and reaffirm their connections to the land. For instance, participation in berry fast ceremonies for young urban Aboriginal girls entering puberty marks their entry into womanhood, and helps young girls understand their power in relation to the earth as mother:

Celebrate that young girl who has just become a woman. That's a gift we are given! Celebrate that first flow, that is like the earth, when she's flowing in the springtime. (Edna Manitowabi, as quoted in Anderson, 2000: 186) 
Certain rites of passage such as the berry fast are experiencing a rebirth in urban Indigenous communities, and are being practised in such as way that they support the needs of contemporary Indigenous people.

In additional to small-scale cultural practices, links to the land can also be facilitated through the creation of safe cultural places within cities which exist at the community level. Greenop (2009) found places with the Indigenous community of Inala (an outer south-western suburb of Brisbane, Australia with an Indigenous population of $7.3 \%$ which was established sixty years ago) that were significant included an urban Indigenous preschool which taught Indigenous languages and cultural practices, a park often used for gathering, and a group of Indigenously-run shops. This desire to be rooted in place involves finding or creating social networks which support urban Indigenous people in their desire to maintain their identities within a mixed-race setting. Contemporary people who may live far from their home countries, or for whom home countries do not hold any direct experience or memory, still feel the need to be rooted in place, a strong cultural value within Indigenous Australia.

Similarly, in a recent place-based study focusing on the articulation of urban Ainu identities in Tokyo, Japan, Watson (2010) found that rather than being 'out of place' in cities or divorced from traditional homelands, Ainu peoples create place for themselves in urban environments which extend their relationships to land and culture across boundaries which are commonly conceptualised as impenetrable. Places of importance to urban Ainu identity and community were found to be a local Ainu-run restaurant, The

\footnotetext{
${ }^{32}$ As compared to $1.4 \%$ Indigenous population in the rest of Brisbane which has a majority Caucasian population (Greenop, 2009).
} 
Rera Cise, which not only served traditional Ainu foods, but also served the community with a place to conduct cultural ceremonies and gatherings. The restaurant provided the Ainu community with a place to congregate, socialize, and practice cultural activities in a safe space without fear of external interference. A second place of importance to urban Ainu was the Ainu Cultural Exchange Centre, a public place dedicated to the promotion of Ainu culture, as well as cultural exchange between Ainu and non-Ainu peoples in Tokyo. Through these examples Ainu living in Tokyo demonstrate the multiple ways they create attachment and belonging in the city, while at the same time asserting their inextricable links to family and historical relations to homelands. Watson found that this challenges both the static idea of Ainu life being tied to ancestral lands, and the notion of urban Ainu movement evolving independently of 'home'.

On her work with urban American Indian peoples residing in the San Francisco Bay area, Lobo (2002) found that in an urban community where there is no land-base to provide a source of identity, urban Indigenous organizations come to powerfully represent Indigenous "space" or "a place that is Indian", and are intimately tied to identity. Similarly, friendship centres in Ontario have met the cultural, social and recreational needs of urban Aboriginal peoples living in cities by promoting and supporting Aboriginal cultures and identities (Howard, 2010; Manitowabi, 2010).

These studies demonstrate the multiple ways urban Indigenous people 'make place' for themselves within cities which foster connections to the land that benefit and suit their contemporary lifestyles. They show that urban Indigenous connections to the land are complex. Rather than a break from tradition, contemporary relationships to the land for urban Indigenous people represent transformation and continuation - that is, an 
evolution of place meaning, attachment and identity - which adds to, rather than depletes, indigeneity (Wilson and Peters, 2005; Howard and Proulx, 2010; Watson, 2010). The following section takes a more focused look on the literature pertaining specifically to urban Inuit, land, and place.

\subsection{Research on Urban Inuit Connections to the Land and Place}

Currently, there are few studies which examine the significance of the land and urban place-making to Inuit living in cities. This is partly because research which highlights urban Inuit issues is a relatively new area of study. Interest in recent phenomena such as Arctic urbanization and increased southerly migration of Inuit to urban centres are credited with improving the profile of urban Inuit issues both in research and policy areas (Kishigami and Lee, 2008). As a result, urban Inuit issues have slowly begun to attract more attention. For instance, a recent issue (i.e. Volume 30 (1), 2008) of the journal Études/Inuit/ Studies entiled "Urban Inuit", focused specifically on some of the work being conducted in this emerging area of research. Though there is a limited amount of literature on the subject, the following studies do highlight the significance of place and land to Inuit living in urban areas.

Fogel-Chance (1993) demonstrates the importance of the home as a place where Inupiat women living in Anchorage can employ cultural strategies which are considered vital to their successful adjustment to city life. Within their households, Inupiat women were able to shelter themselves from outside influences, and create a place that reinforces their cultural distinctiveness from that of the dominant society. The household is a place 
where Inupiat women can maintain cultural values such as sharing country food and other resources, participate in traditional child rearing practices and divisions of labour, and gather to sustain strong social networks with other Inupiat peoples, both those living in Anchorage and in their rural communities. In this way, Inupiat women are able to participate in aspects of land-based practices and values, and feel connected to their rural communities while living in an urban setting.

Examining connections to land at a different scale, Lee (2003) highlights the significance of place in her examination of the multifaceted role of the Alaska Federation of Natives crafts fair in the lives of Yup'ik women who have left their home villages and moved to Anchorage. Clearly the crafts fair is a place that serves many purposes: it is marketplace, social club, and, increasingly, a political forum. It is a place where a diverse array of Indigenous arts and crafts can be showcased and celebrated:

Grass baskets from the Yup'ik area join beaded moccasins and folded birch bark containers from Interior Alaska. From Nunivak Island come hats and scarves knitted of muskox wool as light and as soft as thistledown. Walrus ivory and whalebone carvings from Bering Strait are arrayed alongside caribou skin masks from the North Slope. Dolls with the Siberian Yupik style bead-wrapped hair braids [...] The artisans admire bundled stalks of the rare, purplish basket grass from Goodnews Bay, rolls of translucent sea mammal intestine for doll and parka making; ugruk (bearded seal) boot soles for mukluks, and sealskin for Eskimo yoyos (Lee, 2003: 584).

The fair, in addition to its function as an economic venue and a place where social bonds are created and strengthened, is also a site of political organization and activism in the subsistence debate, as Alaskan Natives struggle to secure priority over resources which are critical to their livelihoods. This study clearly demonstrates that for this group of 
urban Indigenous people, participating in the arts and crafts fair is an effective strategy for maintaining connections to the land, and a significant feature of their lives in the city. Through crafts they are able to remain connected to their rural villages and participate in culturally significant activities, which then translate into great economic, social, and political benefits.

In contrast, Kishigami (2008) presents an examination of how the lack of cultural places impacts the lives of homeless Inuit living in Montréal. He demonstrates how difficult city life can be for seemingly 'placeless' urban Inuit when Inuit-specific community centres and services are absent. Without these 'Inuit places' of belonging it is nearly impossible for urban Inuit, particularly homeless Inuit, to develop strong social networks or participate in significant cultural practices which have been identified as important (e.g eating country foods, gathering with other Inuit, speaking Inuktitut) to their health and well-being in cities. Central to community-building in Montréal would be the creation of an Inuit-specific community centre, where Inuit could receive culturally appropriate programs and services, build strong social networks, and participate in culturally relevant activities.

In contrast, the documentary film "Urban Inuit" demonstrates how the protagonist (i.e. a homeless Inuk man living in Montréal) maintains his connections to the land, primarily by spending time in a specific park. While he recognizes that this park bears virtually no resemblance to his northern community, he is still able to feel connected to the land when he walks barefoot on the grass, wades in the fountain, or spends the night under a tree. This film presents an interesting point of view, and demonstrates not only 
the significance of feeling connected to the land for the character, but also the unique ways he expresses and extends his connections to the land within urban settings.

In terms of urban place-making, identity formation, and links to northern lands, Tomiak and Patrick $(2008 ; 2010)$ demonstrate that for Inuit living in Ottawa, "Inuitness" is re-territorialized through spaces and processes that symbolically, if not physically, connect urban Inuit to home communities and Inuit Nunaat. The urban Inuit spaces that are created and used as sites in this process are of particular importance. These sites provide linkages between networks of long-term urban residents and newcomers, all of whom are connected, in some contemporary or ancestral way, to the territorial Arctic. National organizations like Inuit Tapiriit Kanatami and Pauktuutit Inuit Women of Canada, as well as local organizations such as Tungasuvvingat Inuit, and the Ottawa Inuit Children's Centre, foster a growing sense of collectivity in Ottawa by acting as central nodes in these urban networks. The programs and services offered by Inuit organizations function as nodal points in networks that make it possible to move to and "survive" in Ottawa. They produce a sense of locality that explicitly includes the Inuit Nunaat, rendering migrants "rooted" in more than one society.

Similarly, Olofsson (2004) demonstrates the significance of place for the construction of Inuit identities in Montréal. Olofsson presents the narrative of Mary, a young woman with mixed Inuit and Innu heritage. While born and raised in Montréal, Mary was very influenced by her Inuit mother who had been raised in a small community in Labrador. As a child, spending the summers with her maternal grandparents allowed Mary to develop her sense of Inuit identity. As an adult living in Montréal, Mary was able to reinforce her Inuit identity by working as a counsellor at an Indigenous 
organization. By doing so, she began to feel like a member of the larger urban Indigenous community in Montréal.

This growing body of literature contributes to our understandings of the role of urban place-making for Inuit residing in southern urban centres. However, few of the studies examine with any level of depth the significance of the land to urban Inuit, nor the role of urban place-making in fostering connections to land, culture and identity for Inuit residents of Ottawa, which is a central question of this thesis. The following chapter describes the methodology and methods employed in this study. 


\section{Chapter 3}

\section{Research Approach and Methods}

\subsection{Decolonised Approaches to Research}

The qualitative methodological framework used in this study draws upon decolonising approaches to research. The following section provides an overview of these approaches and highlights why such a framework is appropriate for research with urban Inuit.

Calls for decolonised approaches to research with Indigenous people have become increasingly common (Tuhiwai-Smith, 1999; 2007; Howitt and Stevens, 2005; Denzin et al., 2008; Kovach, 2009). Participatory approaches are deemed the most appropriate methodologies by local people; they have the potential to right past wrongs, address community interests, build capacity, and address inequalities in power dynamics between researchers and local people (Dene Cultural Institute, 1994). 'Decolonised research' attempts to use the research process and findings to breakdown the cross-cultural discourses, asymmetrical power relationships, representations, and political, economic and social structures through which colonialism and neo-colonialism are constructed and maintained (Howitt and Stevens, 2005).

Decolonised approaches to research stand in stark opposition to colonial research; that is, research which reflects and reinforces domination and exploitation through the attitudes and differential power embodied in: research relationships with 'others', 
dismissal of their rights and knowledge, intrusive and non-participatory methodologies, and in the goals and uses of research findings (Howitt and Stevens, 2005: 32).

Colonial-type research is what Linda Tuhiwai-Smith (1999) refers to as 'research through imperial eyes ${ }^{33}$. She describes the approach as one:

[...] which assumes that Western ideas about the most fundamental things are the only possible ideas to hold, certainly the only rational ideas, and the only ideas which can make sense of the world, of reality, of social life and of human beings. It is an approach to Indigenous people which still conveys a sense of superiority and an overabundance of desire to bring process into the lives of Indigenous people - spiritually, intellectually, socially and economically. It is research that from Indigenous perspectives 'steals' knowledge from others and then uses it to benefit the people who 'stole it'. [...] It is research which is imbued with an 'attitude' and a 'spirit' which assumes a certain ownership over the entire world, and which has established systems and forms of governance which embed that attitude in institutional practices (56).

Thus, research practices based on colonial ideals undermine trust, and sabotage communication and collaborative exploration between researchers and 'others'.

In contrast, decolonising approaches to research aim for emancipation through respect for multiple forms of knowledge, ways of knowing and being, and through activism in support of Indigenous political pursuits, such as self-determination. Thus, decolonising research requires a fundamental shift in research approach and conduct that begins with a perception and response to difference and 'others', that is the opposite of the perspective and practice of colonial research. As such, decolonised research is:

[...] attracted to difference rather than wary of it, it seeks to interact rather than to remain distant, it coexists with, respects, and honours difference rather than

\footnotetext{
${ }^{33}$ In reference to Mary Louise Pratt's "Imperial Eyes" Travel Writing and Transculturation". 1992. London and New York. Routlege. 257 pages.
} 
dominating or exploiting it. This difference of attitude and intention makes for very different conceptions of the purposes of research [...] The purpose of the research instead become cross-cultural understanding, the celebration of diversity, and especially empowerment and emancipation (Howitt and Stevens, 2005: 36).

While decolonised approaches to research sound noble and straightforward on paper, negotiating these new relationships on the ground is often fraught with difficulty and uncertainty for both researchers and research participants/collaborators. Much tension and suspicion stem from the fact that research is often considered a "dirty word" to many Indigenous people, whom have had negative experiences with exploitative researchers and research practices in the past (Tuhiwai-Smith, 1999; 2007). While enlightened researchers attempt to forge new working relationships with Indigenous people it is often challenging to be viewed in a favourable light. Howitt and Stevens (2005) elaborate on the complexity of negotiating decolonised research relationships which:

[...] require acknowledging and challenging the dynamics that shape colonial research interactions with marginalised peoples, attempting to overcome whatever ethnocentrism and paternalism we bring to the research process, and whatever suspicion we are greeted with, persuading people that we are worthy of being taught and capable of learning, and being willing to put aside preconceptions (and academic and activist preoccupations), to listen and to be able to be of services to local concerns and projects (35).

This leads us to question, how does one go about "doing" decolonised research? For Tuhiwai-Smith (1999), cross-cultural research that is both ethical and concerned with outcomes that benefit Indigenous people, begins with critical awareness of how research is shaped by relationships, power, and ethics. She outlines the following strategies that 
can be used as guidelines to promote the shift towards more respectful and culturally sensitive relationships between Indigenous and non-Indigenous researchers:

1) The strategy of avoidance whereby the researcher avoids dealing with the issues of Indigenous people

2) The strategy of personal development whereby the researchers prepare themselves by learning the local language, attending community events and frequenting community centres, and becoming more knowledgeable about Indigenous concerns

3) The strategy of consultation with Indigenous people where efforts are made to seek support and consent

4) The strategy of 'making space' where research organizations have recognized and attempted to bring more Indigenous researchers and 'voice' into their own arrangements (Tuhiwai-Smith, 1999: 176-177).

These strategies involve different ways of making changes, although the first strategy of avoidance may not be helpful to anyone. Rather, Tuhiwai-Smith emphasizes that while the path towards negotiating new research relationships may be difficult and fraught with uncertainty, not doing so eliminates the possibility for change, growth, and a redefinition of relationships between researchers and Indigenous people (Tuhiwai-Smith, 1999). This perspective places emphasis on the roles and responsibilities that both Indigenous and non-Indigenous people have to play in decolonising research in order to foster more equitable relationships which can benefit all parties involved. Research conducted in this way challenges stereotypes which may be held on either side of a research relationship, and seeks to define new equitable positions from which to speak and act (Anderson and Jacobs, 1997; Peters, 2004; Denzin et al., 2008). 
Increasingly, Indigenous people are attempting to exert some degree of control over research that concerns them by writing their own research guidelines and protocols. For instance, consider: Guidelines for the Conduct of Participatory Community Research (Dene Cultural Institute, 1994); and Negotiating Research Relationships with Inuit Communities: A Guide for Researchers (Inuit Tapiriit Kanatami and Nunavut Research Institute, 2007). The need for community-based guidelines and protocols has arisen from the significant concerns local peoples have regarding the ways in which research is conducted and about the impacts of research activities on their communities (ITK and NRI, 2007). According to ITK, concerns include:

-Lack of input/consultation in identifying research needs and questions and in designing studies;

-Lack of involvement in the research process

-Token or cursory inclusion of local expertise in research

-Lack of recognition or compensation

-Generalization/decontextualization of local knowledge

-Appropriation of expertise and knowledge

-Inappropriate research methodologies

-Short, typically summer field seasons

-Lack of locally relevant or beneficial research

-Lack of funding for locally initiated projects

-Lack of data ownership

-Inadequate reporting by researchers, among others (ITK and NRI, 2007).

In recognition of the concerns listed above, and in the interest of redefining research relationships between Indigenous people and researchers, some government agencies and academic institutions have developed similar ethical guidelines. For instance, consider 
the Tri-Council Policy Statement: Ethical Conduct for Research Involving Humans (CIHR, SSHRC and NSERC, 2010); and Protocols and Principles for conducting Research in an Indigenous Context (University of Victoria, Faculty of Human Social Development, 2003). Matters of particular importance when negotiating research relationships with Indigenous communities include:

-Community consultation

-Involvement/employment of community members

-Informed consent

-Privacy and confidentiality

-Explicit attention to conflicts of interest

-Fairness and equity

-Respect for local cultures, customs, and authority

-Use of local languages

-Data control

-Financial compensation

-Recognition

-Communication of results, among others.

An underlying theme present throughout these protocols is the need for collaboration between researchers and community members. According the Tri-Council Policy Statement: Ethical Conduct for Research Involving Humans: "Collaborative approaches in research with Aboriginal communities are a means of facilitating mutually respectful and productive relations" (CIHR, SSHRC and NSERC, 2010: 123). The rationale for collaboration is grounded in a desire to protect the cultural property of Indigenous communities (i.e. traditional medicines, ceremonies, songs, rituals, and other sacred cultural traditions); in finding ways of avoiding negative stereotypes and 
misrepresentation; and in giving back to the communities that participate in the research, to ensure that Indigenous communities benefit from the research by influencing the topics being researched, learning skills, obtaining data for their own use, among others (Tuhiwai-Smith, 1999; Peters, 2004; Denzin et al., 2008).

Collaboration can be achieved in various ways, and requires consideration on a case by case basis. Areas of collaboration include: defining terms of the questions and the methods used; participating in and monitoring the research process; being trained in research skills; interpreting results; writing and being acknowledged in reports and papers; and making decisions about dissemination (Peters, 2004). In addition, as noted above researchers can make greater efforts to work in culturally sensitive ways, for instance by: preparing for research by learning the local language; interacting with participants in their own community venues; becoming informed about local concerns; seeking local support and consent for research; and honouring local cultural research protocols and negotiated research agreements, among others ((Tuhiwai-Smith, 1999). While not all communities are ready, able, or willing to participate in collaborative research efforts in the same ways, honouring collaboration as a guiding principle for research with local people can lead to unexpected opportunities for participation and involvement on equitable terms.

In terms of this research project, I have adopted strategies of personal development, consultation, and 'making space', as defined by Tuhiwai-Smith above. In terms of personal development, I have taken the time to develop relationships with Inuit community members and local organizations in Ottawa. I have done this through my work as a research assistant, participation in Inuktitut language classes, volunteer work at 
the Ottawa Inuit Children's Centre, and participation in community events. Through involvement and engagement with members of the local Inuit community in Ottawa, I have been able to build relationships and trust, while also gaining invaluable experiential knowledge which has served to better inform this research.

Through consultation I was able to gain a sense of community interest, "test the waters" regarding my research ideas, and see what overlaps may exist between them. In consulting with Elders, it became apparent they shared a desire to document their life experiences, both for preservation and for the education of others (e.g. younger generations, new migrants, non-Inuit). In terms of giving back, each Elder will be provided with a published copy of their life histories to share with their families, friends, or even the wider community if they choose to make their narratives available through local Inuit organizations.

The strategy of 'making space' ties into the primary method of data collection for the research, that is, the collection of life histories and semi-structured interviews. This method not only made space for clear and distinct Inuit voices within the thesis in the form of narratives, but also allowed for a certain degree of freedom and openness to be embedded within the research process itself. Although, my own inquiries were guided by a set of topics, the participants were by no means restricted. The participants spoke about a wide range of topics, at times guided by my questions, and at other times not. This openness and flexibility led to a far richer collaborative experience for both the participants and myself. 
However, it must be noted that even the most well-meaning research agendas may still bear attitudes of intellectual arrogance, paternalism, and evangelism. As Jones (2008) reflects:

Interrogating the logic of my own White/settler enthusiasm for dialogic collaboration, I consider how this desire might be an unwitting imperialist demand - and thereby in danger of strengthening the very impulses it seeks to combat (471).

The quote above highlights the importance of critical self-reflexivity. Furthermore, as Stevens (2005) cautions, collaborative and cross-cultural research is not easy to put into practice, and advises researchers "not to underestimate the time, care, emotional commitment, self-reflection, learning, and stress this can entail on everyone's part" (Howitt and Stevens, 2005: 44). Despite the challenges, however, collaborative pursuits are not only appropriate, but necessary in order for equitable research relationships to be developed between researchers and local people. In the section below, I expand on this discussion of critical reflexivity and share my own experiences with the reflexive process.

\subsection{Critical Reflexivity: Situating Myself within the Research}

A critical aspect of the research process for geographers engaged in social research is to constantly consider the ethical implications of our research activities. Because research is a dynamic and ongoing social process that constantly throws up new relations and issues that require constant attention, self-critical awareness of ethical research conduct is paramount (Dowling, 2005). 
Critical reflexivity can be defined as a process of constant, self-conscious, scrutiny of the self as a researcher and of the research process (England, 1994). In other words, being reflexive means analysing your own situation as if it were something you were studying (Hay, 2005). Critical reflexivity prompts researchers to inquire at a deeper level: what is happening throughout the research process? What social relations are being enacted? Are they influencing the data? (Dowling, 2005: 22). It means acknowledging rather than denying our own social position and asking how our research interactions and the information we collect are socially conditioned (Rose, 1997; Mullings, 1999). In other words, how are our social roles and the nature of our research interactions inhibiting or enhancing the information we are gathering? This is not an easy task since it is not always possible to anticipate or assess accurately the ways in which our personal characteristics affect the information we accumulate (ibid).

Keeping a research diary is commonly used by researchers to help foster the reflexive process: "a research diary is a place for recording your reflexive observations. It contains your thoughts and ideas about the research process, its social context, and your role in it" (Dowling, 2005: 22). Considering the following questions can be useful in prompting the reflexive process before beginning the research:

- What are some of the power dynamics of the general social situation I am exploring and what sort of power dynamics do I expect between myself and my informants?

- In what ways am I an insider and/or outsider in respect to this research topic? What problems might my position cause? Will any of them be insurmountable?

- What ethical issues might impinge upon my research (for example, privacy, informed consent, harm, coercion, deception)? (Dowling, 2005: 27) 
In the following section I will address these questions. In terms of the first point relating to power dynamics, England (1994) identifies three types of power relations typically encountered by social researchers. Reciprocal relationships are those whereby the researcher and the participants in the research are in comparable social positions and have relatively equal benefits and costs from participating in the research. In asymmetrical relationships those being studied are in positions of influence in comparison to the researcher. In potentially exploitative relationships the researcher is in a position of greater power than the research participant. These categories are useful when considering the power dynamics that exist between myself and those that I will be working with on this study.

One way of examining underlying power dynamics is by considering one's position. As Haraway (1991) argues all knowledge is situated. She proposes a different concept of 'objectivity', one that attempts to situate knowledge by making the knower accountable to their position. All knowledge is the product of specific embodied knowers, located in particular places and spaces. In other words, no knowledge is innocent - it is shaped and influenced by a host of interacting characteristics, such as race, gender, class, religion, etc (Flax, 1992).

In reflecting on my own position, several factors may influence this research and/or my relationships with community members, such as: education, class, gender, and background. I'm a well-educated, middle-class woman of East Indian descent. I'm also a student and a researcher. These attributes may impact my research in both positive and negative ways. For instance, in the case of gender and background, I have observed that being a woman of colour has made me appear less threatening. This is likely because as a 
woman of colour, I am not perceived as the 'typical' researcher (e.g. middles-class, middle-aged, Caucasian, male) who has conducted research with Inuit in past. In addition, as a visual minority and a woman, I may be perceived as marginalized in relation to the dominant society (i.e. 'White', patriarchal). In my experience, having gendered or racilized experiences can often provide common ground between groups that are perceived by mainstream society as 'different' or 'other'. In terms of my position as an academic and a researcher, I have observed that my position as a student (rather than a senior researcher) also makes me appear to be less threatening. Thus, in terms of power dynamics, my relationship with participants would tend be more reciprocal, rather than asymmetrical or potentially exploitative.

In terms being an insider and/or outsider, I've found myself in the unique position of being both. My position as an outsider to the Inuit community in Ottawa brings with it its positives and negatives. In terms of positives, community members often feel comfortable speaking to me about contentious subjects (e.g. inter-agency politics) because I am impartial. As an outsider, I am able to distance myself from difficult situations. In terms of negatives, being an outsider means at times being treated with suspicion. However, taking time to build trust and develop relationships usually addresses this issue. Interestingly, I've found myself to be a 'double outsider'; that is, not only am I an outsider to the Inuit community, in many ways I am outsider to the dominant society. Being a 'double outsider' has actually provided me with an insider's perspective. As the daughter of East Indian immigrants, many of the issues I explore with Inuit (e.g. impacts of colonialism, migration, culture, language, land, belonging, identity, among others) are matters I have spent long hours contemplating myself. Rather than 
being identical, there are parallels that may be drawn between the experiences of participants and my own which provide common ground and understanding.

Throughout this research process, I have become more aware of these parallels. It was a connection that was not only apparent to myself, but to participants as well. Several times during our conversations related to land, language, food, cultural identity, racism, belonging, etc, participants would often remark, "It must have been the same for you and

your parents?" Participants were often just as interested in my own immigrant experience as I was in their migrant experience. I always openly shared information about my background, my parents' immigration to Canada from India, and the struggles I experienced growing up as one of only a handful of Indians residing in a predominantly Francophone town in Québec. These parallel experiences provided common ground, helped to build trust, and also made participants feel more comfortable sharing their experiences with me. In the end, my position as an outsider to mainstream society allowed for more comfortable and equitable relationships to develop between myself and those I collaborated with on this project.

The following section describes the qualitative methods employed in this research.

\subsection{Methods}

\subsubsection{Study Area}

Fieldwork for this research took place in Ottawa, Ontario. Ottawa was chosen as the ideal location for this study for the following reasons. First, Ottawa is home to the largest population of Inuit outside the north. This is confirmed by both the results of the 
most recent Census (e.g. 725 individuals in the Ottawa-Gatineau region; Statistics

Canada, 2006), and the reports of local services agencies who estimate the Inuit population to be closer to 2000 or more.

Ottawa is also a hub of social and political activity as the centre of federal politics in Canada. As a result many national, regional, and international Inuit organizations, which lobby the government and represent Inuit interests, are headquartered in Ottawa, such as: Inuit Tapiriit Kanatami, Nunavut Tunngavik Incorporated ${ }^{34}$, Pauktutiit Women's Association $^{35}$, and Inuit Circumpolar Council-Canada ${ }^{36}$. In addition, Ottawa is home to Inuit-specific community-based service agencies such as Tungasuvvingat Inuit and Ottawa Inuit Children's Centre, as well as other organizations which provide services to Inuit (e.g. Nunavut Sivuniksavut Program ${ }^{37}$, Inuit Art Foundation ${ }^{38}$, Larga Baffin Home $^{39}$, Wabano Centre for Aboriginal Health ${ }^{40}$, Inuit Non-profit Housing Corporation ${ }^{41}$,

${ }^{34}$ Nunavut Tunngavik Incorporated (NTI) is the legal representative of the Inuit of Nunavut for the purposes of the implementation of the Nunavut Land Claims Agreement.

${ }^{35}$ Pauktuutit is the national non-profit organization representing all Inuit women in Canada. Its mandate is to foster a greater awareness of the needs of Inuit women, and to encourage their participation in community, regional and national concerns in relation to social, cultural and economic development (http://www.pauktuutit.ca).

${ }^{36}$ ICC in Canada is a non-profit organization led by a board of directors comprising the elected leaders of the four land-claims settlement regions: Inuvialuit, Nunatsiavut, Nunavik, and Nunavut. It represents the interests of Inuit at the international level (http://inuitcircumpolar.com).

${ }^{37}$ Nunavut Sivuniksavut is a unique eight-month college program based in Ottawa. It is for Inuit youth from Nunavut who want to get ready for the educational, training, and career opportunities that are being created by the Nunavut Land Claims Agreement (NLCA) and the new Government of Nunavut. Students in the NS program learn about Inuit history, organizations, land claims and other issues relevant to their future careers in Nunavut. They also gain valuable life experience by spending eight months in the south and learning to live on their own as independent adults. The program is open to youth from Nunavut who are beneficiaries of the NLCA. It runs from September until May. Approximately 22 students are chosen each year for the 1st year of the program (www.nstraining.ca/about).

${ }^{38}$ The foundation has been providing professional development services to Inuit artists for over a quarter of a century. Its most visible activity is the publication of the Inuit Art Quarterly, the only magazine in the world dedicated to Inuit art. Unfortunately, citing reasons of financial instability, the IAF terminated its operations after 27 years (http://www.inuitart.org/foundation).

${ }^{39}$ Larga Baffin Home is an 87 bed residence for Inuit who travel to Ottawa for medical care. Designed to function as a "home away from home", clients are provided with support such as airport and hospital shuttles, flight bookings, etc. In addition, the culturally-specific services, such as services in Inuktitut and northern foods in the cafeteria. 
Gignul Non-profit Housing Corporation ${ }^{42}$ ). Having access to Inuit organizations, and to local organizations in particular, has been invaluable in building relationships, gaining an understanding of community interests, and facilitating participation.

Perhaps most importantly in terms of decolonised, participatory approaches to research, being a full-time Ottawa resident has enabled me to be more present than I would have been if this research been conducted elsewhere (e.g. so-called 'fly-in, fly-out' research). Being present has enriched this research by allowing for a deeper level of collaboration to develop. As a result, trust and relationships have developed naturally over time; I have been able to participate in community activities; I've been able to get a more accurate sense of the community's interests; and I have been able to give back to the community. When considered together, all of these reasons make Ottawa the ideal location for this study.

\subsubsection{Ethics}

During the spring of 2010, I applied to Carleton University's Research Ethics Board for approval. Please see Appendices A-C for most recent ethics clearance form and consent forms.

\footnotetext{
${ }^{40}$ Wabano Centre for Aboriginal Health is an urban health centre that provides quality, holistic, culturally relevant health services to First Nations, Inuit and Métis communities of Ottawa (www.wabano.com).

${ }^{41}$ Offers rent-geared-to-income housing for Inuit families and singles living in the Ottawa area. Inuit are given priority on waiting list for 63 units, after which Métis and Status Indian applicants are considered.

42 Gignul Non-Profit Housing Corporation is committed to a holistic and comprehensive approach to housing that includes both those Aboriginal people at risk of losing their housing, or those who are currently homeless. Gignul, working in partnership with other Aboriginal organizations, focuses on both short and long term solutions, including supportive shelters to affordable, independent living (http://www.gignulhousing.org).
} 


\subsubsection{The Research Process: Building Relationships}

As detailed in the methodological section above, building relationships based on trust and reciprocity is key to fostering collaboration between researchers and Indigenous people. This section will provide insight into the research process I've undertake over the past five years and illustrate the efforts I've made to nurture and build equitable relationships between myself and members of the Inuit community in Ottawa.

My interest in working with Inuit stem from my Master's dissertation (Kushwaha, 2007) which documented local observations of environmental change in the community of Cape Dorset (Kinngait), Nunavut. During my first year of the doctoral program (i.e. 2007-2008), specifically during the doctoral core seminar class, my research interests began to shift from northern, rural to southern, urban. Part of my motivation was a desire to participate in a deeper level of collaboration than I was able to achieve during my Master's. Around this time, Statistics Canada had published some of its latest finding from the 2006 Census. One headline in particular which got picked up by local and national media was the finding that the population of Aboriginal people in Canada had surpassed the one million mark. The Census also reported that the Ottawa-Gatineau region was the southern, urban city with the largest population of Inuit residents living outside of the North. Suddenly, the chance to base my work in Ottawa seemed, at the very least, possible. However, this merely marked the beginning of my research journey.

Curious about this new-to-me topic, I consulted the academic literature to see what had been published on "Urban Inuit". My searching produced only a handful of academic journals on the subject. Searching online led me to Tungasuvvingat Inuit (TI), a 
local Inuit organization in Ottawa. I contacted TI requesting information about their organization and the types of services they provide to the local community. I was invited to their administration office to have my questions answered in-person. At the office, I had an informal meeting with five community service workers. Over the course of an hour we talked about many topics: the programs and services provided by TI; the challenges faced by Inuit who migrate to Ottawa; their own personal migration stories, among others. After our discussion, I was given a tour of the Family Resources Centre. At the time of the visit, a pre- and post-natal health class was being held in the FRC. I was invited to attend a few session, which were held every Tuesday, in order to give me a better idea of Tl's programming, as well as give me the opportunity to meet some of the clients of the Centre. I visited the FRC for the maternal health classes for one month. During that time I observed how the FRC operated like a community centre. People floated in and out of the Centre, to use the computers, drop off their children for day care, or simply make a cup of tea and socialize. I also made the acquaintance of several mothers who I later interviewed for this research.

After my visits to the maternal health classes I attempt to secure a volunteer position with TI to deepen my participation and contribution to the local Inuit community. However, at the time it was difficult to find me a placement. Despite this, I formed a good relationship with then Director of Counselling Services. In the early stages of this thesis, in particular, I relied on this relationship a great deal to help ground my research, to help gauge the interests and needs of the community, and to provide valuable advice. We had several frank discussions about the nature of research and how it has been conducted with Inuit in the past and present. These discussions caused me to reflect 
deeply on the relevance of my own research and how it could be designed to benefit the local community.

In the early stages of this research, I contacted several local Inuit and Aboriginal organizations (e.g. Tungasuvvingat Inuit, Ottawa Inuit Children's Centre, Inuit Tapiriit Kanatami, Pauktutiit Inuit Women of Canada, Nunavut Tunngavik Inc., Nunavut Sivuniksavut, Wabano Centre for Aboriginal Health) with the idea of developing a collaborative research project based on the needs and interests of the community. My naive enthusiasm was quickly dampened by the reality faced by many (if not all) of these organizations. The typical response I received to my inquiries was they were interested but had limited time and resources to devote to yet another project. I had been confronted with some of the challenges of conducting research in Ottawa as opposed the northern communities I'd worked with in the past. In Ottawa, the Inuit community is large and spread across the city. It's difficult to get a sense of where people are, how to reach them, and how to draw them together. Whereas up North, gathering people together would be as simple as making an announcement on the local radio. Also, it can be argued that the pace of life in Ottawa as opposed to up North is fast. People seem to have less time. All of these factors made building relationships and developing a collaborative project challenging at first.

In lieu of being able to develop a project with collaborators from the ground up, like I had originally aspired to do, instead I tested the waters with contacts I had made at TI. As a way of verifying to see if my interests aligned with those of the community, I presented the services workers I had met at TI with a set of research questions, and asked 
if they would be relevant to Inuit residing in Ottawa. My interests in Inuit connections to the land seemed to resonate with them.

While a truly collaborative partnership did not flourish for this research, there were several ways that I made my involvement with the community as participatory as possible. Over time, my involvement with members of the local community has increased steadily. I've worked as a research assistant on a literacy project led by my co-supervisor Dr. Donna Patrick the Ottawa Inuit Children's Centre (OICC), and helped to document the activities of children's Inuktitut classes. I've also attended adult Inuktitut classes and volunteered at the OICC (more details about these activities are provided in the participant observation section below). This involvement in the activities at the OICC has been critical for building trust and relationships. Spending time with people at the Centre and helping out are also an important part of 'giving back' to the community and learning experientially. In addition, I've relied on the community contacts that I've made for guidance with regards to my research. Through these efforts I have, to the best of my ability, tried to build connections and make my research as relevant as possible to members of the local community.

Following the completion of course work, I completed my comprehensive examination during the Spring semester of 2009. During the Winter semester of 2010 I presented my thesis proposal and that spring I applied for ethics clearance from Carleton University (see Appendix B). Once I received ethics clearance, I began semi-structured interviews and also began documenting oral histories with Ottawamiut Elders. The collection of "data" was complete by the Spring of 2011. From that point onward, I shifted my attention to the analysis of "data" and the writing process. 
This section has provided an overview of my research process with an emphasis on the efforts made to building relationships with members of the local Ottawamiut community. The next section outlines the methods of "data" collection employed in this research.

\subsection{Data Collection}

\subsubsection{Life histories}

Life histories are defined as the systematic collection of living people's testimony about their own experiences (Thompson, 2000). In oral history projects, an interviewee recalls an event for an interviewer who records the recollections and creates a historical record. The collection of life histories allow:

ordinary people [...] to understand the upheavals and changes which they experience in their own lives: wars, social transformations like the changing position of youth, technological changes like the end of steam power, or personal migration to a new community. (emphasis added; Thompson, 2000: 2)

Oral histories "can give back to the people who made and experienced history, through their own words, a central place" (Thompson, 2002: 3). This centrality and giving voice to personal perspectives is a critical aspect of decolonised, participatory approaches to research as outlined previously. Hence, the documentation of life histories was deemed an ideal method for this research.

Life histories were documented with three $(\mathrm{N}=3)$ Inuit Elders (women ${ }^{43}$, aged 6070; see Appendix D for a list of participants) who are long-time residents of Ottawa, from

\footnotetext{
${ }^{43}$ Though attempts were made to identify male participants, none were found to participate in this study.
} 
the summer of 2010 to the Winter of 2011. Life histories were used to gain a deeper understanding of the transition from northern, rural to southern, urban life; the significance of 'nuna' (the land); the role of urban place-making in fostering connections to the land; and the cultural meanings, practices, values associated with the land within urban settings. While these were the general areas of interest which provided some structure to the process (see Appendix E for the interview guide), our informal conversations were by no means restricted to these topics. The Elders were free to share whatever stories and knowledge they wished. This led to a far richer experience for both the Elders who participated, and for myself. As a result, the actual volume of narratives documented was far greater than is represented in this thesis. However, complete narratives will be provided to each Elder.

The Elders who participated in the project were identified with the help of community advisors (i.e. individuals who worked with the community), and based on certain criteria (i.e. purposeful rather than random sampling). Given the research objectives, ideal candidates would have experience and knowledge living in both northern communities and Ottawa. Thus, participants would have knowledge of the land, as well as knowledge of living in urban environments. Once potential participants were identified, they were then contacted to see if they would be interested in participating in the study.

I met with each Elder separately in their homes, on multiple occasions (between four to eight sessions depending on the Elder). Most conversations occurred at kitchen tables over cups of tea, generally lasted between two to three hours, and were audio recorded. Each Elder was given an honorarium ( $\$ 25$ per session) for their participation 
and generosity in sharing their life experiences and knowledge. At the end of the project, each Elder will be provided with compilation of their life histories in published form.

\subsubsection{Semi-structured Interviews}

In-depth, semi-structured interviews were used to gather information with both younger generations of urban Inuit, and key informants working in relevant government departments and Inuit organizations, respectively (further details provided below). This form of interviewing has some degree of pre-determined order, while ensuring a fair amount of flexibility and adaptability for the researcher and the participant (Usher, 2000). The participant can express his/her point of view, relate to personal experiences, and narrate stories or anecdotes. While the researcher proposes guiding questions to provide some structure to the conversation, the interviews take more the form of a dialogue than a formal question and answer session (Poirier et al., 2000). The researcher employs the use of an interview guide which covers major themes or questions used to facilitate discussion. As a discussion facilitator the research may also intervene to redirect the conversation if it has moved too far from the research topics (Dunn, 2005).

Participants were selected purposefully using 'snowball' or 'chain' sampling techniques (Bradshaw and Stratford, 2005) with the help of community advisors. Snowball sampling uses a small pool of initial informants to nominate, through their social networks, other participants who meet the eligibility criteria and could potentially contribute to a specific study (Morgan, 2008). Community advisors were individuals who worked with the Ottawa Inuit community and therefore were helpful in identifying potential participants. Making contact with one individual generally led to being referred 
to another. The advantages of snowball sampling is how it enables researchers to gain access to populations that would otherwise be difficult to access, such is the case with Ottawamiut, who like other urban Indigenous communities, make up a 'community' which tend to exists as a fluid, non-geographically bounded entity (Lobo, 2001), but rather is visible as a social network in which community-based service agencies and the programs and services they provide act as key nodes (Patrick and Tomiak, 2008). However, disadvantages of the methods include the potential for the sample to show a community bias (Biernacki and Waldorf, 1981). The sample is strongly influenced by the first participants, their social networks, and ability to connect with other participants to represent the population accurately. In this study, the community bias is apparent in that all of the participants (with the exception of some of the key informants) are in one way or another linked to local Inuit organizations, either as service providers or clients of the centres. While this provided great insights into the internal workings and influence of local Inuit organizations, it limited my ability to access participants outside of this realm, leading to certain silences in the work.

For instance, there is a lack of male participants in this study. There are likely several reasons as to why this was the case. It is my observation that there tends to be an over-representation of women and under-representation of men who participate in the day-to-day activities at local Inuit organizations, either as clients or as services providers. The exception would be the larger community events, like feasts or other celebrations, which tend to draw out men, women and children. Thus, I had fewer opportunities to interact with male community members and develop trusting relationships that might have translated into their participation in my study. Also, because the social networks at 
local Inuit organizations tend to be female-dominated, it just so happened that one female participants often connected me another, and so on.

The other silence in this work, as mentioned earlier, is the fact that I was not able to reach members of the Inuit community in Ottawa beyond those contacts I made through local Inuit organizations. Thus, the arguments I make in this thesis are reserved to a sub-section of the Ottawa population who access these services.

In terms of sample size, I followed the rationale that "in qualitative research, the sample size is not expected to be representative of the entire populations since the emphasis is usually on an analysis of meanings in specific contexts" (Robinson, 1998: 409). Patton elaborates further in stating:

There are no rules for sample size in qualitative inquiry. [...] The validity, meaningfulness, and insights generated from qualitative inquiry have more to do with [...] information richness [...] and the observational/analytical capacities of the researcher than with the sample size (184-185).

Thus, in both cases, the richness of the information collected determined the number of interviews which were carried out. In this study, my objective was to acquire a depth of information, rather than a breadth of information, that may have been possible through a survey-style approach to data collection. That is to say, my objective was not to make generalizations about Ottawamiut, but rather to gather insights from the unique and particular knowledge and experiences of the participants. 


\subsubsection{Younger Generations of Inuit}

Semi-structured interviews were conducted with twelve $\left(N=12\right.$; women ${ }^{44}$, aged 27 to 54) Inuit residents of Ottawa. Interview topics centred around: the significance of 'nuna' (the land); the role that urban place-making plays in fostering connections to the land, and the cultural meanings, practices, values associated with the land within urban settings; urban Inuit experiences; and urban Inuit identity, among others. Please see Appendix $\mathrm{F}$ for a list of participants.

These interviews reveal inter-generational perspectives regarding the significance of the land, the role of urban place-making, community-building, and the construction of Inuit identities, to name but a few. Interviews also reveal how urban Inuit experiences have changed over time (e.g. access to country food, access to services, etc), and the influence of 'Inuit places' in facilitating such changes.

The interviews were audio recorded at Inuit community centres, at the participants' place of work, or in their homes. Interviews ranged from one to two hours in length. Each participant was given an honorarium (\$25) for their time and participation.

\subsubsection{Key-Informants}

Key-informant interviews were conducted with seven $(\mathrm{N}=7)$ men and women who work at relevant government departments and Inuit organizations to reveal how urban Inuit needs and concerns are considered and represented by these governing

\footnotetext{
${ }^{44}$ In this case, as with the Elder life histories, all interviews were carried out with women. This was not a deliberate decision. However, it should be noted there tends to be an over-representation of women who work at community-based service agencies, and who participate in the community activities/events. As a result, the contacts I have made are for the most part with other women.
} 
bodies, and to determine how support for urban Inuit interests may be improved. The interviews were conducted at the individuals' place of work, were audio recorded, and were on average an hour in length. Organizations interviewed include: City of Ottawa; Inuit Relations Secretariat; Ottawa Aboriginal Coalition; Tungasuvvingat Inuit; Ottawa Inuit Children's Centre; Aboriginal Non-Profit Housing Corporation; Montréal Inuit Association. Please see Appendix $G$ for a list of participants and Appendix $\mathrm{H}$ for the interview guide. It should be noted that prominent national Inuit organizations (Inuit Tapiriit Kanatami, Nunavut Tunngavik Corporation, Pauktuutit Inuit Women of Canada) were contacted several times for interviews but in all cases I was referred to Tungasuvvingat Inuit, the local Inuit community centre in Ottawa.

\subsubsection{Participant Observation}

Developing a geography of everyday experiences requires us to move beyond sole reliance on formalised interactions such as those occurring during interviews (Hay, 2005). Interviews, however unstructured, remove the researcher from the flow of everyday life in both time and space. In contrast, the goal of participant observation is developing understanding through being part of the spontaneity of everyday interactions.

Participant observation as a method is often difficult to define in absolute terms, however, it can be thought of as "conscious and systematic sharing, in so far as circumstances permit, in the life activities and, on occasion, in the interests $[\ldots]$ of a group of persons (Jackson, 1983: 39). It is the systematic and intentional character of observations that contrasts the activities of a participant observer with those of routine participants in daily life (Spradley, 1980). Often, participant observation for a geographer 
involves strategically placing oneself in situations in which systematic understandings of place are most likely to arise (Hay, 2005).

Participant observation for this research has taken place through my volunteer work facilitating youth art classes at the Ottawa Inuit Children's Centre, participation in community events (e.g. volunteer work at Inuit Day celebrations, elder nights, game nights, Christmas celebrations), participation in Inuktitut language classes, and work as a research assistant with Dr. Donna Patrick on a project examining Inuit literacy, as well as two photovoice projects. Participation in these activities not only provided me with experiential knowledge and a window into community life, but also facilitated the building of trust and relationships, without which this research would not have been possible. Furthermore, participation enabled me to give back to the community which has been so supportive of this work.

Here I present a short series of 'vignettes'; that is, personal narratives based on the observations I have made while participating in community events. I chose to highlight three events which in my view illustrate the significance of the land to urban Inuit, as well as the role of urban place-making in fostering connections to Inuit lands and culture in Ottawa. The first narrative highlights the annual 'Spring Equinox Festival' hosted by a local organization, Tungasuvvingat Inuit. The second narrative describes 'Inuit Day' celebrations which took place at the Ottawa Inuit Children's Centre. The third and final narrative describes a community seal feast which took place at the Ottawa Inuit Children's Centre. 


\section{Tungasuvvingat Inuit Spring Equinox Festival}

In 2008, I started building relationships with local Inuit organizations in Ottawa. One of the first contacts I made was the Director of Counselling Services at Tungasuvvingat Inuit's (TI) Mamisarvik Healing Centre ${ }^{45}$. The Director invited me to attend TI's First Annual Spring Equinox Festival. The event was advertised as "a celebration of rebirth and awakening of the land" (see Figure 1 below) and was held at the Jim Durrell Recreation Centre in Ottawa. When I arrived, the hall was bustling with activity as people socialized, children played, and organizers arranged the finishing touches. There were tables filled with country food, such as caribou, arctic char, and maktaaq (beluga whale), and plenty of other 'southern' food and drink to feast on. The room was decorated with several displays informing participants about the various programs and services TI offer to Inuit living in Ottawa.

The emcee for the evening was popular Inuit singer/songwriter, Susan Aglukark, who had travelled from Toronto to attend the event. During her opening speech, Aglukark spoke about the relevance of springtime for Inuit. After a long and bitter winter, the arrival of spring represented a time of rebirth, and a break from harsh weather. That was why it was important for Inuit to celebrate the commencement of this special time of year. She also spoke about the importance of TI in her life when she was an Ottawa resident. Aglukark reminisced about spending time at the drop-in centre nearly every day, just to have the chance to enjoy the company of other Inuit. She candidly spoke of the challenges she faced while adjusting to life in Ottawa, and how the community she

\footnotetext{
${ }^{45}$ The Mamisarvik Healing Center is an Inuit-specific, 53-day, residential and day, addiction and trauma treatment program, located in Ottawa. The Centre provides culturally-specific therapeutic treatment to Inuit men and women aged 18 years or older, who are suffering from dependency on drugs and alcohol and the effects of trauma and physical and sexual abuse.
} 
discovered through TI helped her through those difficult times. Aglukark then spoke about the changing characteristics of the Inuit community in Ottawa; how it is less of a transient population, and more of a settled, unified community which has made Ottawa their home. Aglukark acknowledged the efforts made by TI in bringing Inuit together, and facilitating community-building in Ottawa. Aglukark spoke about the diversity of the Ottawa Inuit community; that is, in Ottawa one could find hundreds of Inuit, from all different northern regions and communities, gathered in one place, forming a new and distinct urban community.

After Aglukark's speech, an Elder recited an opening prayer in Inuktitut to mark the beginning of the evening's festivities. The community feast began, with Elders starting first, followed by the rest of the community. It was a lively event, as for the next couple of hours community members gathered, feasted, and enjoyed each other's company. Following the meal, the crowd was entertained by performances by Susan Aglukark, throat singers, drummers and drum dancers, and several youth performances which combined both traditional and 'southern' influences (e.g. pop songs, hip hop dancers). 


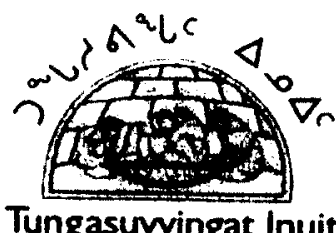

\section{Inuit Spring Equinax Celebration}

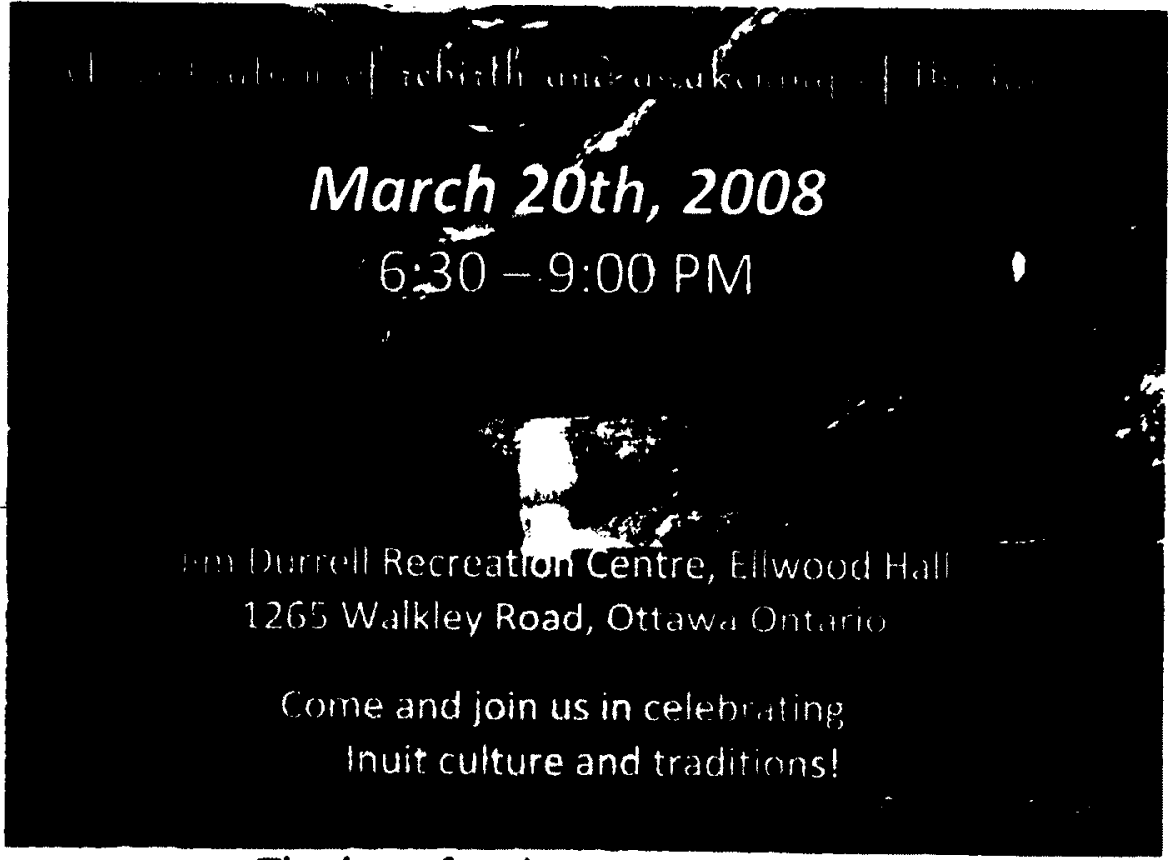

The host for the evening will be

\section{Susan Aglukark}

A 'toste of the Antic' will be ovolloble for sompling

Admission for the Celebrotion is free; donations will be accepted ot the door and tax receipts will be ovalloble for contributions.

\section{(8) Ontario}

Funded by the Government of Ontario

Figure 2. Poster advertising Tungasuvvingat Inuit's $1^{\text {st }}$ Annual Spring Equinox Festival.

\section{A Snapshot of Inuit Day}

It was a mild, mid-February day in 2010 . Dozens of community members, both Inuit and non-Inuit, gathered outside the Ottawa Inuit Children's Centre (OICC) awaiting 
the commencement of 'Inuit Day' festivities. Inuit Day began with an opening prayer in Inuktitut. This was followed by several other welcoming speeches by board members of the OICC, local MPs, and funders. While the speeches varied they shared a common thread; that is, the importance of developing a sense of Inuit culture and community in Ottawa.

After the speeches, Elders were invited to begin the outdoor community feast. Several long tables were adorned with both store-bought foods and country foods, the latter of which had been brought in from up North. Community members feasted on hot bowls of char and caribou stew, soft pieces of bannock, and warm cups of tea, among other delights.

Throughout the day, community members were treated to several presentations. Throat singers dressed in elaborately decorated amauti (woman's parka) entertained the crowd with their skill. Students from the Nunavut Sivuniksavut Training Program performed Inuktitut songs and dances. There was also traditional drumming demonstration. Students, both children and adults, of the OICC's Inuktitut language classes sang their "i, pi, ti, ki's" (i.e. syllabic alphabet song). Needless to say, the children's performance was far better than our adult class.

Inside the OICC there were several activities planned. At one station, visitors could learn how to write their names in Inuit syllabics. At another station, visitors were invited to make a puppet of their favourite arctic animal, or build an Inuksuk out of river rocks and hot glue. Whether inside or outside, the OICC was bustling with activity. It 
became evident that Inuit Day was about friends and family, gathering together and sharing - food, culture, laughter, company.

\section{Qulliq lighting}

As the day began to wind down, a small group of women gathered inside the OICC. Many of us had been volunteering, and scarcely had time to rest all day. There, set on the table between the couches we rested on, was a qulliq - a traditional Inuit oil lamp (Figure 2). Earlier in the day, there had been a qulliq lighting ceremony. However, many of us had missed the ceremony due to our volunteer duties.

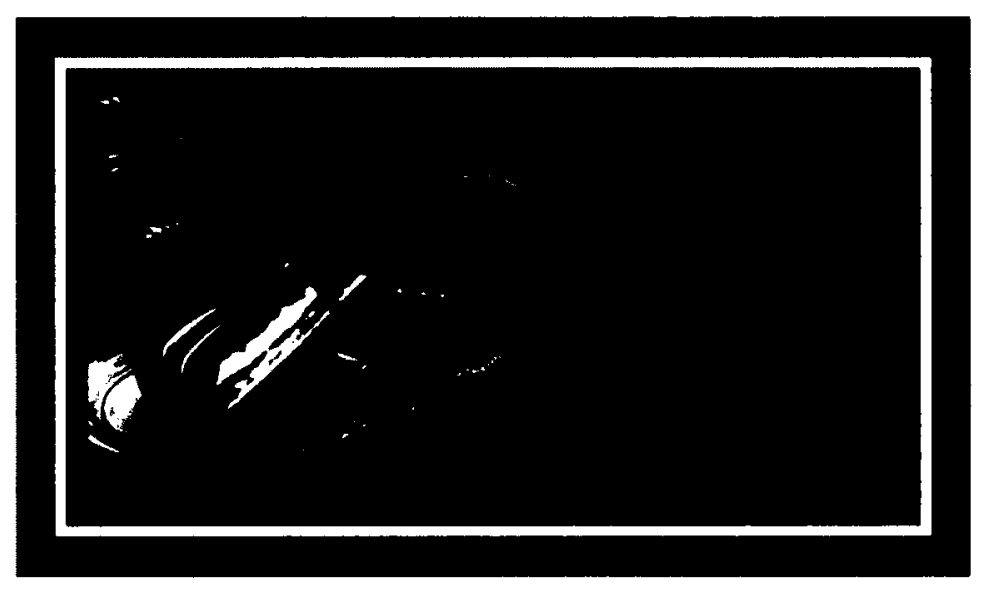

Figure 3. Image of a qulliq, a traditional Inuit seal oil lamp.

"Does anyone know how to light it?" someone asked. Many of us had seen the oil lamps lit, however none of us knew how to light a qulliq ourselves. We were delighted when one of the Elders present agreed to teach us how to light the qulliq. We gathered around her like children around a campfire. The Elder explained that traditionally a qulliq was lit using seal oil for fuel, and the wick was made with plants collected from the land, like Arctic cotton. However, since those materials were difficult to find in Ottawa, Inuit here 
adapted their practice by fuelling their qulliq using canola oil (or any cooking oil), and constructed the wick out of cotton wool. Using cotton and oil bought at the store as opposed to materials collected from the land worked just as well. Although, she remarked that lighting the qulliq would be easier and faster if we had seal oil and Arctic cotton or moss.

The qulliq itself was made of carved stone. Its shape was long and oval, and its bowl was shallow. The bowl was filled with canola oil. Along the stone rim of the qulliq was a thin row of cotton. The tips of the cotton were singed black from being lit, and its ends were dipped in oil. The Elder began by dipping a wooden stick in the canola oil and transferring oil onto the cotton wick until it was fully saturated. She then created a row of tiny peaks out of the cotton with delicate flicks of her wrist. Using a lighter the Elder lit the cotton on one end of the lamp. She continued to wet the cotton with oil, and using the wooden stick carried the flame along the entire row of cotton. The qulliq was lit! The Elder explained that it was important to keep the flame at a constant level. This prevented too much smoke from forming. As the Elder maintained the constant level of light of the qulliq, she told us that traditionally the qulliq was used to provide light and heat in Inuit homes. They were even used for cooking and drying clothes. They were a very important part of the survival of the people. It was part of the women's duties to keep the qulliq lit, even during the night. Qulliq could be made out of stone in various sizes. One household could have several qulliq.

I was spellbound by her skill and the knowledge she shared. The Elder offered to teach anyone who wanted to learn how to light the qulliq; Inuit and non-Inuit alike. Each student followed her patient and careful instructions. Learning to light a qulliq took a lot 
of practice, she told us. Stories began to emerge. One woman suddenly remembered gathering Arctic Cotton with one of her neighbours when she was a child living up north. The Arctic Cotton was to be used to light her neighbour's qulliq. She had not thought of that for a very long time, and laughed with delight at the resurfacing of this childhood memory, a connection which was inspired by the lighting of a qulliq in Ottawa.

\section{Natsiq feast in Ottawa}

Here I provide a retelling of the natsiq (i.e. seal) feast which took place in March 2010 at the Ottawa Inuit Children's Centre (OICC). Dr. Patrick and myself were invited by an educator at the OICC to participate in the seal feast, and to take photographs and videotape the afternoon's activities. When we arrived at the OICC, dozens of adults and children were excitedly gathered in the yard. They were standing around a plump ringed seal which had been laid on the ground on a bed of cardboard, covered by a plastic tarp. The ringed seal had been harvested by a hunter in Kimmirut, Nunavut, and shipped to Ottawa earlier that week.

The crowd curiously watched as a community member began to butcher the seal. As he worked he addressed the crowd in Inuktitut to impart some knowledge about what he was doing. He pointed to certain body parts and organs and told us their Inuktitut names. Another Inuk woman stepped in and spoke about the seal organs, making a point to educate the many school children that were huddled around the seal. She pointed out which parts were eaten by men and which parts were eaten by women. After the first stage of butchering was complete, several Inuit women took to the task of preparing and distributing the seal meat, as is traditionally the practice. 


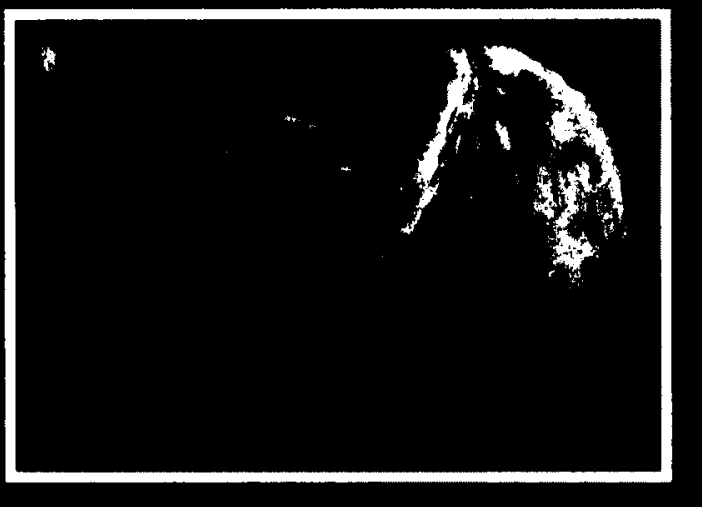

Figure 4. Image of an Inuk woman preparing and distributing seal meat at 'Inuit Day 2011' celebrations held at the Ottawa Inuit Children's Centre ${ }^{46}$.

Many skilled hands armed with uluit (Inuit women's knives) portioned the seal. Certain sections of the animal were set aside to be boiled for broth. However, the majority of the seal was eaten fresh and raw. Elders and children were invited to eat first, and then other community members. In addition to seal, community members enjoyed a mixed fare of moist bannock, and cups of seal broth.

Throughout the couple of hours we attended the seal feast, there was a steady stream of people coming in and out of the yard to partake in the sharing of country food. Clearly, news about the seal feast had travelled quickly throughout the community. There was a distinct sense of celebration in the air as people gathered together to enjoy the sharing of seal meat, as well as each others' company. For some, it was their first visit to the OICC. Through the seal feast, they had been connected to an important social and cultural network in Ottawa. For many, it was the first time they had eaten seal in months.

\footnotetext{
${ }^{46}$ Images accessed from Ottawa Inuit Children's Centre website: http://www.ottawainuitchildrens.com/eng/index.php?option=com_content\&view=article\&id=169\&Itemi $d=127$
} 
In the words of one Inuk woman, she was "craving it", a sentiment that was repeated throughout the afternoon. After a couple of hours, there was nothing left of the seal but its skin. The skin itself was given to a community member to clean, dry, and use for sewing traditional clothing.

Reflecting on my observations, common themes emerge, such as the emphasis on gathering. Despite originating from various northern communities [primarily from Nunavut, but also Nunavik (Northern Québec) and Nunatsiavut (Labrador)], Inuit gather together in Ottawa, creating a new community, in order to share important aspects of Inuit culture. Gathering provides an opportunity to share in each other's company, speak Inuktitut, and to share country food. Gathering also provides an opportunity to share knowledge and practices (e.g. lighting the qulliq, or drumming, etc). During these gatherings connections to the land were most obvious through associations with country food (e.g. the seal feast), but also through language, clothing, and the other practices described above. After participating in these events, the significance of place in order to facilitate the sharing of Inuit food, language, and knowledge became evident. In addition, I became aware of the role of community-based Inuit organization in providing support in order to facilitate these culturally-based community interactions. For instance, the Spring Equinox Festival was organized by Tungasuvvingat Inuit, and held at a multipurpose community centre in the west end of Ottawa. For the few hours of the event, this multiuse urban community centre was transformed into 'Inuit place'. In the latter two examples (e.g. Inuit Day and the seal feast), the events were organized by, and held at, the Ottawa Inuit Children's Centre. In these cases, not only are important aspects of Inuit culture 
shared on a specific occasion, but consistently through the day-to-day programs and services provided by both centres.

\subsection{Analysis}

\subsubsection{Life Histories and Interviews}

Participant observation supplemented my interview data; however, it was not the primary source of data for this research. Transcribed interviews underwent qualitative content analysis (Bryman and Burgess, 1994) without the assistance of analytical software. Content analysis involves closely examining transcribed documents for themes in order to reveal the underlying meaning of what has been said. As described by Tesch (1990), data are not reduced to simple frequencies of their occurrence. Instead, this type of analysis endeavours to take into account the context, content, and significance of all responses given during interviews. In this study, the narratives have been thoroughly reviewed to develop categories of related information, which are presented in the thesis as quotes. In terms of process, I spent long hours reading the narratives closely. I employed the use of highlighters, self-stick notes, as well as a notebook to document ideas, questions and themes. Doing this by hand without the use of computer software was more lengthy, however, provided me with an in-depth knowledge and familiarity with the narratives. This method of analysis was chosen as a powerful way to present the everyday experiences and knowledge of the participants in its rich form. For reasons of confidentiality, interview participants' names have been concealed based on the wishes the participants. However, Elder names have not been concealed, as they desired to be acknowledged for their contributions. 


\section{Chapter 4}

\section{Elder Life Histories}

Throughout human history, elders have occupied a special position in society. They have painstakingly accumulated reservoirs of personal experience, knowledge, wisdom - or compassionate insight and a sense of the enduring qualities and relationships around them. They freely offer this wisdom to living generations of their people in an effort to help them connect harmoniously with their past, present, and future. (Knudtson and Suzuki, 1992: 179)

The above quote eloquently embodies what I have witnessed during the past seven years of working with Inuit residing in both northern communities (e.g. Cape Dorset, NU; Iqaluit, NU; Kimmirut, NU) and in Ottawa; that is, the respected position of Elders cannot be overstated. The Elders who participated in this study take great pride in their position in the Ottawa Inuit community, as well as in the northern communities from which they originated. As holders of cultural knowledge and practice, they feel a great responsibility to disseminate such information to future generations. In sharing their personal narratives the Elders hope to educate other Inuit, as they feel a great many lessons may be learned from their varied life experiences. Their urban experiences also add to Inuit history, and enrich and expand what it means to be Inuit. Furthermore, the Elders expressed a desire to educate non-Inuit about their lives and their community, in the hopes of making Ottawa a more diverse and inclusive place for all the residents who make the city their home.

This research focuses on exploring the significance of nuna, 'the land', to Inuit residents of Ottawa, and the role urban place-making plays in fostering connections to nuna and Inuit culture. In addressing this topic, the narratives documented below speak to a great many things past, present and future. In the literature, the life histories (e.g. 
Bennett and Rowley, 2004; Wachowich, 1999; Mannik, 1998) of Inuit Elders have tended to focus on "traditional ways of life" and "Inuit knowledge" situated within northern contexts, often equating one with the other. The life histories collected here document Inuit knowledge as well; however, they represent both northern and urban contexts. These life histories help to challenge what is typically conceptualized as the 'place' of Inuit knowledge, by broadening both the context and ways in which it is shared.

In the following chapter the life histories of three Inuit Elders are presented. First, the personal narrative of Ovilu Goo-Doyle. Ovilu is an Elder originally from Cape Dorset ('Kinngait' in Inuktitut meaning 'mountains'), Nunavut ('Our land' in Inuktitut; South Baffin region), who has resided in Ottawa for over forty years. Next, is the narrative of Maria Brazeau, an Elder originally from Nain ('Nunajnguk' in Inuktitut), Nunatsiavut ('Our beautiful land' in Inuktitut), who settled in Ottawa in 1970. Finally, is the narrative of Sally Webster, an Elder originally from Baker Lake ('Qamani'tuaq' in Inuktitut meaning 'where the river widens'), Nunavut (Kivalliq region), who has lived in Ottawa since the early $1980 \mathrm{~s}$.

The narratives are organized chronologically. As each Elder narrative unfolds, the reader moves along with them, and witnesses the dramatic social and cultural experiences these Elders have lived through, particularly since the mid-twentieth century when the government adopted an interventionist policies when dealing with Inuit (e.g. centralization, residential school, TB treatment, etc; see Chapter 1 for detailed overview). In terms of structure, each narrative begins with a short introduction, to highlight its uniqueness and relevance to the overall research question (i.e. the significance of the land 
to Inuit living in Ottawa, and the role of urban place-making which foster connections to the land).

While each Elder narrative is unique, and speaks to their individual circumstances and experiences, there are also common threads which link their life stories. The Elders speak of change often, both in northern and southern contexts, which highlight some of the dramatic changes which have taken place during their lifetimes. For instance, they discussed the transitions from living on the land in outpost camps to more sedentary lives in northern settlements. They speak of fluid meanings and significance of nuna (meaning 'the land' in Inuktitut) which surpass geographic boundaries. They speak of their urban experiences, during a time when only a handful of Inuit had settled in Ottawa. They share how they actively made (and continue to make) place for themselves, their families, and their community in Ottawa. They reflect on the meaning of identity, community, urban Inuit rights, and their hopes for future generations of Inuit being raised in Ottawa.

The importance of the land is interwoven in different parts of their stories, whether situated in the North or the South. Based on the narratives, it is evident that the significance of the land appears to surpass geographic boundaries (e.g. North versus South, rural versus urban), making it an integral part of Inuit identity, history, knowledge and culture. In their narratives, the Elders express that the importance of the land and what it represents for Inuit is not only significant for them, but also for younger generations of Inuit being raised outside the North. To that effect, the role of urban place-making becomes evident. The creation of 'Inuit place' within urban space facilitates the construction of connections to the land, and the various meanings, knowledge, practices and values it possesses. I invite the reader to step into the candid 
narratives shared so willingly by these respected Elders, with a sense of reverence towards their life experiences. I encourage the reader, as I have encouraged myself throughout this process, to be open, to learn, and to be willing to be changed by the knowledge and experiences bestowed below. 


\subsection{Life History of Ovilu Goo-Doyle}

Introduction:

Ovilu Goo-Doyle is an Elder from Cape Dorset, Nunavut. During her life time she has witnessed great changes that are not only personally significant, but also reflect the dramatic socio-cultural changes Inuit have experienced since the mid-twentieth century. Her narrative is significant for several reasons. Ovilu's narrative highlights not only the transitions she experienced in the North, but also documents the growth and development of the Inuit community in Ottawa from its early, to present, day. Woven throughout the narrative is Ovilu's connection to the land, though country food, language, art, etc. Her connections to the land surpass boundaries of North versus South, or rural versus urban. Ovilu connects to Inuit land and culture through her strong sense of identity and her involvement with the community as an Elder. Her narrative highlights the importance of 'Inuit places' in Ottawa, such as Tungasuvvingat Inuit and the Ottawa Children's Centre as places were Inuit can gather and share Inuit knowledge and practices. These agencies provide services that Ovilu did not have access to when she first arrived in Ottawa. They provide support for Inuit which she feels is important for the younger generations of Inuit, like her grandchildren. Her narrative demonstrates how through these places Inuit are able to foster connections to the land, and the meanings, practices and values associated with the land. In addition, Ovilu's narrative highlights the issue of urban Inuit rights and identity.

Ovilu's narrative begins below in her own words. Her narrative begins with her memories of childhood, growing up on the land. She then provides insights into her life 
when she and her family moved to the settlement. This period is followed by her early urban experiences as a resident of Ottawa. Her narrative ends with her reflections as an urban Inuit Elder, and her hopes for future generations of Inuit being raised in Ottawa.

\section{From Outpost Camp to the Settlement of Cape Dorset}

When Ovilu first moved to the community of Cape Dorset, she remembers it as being a simpler place. Seeing an old photograph of the community 'back then' reminds her of her childhood and the changes that have taken place since then.

I'm originally from Cape Dorset, on Baffin Island. We were looking at some pictures the other day on the internet, and when I saw the really old pictures of how many building we had, I kind of miss that. It brings me right back to my childhood. It was so wide open. Except for the Hudson's Bay, and the old little schoolhouse I went to as a child. And there was a tiny, tiny nursing station. The buildings were all in one line. And that was it. When I saw those pictures it brought me right back to my childhood.

Ovilu and her family moved to Cape Dorset when she was a young girl after her father passed away. At the time, only a few Inuit families had settled in the community. The majority of Inuit lived on the land in outpost camps. Some members of her extended family who had found paid work with non-Inuit (at the Hudson Bay Company or government services) lived in the community.

We moved into the community (Cape Dorset) in 1959 or 1960 . We moved to the settlement after my father passed away. I was six. There were only a few Inuit in the community at the time when I was growing up. There was my aunt and her husband and their kids because he was working for the Hudson's Bay. My other aunt, she used to work for a nurse. And then my mother, sister, brother and myself moved into the community. So, there were only a few Inuit families living in the community at that time. 
Before her father died, Ovilu and her family only rarely stopped in Cape Dorset. For instance, they would occasionally stop in at Christmas, or in the spring to have medical check-ups to test for tuberculosis.

When I was small, when I was growing up, nobody really lived in the community, they called it 'hamlet'. We lived out scattered around the outpost camps. Everything was outpost camps. Before we moved to the settlement permanently, we would just come into the community by dog team at Christmas sometimes, but not very often. And we all moved into the community during the Spring by boat, because it was the only place we could get medical care and have a doctor look at us. We would move in the community probably in the beginning of July. Every June or July people from the different camps would go to Cape Dorset because the medical ship - the CD Howe - would be docked there, and all the Inuit had to be assessed to see if they had TB (tuberculosis). People would move into Cape Dorset and it would be all tents. There were no houses back then. You'd look around and see everywhere all these beautiful Inuit-made white tents. In the evenings they would light up. That memory was so wonderful. We'd go back out to the camps for the winter. We would go back out by boat, Peterhead boats or row boats, for the wintertime. I did miss that a lot, having freedom to go around, and having all this space around you everywhere you look. And travelling by dog team and stuff like that.

Slowly, things started to change in the community with the arrival of more non-Inuit

from the south.

In the settlement of Cape Dorset, there was only the Hudson's Bay, one church minister, one nurse, one teacher. The church minister came in 1957, I believe. And then later on the RCMP came and the community administrator which was federally run by Indian and Northern Affairs. When the government administrator came to town my mother was a housekeeper there. But before those two groups came, there was only Inuit living in the area.

\section{Memories From Childhood: Living on the Land}

Thinking back to her childhood reminds Ovilu of living on the land with her relatives in an outpost camp. It is a part of her childhood she misses even today. Her connection to land and family history is a connection she keeps through the power of her own memory, and by visiting all the 'old places' when she visits her relatives up north. 
I have really good memories of my childhood, growing up on the land with all my relatives in one outpost camp. I miss that even today, I do miss that. So, when I go up in the summertime (my sister and her family still live up there) we go to our old places. Maybe five years ago, my sister and I took a trip by boat. We went to see my mother's place, where she lived when she was a child. When we were growing up we didn't have toys, we used rocks. And then they would collect the most beautiful rocks as ornaments for inside a winter hut or tent. So, we went to see my mother's old camp, and in the place that she used to play we found those rocks, still arranged the way she fixed them. They were still there. That was really wonderful to see again.

Living on the land meant being both resourceful as well as unencumbered by an excess of material things. Far from the settlement area, Ovilu and her family relied on the materials the land provided them for clothing, shelter, food and even toys.

When I was a child we always lived in outpost camp with the hunting ground. My parents, or the other people in the camp, would travel the hunting grounds to see where the hunting would be good for the winter season.

At the time of winter sometimes we would live in snow houses, igloos. Or we lived in huts that were made with bone. But they also used scraps of wood to build winter huts. They put layers of tents over the wood or bone frame and they would insulate the tents with berry bushes they gathered during the Fall. Some winter huts they would plaster them with flour paste inside. I found that that was amazing! I would look at all the cut-outs from magazines plastered on the inside of our winter hut and imagine how people - how white people - lived down here. Pictures of things we had never seen.

Everything in the material, everything we wore was handmade by the family, because they didn't have any dresses, or anything like that. Not that I wanted to have dresses! Even when we were growing up, we never had a lot of things. We didn't have any things like southern toys or any kind of stuff like that. So, our parents would make us homemade toys out of bone or wooden toys. It's like when you grow up down here you play with dolls, we used to have little wooden dolls called Inuyuk. Our parents would make the boys sleds and a little dog team with little whips. Then they would make us a tiny wooden family of dolls. And they would make them clothing. I actually have one here, but I packed it away because it is very old. 
Life on the land could also be marked by periods of hardship, particularly when food was in short supply.

Sometimes through the winters it was really hard because you have to ration everything. The hunting was probably not good that year. So, what little we had to eat the children were always the first to eat. And you have to ration what you get, because you're not going to get anything else from anywhere else.

Early encounters with non-Inuit were often marked by fear of the unknown. It was a fear which eventually dissipated as they got used to living in Cape Dorset.

When we were growing up, when we were kids, if ever white people came into our camps we would run and hide! We were scared of them! We'd go hide behind the hills. We were afraid they were going to take us. Even when we lived in the camps the teacher would travel to the outpost camps to check-up on what we were doing with school work. It was just the fact that they were different from us. Eventually, after moving into the community, we got used to other people, to the white people in the community.

After her father passed away, Ovilu's mother took on the role of providing country food for the family. Tucked into one of the ends of a seal skin kayak, her mother would take her hunting.

My father had a stroke when I was very young. So, my mother became like a father and a mother. She would go out hunting all the time in the kayak. Of course, we would always want to go with her. And because it's a one man kayak made of seal skin, an Inuit-made kayak, she would put us underneath, one each in the front and the back of the kayak. It was so boring because you can't look up and out, since you are lying down watching the water. When I got bored I used to say, "I have to go to the bathroom!" and my mother would say, 'But, you just went!".

When travelling between camps, all belongings were collected onto several qamutik (Inuit sleds). Children were wrapped in warm caribou skin clothing and safely secured on the qamutik for the long journey with nothing to do but watch the landscape pass by. Travelling the land is something Ovilu misses even today. 
We only travelled by dog team from camp to camp. When we traveled when we were kids they took everything, what little they had, everything they owned. So, the qamutik would be really high with all the belongings. And they would wrap us up in caribou skins to keep us warm over long distance trips. We would get kind of tired of being wrapped in the qamutik. If it tips in rough ice, you go down with the qamutik. All you see is the blue, blue sky. Nothing else! And white snow. I miss those, even today, I miss them.

\section{Adjusting to Life in the Settlement}

For Ovilu, adjusting to life in the settlement was not a particularly difficult transition primarily because she had family already settled there. She knew if she wanted to go back on the land she could simply ask one of her uncles' to take her out.

Moving to the community wasn't that hard a transition, not really. Not for me anyways. It probably was for some people. But because two of my aunts were in the community and my uncles, we were alright. If we wanted to go to my uncles' camps they were close enough that we could go by dog team, and we would not have to stay overnight.

A feature of community life which was difficult to adjust to, however, was attending southern-Canadian style school. It was a frustrating time, because the instruction was in English, which she did not understand. Even when her family lived on the land, southern educators began introducing English books to Inuit, books Ovilu remembers burning in defiance.

I think the most difficult thing about having to move into the community was having to go to school every day. And not knowing what the teacher was saying to us. We didn't speak any English or anything like that. That I found it was very, very hard. I actually burned my school books one time. When I was still in the camps. I vaguely remember, my sister said, "The teacher is coming into our camps". And I burned our school books. I didn't want to be involved. We didn't want to be involved with that. Not knowing anything about a different culture than ours. And they were not much of school books anyways. I think of that sometimes. They weren't much in terms of school books. They were like, "Dick and Jane" and "See Spot Run", that sort of thing. That part was difficult. 
In school, the children were not permitted to speak Inuktitut, despite not knowing any English. If they did, teachers could be 'nasty' and add to the hardship the children experienced. Not being permitted to speak Inuktitut was a very negative experience which has left a lasting impression on Ovilu. Based on her narrative below, it is evident that Inuit language is a strong part of her identity.

When we moved to the settlement we had to start going to school and that was the hardest part. None of us knew how to speak English or how to read and write. If we talked Inuktitut in school, because we didn't know any other language, the teachers sometimes were very nasty about it. We weren't allowed to speak our own language in school growing up because they were so determined that we have to learn English. That was really hardship for a lot of us kids. When you were told to not speak your own language, that's a hardship, I didn't like that. Never liked it, even to date, I don't like it when people say don't speak your language. I am here!

There was a strong presence of Europeans (predominantly English and Scottish) in the community when Ovilu was growing up. They held positions as teachers, nurses, and clerks at the HBC. The result of having 'European' as opposed to 'Canadian' teachers to teach her English, she had a difficult time understanding the nuances of 'Canadian English' when she later moved down south.

When we started going to school in the community, that was hard too because for a long time we only had teachers that were Europeans, like English or Australian or Scottish. We never really had Canadian people in the community. So, when I was growing up I learned European-style English. When I came down south I had a hard time understanding Canadian English because I was so used to the terms of European English. To me it was like they were talking so fast, just like cowboys from the movies! It took me a while to follow the terms. Later on, like in the '70s we had Canadian teachers starting to come in. All the nurses we had were European too. They had to be from Europe or England because they were trained as midwives, which the Canadian nurses didn't have. So, they would send these nurses to the community. Even all the Hudson's Bay people they were either from Scotland or England. 


\section{Early Urban Experiences: Visiting Toronto}

Toronto was the first southern city Ovilu visited as a teenager. She travelled there with another family she grew up with in Cape Dorset. It was the first time she ever saw trees.

I actually didn't move to Ottawa from up there right away. When I was fifteen I went to Toronto. I went there with a family. The first time I touched a tree when I was in Toronto, I said to the family I was with at the time, "Wow, you white people even know how to make trees!" I didn't believe them, but they said, "We didn't make those trees, God did!". "Yeah right", I said. "You made them!"

Other memorable urban experiences included encountering people of different backgrounds. The first time Ovilu saw a group of Chinese people, she thought they were

Inuit. It is an event she looks back on with humour.

When I went to Toronto I had never seen Chinese people before. When I saw a group of Chinese people in Toronto when we were walking downtown, I thought they were a whole bunch of Inuit! I remember one of my friends running over to one of the Chinese women thinking it was my mother, he was so fond of my mother. He ran up to her and started kissing her! And this oriental woman said, "What are you doing? Who are you?!". We thought they were a whole bunch of Inuit!

The journey back home to Cape Dorset was long, and took them through Ottawa and Montréal. After being in the south for a while, Ovilu remembers how much she missed the land.

When we went back up north, we travelled by ship because we didn't have an air strip at home, and it was break up season. From Toronto we took the bus to Ottawa, then to Montréal to catch the CD Howe, which was the medical ship that travelled all across the arctic and northern Québec. So, I took that trip back up north. You don't know how much I missed snow! When I went home I really, really, really missed the mountains, the fresh air, the smell of the ocean. Those were so hard to not have them around me because when you grow up around mountains and the ocean you miss those, the aroma, the freshness. 


\section{Living in Montréal and Ottawa}

Ovilu got the opportunity to live Montréal when her artwork ${ }^{47}$ was featured in the Canadian Pavillion of the 1967 International and Universal Exposition, more commonly known as Expo '67. While living there, she would travel back and forth between Montréal and Ottawa to visit a family she knew from Cape Dorset who had moved there.

I was living in Montréal because my art was used at Expo '67. That's when I first lived in Montréal because I did some art for the Expo. I used to come here (Ottawa) because I knew a family I grew up with in Cape Dorset who were living here. An Inuit family. They always spoke Inuktitut. I would go back and forth to see them from Montréal.

The following year, Ovilu moved to Ottawa for work. She remembers only a handful of Inuit lived in the city at that time.

After that I moved here to Ottawa. I moved to Ottawa in "68 to work for, it used to be called, Canadian Arctic Producers, which is the art dealer across the north for the galleries across the world. There were maybe four or five of us Inuit in Ottawa when I first moved here.

\section{Adjusting to Life in Ottawa}

Adjusting to life in Ottawa was a challenge, especially because at the time there were no programs or services available to Inuit to help them with the transition, as there are now.

\footnotetext{
${ }^{47}$ Ovilu learned the art of printmaking from Canadian artist James Houston, who played an important role in the recognition of Inuit art in Canada and around the world. Houston, who had studied printmaking in Japan, introduced the art form to the Inuit residents of Cape Dorset in 1957. In 1958, Houston helped establish a printmaking shop in order for residents to make prints for sale to the outside market. This coincided with the development of Arctic Co-operatives during the late 1950 s and 1960s, the first locally owned and controlled business enterprises in Inuit communities. Canadian Arctic Producers (first established in 1965) is the wholesale art marketing arm of Arctic Co-operatives Limited, a co-operative service organization owned and controlled by the 31 community-based, multi-purpose Co-operatives in Nunavut and the Northwest Territories. Since the 1950s, Cape Dorset has been world-renowned as the 'Capital of Inuit Art' and has been a centre for Inuit drawing, printmaking, and carving, all of which make significant contributions to the local economy. Well-known artists from Cape Dorset include, Nuna Parr, Kenojuak Ashevak and Peter Pitseolak, whose works have been exhibited at the National Gallery of Canada.
} 
When I moved to Ottawa there were no programs for Inuit here. As the years go by, you have to learn how to fit in, to teach yourself, and to ask questions. It's good to have friends that you can ask, for instance, "What do I do if I want to go register at Manpower?" or "How do I find a doctor?", all that kind of stuff. That was not very easy at times. Then after a while I learned to cope with it. You have to learn, and teach yourself to be part of the community even if there was no Inuit there.

Fortunately, Ovilu was able to live with the family she knew from Cape Dorset until she was ready to move out on her own. They were a great resource to her during a challenging time. They also spoke Inuktitut which was a comfort. Eventually, Ovilu got her own place and learned what it meant to be independent.

When first I moved to Ottawa I lived with a family that I grew up with up north. That was a lot easier for me because they always spoke Inuktitut, and they helped me a lot by telling me what I should expect living down here. Then I got my own place in ' 68 for the first time. That was very hard for me because I never cooked, and I never had to do my own laundry. It was fun having your own place, but it was hard at the same time because I wasn't used to being on my own. Suddenly, all at once, I had to pay bills and the rent. It really was stressful for me because I never had to look after those things for myself before. I had to learn that to become an independent person. My mother told me: "You're always learning something new, and you have to be independent if you're going to be away from home." But you run into a lot of things that you don't expect coming from up north, and that was kind of hard. Like, if you want to go back to school who do you talk to? How do you go about buying things in a big city? We're not used to that.

Although she faced many challenges, living on her own filled Ovilu with a sense of pride,

knowing she had the adaptability to learn and cope with her new surroundings.

When I first lived here I was really happy. Once you get to know yourself, how you can live in the city. You learn and listen from other people. It lifts you up, now you know, you're learning to live independently. That was a big challenge for me anyways.

Eventually Ovilu's mother came to visit her in Ottawa. Although Ovilu had adjusted to her new environment, her mother did not have a taste for the city. Unlike being on the land, where you can see for miles on the open tundra, the city felt too close. 
My mother would come down to Ottawa to visit me when she was alive. The day after arriving she would say, "I want to go home now". I would say, "you just got here!". She would say "Yeah, but I can't see anything far! There are too many trees, too many buildings!" She always said, "It's suffocating!" It's so open up north. So open wide!

\section{Challenges of Living in Ottawa}

Despite enjoying her newfound independence in the city, Ovilu went through a period of terrible loneliness. It was this loneliness that would later motivate her to help organize the Inuit community in Ottawa, and start building social networks.

I felt lost. Then the loneliness hits pretty hard, missing your family. I could see that happening, and I thought, I don't want people to experience that. Loneliness takes over your life.

Not only did Ovilu long for her family, she craved country food such as caribou, seal, and

fish (e.g. Arctic char). Not having access to the food she was raised on was one of the greatest hardships she faced living in Ottawa.

The diet in the south was something else to get used to, when all your life you've grown up with country food. When I first moved down here I didn't have any country food! I saw fruit and other stuff I'd never seen before. We used to always get cans of the perishable food from the Bay, and there was very little of it. So, it was really hard for a while not having country food. You crave for your own food, country food. That was hard, very hard.

At the time, there was no way to send country food down south, like there is now. The only country food that could be sent by mail was dried caribou. Though it was a greatly appreciated, it still took a long time for the caribou to be sent by mail.

In those days too they didn't have much of a way to send country food down to the city because most of the planes didn't have freezers to keep anything fresh. But when I started living down here my mother and my sister would send dried caribou to me by mail. That was such a treat for me. Such a wonderful treat! It would take so long to get to me, though. The mail would take one month to get here. It was very hard.

Living in Ottawa brought with it other challenges, such as encountering racism. 
Racial slurs, that was really hard for me. But I just kind of talked back to them and said, "I'm not racist towards you, why are you doing this?". I said to them: "You have the same blood as I have. So, I don't want to hear stuff like that towards me or my fellow Inuit people. Or to anybody as a matter of fact, you shouldn't be doing that!"

While living in Ottawa, Ovilu wanted to take advantage of the greater educational opportunities available here. However, because she lived in the south, she was not able to access funding.

Another challenge was after they cut off schooling in Ottawa for the Inuit community. That was hard because I could not get funding if I wanted to go back to school. When I went to the school I had to fund myself to go to school. I worked part time and paid for everything to go to school.

Inuit who migrate and live in Ottawa now have an 'easier' time, due to the programs and services available to them through community-based service agencies.

Now it seems so much easier for other Inuit coming down to live in Ottawa, because TI (Tungasuvvingat Inuit ${ }^{48}$ ) is helping them. They can just go to there and they have different programs. They get a lot of help. There are people to find them a home, or help them with health organizations, everything. But we didn't have those.

\section{Inuit House}

Ovilu recalls how a small Inuit community began to form around 'Inuit House', a gathering place built by the federal government for Inuit students being educated in the south. Gathering and being with other Inuit helped ease feelings of loneliness.

In the late 60 s and the early ' $70 \mathrm{~s}$, there were Inuit students who were being brought down to Ottawa to go to school here. They were put into family homes to board. But what the government did - the federal government, the education department - so the students could get together, they built what used to be called

\footnotetext{
${ }^{48}$ The Inuit community centre Tungasuvvingat Inuit (meaning 'a place where Inuit are welcome') provides Inuit specific programs, services, and support to empower and enhance the lives of Inuit. Since 1987, TI has been operating in Ottawa as a community-based counselling and resource centre. Tl offers a supportive environment that attempts to duplicate the community spirit and cultural surrounding of the Inuit homelands. (http://www.tungasuwingatinuit.ca/eng/ti.htm)
} 
"Inuit House". It was on Somerset down near the Canal, and it was run by the federal government education department. There was an Inuit woman there from Kuujjuaraapik (Arctic Québec) and her partner who ran the Inuit House. We would all get together over there, a little tiny Inuit community over there.

Inuit House was geared mostly towards the students who were going to school here because they were living with host families. They were not living in the residences when they came to Ottawa to go to school. They were actually living with nice host families, but I know how lonely you can be when you first leave your family from the Arctic. So this was a very good idea to have this 'Inuit House'.

\section{From Inuit House to Tungasuvvingat Inuit}

Towards the mid- to late-1970s, 'Inuit House' was shut down, and the building was sold. However, around the same time northern patients seeking medical care in the south started being directed to Ottawa as opposed to Montréal. Ovilu saw the Inuit community was starting to grow. She knew the Inuit living in Ottawa would need a place to gather to help ease culture shock.

When students were no longer coming to Ottawa for school, they closed that 'Inuit House' down and sold the building. Still in the late '70s, I said we have to have an Inuit community centre.

It's very much a culture shock when people come down from the north to experience southern living. I was worried about that. That the community would start growing and growing. Patients used to go to Montréal for hospital care from Baffin Island, but when they changed it to Ottawa, the Inuit community got bigger and bigger. They would get escorted to Ottawa for medical treatment, and then for whatever reason many chose to stay here.

Motivated to help her fellow Inuit, Ovilu gathered people together in support of building an Inuit community centre. This marked the beginnings of Tungasuvvingat Inuit. She found the first building for the drop-in centre herself, a small space the community outgrew in a couple of years. 
I gathered lots of people and that's when TI started. I found the building. It was a really, really small building so TI could start a drop-in centre. I found a very, very tiny place on Bronson through a friend of mine who is a restaurant owner in Ottawa. He was nice enough to rent us a tiny place. I think it was two years later, when the community got bigger, we had to find another place because that place was way too small! When the events were happening people were crammed in there.

It was not very big but it did very good things for the people that were coming down to Ottawa either for work or for higher education. People didn't just come down here to do nothing. In those days people actually came down for jobs or education. And then families eventually started to come down.

Tungasuvvingat Inuit: Early Days

After receiving funding from the federal government, TI was able to hire an executive director and small staff. Eventually they had acquired sufficient funds to purchase their own building.

When they realised TI was really going to happen, and become established as an organization, Brenda Conboy was hired as the first Executive Director. Then another person was hired, and the organizations started applying for funding from the federal government, probably from Indian and Northern Affairs, and other sources. Years later they got another place, I believe it was the building on Laurier Avenue. I'm not sure if they had another place before 604 Laurier, but anyways, that was a very good start, owning that building.

After helping to organize the community in the early days, Ovilu chose to step back. As the years passed and TI was able to acquire more funding, programs and services available to Inuit started to expand.

After getting the community organized and getting TI started I stepped back. I felt like the community was secure and going in the right direction, so I stepped back. When they funding started coming through, TI started having really good programs, and started to develop services with the Inuit community. People could get enrolled in education programs. They started developing all these different programs through TI, and a lot of it was very good. A lot of it took years because they had to look for funding for the programs. 
So, we got TI going so people could have a place where they could find help getting a job, and for instance, get help applying for OHIP or dental coverage, or any kind of health or medical care. Or if they wanted to continue their education, stuff like that.

As time passed, TI's programming expanded to address the growing homelessness of Inuit living in Ottawa, as well as addictions. This led to the formation of Inuit-specific treatment programs, such as counselling, and eventually to the formation of a live-in treatment centre.

By the late 80s and 90s people started talking about homelessness, and the drug and alcohol abuse within the community. TI started hiring more Inuit employees which helped get some Inuit off the streets. The next thing they developed were treatments for drug and alcohol abuse. At the beginning they didn't have a live-in treatment centre, but they would have counselling for the people that were interested. Now, the treatment centre has grown to have in-patient care. They have two buildings now. People who want to come down to Ottawa from Nunavut for treatment can come, or elsewhere or from other cities for treatment.

\section{Reaching Out to Inuit and Non-Inuit: Work at ITK and Pauktuutit}

Ovilu has always been motivated to help her fellow Inuit. Before TI began operating she worked at what was then called Inuit Tapirisat of Canada ${ }^{49}$ (ITC). She spearheaded the development of a booklet of information designed to assist Inuit who migrated to Ottawa, of what to expect from urban life.

Before TI really came into existence, I was working with ITC. I decided I had talked to the board of directors about creating a booklet for Inuit that come down to Ottawa on what to expect, since the Inuit population was getting bigger. So we had a booklet through ITK, and we had very good writers that worked on it. We hired David Boult who created this beautiful booklet. That was the first booklet for guidance, and it really helped those Inuit who first came down.

\footnotetext{
49 At the time called Inuit Tapirisat of Canada, now called Inuit Tapiriit Kanatami, is the national voice of $\mathbf{5 5 , 0 0 0}$ Inuit living in 53 communities across the Inuvialuit Settlement Region (Northwest Territories), Nunavut, Nunavik. (Northern Québec), and Nunatsiavut (Northern Labrador), land claims regions. Inuit call this vast region Inuit Nunangat. (http://www.itk.ca/page/about-itk)
} 
Then later, when Ovilu worked at Pauktuutit Inuit Women's Association ${ }^{50}$ she was involved with developing another booklet, this time with the focus of creating crosscultural dialogues and understanding between Inuit and non-Inuit.

When I was working at Pauktuutit Inuit Women's Association as the Secretary Treasurer, I wanted there to be another resource to educate non-Inuit about Inuit. We created a booklet called "The Inuit Way" "51. Again, we hired David Boult to design the booklet. He's a very good writer. He interviewed Inuit not just in the city, but also all kinds of people in Labrador and other communities in Nunavut and Nunavik. It helped the Inuit because it was not written by a white person. It had all the information from interviews from Inuit elders and youth. That was the beginning of a good relationship between Inuit community and non-Inuit because it helped us to reach to each other, and understand each other's cultures.

\section{Living in Ottawa: Reflecting on Life 'Back Then and Now'}

Ovilu reflects on how the Inuit community in Ottawa has grown and changed over the past forty years.

A lot of things have changed. I've been living down south for over forty years. In the early days we didn't have those programs for Inuit. If you came down on your own, then you were completely on your own without anybody there to help you. You had to find yourself a job if you were going to survive. I was always lucky when I first came down, I always landed a good job.

When I first moved here there were only four Inuit here. Now it's a very large community, it's so wonderful to have that, you know. It's so different now. I just love it because we didn't have that when I first came down to live down south.

\footnotetext{
${ }^{50}$ Pauktuutit Inuit Women of Canada was established through ITK in 1984 as the national organization representing Inuit women. It has no membership fees and all Inuit women are considered members of this organization. It operates from Ottawa, and is mandated to foster greater awareness of the needs of Inuit women, advocate for equality and social improvements, and encourage their participation in the community, regional and national life of Canada. Pauktuutit leads and supports Inuit women in Canada in policy development and community projects in all areas of interest to them for the social, cultural, political and economic betterment of the women, their families and communities. (http://www.pauktuutit.ca)

51 "The Inuit Way: A Guide to Inuit Culture". First published in 1989, most recently revised in 2006. With more than twenty thousand copies in print, this publication is touted as Pauktuutit's most influential publication by creating a bridge of understanding between Inuit and non-Inuit cultures. (For a copy: http://www.pauktuutit.ca/index.php/home/publications)
} 
In Ottawa, thanks to community-based agencies, Inuit are able to gather to enjoy each others' company, speak Inuktitut, and participate in cultural events such as 'Inuit Day' and community feasts which serve country food. Ovilu appreciates how communitybased agencies provide the community with 'a place to go'.

We gather together in different kinds of Inuit traditional functions. You are able to speak your own language, talk to them, and get together with your Inuit fellows. Like the lunch program or, for instance, on Inuit Day. People really put effort into doing these sorts of things in the community and the Children's Centre. I appreciate it so much because Inuit have more places to go to. We gather and it's wonderful, it's like a feast for us, like up north, our traditional way. With games as well. It's so much easier now than it was in the early days living here. You have a place to go to. Inuit have a place to go to.

I'm really, really happy that TI exists here in Ottawa because the Inuit community is so large now. They have somewhere to go to talk to somebody, if they need anything. I would say we are very lucky to have TI because I have met wonderful people who work there. They are able to help the Inuit when they first come down. The people know where to go when they come down. Or someone will introduce them to TI, so they get through the culture shock with help from TI.

It is easier to ship country food to the south now that planes are equipped with freezers.

However, the cost of shipping remains prohibitive for many. Still, Ovilu is able to access country food more often now through her relatives who send it down.

Now we can get country food you know, because it's so different. The planes have deep freezers. But still the cost of shipping country food is very expensive because of the cargo prices. I seem to have country food quite a bit because I have really nice relatives and family. And my cousin, he's a senator. He loves hunting he lives in Northern Qc, he's from Nunavik, Kuujjuaq. He's out hunting all the time when he's not sitting at the senate. So he always saves me when I'm most craving for country food. And then my sons or my relatives from Nunavut they send me like muktuk and seal meat and different things like that. If I want something from country food store in Iqaluit, but that's still too expensive so I get it directly from my family relatives. 
She occasionally attends community feasts to access country food. However, more often than not she shares her country food with others. Often she donates country food to the community feasts so that others may take some home.

Now I go to the community feasts sometimes. And when I have extras I try to bring it to them. Not so they can cook it at the feast, but so people can take some country food home with them. The lunch they have through TI at the St Margaret church. When I have spare I try to take some for them to take home. A lot of people go the feast. I ask them to take everything from my freezer and they were very happy to have that to take home. Because at the lunch program they still get caribou stew, or seal, or char.

Aboriginal community centres have also improved the situation of Inuit living in Ottawa.

Through Aboriginal community centres Inuit are able to access a variety of services. This

is particularly useful on the weekend when Inuit community services tend to be closed.

And not just Inuit community centres but there are also Aboriginal community centres that work very hard as well to make sure the Aboriginals and Inuit have that sort of things going for them. Because Inuit community centres are closed all weekend, unless there is some special function going on. The Aboriginal community centre is open all weekend long. So Inuit are also so welcome there, they can have breakfast, lunch, and dinner at the aboriginal community centre on Rideau $^{52}$. I have visited there, and they have a lot of kind people working there. And they have different programs if people want to do artwork or things like this, same with the Inuit community centres. But on the weekends, I appreciate that it's open for the people that don't have a place to go to, or for the people that don't really have an income and they don't have food there's a place to go to. I really appreciate the OICC (Ottawa Inuit Chidlren's Centre ${ }^{53}$ ) and the Inuit community centres. Not just those, but also the Aboriginal community centres are very, very good. They help Inuit, and vice versa. So it works out pretty good. You have choice.

\footnotetext{
${ }^{52} 510$ Rideau Shawenjeagamik (House of Compassion) Aboriginal Drop-In Centre

${ }^{53}$ The Ottawa Inuit Children's Centre serves Inuit children and youth from birth to 13 years of age and their families. The objects of the organizations are: 1) to provide inuit children and youth with a learning environment that will enhance their overall development; 2 ) to foster positive parenting through support and education; 3) to promote the retention of the Inuit culture and language. The are the home of the Sivummut Head Start Program, Tumiralaat Child Care Centre, Family Literacy Program, youth programs, Inuktitut language program Uqausivut, among other services.
} 
In addition, part of what enriches the urban experience of Inuit living in Ottawa is the presence of Elders. As an Elder, and a holder of cultural knowledge, Ovilu feels responsible for passing on traditions to future generations. Elders in Ottawa help to keep Inuit culture alive and thriving.

I think we are very lucky in Ottawa. We have elders. I am one of them! We keep up with Inuit culture. You know, we have elders that are very, very wise. People like that keep the Inuit people going, not to forget our own people, not to forget our own culture, and to be proud of who we are. I would like to see that tradition continue, to have Inuit educate other Inuit about their culture.

Ovilu's responsibilities as an Elder also take her beyond the Inuit community and into the local political realm. Through the Ottawa Aboriginal Coalition she and other Indigenous people involved make their interests known to the City of Ottawa.

I try to go to the Aboriginal-Inuit gatherings because we work together to see how we can help the youth living in our city. We think about ways we can help our people: Inuit, Aboriginal and Métis. We created a coalition (the Ottawa Aboriginal Coalition) to make sure the city of Ottawa represents our people. Several of us do gatherings as Elders. We gather to decide what should be discussed at the coalition meetings, and then at the actual meetings our representatives bring up our issues on our behalf. That way we have people that make sure Inuit are involved with city hall decisions.

\section{Challenges for Inuit Migrating to Ottawa Today}

Despite the progress made by community-based service agencies in Ottawa, Ovilu has a realistic view of the challenges some Inuit face when they move to Ottawa.

There are some very good things about living in Ottawa nowadays, but there are also on the other side, things that aren't so great.

Ovilu reflects on some of the challenges Inuit continue to face when they move to Ottawa. She identifies that part of the problem is that they do not know what to expect when they move to the city. The reality of what they face is often different than their 
expectation, that life in the city will be easier than in their northern communities. Life is particularly challenging for those that do not speak English well or at all.

Even today, a lot of people don't have any idea about what to expect when they move to Ottawa. I would like to see TI inform people before they move down to the city not to expect it to be easy. It takes time and sometimes it doesn't even happen. I think it would be wonderful to compile together information to help Inuit when they come down to the city, so they know what they're going to face, what challenges they're going to face when they come to live in the cities. It is very hard, especially for people that don't speak English that well. They don't understand.

I think the biggest challenge for Inuit when they move down here is that they think there's not going to be problems. They think they can just find work or a home just like that. But, it doesn't work like that. I think that a lot of people go through challenges like that because they think they can just get what they want easily, but it doesn't happen that way.

Although there are a number of services available to Inuit living in Ottawa through community-based services agencies like $\mathrm{TI}$, not all Inuit know about them or access them.

And if they don't know anything about TI then they get stuck, and not knowing what to do, they feel lost. You feel lost. In the Barren lands. It's not always as pleasant as it sounds. It's not always pleasant.

Ovilu has noticed there are a growing number of homeless Inuit living on the streets. The availability of drugs and alcohol, as well as the differences between Inuit and non-Inuit ways of justice can also complicate the lives of Inuit living in Ottawa.

People still have a difficult time adapting to city living. We have a lot of Inuit who end up in the city and end up homeless. That bothers me a lot to see Inuit on the streets. Being on street, alcohol, drug abuse, takes over the lives of Inuit people, or any other people, if they are not used to be living in the city. When they get into trouble down south they don't realize the justice system is completely different here than in the north. 
Connected to the issue of homelessness is the matter of adequate and affordable housing for Inuit. Although Inuit Non-profit Housing Corporation offers rent-geared-to-income housing for Inuit families and singles living in the Ottawa area, there are few units ${ }^{54}$ available and a long waiting list.

Finding housing is difficult here too. Inuit non-profit housing is very small. The waiting lists for Inuit and Aboriginal housing is always long. So it's hard to find a place unless you have money. If you have a good income coming then you can possibly find yourself in an apartment or a home. But for people with a low income, or no income, it's difficult, very difficult. Unless you get into non-profit housing because at least that's geared to low income.

Being homeless and not having an address adds the further complication of making it more difficult for those Inuit in need to access social assistance.

It's also very hard for some people if you don't have an address. Ontario Works ${ }^{55}$ refuses a lot of people social assistance unless they have an address.

Other challenges include differences in child rearing practices between Inuit and nonInuit. In the north, if difficulties arise in families, children may be taken out of the negative environment to a relative's home, however, access to the child is rarely restricted. In Ottawa, many Inuit have had the experience of having their children taken away by the Children's Aid Society, and being denied access to them.

People have a difficult time with the Children's Aid always taking people's children away. That's really hard on the family because they are not used to that, even though it's in the best interest of the child. Someone needs to be there for those Inuit families to give support.

Although overall life in Ottawa has improved for Inuit residents, some major hurdles still exist. Just as Ovilu was denied educational dollars when she was a student, so too was her

\footnotetext{
${ }^{54}$ Inuit are given priority on waiting list for 63 units, after which Metis and Status Indian applicants are considered.

${ }^{55}$ Provincial social assistance program administered through the Ministry of Community and Social Services. Offers programs which help those in need with temporary financial assistance and help to secure employment. (http://www.mcss.gov.on.ca/en/mcss/programs/social/ow/)
} 
son. Although she and her son remain beneficiaries of the Nunavut land claim, as urban

Inuit they have lost certain rights.

Because I lived down here for a long time, my kids couldn't get funding to go to school from Nunavut like any other Inuit children. For my son, we had to pay for his school last year. He graduated last year from $\mathrm{NS}^{56}$. We had to pay for all of that because they still don't look at us the same way. Because if you grow up in the city, as urban Inuit, I guess they think you don't exist anymore, you know for funding for Inuit. It was the same for my friend and her daughter who is at Ottawa University. She had to look after all the funding for that. That's a real hardship on everybody.

When her son graduated from the NS program, she had the opportunity to voice her dissatisfaction with the treatment of urban Inuit youth like her son. She stressed the importance of supporting the education of all Inuit youth in Canada, not solely those residing in northern communities.

So when my son graduated from NS the parents had an opportunity to talk to the groups who were funding for that school. I said, because the Inuit community is so huge now in Ottawa the Nunavut government should closely look into funding the young adults in the urban cities like Ottawa, to help them to get more education. They always talk about how education is the best thing that's going to help the youth to get ahead. So if they want other Inuit to strive, not just people in Nunavut, all our kids need to get more educated. I have asked them if they can look into that more closely, if they fund urban Inuit youth so they can have an opportunity to go back to school like anybody else. So I hope that will happen because that was very difficult for me when I moved to Ottawa. I couldn't get any funding to go to school if I wanted to go to college.

Ovilu's son was one of two urban Inuit in the NS program. It was the first time urban Inuit were admitted into the program.

I think the Nunavut government should really look into NS, to see if urban youth can get funding, so they have an opportunity to go to this school without making the family struggle for funding. It is a really wonderful program there. For the

\footnotetext{
${ }^{56}$ Nunavut Sivuniksavut (NS) is a unique eight-month college program based in Ottawa. It is for Inuit youth from Nunavut who want to prepare for the educational, training, and career opportunities that are being created by the Nunavut Land Claims Agreement (NLCA) and the new Government of Nunavut. (http://www.nstraining.ca)
} 
first time, there were two urban youth in the program. My son and another young woman. I know there was a big difference for my son, because during that program he learned so much about his own culture and his people. I hope that they will somehow find funding for the urban kids so they can attend, because they are willing to. The urban youth want to learn about themselves, they want to learn about their own people, their own culture, the lives of the generations from before.

Thinking of her son's treatment, Ovilu reflects on what it means to be an 'urban Inuit'. It is more than geography, more than appearance that makes a person 'Inuk'.

Even when you are raised as urban Inuit, if you were born down here, you are with your Inuit family, and your Inuit community. You are still Inuit! You're still Inuk and you still have Inuit values. You are proud to be Inuk. No matter where you were born, you know that you are Inuk. That's your pride, is being Inuk. You know, if you're Indian or African, or anything, you have to proud of who you are. People always make remarks when you are different. And they learned from that to be ashamed. You should be proud to be different. It makes you what you are, and what you do, and whoever you are.

But they are all Inuit. You can be blond and blue eyed, and still Inuk. I have nieces and nephews that look more white than most white men! It's not what's on the outside, it's what's on the inside.

For Ovilu, her Inuit heritage is a source of pride and strength. Pride in Inuit culture is a virtue she aims to inspire in the young people she meets. Especially those for whatever reason have chosen to disassociate from the culture.

I find our children need to learn about their own culture because it makes you, to me personally, it makes me a stronger person. And I am proud to be Inuk, very proud to be Inuk, and you cannot forget that. Because sometimes I hear adults say, "I'm not Inuk, I don't want to be Inuk". But I tell them, you can't get away from being Inuk. I think it's just that they had a bad experience.

To me being Inuk, to be a part of the culture, that makes me very proud and very strong within you. And I think it's the same for you, I think it makes you stronger knowing you own culture. Wherever you come from. Your identity is a very, very important part of your life. You cannot pretend to be what you are not. If you do, you are just putting yourself down. Or you don't feel the same, you don't feel strong within you. If you keep your identity as what you are, as Inuit or as any 
other culture, you are a stronger person in the long run. Learn about your background as much as possible, because it is important in our lives.

Some Inuit pretend that they are not Inuit. Maybe they like the white man's way of living. When I heard that from one particular person, I said "How can you say that? You're a beautiful Inuk and you should be very proud of what you are." And I said to the person, "You cannot pretend to be what you are not. You are not a white person. You cannot to be a white person. You were born as an Inuk." That bothered me to hear that. I don't hear it very often but I heard it from individuals. How they no longer want to be Inuk. You cannot be what you are not. I said "You should be very proud as an Inuk person. You should be proud of your culture, proud of what your great grandparents did centuries ago."

\section{Future Generations}

Ovilu reflects on her hopes for the future generations of Inuit being raised in Ottawa.

I don't know what's going to happen for the urban Inuit in the generations to come. I hope things will be much, much better for those kids. Our grandchildren and our children are the future generations we will be leaving behind. I would like them to be more educated. And hopefully they will land good jobs.

Thinking of the future causes Ovilu to think of her grandchildren who are being raised in

Ottawa. They attend the Ottawa Inuit Children's Centre (OICC) a community-based service agency which focuses on the cultural education of children. Through programming at the OICC Ovilu's grandchildren are learning Inuktitut, learning Inuit history, and culture. There the children are able to learn the "things that we have forgotten how to teach them'.

The OICC is an unimaginable help to the community. They started out as a Head Start. They have wonderful Inuit teachers that can give the child a learning experience about their own people. It is a wonderful, wonderful program.

My two granddaughters go to the OICC and they learn so much stuff there. Things that we have forgotten how to teach them. That is the most amazing thing, I love that. They learn about their own culture. My granddaughter tells me all the time now, she learned something new in Inuktitut. And she learns about what 
Inuit do. That is wonderful, I love that place. Also, I'm happy they have an Inuit run day care, and they also teach them there, no matter how small they are.

Ovilu's train of thought leads her to consider the situation of Inuit living in other cities across Canada.

So those kind of programs, I would love to see them continue. And I would love to see them in other cities as well. Like Montréal, there is also a very large Inuit community there. Winnipeg is very large. St. John's as well.

We are very, very lucky to have all this because other cities don't have the services we do. I hope to see Inuit community centres in other cities in the future. Montréal, St. John's Newfoundland, Winnipeg, Edmonton. Those are the main cities that have large Inuit communities. Hopefully they will all get something like TI in their communities. Montréal also has a lot of Inuit, not as many as Ottawa, but a lot of them. And they struggle too like anybody else because there is nobody really there to help them. Except they can go to the Aboriginal friendship centres where they can get some help. But their lives and culture are so different than the Inuit lifestyle.

\section{The Land}

From here our conversations shifts to discuss Ovilu's connection to the north after over four decades of living in Ottawa.

I missed the arctic very much. When I first moved what I missed was the smell of the ocean, the mountains, and the country food. And my family of course. But, as I got older I got more used to living down here than living up north. I've been living here for so long, I don't even like the cold anymore. Now when I go home if I stay too long up north I miss the trees. I miss gardening! I don't think I'll ever live up north again. It's not that I don't want to. It's the cost of living.

But I'm still very connected to the north. Even for me I've been living down here for many years, for forty-six years. My connection will never stop to Inuit, or Inuit culture. And I will always go back even just for a visit. It's serenity for me. Especially when I go up to visit people up north my family, my grandchildren. I'm still able to go to the land. You feel really good after going on the land.

Ovilu travels north when she can. She has one sister left living in Cape Dorset. She tends to visit her sons in Iqaluit or her extended family in Nunavik. 
I don't go back up north every year, but I do go back when I can. I have only one sister left there in Cape Dorset. Everyone else is gone.

When I go back up north, I usually go to Iqaluit because I have two sons living there. Sometimes I go to Kuujjuaq, I have family there. My family, on my mother's side, they originated from Kuujjuaq, and then they moved to Baffin. Peter Pitseolak, my uncle, and my grandfather they moved to Cape Dorset in the late ' $20 \mathrm{~s}$ and ' 30 s by boat. Because of better hunting in the ocean. Kuujjuaq is all fresh water, you have to go very far to hunt sea animals from Ungava Bay. My family moved to Baffin Island so I have some relatives in Kuujjuaq.

Visiting relatives also provides the opportunity to spend time on the land.

I was there just this past September to go berry picking. Spent time with my aunt, visited with my uncle who is in his eighties, and with my cousins. Every day we went berry picking for the whole day! I almost lost weight walking so much! But it was very fun.

I love being out on the land. When I go home or even when I go to where my sons live in Iqaluit my older son takes me out on the boat and it's so nice. When I go home to Cape Dorset my sister they are always out on the land. So it's nice when I go back I get to do those things.

However, during her visits Ovilu cannot help but notice how things have changed.

I miss the islands, lots of islands and inlands. When I go home sometimes I try to go to those areas as much as I can. But a lot of stuff has changed, even in those camps. Because of the damage of global warming a lot of lakes and river falls are gone, they dried up. When we went out with my sister and her family, and when we went out to where we used to live at the camps, there used to be beautiful rivers and falls. I was really sad to see they are all gone. Where the water was flowing it looked just like a desert. Just dried and cracked like if you were in the warm desert.

Ovilu reflects on what the land means to her.

The land has a lot of wonderful meanings to me. It's the calmness, quietness. Families are very close together. We do everything together with the families, or the camp people, the people that have lived in the outpost camps. And the gathering on the land. Waiting for people to come in from hunting, that was very exciting. We would have a big feast, and stuff like that.

She is reminded of the seasonal activities which take place on the land, and how every season brings with it something special to be harvested. 
With the different seasons up North there are different things you can do up there. Like going out on the land, at the end of the summer was so wonderful for us. Spring was wonderful for us, like July, because the plants would start coming up and we would go pick them. The edible plants. In the early Spring all the plants coming up, that was really wonderful. Going out and walking for very long distances. Keep walking and then going down to the beach and digging clams right there, and catching little fish when the tide goes down. Then gathering certain plants for different uses, and the edible plants the things you can eat or the roots of plants. And also in the spring they have little, actually they look like miniature trees but they grow on the ground. You pull them and you eat the bark part of the roots. And different roots to collect for edible, for food. And little flowery ones, edible ones, we would collect all those. Later on, just before Fall there was berry picking. Those things I miss a lot.

Spending time is still important to Ovilu and it is something she longs for even after all

her years of living in Ottawa.

It was really hard not to do that anymore. I still do miss that. But things are really changed now too up north, because not all the time people are living out on the camps anymore. But a lot of people still do go out on the land to spend the whole summer out there because it's very serenity to us. I really miss my childhood on the land sometimes.

Being on the land has also been a way Ovilu has connected with her ancestry.

When you go walking inland you find where the Thule used to live, and Tuniit. It's very interesting to see where the Tunnit used to be because the rock structures are still, you can still find those. And the older ones, when you go further in from the community there are bigger ones like big pillars of rock. And you can see the path they used to use. People say they were very small people. They were very extremely strong people, so they would be able to build things with big rocks like pillars almost.

Ovilu hopes to share her love of the land with her grandchildren both in the north and south.

I hope that my grandchildren who live up north have the opportunity to see those things. But I hope my grandchildren down here do too. I would love for them to go see those things. I think it's so important for Inuit children, at least to me it is, important for my grandchildren. I want to be able to show them the land. How their grandparents and family lived centuries ago. 
There are ancient Inuksuks everywhere where I come from. A lot of them, the Inuksuks, are different shapes. A lot of them people won't go into those areas because they were used for shamanism, not all shamans were bad but some of the people think they made the Inuksuks haunted. But I still find that very interesting. A friend of mine, Norman Hallendy, wrote a book on Inuksuks. He went to see a lot of those Inuksuks. Since I was eleven years old Norman always came up to my home town every year, every summer, to go out on the land, studying Inukshuks from the Elders ${ }^{53}$. From the people that know what those areas were like.

The high cost of northern travel prevents Ovilu from taking her grandchildren to visit the north and experience the land directly.

One day when I can afford it, I love to take my grandchildren to see those places. But, it's so expensive to travel up north by flight. It's so costly now to travel by air to go to the arctic. Even if we want to go, it's too difficult when you don't have all kinds of money like that to travel. For the cost of a one-way airline ticket to the arctic, I can go to Europe twice. I can go to England or go to Cuba or something like that.

For Ovilu, it is important to expose her grandchildren to the land, so they can experience it firsthand. She wants them to know about their ancestors, and about how they lived years ago.

I want my grandchildren to be able to see those one day. I want to take them up north to see the very old things, to hear the stories of how we lived, and see how we lived. Not only see it in the books but also see it in person. So they can know about how they actually lived in those outpost camps. I would love for them to see those areas.

\section{Summary:}

This thesis seeks to understand the significance of the land and urban placemaking for Ottawamiut. Based on Ovilu's narrative, it is evident that the land continues to play a significant role in her life. Ovilu's direct contact with the land has changed over time (i.e. when she moved from the outpost camp to the settlement; when she moved to

\footnotetext{
${ }^{57}$ Author of /nuksuit: Silent Messengers of the Arctic
} 
southern Canada); however, she has been able to carry the meanings, knowledge, and practices associated with the land with her. For Ovilu, the land has multiple meanings.

For Ovilu, the land is often associated with childhood, a time of freedom before government intervention. Being out on the land is associated with good health (e.g. being active, being out in the fresh air). The land is also thought to have a psychological and emotional impact to health as it is associated with calm and quiet. It is a source of values, such as family closeness, gathering, and sharing. In addition, the land is a source of sustenance in the form of country food (e.g. caribou, seal, fish, clams, berries and other plants). It is the platform upon which cultural practices are performed such as travelling by boat and dog team, hunting, fishing, and seasonal harvesting. Ovilu also mentions how the land is important as a source of history (e.g. Thule and Tuniit archaeological sites).

Conversely, the land can also be a source of negative emotions and psychological strain for someone living outside of the north. For instance, Ovilu spoke of craving country food because it is not readily available in the south. She also talked about missing the land and spending time on the land with her family. Reflecting on the land caused her to long for her childhood, a time before government interference in Inuit lives. She also expressed worry about how the land has changed due to global warming.

In Ottawa, Ovilu connects to the land through the consumption of country food; by speaking Inuktitut; by being active in the community and advocating for Inuit rights; by visiting her relatives in the North; by passing knowledge to younger generations of Inuit; and by gathering with other Inuit at community centres. 


\subsection{Life History of Maria Brazeau}

Introduction:

Maria Brazeau is an Elder from Nain, Labrador (Nunatsiavut). Her narrative is unique because it highlights the particular situation of Inuit in the Eastern Arctic, specifically Labrador. Inuit in this part of the Arctic were the first to encounter European explorers and missionaries. In essence, this area was 'settled' before other areas in the Eastern, Central and Western Arctic. The first missionaries entered the Arctic along the Labrador coast when the Moravians established a mission station at Nain in 1771. For most other areas, however, active contact with missionaries did not get underway for another 100 years (ITK, 2004).

A former colony and dominion of the United Kingdom, Newfoundland and Labrador became the tenth (and last) province to join the Canadian Confederation on March $31^{\text {st }}, 1949$. For Maria, this event marks a dramatic change in the way Inuit residing in Nain were treated. Maria's life goes from one of relative peace with her family, to one that is punctuated by government interference. Her narrative from her early years recounts vivid memories of time spent on the land with her family. Maria remembers the missionaries, as well as the English and Scottish teachers and nurses, having respect for Inuit language and traditions. Pre-Confederation, Maria's family enjoyed status and rank within the community.

However, after Confederation, the English and Scottish teachers and nurses Maria was accustomed to were replaced by their Canadian counterparts from the south. These extensions of the government treated Inuit poorly. Maria describes several painful 
experiences which illustrate the interventionist and paternalistic government policies of that time. For instance, at the age of six she remembers being taken from her parents to undergo treatment for tuberculosis in Northwest River. Maria stayed in Northwest River for a couple of years. When she returned to her family, at their insistence, she remembers no longer being able to eat country food or to speak Inuktitut. While these things came back to her in time, while she was with her family, her experiences illustrate the dramatic and traumatic consequences of the government's interventionist actions. In addition, Maria's family lost its status in the community, because the government did not recognize local forms of organization and governance. Maria was also forced to attend residential school, and leave her community as a young adult to further her education.

Like Ovilu's, Maria's narrative documents the dramatic socio-cultural changes experienced by Inuit during the mid-twentieth century. However, Maria's situation is specific to her region and therefore provides a broader perspective to the circumstances faced by Inuit in other regions outside of Nunavut. Maria's narrative also expresses her connections to the land, which she developed in childhood, and carried with her to Ottawa. Her narrative also highlights the importance of urban place-making in fostering connections to the land in Ottawa, for herself and for younger generations of Inuit being raised in Ottawa.

Maria's narrative begins below in her own words. It starts with her recollections of living on the land. Then, she describes the traumatic events of her childhood: when her family lost their influence in the community, post-Confederation; when she had to undergo TB treatment in Northwest River; when she was forced to attend residential school. Maria then goes on to talk about her experiences as a young adult attending 
university in St. John's, and later as a young woman living in Ottawa. As an urban Inuit Elder, she reflects on how life for Inuit in Ottawa has changed over time and her hopes for future generations. Based on her narrative, the relevance of community-based Inuit organizations and the role they play in fostering connections to Inuit land, culture and identity is evident.

\section{Living on the Land}

For Maria, memories of childhood are intertwined with her memories of living on the land. She cherishes her childhood as being a carefree time, spent with family. She learnt many valuable lessons about living off the land from her parents.

I lived in Nain, Labrador. That's where I was born: Nain, Labrador. Before going to residential school I learned a lot from my parents by living off the land. You knew what the seasons were, you knew what animals were to be hunted. I remember when we were to harvest the eggs and the berries. Most of our growing up years were with the family. We would travel together for hunting and fishing. It was a beautiful childhood. I cherish it. It was a carefree time. It was beautiful living out on the land, in the sunshine. Sometimes it must have been hard for our parents, but we were so cared for as kids. We loved being outside and running around. We played until we dropped.

Maria learned how to arrange a tent from her mother.

I learned how to make a tent really comfortable from my mom. When I was young we used to live in a caribou tent and later a canvas tent. There would be a layer of wood and branches on the floor to keep away the moisture from the earth, and on top of that two or three layers of caribou skins. My mom would sew together flour bags bleached in the sun and fill it with feather down until it was nice and thick. And on top of that my mother had a goose down blanket. Everybody just picked a spot. On one side of the tent was a stove made of the bottom of a metal oil drum. My mother would put rocks on top and that would be where she would bake the bread inside in the tent.

Her father taught her how to mend nets and how to read the stars for navigation. 
My dad was so busy he would be mending his nets. He taught me how. He said he never had a son and so he taught me how to mend nets. He taught me all about the stars. He said that in the winter if you are going somewhere by dog team the wind can blow the snow everywhere so you can't see or go by that, so you have to know the position of the star in each season.

Unlike many Inuit who live above tree line and are not used to seeing trees, Maria and her family had access to trees in the area they lived. Trees would be used to build frames for shelters.

We were right on the tree line. Ten miles north and there were no more trees. So, we included wood and we used it a lot. We used wood for frames for huts. A lot of people only heard about igloos that are made of snow, they never heard much about the huts we used to make. Some of them would stand on their own but most of them in Labrador, because it is so hilly, were built into the side of the mountains. They would dig a hole and put a wooden frame around it. I remember being inside one. They are called a "hamma" which means walls for houses.

Maria reflects on why the land is important to Inuit. The land was a source of life: of food, clothing, everything.

To me the land was our source of life. It was the resource for everything you could think of. The land is important because it was our only source of food and clothing and everything. Our housing, our food. All the animals we got from the land were our food and clothing. Everything we caught from the sea was our food and clothing.

The word 'nuna' comes to mean more than just land. Its meaning encompasses a place of belonging, a way of life, a source of livelihood, and social organization, among others.

Nuna inspires emotion and memory.

Nuna in my mind, it's the actual land. But when I say nuna a whole bunch of things come to mind. It's chalk full of imageries and different seasons. Like getting different things from the land. I have all kinds of memories of the land. Every time we would go back to the land which was our land, or home, our living place. 'Our land' means our home, the place where we get everything, it provided everything for us. To live of the land, it kept us fed and clothed. It kept us happy. We had our own systems. We had our own society. We had our own way. It was almost like we were part of the land. When I say 'land', I see my whole family in it, I see my whole everything in it. My feelings. Where I got my food, my 
clothing, where we got our stuff to make tents and everything. The land was like my home.

For Maria the land and the sea had the power to heal. From the land she was able to feel an energy with the power to cleanse and comfort.

I love going by the sea because I would look out my window at home and see the Atlantic ocean and mountains all around. I miss the mountains! And I miss the sea! Water always makes me calm. Whenever I would have problems or troubles at home I would take a walk along the shore, and the sound of the waves and the look of the water and the feel of the water. An energy from the sea and it would heal you. Sometimes I would imagine the sea actually come out to touch me, heal me, comfort me. That's how connected we were to the land. Like the mountains were an actually energy that could be felt. The land, the grass, the rocks were an energy that comforted you. You could feel the energy of a lot of things when you were out in nature. And it's an actually living energy entity.

Maria longs for being on the land, and for country food.

I miss the land a lot. And I miss the food. I miss the food so much it hurts. Because it's all kind of different food, what you eat up there. I miss the smoked fish, the dried fish, the dried char.

Every season brought with it particular plants and animals to be harvested.

There were seasons for everything. Like in the summer it was time for sea urchins, mussels and clams. Summer and Fall would be time for harvesting, and we would be drying meats and smoking fish.

During the summer, when we caught caribou it would have moss that it ate in its stomach, partially digested. We ate that moss. It was like it was partially cooked and had the texture of cabbage, and it had a sweetish taste. It kind of had the taste like peas when they are raw. That was some of the greens that we had to eat.

Then in the mountain cracks there are little plants which are our sour plants. We used to just go and eat them just like that. Then there was Labrador tea and it was good for cleaning your blood. Then there's the berries. All kinds of berries. There's a cranberry up there we call Partridge berry. They grow on the ground. Red berry is the common name.

Living on the land provided Inuit with freedom and self-sufficiency.

We had times and seasons for everything. All year we were busy doing something. We were nomadic people. We followed the seasons and the animals. 
We were nomadic for a couple of hundred years after the settlement of Nain was formed. They couldn't control us because we lived off the land. They couldn't make us do anything. We didn't need them, we didn't need anybody. We could make our terms in terms of trading. We were trading with all kinds of people before Columbus arrived to America.

The interference of non-Inuit into Inuit lives, and the claiming of Inuit lands, marks a pain aspect of history.

The audacity of those people to claim us. To claim our land. It's always very hurtful and upsetting to just think of it. We are a docile people. We believe in living in harmony.

\section{Tuberculosis Treatment in Northwest River}

When she was six, Maria was sent away for tuberculosis treatment in Northwest River.

When I was six I was blind for a year. I had tuberculosis in my eyes and my knee. I was taken for treatment in Northwest River. It took one to three days to get there by boat, so you slept in the boat. I don't remember the boat ride there. I hated being away from my family so much that I kicked and scratched and bit everyone that came near to me. I didn't speak English or understand what the doctors or nurses said to me. Being a kid I ate what they gave me, and at the time I didn't remember missing Inuit food. A year later, my vision started coming back.

When her eyesight began to return Maria's parents were encouraged to have her stay in

Northwest River for schooling. She was beginning to learn English. She ended up staying

in Northwest River for two years.

When the summer came they asked my parents if I could stay in Northwest River because they didn't want me to lose my English. They asked $\mathrm{f} I$ could stay for the school year for a couple of years. So I stayed until I was eight. I stayed with a family in their home during the summer. The house mother of the school would start early, so she could take care of me before the school year started. I remember she sewed me a dress and I was so proud of it.

After being away from home for two years, Maria's mother asked that she return home. It was a long journey. 
When I was eight my mom asked for me to come back home. Another family were going home from Goose Bay to Nain and my mom arranged for me to travel with them. On the way home we stopped to go egg picking. That set the tone for a very good trip. It took three days to get home.

After not eating country food for so long, Maria had lost the taste for it. She had grown accustomed to non-Inuit food. In addition to losing her taste for country food, Maria lost her fluency in Inuktitut. At the time, she could only speak English.

When I got home, I could not eat Inuit food anymore. I got used to white peoples' food. When I got home I didn't eat anything but bread and tea. My parents got worried for me, so my dad took me to the government store and asked me what I wanted. I couldn't really tell what he was asking me in Inuktitut because I had lost my own language. It's embarrassing but I could only speak English. When I saw the canned tomatoes I pointed to them. So that's all I lived on for a while: canned tomatoes, bread and tea. I don't know how long I was on that diet. Eventually I started eating country food again. I must have because I don't remember ever being hungry.

Eventually, after spending time with her family Maria became reacquainted with country

food. She remembers eating seal again for the first time on a special occasion.

The rest of that year I remember going up to the islands with my family, having my first country food again, and someone catching his first seal. His father cut open the seal and said the heart had to go to a special person and the liver had to go to a special person. The women could only have certain parts of the seal and the men could only have certain parts of the seal. They were all handed out and he was giving out big chunks of meat. It was so good, it was a big celebration for that young man.

\section{Pre- and Post-Confederation}

For Maria and her family, life in the community changed after Labrador joined Confederation in 1949. She speaks about her family history to help explain why governance in Nain post-Confederation was particularly damaging for them. She was greatly influenced by her grandfathers. On her mother's side she was influenced by her 
British grandfather. On her father's side, she was influenced by her grandfather who was a the leader of their community.

I loved my grandfathers. My maternal grandfather was British. He learned our language and lived the Inuit way of life, and taught my mother English values. My grandfather on my dad's side was the ruler of the Inuit in our community. He raised my dad. Inuit at that time had kings that were all powerful, that ruled the religious and non-religious parts of life. We always looked to him and his counsellors. My father's father name was Parau meaning "someone you measure your strength against." He was such a gentle man. He and my dad were so gentle.

My grandparents changed their name from Parau to Samuel and Mariam Brown because it sounded more familiar. It was the missionaries who did that, but it was their choice. They knew that they were becoming Christians. Some didn't like it, but they did it because they wanted to become Christians.

After Labrador joined Confederation, the Canadian government did not recognize Inuit leadership or social organization. Thus, her paternal grandfather was stripped of his role and status in the community. Power was transferred from unilingual Elders to young people who could speak English.

When I was a kid we grew up with Inuit kings, and the king would have councillors. But when we joined Confederation, the Canadian government didn't recognize our customary leadership. Instead, they selected the young people in the community who could speak English, and made them leaders, even though they knew nothing about ruling.

This pulled the rug right out from under my paternal grandfather who was the king of our community at the time. It was very hurtful to my family because we were directly affected. My grandfather lost his power and authority in the community. Power went from those who were wise to those who were inexperienced. They were chosen because they spoke English at home, which meant they got all the jobs. I was lucky that one of my grandfathers was British and he made sure that we all spoke English and he spoke Inuktitut too. And taught us to be self-sufficient.

Up until that time, teachers, nurses, and church ministers interacted with the local people in Inuktitut. 
Before Confederation, all of our teachers and nurses were British. They had a British accent and British ways, like very proper. When the British came they taught us in our own language. For the first thirteen years of my life we had British teachers and nurses, and they let us govern ourselves in our own language. And they had to learn our language to communicate with us. The church minister learned to speak Inuktitut and worked as a translator.

However, with Confederation the use of English suddenly became more favourable in the community than Inuktitut.

Then in 1949, Labrador joined the Confederation of Canada. Then all of a sudden life changed from the British who favoured our ways and language to Canadian rules. We couldn't use our language anymore and we had to use English. People who spoke English got the jobs. So, it became desirable to speak English.

British teachers who Maria felt respected Inuit culture and traditions, were replaced with teachers from Newfoundland. Inuit began to be treated as inferior.

We started having "Newfie" teachers and nurses and there was a big difference in the way that we were treated. We were treated very inferior. We were treated as if we didn't matter, as if we were of no significance, our opinions didn't matter. They felt that they were superior to us.

\section{Residential School}

In addition to attending the Northwest River Dormitory residential school (Northwest River, Labrador) from the ages of 6 to 8, Maria also attended the residential school for three years to attend high school from the ages of 17 to 19 . When she was separated from her parents, she was no longer able to learn from them. In particular, she was not able to learn traditional Inuit parenting skills.

We were taken from our families and put into a residential school. Our parents raised us really good until then. When we were in the residential schools we were taken care of my our house mothers, so we weren't learning how to be parents. So, now we are lacking in how to react to a teenager when they reach that troublesome age because we weren't at home. So that has been hard for our people in the north, not just in Labrador. The residential high school was in Northwest River, thirty miles from Goose Bay. 
Maria's parents were pressured by the local missionary, nurse and RCMP officer to send her to residential school. Though she does not remember being asked if she wanted to go, she trusts her parents made the decision in her best interest.

I remember thinking no one asked me about it, about being shipped off to the residential school. The missionary, the nurse and the RCMP came to talk to my mom to convince her to send me away to school. My mom was a very farthinking woman. She didn't have an education. She must have known it would be good for me. We were so poor. I went with a dress, a shirt, trousers, and pair of shoes. I didn't even have a toothbrush. They provided soap, but not toothbrushes or paste. So if you didn't have one that was it. Sometimes my friends would lend me a dress if mine was in the laundry.

It was painful to be away from her family. She remembers being punished for speaking

Inuktitut at school and reflects on the inter-generational effects of residential school.

I still think it's wrong that they took us away from our families. My dad was a unilingual Inuk, he didn't speak English or French. It broke his heart to have us learning English in school. They would hit our hands with the strap if we spoke our language. I never understood why. If you didn't speak properly they would strap you, or make you speak with a book on your head, or they would speak very angrily to you. And say, "Speak English! Don't speak your language!"

A lot of things were done for us to lose our language bit by bit. My issue is we lost out language; not me, but the majority of Inuit did. It was a planned thing to assimilate us so they could control us. That's the definite truth. I don't know how anyone could be so heartless. Now most of our kids don't speak their language. Although now people your age are starting to want to learn it again. Language is important because it is part of who you are.

In addition to being forbidden to speak Inuktitut, Maria's diet changed drastically too.

There was no country food served at the residential school. Maria remembers not having much to eat.

In the dorm we ate what the white people cooked. We didn't have much to eat at all. We ate everyday but it was all soup and bread or baked beans. Sometimes we had chicken but not often. It wasn't like eating at home. So different from our own food. 
Being at residential school felt like a prison. It was frustrating not being able to go on the land. But even on short walks Maria made the best of the situation.

You felt like you were in a prison almost because you didn't have the freedom to go out on the land when you wanted to. In Northwest River you could still connect to the land. Every time we would go for walks or something I would go berry picking.

Attending residential school also had a negative impact on Maria's self esteem. The prejudice she encountered while attending school in Northwest River made her feel ashamed of being Inuit.

When I was living on my own after being in school, or even when I was in high school, I was ashamed of being Inuit because we were in residential schools. The other kids that were in the community where our residential school was looked down on us. Mostly because we didn't have what they had, which is mostly southern things. We loved our life. We were comfortable in our tents and huts. We had our own customs and festivals and values. We were happy nation within ourselves.

Prime Minister Harper's officially apology to Canada's Indigenous people who suffered in residential schools deeply impacted Maria. It was acknowledgement which fostered healing, and a renewed sense of trust in the ability of Inuit and the government to work together and correct past wrongs.

When Harper apologized to us, I cried. Because it did a lot of healing. I wish he put the money where his mouth is, but it meant a lot just the same. That he was saying officially sorry on behalf of the generations before, the wrong they had done to us. And they did do us wrong. It was very meaningful and effective in our lives. I think it's put trust back in the Inuit people. Before that Inuit had no trust in the government at all. And we realized it's a better generation now. They are righting a lot of wrongs. They are more careful to listen to what we are saying. They are actually making changes. 
First Time in St. John's

Maria first urban experiences began when she moved to St. John's to attend university. Living in St. John's required learning a different set of skills and values.

The first time that I ever lived in a city was actually in St. John's, Newfoundland, when I went to Memorial University to study a Bachelor of Arts in Education. St. John's was like a small town back then. I thought everybody was rich because they all had hot and cold running water and had toilets that flushed. And the water that came right into their house. They didn't have to go fetch it like we had to do every day.

It was so different because you have a whole set of values based around surviving because you live off of the land and what the land produces. And then when you go out to St. John's everything is about money. You have to learn how to budget, you have to learn how to make some kind of a living. And it doesn't have any of the things that were important from before, like living off the land.

Taking the bus, something that seems like a simple task now, was a source of confusion.

For the longest time I didn't know how to use the bus. I didn't know what to do the first time. I didn't know if I should give the bus driver the money or if I should talk to him. So eventually he talked to me and gave me back change. Back then, we used money, not tickets. After a while, taking the bus became normal.

While attending university, Maria struggled with spoken English. However, due to her strong reading skills she was able to succeed with her coursework.

When I first went to school in St. John's I realised that they spoke a level of English I never heard. But the one thing that saved me was that I read a lot. I used to read under the covers. When I was in class, I could keep up. Since then my English has improved a lot.

During the summers, to help support herself, Maria worked as a translator.

In St. John's I worked in the university. I did a linguistic tape of a thousand words in Inuktitut. It took me all summer to do that because I had to call around and find out how to say this or that in Inuktitut. The next summer I worked at Department of Health and Social Services. They had me translating and doing administrative work. 
In university, Maria was fuelled by a sense of curiosity and desire to help her people. She wanted to learn more about non-Inuit and how they came to dominate the lives of Inuit.

When I was in university, I was in search of knowledge. I wanted to understand why they have so much power over us, and how I can help my people. I do that now as an Elder, I speak for Inuit that can't speak for themselves.

Not knowing she was eligible for tuition funding, Maria stopped attending university after two years. Her plan was to work and pay off her student loan, however, she did not return to her studies.

I stayed for two years, but I owed $\$ 2000$ in tuition so I wanted to take time off to pay it back. I didn't go back to university after that. They didn't tell me I had funding.

\section{Travelling the North}

When Maria returned to Nain after university she got a job teaching. Being a teacher took Maria to a few different communities across Labrador, and northern Québec. While teaching in what was then called Fort Chimo (now Kuujjuaq), Maria met her future husband.

I lived in Nain for the first twenty years of my life before I went to university. And then I taught in Nain for two years. Then I taught in Goose Bay for two years. Then I taught in Fort Torn, Labrador for a year. Then I taught in Fort Chimo which is now Kuujjuaq. I taught there for a year, and that's where I met my husband. He was transferred further north to Rankin. In 1970 we were married there in a little community of two hundred and twenty people.

The year after they were married, Maria and her husband decided to move to Ottawa.

After we were married we moved to Ottawa in 1971. He said he liked Ottawa. He had worked in Ottawa before. He said he had enough of the north. He loved the north, he loved experiencing it but he said he was getting too old to be in a cold place. He wanted the rest of his years to be easier ones. He was working in 
Kuujjuaq three years before I met him, and he got to know the Inuit people there. It's a hard place the north.

Since then Ottawa has been their home, apart from a seven and a half year work transfer to Terrace, BC.

Ottawa has mostly been our home since then. Although we did move to Terrace, $\mathrm{BC}$, for seven and a half years. My husband was transferred there for work. But we didn't like it in the end. We were too far away from our friends and family. The thing was we missed family contact.

\section{Adjusting to Life in Ottawa}

Moving to Ottawa was both frightening and exciting. The city felt like a giant place, filled with tall buildings, lights, and encounters with many different kinds of people.

I'm hoping my grandchildren will read this and know what it was like. They grew up in Ottawa so this is an opportunity for them to learn.

It was so different coming down to Ottawa. Ottawa is like a giant place. There are so many big buildings, it's so busy, there are so many lights everywhere. It was scary and exciting because you would see all kinds of different people like the ones you saw in the movies.

Given the size of Ottawa, getting around could be challenging, especially taking the bus.

At times, Maria felt small in the big city, and struggled to connect with others.

Taking the bus was difficult. I was always afraid that I was on the wrong bus because they went all over the city. It made me feel like an ant, like how will they ever connect with me? How will I ever get to know anything because I am so small and insignificant. You could get lost here. I felt small.

People in Ottawa were not as friendly as back in Nain. When she tried to talk to people of the street as she was accustomed to doing back home, Maria was often reproached. She felt disconnected and lonely. 
At home in Nain we were used to speaking to everybody, but down here when I first came here when I would talk to people in the street they would look at me like I was crazy! I found that was very odd, like I thought they must not be connected, you know. I felt very alone because of it. Like, one of the most important things is to communicate person-to-person and with that gone I thought I was going to have a hard time down here. I didn't know that once you were introduced to somebody you could talk to them. We were just used to talking to anybody that we passed on the street.

Living in the city brought with it certain modern conveniences, like running water and toilets that flushed. Back in Nain, typically only the non-Inuit in the community benefitted from such luxuries.

Everything was new. I thought everyone was rich because they had running water. We used to have outhouses, or we went and did our business in the bush if we were out on the land. There was no flushing toilets except in the church mission house, or the RCMP, or the store managers house. They had running water. We used pots for the bathroom, that was our bathroom. We had to share the bathwater. Then when we came down here everything was different. It was like, boy! You don't have to fetch water here!

Living spaces were structured differently as well.

I thought everyone was rich because everyone had houses with rooms! We never had rooms. We lived in just one big room. We thought everyone lived in mansions because everyone had all this room! Like rooms to sleep in, and a room for the kitchen, and a room to sit in. I thought that was the height of luxury. It was so different. Most Inuit didn't have anything.

Living in Ottawa was a culture shock. Maria found herself missing many things about her northern community. She was able to make frequent trips to Nain to help ease her homesickness. Maria describes visiting the north and living in the south like living in two different worlds.

It's a culture shock, a very big culture shock. Even for myself. I've always considered myself to be outgoing and well-read. But I always missed my culture, my people, my land, and everything that came from the land. So much so, that every year I went home for Christmas and went home for the summer and couldn't wait to go. But it was like living in two different worlds. You have to do certain things when you're with the Inuit up north, and you have to do certain 
things when you are down south. It's like changing yourself to fit in. Down here, you couldn't really be yourself. Certainly you couldn't speak Inuktitut unless it was to another Inuk. Up north everything was different, everything was simple. It was down to the land and working for your food. You were busy so there is no time for trouble. It was simple, and it was a good way of life.

Feelings of loneliness caused Maria to cling to the other Inuit she met in Ottawa.

One of the big things, you don't feel like you are connected down here. So, you cling together with other Inuit and it makes it easier when you're together. Because you know where you come from, and we all come from the same background.

It would be so good meet another Inuk person. There was a lot a camaraderie, like you felt like instantly hugging them. I knew that no matter what I said, they would understand me, even if they didn't know my dialect very much. They would pick up on a word here and there, and they would understand me.

There was only five of us Inuit in Ottawa at that time. Now there are between fifteen hundred and two thousand Inuit living in Ottawa!

Maria and the other handful of Inuit who lived in the city at the time formed a social network. The gathered at each other's houses, spoke Inuktitut, and shared what little country food there was available.

We stuck together. We saw each other in our homes. We helped each other. Whoever had Inuit food would share it. We missed Inuit foods.

Craving country food was a major challenge Maria and her fellow Inuit faced living in

Ottawa.

I missed Inuit food. Like wild game: caribou, seal meat, ptarmigans, hare, geese, duck, arctic char, cod. We ate everything, and it was healthy for us. If you cooked them for a long time you could even eat the fish bones. I still eat bones, I just chew them, and that's how we would get our calcium. 
Country food became somewhat more accessible after ITK formed. They would hold a feast at Christmas time and provide country food to the community. However, it was not enough to satisfy Maria's craving.

When I moved to Ottawa it was like a drought of Inuit food until ITK came around. And when ITK came along, they would have a feast every year at Christmas time. They would have frozen caribou or something else. But you would always want to have Inuit food more often because we ate it every day at home in Nain. Wild game, that was our meal every day.

Other challenges of living in Ottawa including dealing with racism. This was particularly difficult for Maria's son. Her son suffered great abuse from the other children at school for being the only Inuit.

Here my son was teased by kids because he was the only Inuk child around. $\mathrm{He}$ used to be treated really bad. Also because he was always a little on the heavy side, and also because he was Inuit. They were very racist when he was a child. In the school the kids would get together and they would ostracise my son, at recess or lunch hour they would all surround him and push and kick him. My son was just a gentle person, he was strong and could of hurt them if he wanted to, but he didn't want to do that. And when one gang would finish another gang would come do the same because he was the only Inuit. There was no one to help him.

\section{Tungasuvvingat Inuit}

When the population of Inuit in Ottawa began to grow, the community began to organize.

They wanted to be able to provide services to other Inuit to help them adjust to life in the city.

When we first came there was only five of us Inuit working at Indian Affairs. And we had our families also. We stuck together, and met after work at each others' homes, and went out together. With other Inuit it's a natural thing to gather, right away you have your background in common. 
Gradually our numbers grew to the point that we had to organize. We always knew that we would have to organize, because of how we felt when we came down. It was so strange compared to what we were used to up north, and there was so much to learn. You felt like a fish out of water when you first came to Ottawa because everything was so different.

Maria worked at Tungasuvvingat Inuit (TI) for a couple of years. It became a popular gathering place for Inuit to gather, socialize and eat country food.

I was working at TI (Tungasuvvingat Inuit) for a couple of years when Brenda Convoy was the executive director. I used to be in charge keeping people occupied and interested. Everybody called it 'Inuit house' at that time. Everybody would come there all the time once they heard about it. We used to play scrabble, and shoot the breeze and have Inuit food there.

TI also held larger community events which gave people the opportunity to share cultural experiences in Ottawa.

We would do a Christmas party, and then we would do a barbeque in the summer. We would make sure our gathering were very cultural. We would have an opening prayer in Inuktitut. We would have a cultural presentation which I would give, as well as a spiritual presentation because Inuit are very spiritual people. And then our Inuit food. We would have caribou meat and arctic char. It would be frozen, and we would eat it on cardboard spread out on the floor. That used to be our way of just being among Inuit, to eat together like that.

\section{Living in Ottawa Today}

In the early days, ITK and TI were responsible for providing most services to Inuit living in Ottawa. More recently, however, the list has expanded to included the Ottawa Inuit Children's Centre (OICC). For Maria, the OICC is extremely important because it is there that Inuit children being raised in the south are able to learn about Inuit culture.

Another place that has come up since then is the Children's Centre which is the most important one, because we want the children to know where they come from. It's very needed in there and we don't want to lose that ever. They will have a very strong sense of Inuit knowledge.

The OICC also helps to provide parenting support and learning opportunities. 
It helps the people, the generation that are the parents now. They are getting to know about a lot about parenting. They used to have a parenting course there, it must be still be happening.

All of Maria grandchildren have gone to the OICC. The centre provides children the opportunity to learn about Inuit culture and develop a sense of pride.

We support the people who run the OICC. They represent us culturally. They have uluit, which are Inuit knives. And they have actual replicas of dog team sleds. They have Inuktitut words posted all around on the walls, so the children pick it up naturally. My younger grandson, nobody taught him anything at home, but he can speak Inuktitut. He understands everything. I just can't get over that.

The children love the OICC so much! My grandson was one of the first to graduate from the Head start program in my family. He started when it first opened. And he loved it so much! We got to celebrate at his graduation. He was so happy when he went on stage. But then at one point he lay down on the steps and look really sad. We asked him why. And he said that he didn't want to graduate, because it meant he wouldn't get to be there at the OICC anymore. He was so happy learning about who he is as an Inuit boy.

Without the OICC, Maria believes her grandchildren would not be proud of their Inuit heritage. Her son, who was severely teased and harassed for being Inuit in school, did not have a place like the OICC to build up his self-esteem. Her grandson on the other hand, who attended OICC and has developed a strong sense of who he is, is able to better cope with the racism he encounters while attending mainstream school.

All my grandkids went through that program and they are all proud to be Inuit. Which they never would happened otherwise. I know, because of what happened to my son, and what he went though at school. Mind you, they still feel it, as they go through mainstream school. My grandson is still grappling with it, like with racism and it's affecting him. He has a better chance, because he is not afraid of saying he is Inuit and saying that he is proud of being Inuit. He talks about how his grandmother is Inuit and how his father is Inuit, and all in a positive way.

In Ottawa, the inclusive sense of community helps to foster an increased sense of Inuit pride and connection. Even though Inuit residing in Ottawa may come from many 
different northern communities, it is their Inuit identity that draws them together. Gathering, being connected, helping one another are strong values which define northern communities, and as Maria points out, the Ottawa Inuit community as well.

The main thing is to rebuild the self esteem of our people, to make them proud of who and what they are. And that's coming out. Even though we are displaced down here, we cling to each other and that makes us feel like we are in our own Inuit community down here. It's a community of people from every area, and that makes us very cosmopolitan. We accept each other as being Inuit. Inuit have always been known to be accepting of everybody. It's from our teachings from way back that we treat people well. And we share everything. You help each other. You help them and they'll help you. There's always the feeling that it's your community. Up there, in the north, you're connected. You are connected to everybody. The Inuit community here are connected to everybody too.

The OICC, like TI and ITK help to build a supportive sense of community for Inuit living in Ottawa.

It's changing because of the Children's Centre because their self esteem is being built up there. The teachers speak in Inuktitut and passes it off as a positive thing. And it's all about being Inuit. By the time they get out of there, they are there from the age of two to six, their self esteem is really built up about who they are. So it's made a real difference. And it's going to keep on making a real difference. As they learn more they grab more, so that our culture is going to be strong Inuit culture here. A warm, close community. Because of places like Children's Centre and TI and ITK, it helps. They all promote being Inuit.

Emphasizing the importance of speaking Inuktitut is a matter close to Maria's heart given her negative experience in residential school. She is pleased that organizations like OICC, TI and ITK promote important aspect of Inuit culture, such as speaking Inuktitut, and values like sharing and helping each other.

One of the things that ITK promotes, is that we should all speak Inuktitut and nobody can stop us from doing that. So whenever we get together we speak in Inuktitut even if we are different dialects. Basically it is the same, even though you sometimes have to listen really hard to get the meaning sometimes. And they promote Inuit values like the only way we could survive was by helping each other, even if it isn't your family. It was one of the biggest things was helping 
each other and sharing. Whatever you had you shared with each other, so there was a lot to eat, a lot of variety, and we were healthier.

Despite the expansion of services provided by community-based organizations, certain challenges to living in Ottawa remain. Even now, Maria craves country food, to the point that she mourns not being able to eat it more often. Over the years, it has been a source of emotional strain. Country food is viewed as healthier than southern food.

I've been out here since 1970. I've been out here 30 years and I'm still craving it. I really miss it. I crave it. I mourn that I don't have it. When I crave it, I keep thinking about it. And when I think of it, the craving will stay with me for a couple of days. Cravings for caribou or arctic char, especially. Seal meat too. When I do eat Inuit food, it's so satisfying for my body because I grew up on it. I'm used to beef and pork and chicken now, but it is not the same. Wild game has a lot more vitamins and things in it, I think. They live out in the wild, they roam, and eat and live a healthy life. The air is pure up there.

Maria believes funding should be put in place to go towards supplying the urban Inuit population with great access to country foods. Country foods are served in community centres, however, not in great supply. Making a 'community freezer' type service available will benefit the health and well-being of the community.

I've been out here since 1970 and I've been craving country food all this time. It does bring you down. You can't get home to have some because it's too expensive. I think it would good for the whole Inuit community, if they have funding to supply us with Inuit food at the community centres. It's for the wellbeing of the Inuit living here. Otherwise you have people thinking about it all the time, and being depressed. And it makes them feel like life is bearable if they have access to it. It's such a basic need, it's a basic need. Some of the funding should be set aside just for that. It should always be there, and the funding shouldn't be used for anything else.

At times, when Maria's relatives visit her in Ottawa, they bring her country food, especially her daughter. However, these visits are infrequent, and the country food does not last. 
Here in Ottawa it cost a lot to get country food sent down. People would sometimes bring it down for me, but then they started asking how much frozen food they were bring down. And if you didn't get away with sneaking it in your suitcase, it could cost you an extra $\$ 100$ for the weight. So, a lot of people don't want to bring it down anymore.

But my daughter when she visits she brings Inuit food for me. She would bring down enough food to last between visits, but I go through them fast. One time I made an order through Pangnirtung fisheries for $\$ 100$, and there were seventeen fish. Oh, that was so great! I gave some away so it didn't last very long.

\section{Northern Connections}

For Maria, family closeness is an Inuit value of great importance. However, due to the high cost of northern travel, she is not able to visit as often as she would like. Communication technologies (i.e. telephone, internet, mail) help to keep her in touch with family in between visits.

I go to visit Nain as often as I can which tends to be maybe every three years or so. Because it's $\$ 1800$ per person. You can go to Europe for less than that, or even across Canada like east coast to west coast. I phone my daughter at least once a week, and when we are really close. After we have just seen each other, after a visit, we call each other every day. Family closeness is something very strong with Inuit. Sometimes we send packages back and forth in the mail but it costs a lot. This past year we didn't send anything because we didn't have the money.

I stay connected to the north because I have a big family up there. I keep connected with them almost daily. My husband always says, "I can't send you up there whenever you want, but you can call whenever you want." So, sometimes I call them almost daily when I'm feeling really homesick, or when I really need family to talk to. It's the personal contact with your family that is the most important contact. It's the most important way of staying abreast of what's happening. When you talk you hear about this and that. So, when I go back to Nain I know everything, and I'm up-to-date.

Not being able to visit Nain as often as she would like causes Maria to experience periods of homesickness. The things she longs for the most are her family, celebrations, living off the land and eating country food. 
I still get homesick. I am homesick for the celebrations, for living off the land, for the food we eat. Berry picking. Picking eggs in the Spring. All the seasonal things that happen that you can be a part of. Fishing used to be a big part of life. And preparing whatever we caught, the fish or the meat. Drying them or cooking them.

I really miss the winter when the seal is freshly caught, it freezes instantly. It's like fresh, fresh, fresh! Same with the fish. When you take a slice of seal meat when it's freshly frozen it has a different feel to it. It has a different texture to it than if it was frozen in the freezer. It flakes off into little splinters when it's really fresh, and you pick them and they look like glass almost, because they're frozen in little pieces. You just break off a chunk and put it in your mouth and it's like having ice. You know the meat is good for you. Your body craves the goodness of it. Seal is the best eaten that way. Everyone looks forward to having seal meat that way. When they know someone caught seal and it's winter they always ask if they can come have some, or they know that so they invite people over. When I went home last time my cousin's son had caught a seal and he invited me and my daughter down for some. It's like a very special treat to have that.

Though Maria's connections to both the north and the south are strong, she feels like she has two homes: one in Nain and one in Ottawa.

I used to think about moving back to Nain a lot. My husband didn't want to, though. He had enough of the north. The isolation is what he really didn't like about it. He didn't know how to enjoy it. It was good for him to experience the north, but I can understand that if you are not meant to live that kind of life. Some people love it so much that they stay. If my husband wants to and if I'm healthy enough I think I would move back. But, then again I think I would miss the south too much because I'm used to all the comforts down here now. So, I would probably move back and forth.

I feel like I have two homes. And I slip back into the other one like I was never away. When I walk down the road, I'll see some new buildings but it's exactly the same pretty well, to what it was when I was there. Except the community extends out further now. Still the same people live in the same places, so when I go back home I know exactly where to go because it's so tiny.

Maria brought one of her granddaughters to Nain as a toddler. However, due to the high cost of northern travel she has not been able to bring any more of her grandchildren to 
visit the community where she was raised, or meet their extended family. For this reason she values places like the OICC.

I brought my granddaughter to Nain once when she was two years old. And I never brought anyone else because it cost too much per person. That's why a place like the OICC or other Inuit places are so important. It's so important because the children get to know that they are in an Inuit community here. It's very important, knowing that you're part of the Inuit community. One of the biggest things that Inuit do is they help each other. No matter what area you're from that's one of the most important things.

\section{Summary:}

Like Ovilu, Maria's memories from childhood are interwoven with memories of the land. It was a time she associates with freedom. The land is a source of knowledge (e.g. how to mend nets, how to build a comfortable tent, how to clean skins) passed to her from her parents and other relatives. The land enabled her family to be self-sufficient and independent up until the time Newfoundland and Labrador joined Confederation in 1949. The land is a source of life because it was her family's primary source of clothing, food and shelter. But the meaning of the land goes beyond the physical, for Maria. The land is home, a place of belonging. The land is a source of feelings, emotions and energy that can be experienced and can even heal. The land is a living entity. The land represents the Inuit way of life before government intervention. For this reason, the land can also be a source of pain. For example, Maria remembers what it was like to be taken from her family, taken from their life on the land, in order to undergo medical treatment and to attend residential school, respectively. After these periods of separation, Maria lost both her fluency in Inuktitut and her taste for country food. While both returned in time, it is 
still a painful period in her life, and one which demonstrates the harmful impacts of government intervention into Inuit lives.

As a longtime resident of Ottawa, Maria admits to still longing for the land. She continues to crave country food even though it is somewhat more accessible in Ottawa than it used to be. She is able to make periodic visits to Nain to visit family and spend time on the land, although wishes she could go more often. In Ottawa, Maria maintains her connections to the land through country food, through language, and by gathering with other Inuit primarily at local Inuit organizations, like the Ottawa Inuit Children's Centre. 


\subsection{Life History of Sally Webster}

Introduction

Sally Webster is an Elder originally from Baker Lake, Nunavut. Unlike many Inuit communities that tend to be coastal, Baker Lake is an inland community, located in the Kivalliq region of Nunavut. Sally's narrative is unique because it describes the experiences of a person who was raised primarily within a settlement. As a result, Sally describes herself as "in between" - someone who knows about Inuit culture, who knows about the land, but because of the circumstances she grew up in, would like to know more.

Sally's knowledge and experience of the land primarily come from the two years she spent living in her grandparents' camp when she was a little girl. Her mother moved the family to the camp when Sally's father died. During this period of time, Sally's mother was also diagnosed with tuberculosis and had to undergo treatment in the south.

While living with her grandparents, Sally was exposed to the realities of living on the land, for the first time. It is an experience that she credits for teaching her a great many things about Inuit culture she had not known or experienced until that time. Her experiences on the land had such a profound impact on her, that later in life Sally was inspired to tell these stories by constructing a handmade wall-hanging (see below). Sharing these experiences with other (e.g. non-Inuit, younger generations of Inuit) has become an important role for Sally as an Elder. The wall-hanging, along with other educational tools Sally utilizes, serve the dual purpose of educating others, and creating connections to the land and Inuit culture, even while Sally lives in Ottawa. Based on her 
narrative, it is that evident connecting to the land and to Inuit culture this way is important to her sense of identity.

Sally's urban experiences are also unique. She moved to Ottawa with her husband and children when they were to begin high school. Rather than send the children away to Iqaluit or Yellowknife, her husband was transferred to Ottawa for work, and the family remained together. Sally describes this period of time as sheltered, and preoccupied with raising her family. Due to the support she received from her in-laws (who also lived in Ottawa) and her husband, Sally did not experience the type of culture shock Ovilu and Maria describe so vividly. Instead, Sally describes herself as "one of the lucky Inuit" because she did not require assistance adjusting to urban life. In addition, Sally had the financial means to travel North every year or so, which she credits with alleviating the feelings of homesickness she may have experienced. Despite not requiring the services of community-based organizations herself, Sally relies on the social networks that community-based organizations provide. As an Elder, she stays connected to community organizations like the Ottawa Inuit Children's Centre, who often ask her to come in and hold a sewing circle or talk to the younger children about the North.

Sally's narrative begins below. It describes her early life in the settlement, the time she spent with her grandparents, her urban experiences, and the role of cultural educator she has taken on as an urban Inuit Elder.

\section{Growing up in Baker Lake and on the Land}

Sally Webster grew up in Baker Lake, NU. Her father worked for the RCMP. When he passed away, however, her family had to leave the settlement. 
I mostly grew up in Baker Lake until my father passed away. I lived in the settlement. My father was a special constable for the RCMP. There were only thirty-nine people living in the community at that time. I would go three times a week to the Anglican mission to learn English, like my A, B, Cs and numbers. That's about all I learned of English, nothing else. And that's how I learned English. Also from the RCMP, by listening.

Then we had to go to live on the land when my father passed away. Because when you were not working in the settlement, you were told to go out and hunt yourselves. If you were working for RCMP or HBC, then you could live in the settlement. If you're not they told you to go out and hunt for your family.

Sally and her family went to live with her grandparents at their outpost camp while her mother was being treated for tuberculosis in the south. It during this time Sally got her first real experience of what living on the land was like. Sally lived at her grandparent's camp for about two years before attending school in the settlement.

And that's when I learned a bit about traditional stuff from my grandmother. I never really did live out on the land until I went out to live at my grandmother's camp. When I was about ten or eleven years old. It took about a couple of days by boat up the Thelon River to get to my grandmother's camp. I stayed there for about two years, maybe. We went up to the camp at the end of July from the settlement. I moved back on the land for a couple of years before the school started. We ended living with my grandmother because my mother ended up moving down south with TB, for treatment. So, my grandmother was looking after us. We lived in an igloo in the winter and a tent in the summer. Then we moved back to Baker Lake when we were ready for school.

While living with her grandparents on the land Sally began to build her own sense of connection to the land. Before that, she did not understand why her mother often spoke of wanting to be on the land.

The land has special meaning for me. My mother would have preferred to live out on the land. She used to long to go out on the land, to go back to the land where she grew up. I didn't understand that until I actually went up with her to my grandmother's camp, my grandparents' land. They called it 'our land'.

At her grandparents' camp Sally experienced things she never would have in the settlement. Like learning how to live on the land by using what the land provides.

I could not understand my mother, why she used to wish to go back to the land. Until I went to my grandparents' land. But when I went to live with my 
grandmother, I saw things on the land that I see that I could not have seen in the community. Like how they know what to use out on the tundra when they could not come in to the settlement to get what they needed. They would find a way to use things from the land or from caribou bones.

For Sally, knowledge of the land has its greatest impact when it is experiential. It's a belief she came to based on her own experience.

Even though I lived in Baker Lake as a child, I used to wonder why my mother used to talk about the land. That her wish was to go out to the land. I could not understand her what she was talking about, because I never really experienced it until I went to my grandparents' land.

You have to experience the land. That's the way you will learn about it. Not from the books or by someone telling you about it. You cannot know the land by people telling you about it. By doing things or by being taught by our parents, that's how we learn about the land. By helping each other. You do not really know about the land until you have seen it with your own eyes. You will never get tired of seeing the land.

Sally's grandparents taught her about more traditional ways of life.

I saw with my own eyes how they use things, what they had around them. Because they did not go to the store and get what they wanted or needed right away. It was about a two-day trip just to get to the settlement and the store to get what they needed. There are lot of things out on the land, what you need. They know where to gather the moss to make fire to cook or to make tea. Or how to use caribou bones or skins. They know where the caribou crossings are or good fishing spot in order to survive.

I learned a lot of traditional things when I lived with my grandparents. Like how to shoot caribou. I'd never seen anything like it! What grandmother did, she would cook caribou, and my uncle would teach me about the parts of the caribou, like what parts are for what. It has all different names, and I could never remember them all. He was trying to teach me. I was hopeless for naming everything! Because I didn't grow up with it. They taught me which part is good for man, and which part is good for woman. Which is really nice tender part in the rib area, from the neck down, that's what women would eat. And men would eat something else. I didn't know if there was any difference, but that's what they said anyways. Which part is tender, which part is good to fry or boil. Some parts when they have tougher parts you have to cook it longer. The tender parts you don't have to cook it for as long.

When we didn't have enough snow, and when the ice is one to two inch thick, my uncles would use a saw to build a shelter. Because there wasn't enough snow, 
and it was too cold in the tent. They would build a shelter for us out of the ice and cover it with the tent. They would make the ice house with straight walls and put the tent on top of it. And when there was enough snow they would build us an igloo.

Although she missed living in the settlement because it was all she knew, reflecting back,

Sally is grateful for the time she spent on the land with her grandparents. Without it, there

was a great deal she would not have been exposed to.

I would have never experienced all that on the land if I had not gone to live with my grandparents. When you are living in the community you never see things like that. You use the stove and lanterns. Not like the moss to light a fire or make a candle. I would never have learned how to use that if I didn't live with my grandparents. We didn't use those things in the settlement. The HBC is right there when you need something, you just go out and get it. But when you are living out on the land, you can't just go down to the store and get something. Unless you went down to the settlement to get supplies that would last you for a long time. When I was living with them, I wished I could come back to the settlement where I grew up, because that is what I knew. But there's things I would have never seen if I wasn't living with my grandmother.

\section{Stories from childhood}

Living on the land with her grandparents had a great influence on Sally. She has immortalized her childhood memories in a wall hanging used to facilitate the telling of some of experiences living at her grandparents' camp (see next page). 


\section{Stories from childhood}
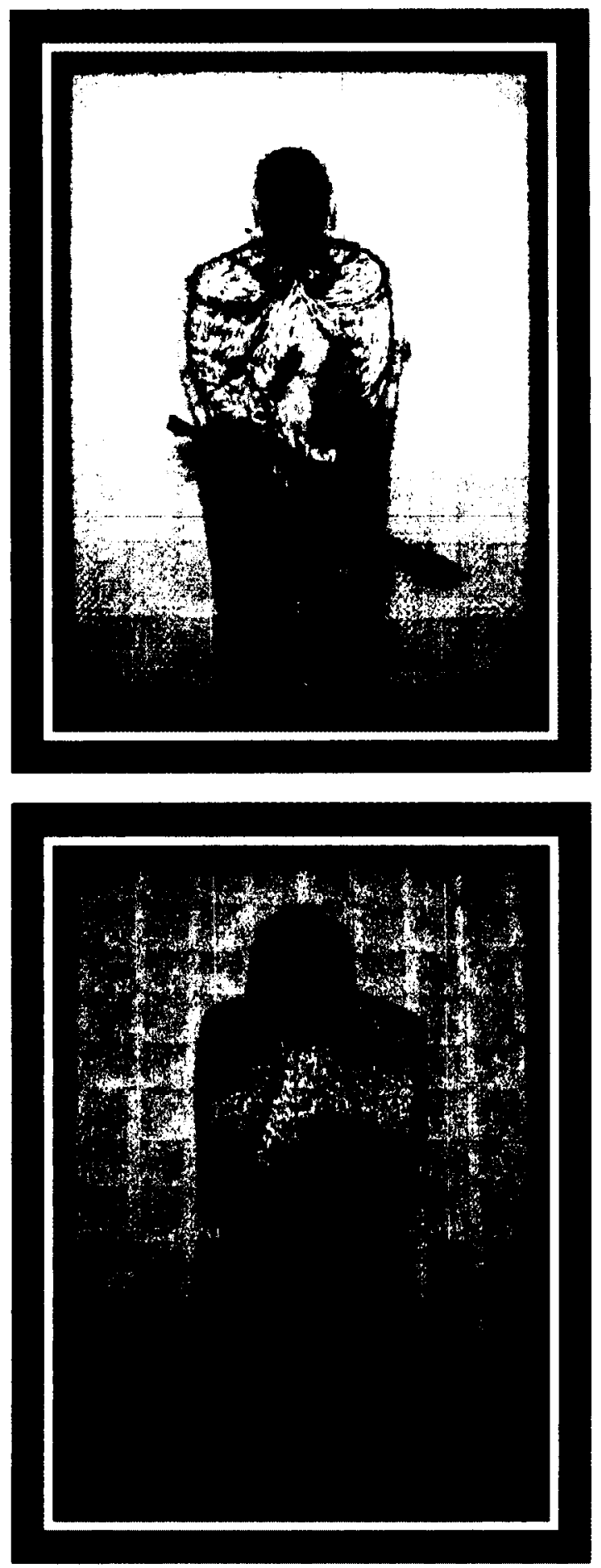

Figure 5 and 6 . When I was born, my grandmother was telling me that she made me a bonnet. And she came with the bonnet to my mother when I was born. She came over with the bonnet in her hand. 


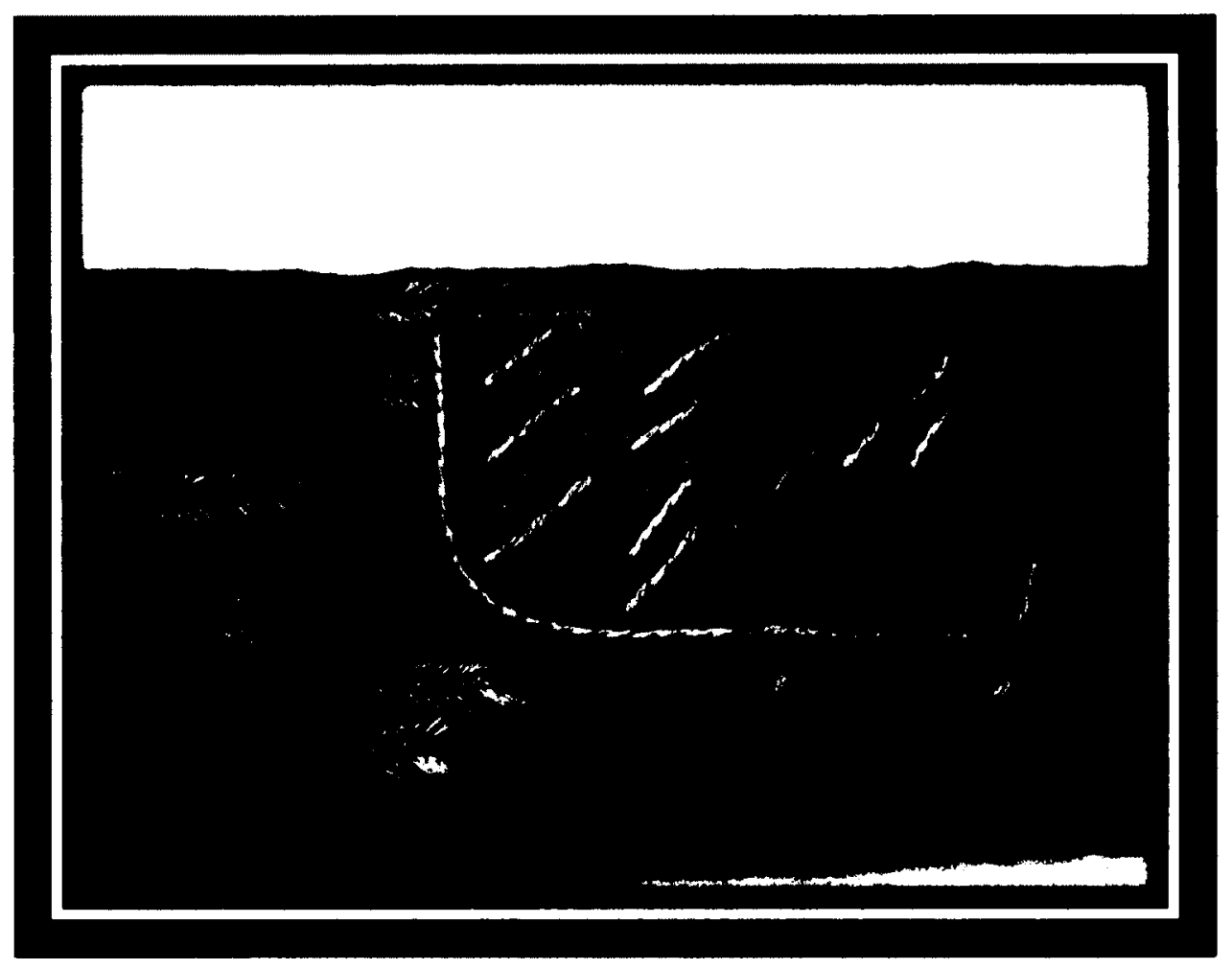

Figure 7. She started making stew out of caribou skin in the morning and by mid afternoon she was finished the whole thing with the fixings and all. 

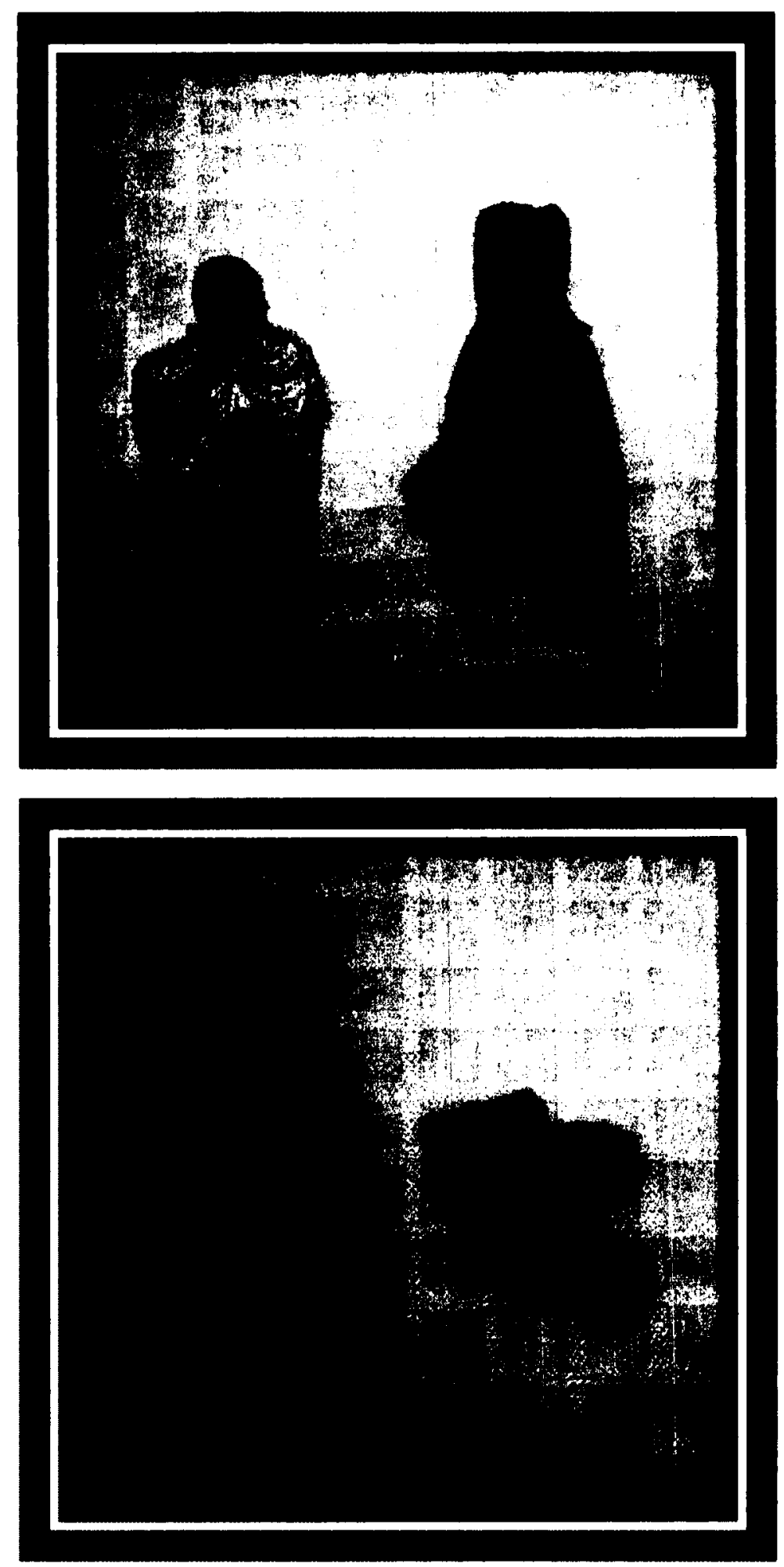

Figure 8 and 9. And she said the sun is still up, I think I can make a pair of kamiks for my son. 


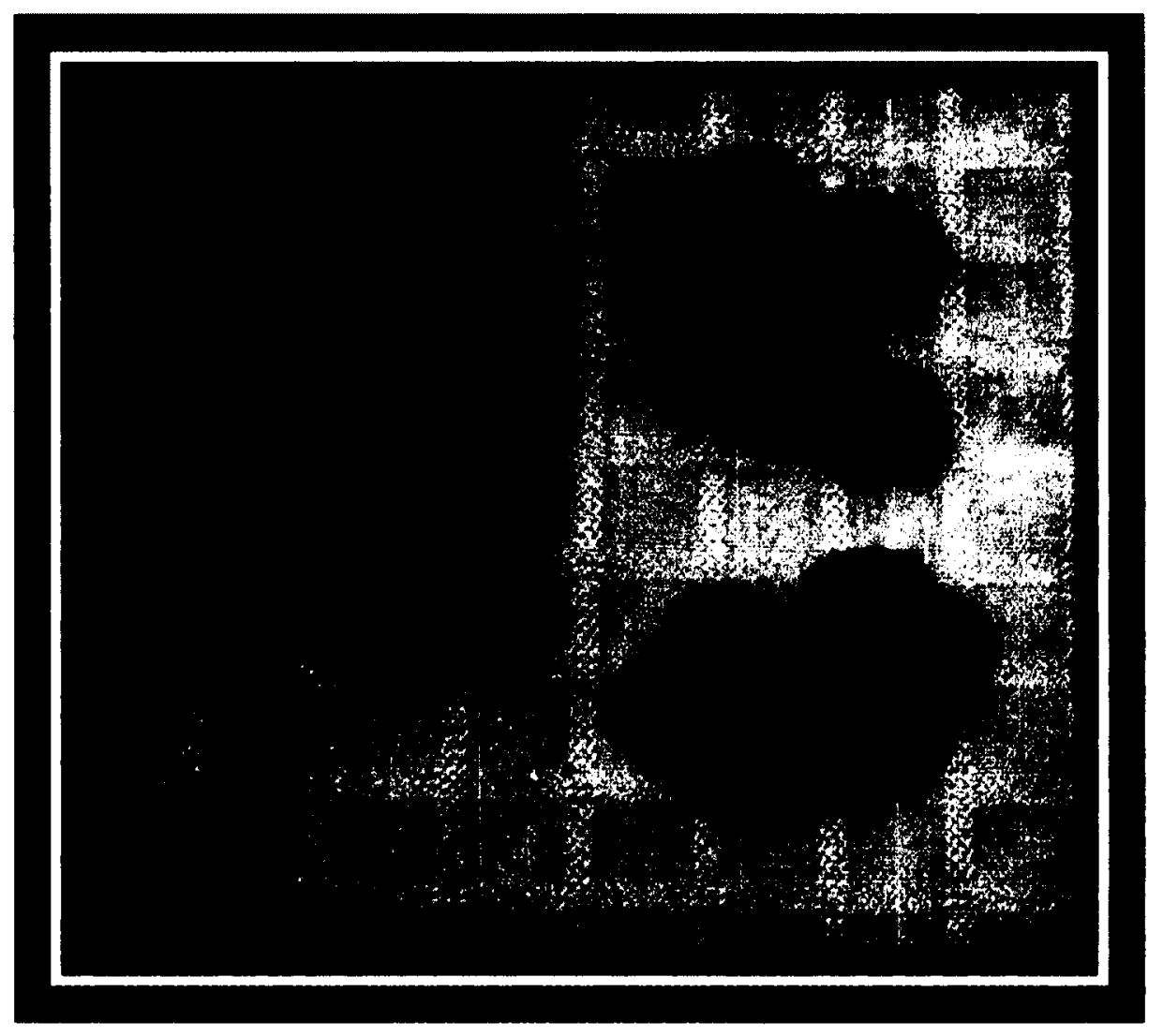

Figure 10. When she finished that, she said the sun is not set yet. I still have time to make caribou skin mitts. 


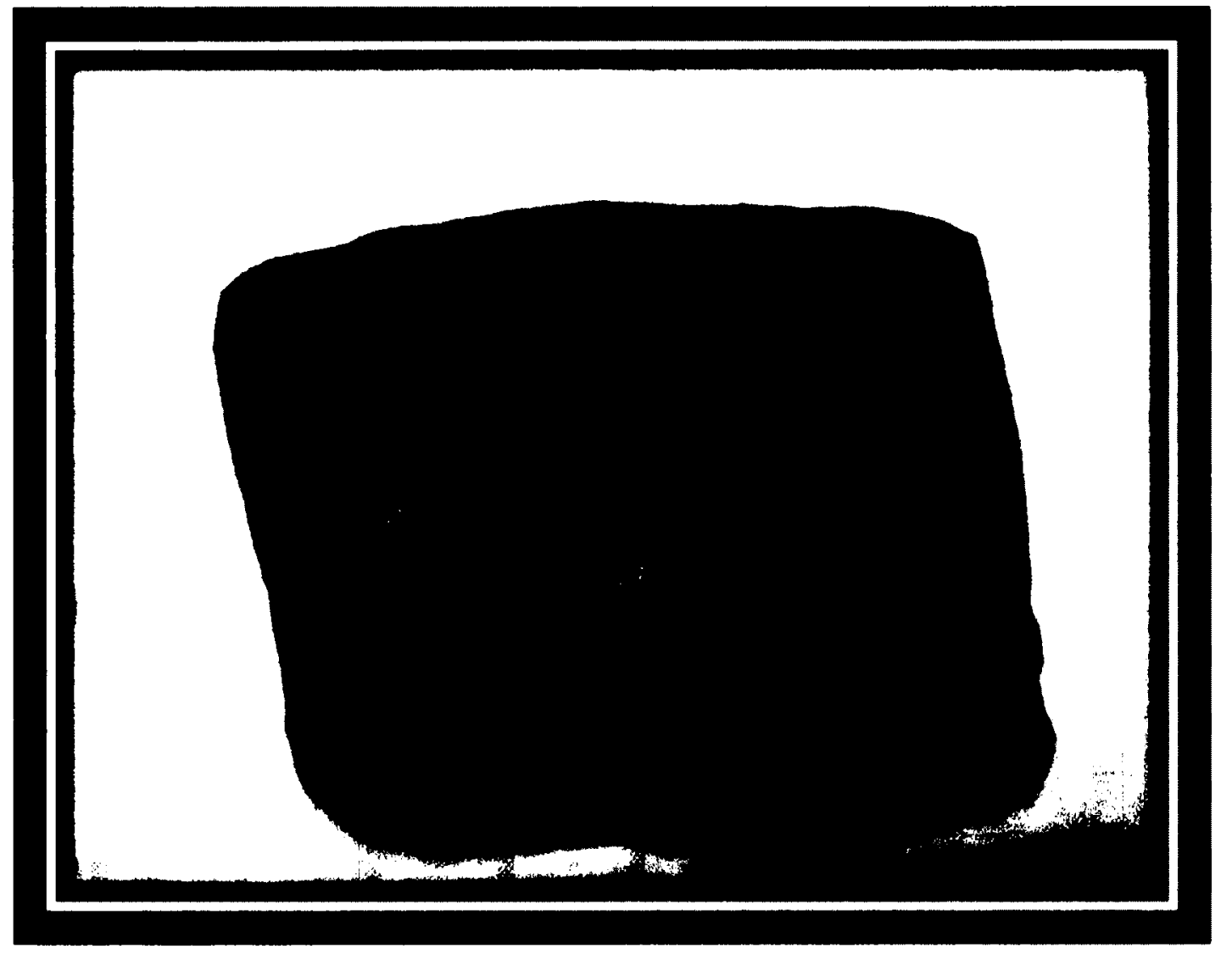

Figure 11. And then my uncle Moses came to pick us up my boat. with his helper to take us back to the land. 


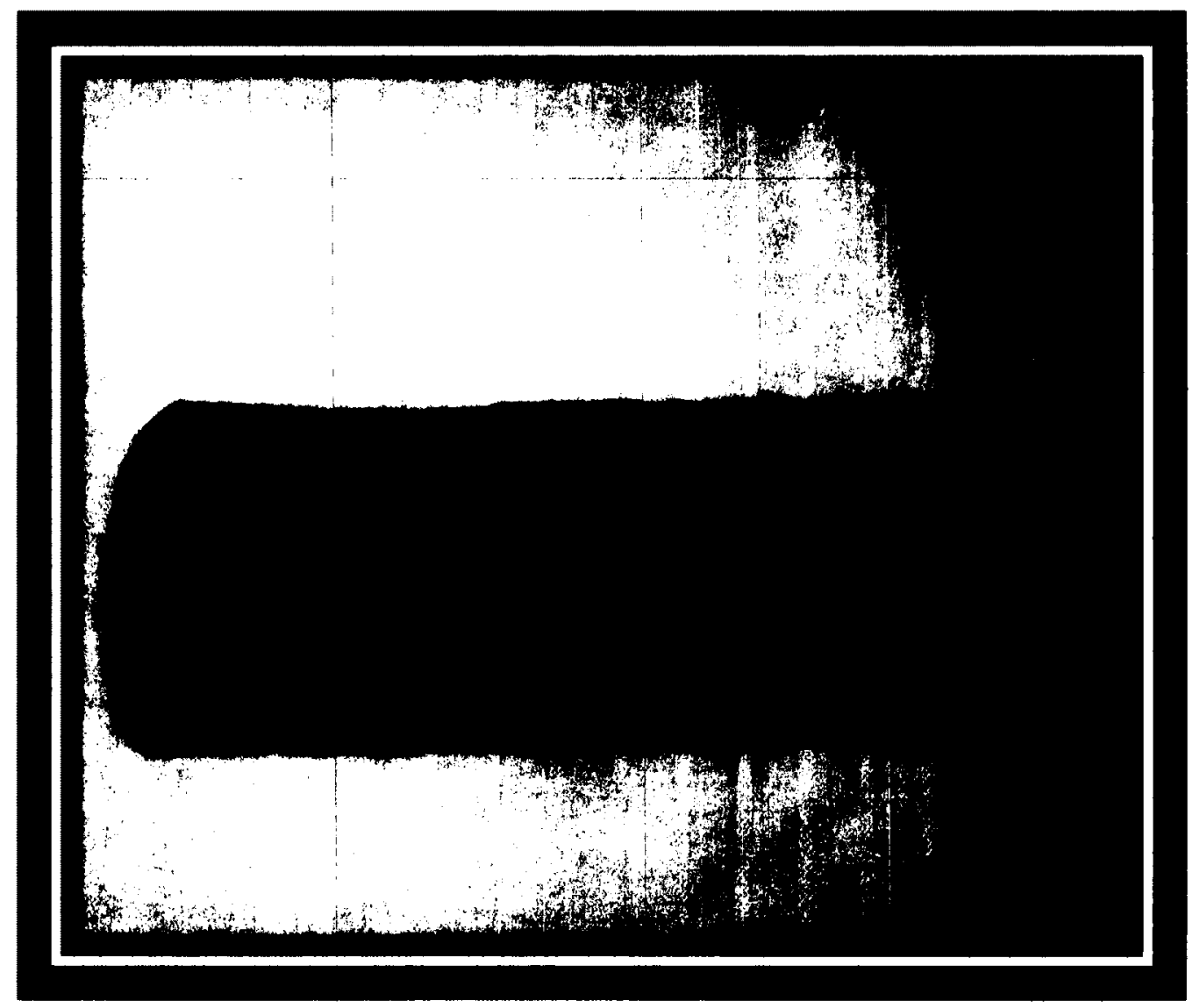

Figure 12. In the distance, I could see three tents when we were approaching the camp. And I could see a smoke in the distance. And moss, a really big pile. My grandmother was cooking caribou stew in a big pot that was cut in half. A 45 gallon drum cut in half. 


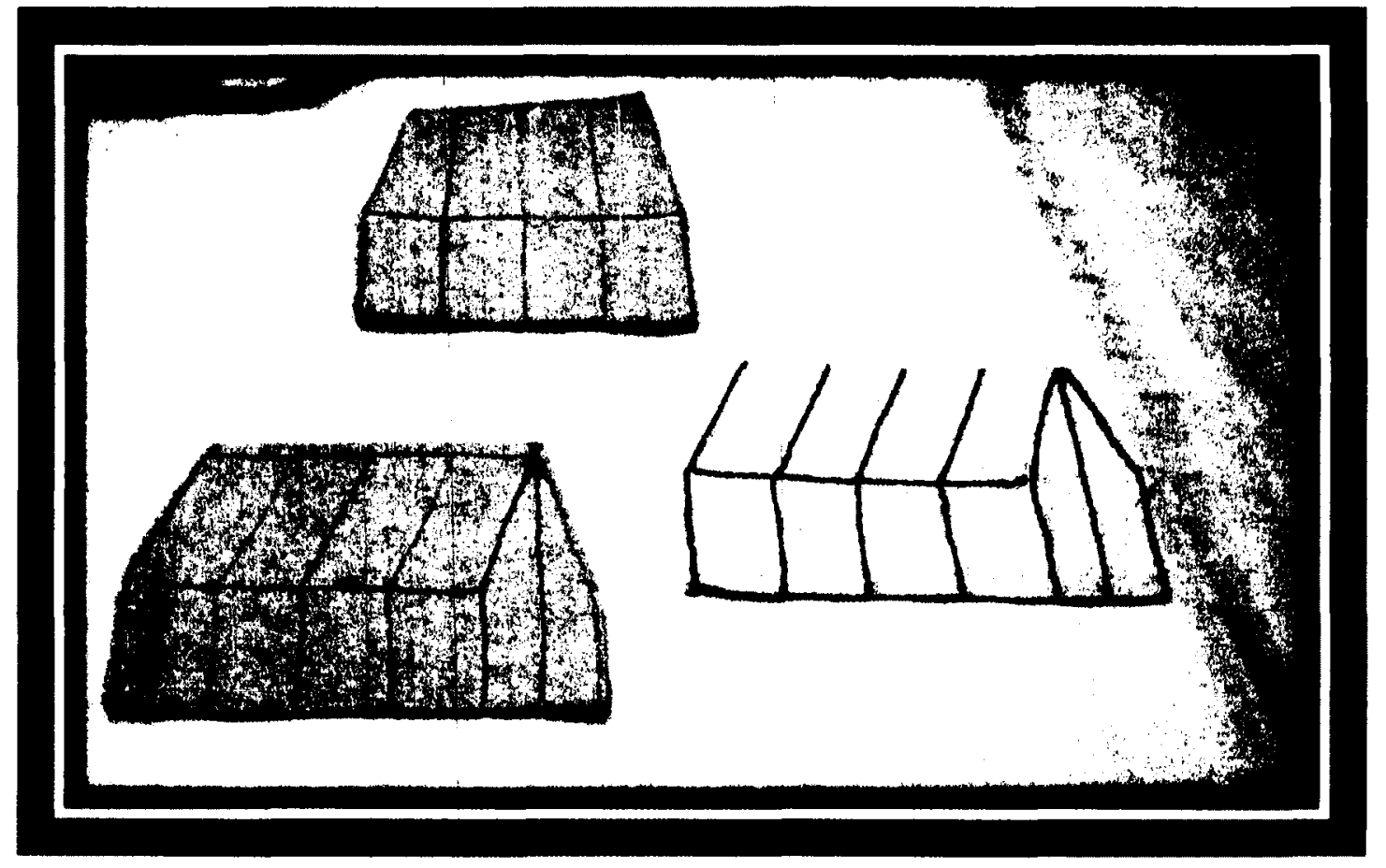

Figure 13. That's when I saw smoke and three tents in the distance as I came in to the camp by boat. 


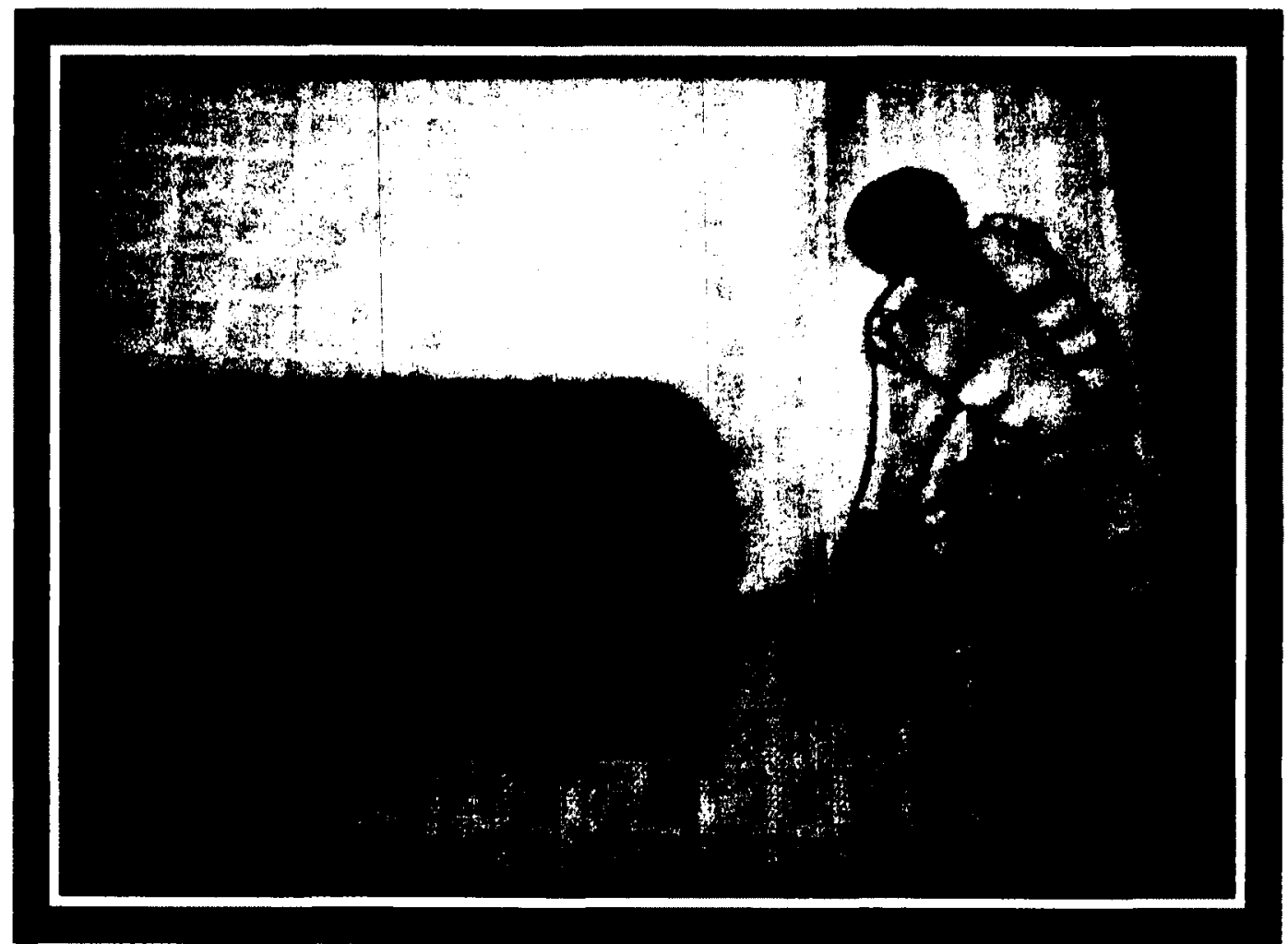

Figure 14. This is my grandmother's daughter-in-law. My grandmother says to her, "Go and get some water from the river and make some tea, so we can have tea after dinner." 


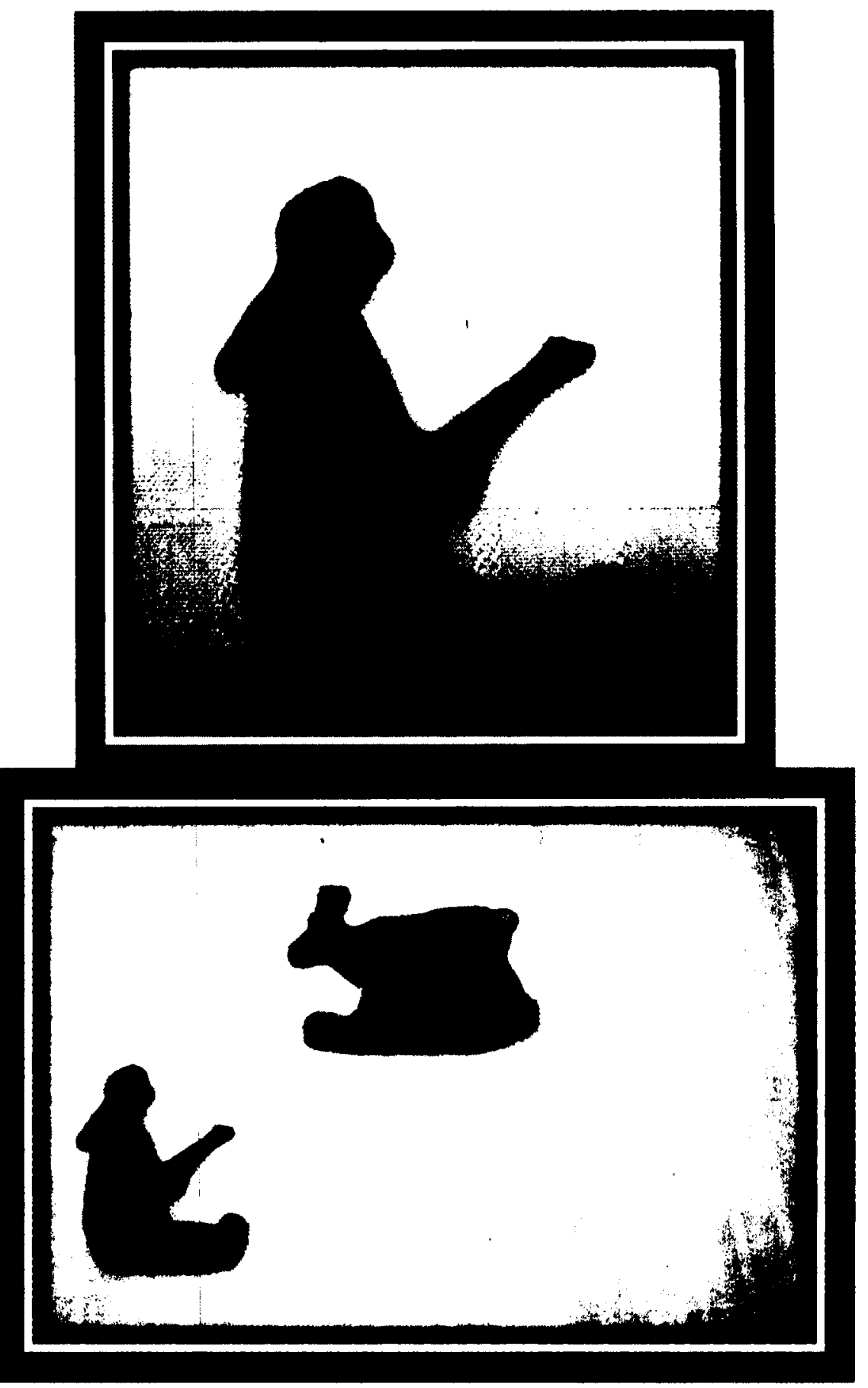

Figure 15. Then during the summer my uncle said, "It's time for me to teach you how to shoot caribou. And where to aim at it." 


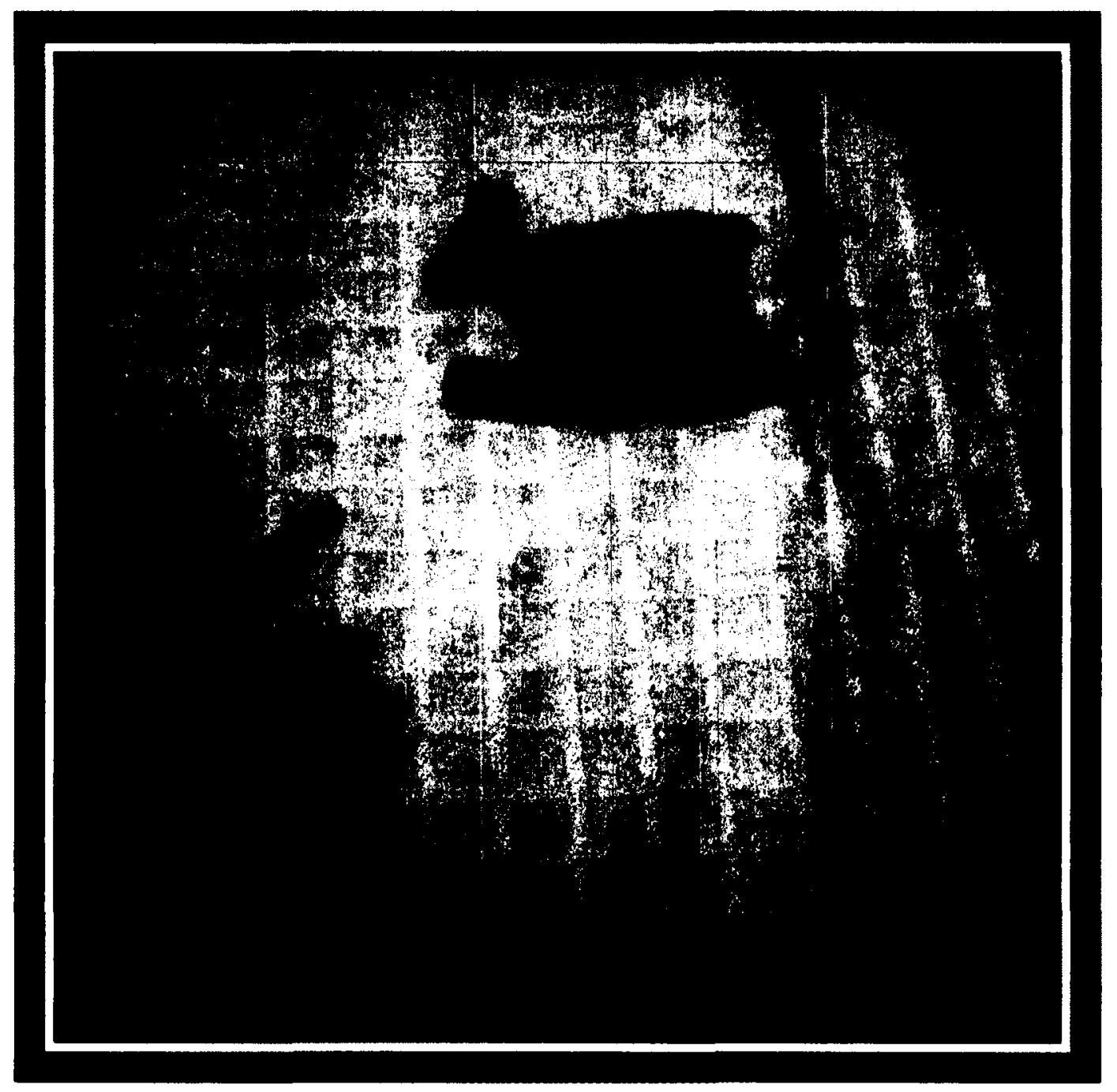

Figure 16. That's me and my sister waiting for my uncle to teach us how to shoot caribou. 


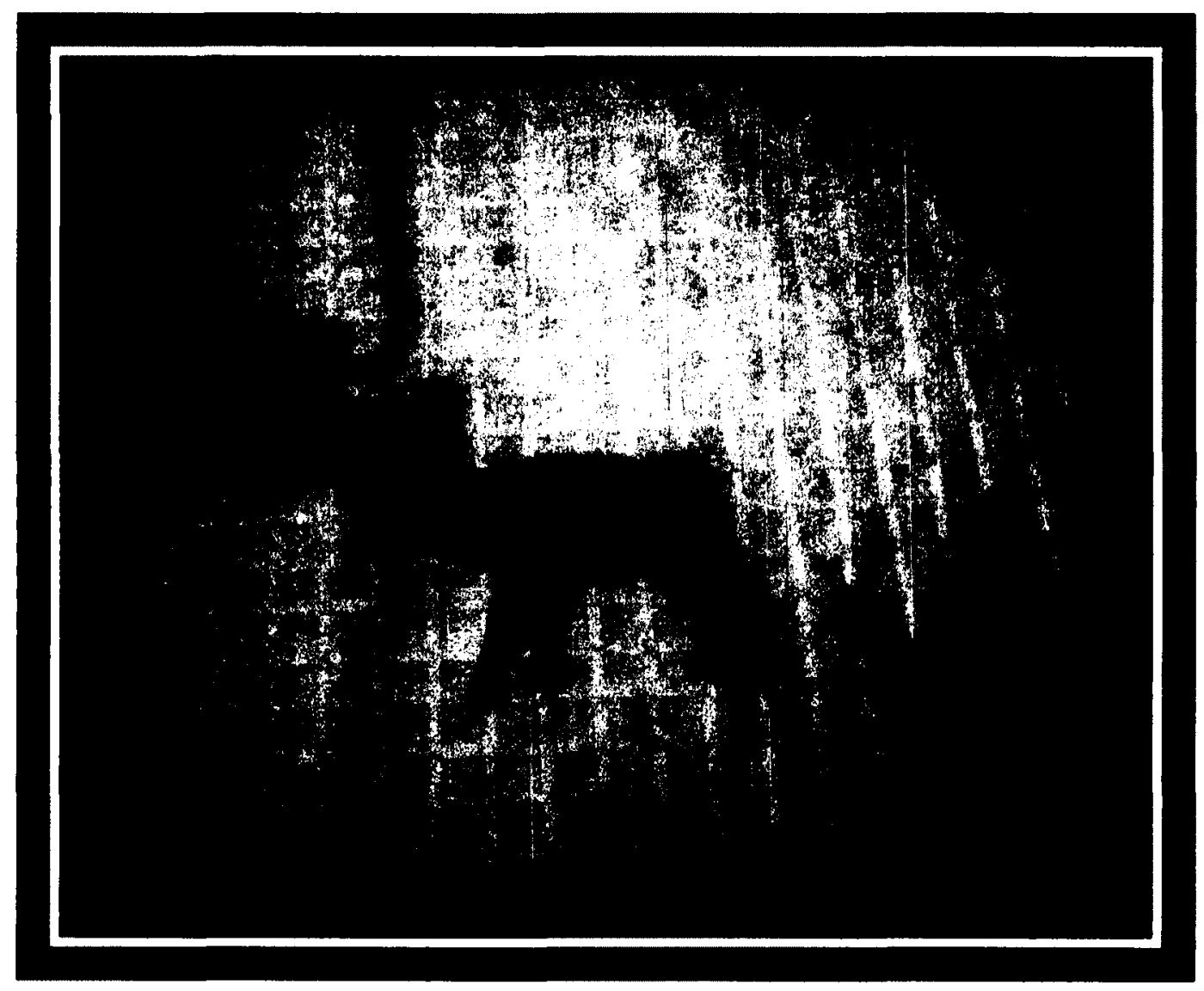

Figure 17. Then my older uncle took us hunting with my grandparents in the boat. In the distance they could see the whole herd of caribou. He started running after them, behind the hill, to shoot caribou. That's him running after caribou. My grandparents were in the boat waiting for him. They could hear somebody shooting. And my grandfather said, "I didn't know there were some people behind the hill." And my grandmother said, "You saw my granddaughters running after the caribou! It's them, there's nobody else!" 


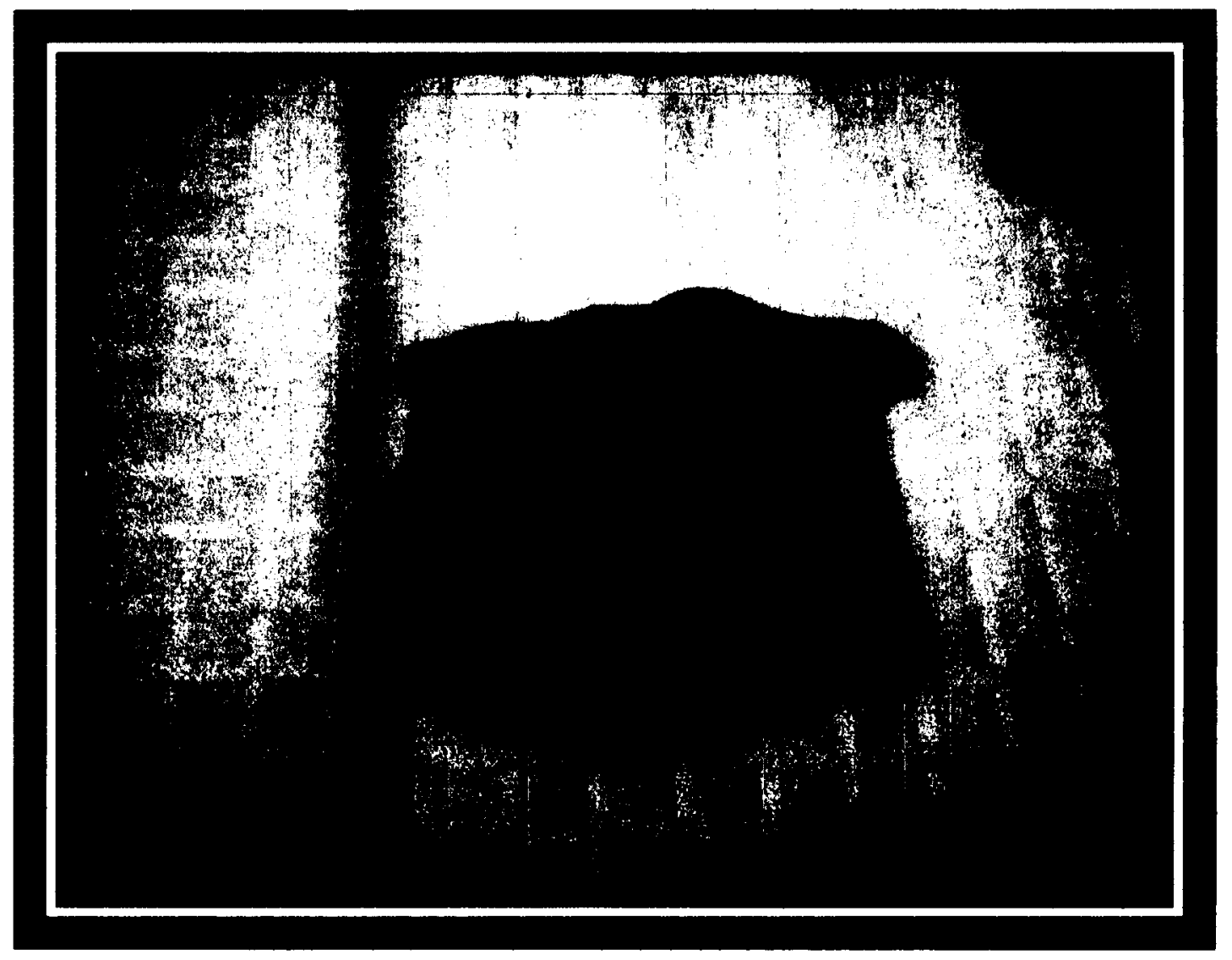

Figure 18. By the end of the Fall there wasn't enough snow. That's a quarmak. It is made out of ice. 


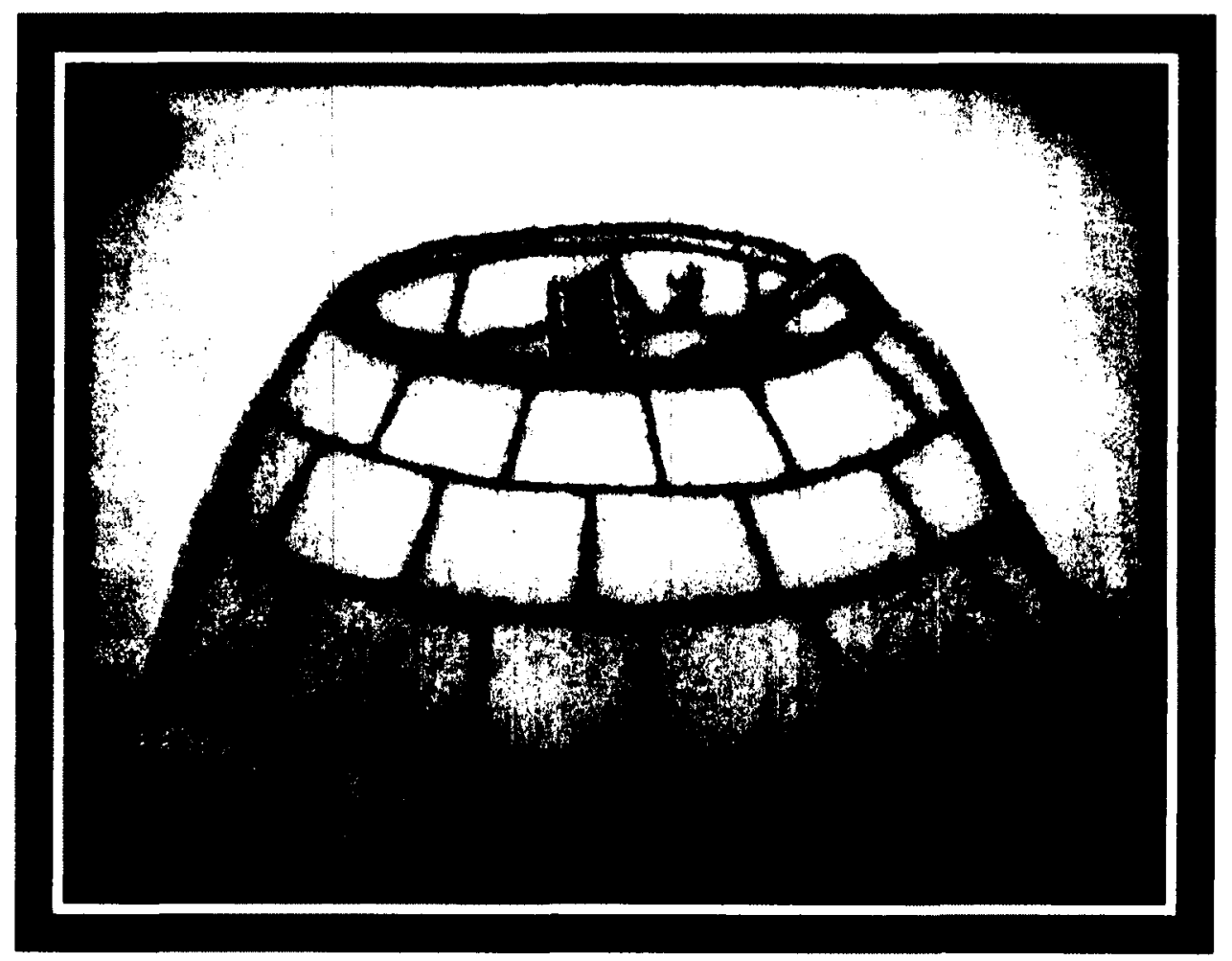

Figure 19. When there was enough snow my grandfather made us an igloo. 


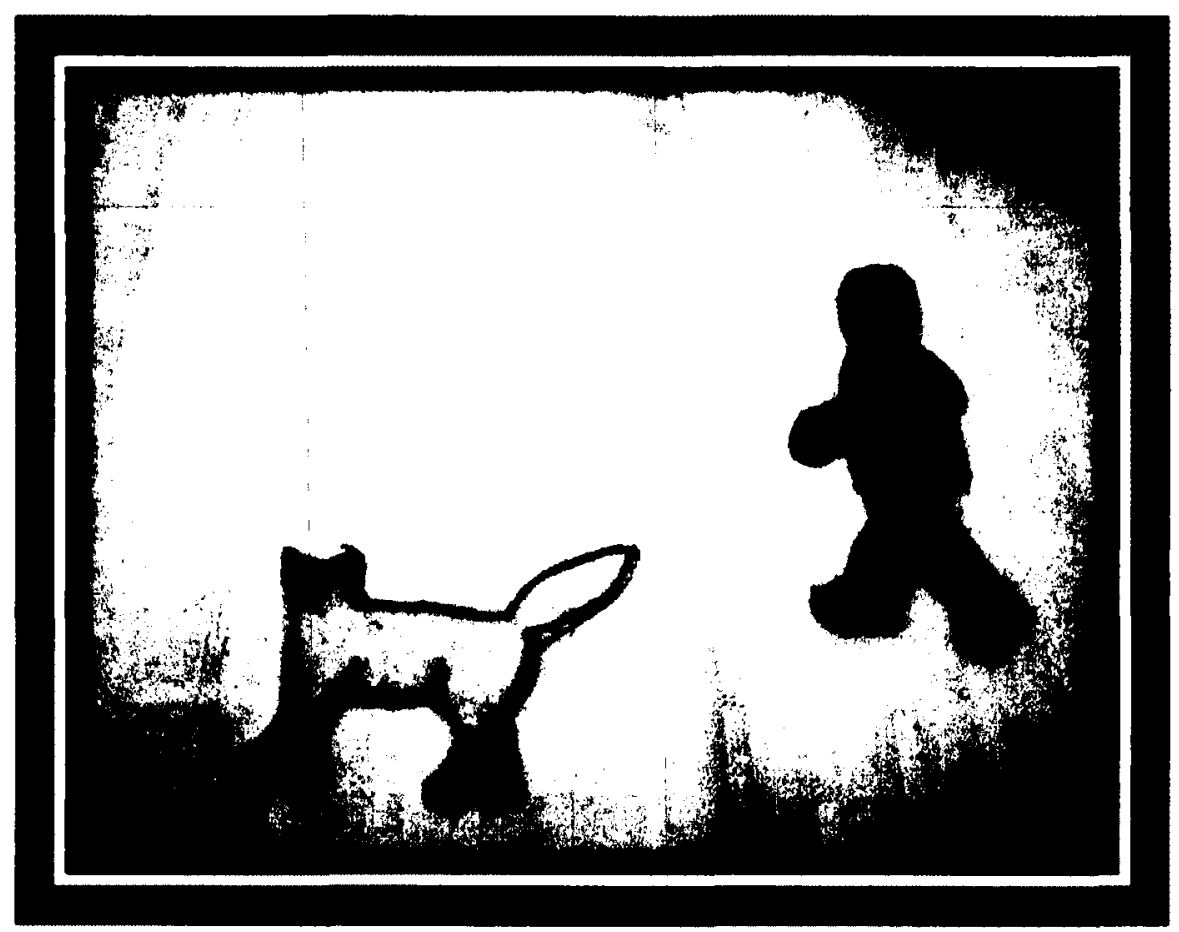

Figure 20. By November 1st they said to me, "It's time for you to learn how to set up a fox trap." Each of us had a fox trap with us. They told us to go find a spot to set up our traps to hunt foxes. We said we were going to lay our trap across the lake because we could see it from the igloo. We went out at about nine o'clock in the morning to set the traps out. In the distance, I could see there was a little fox trying to pull the trap out. He got free. I started running after it! And my uncle stated running after it too. I said to my uncle, who is two years older than me, "Go and try to catch it before it gets away!". So he ran after it and he caught it just in time. We brought it back to the igloo and showed it to my grandmother. She was so happy that my first fox, that I trapped. Then she asked me, "When your uncle goes down to the Hudson's bay store to get supplies, what would you like him to get you?" I said gum. I got my gum! 


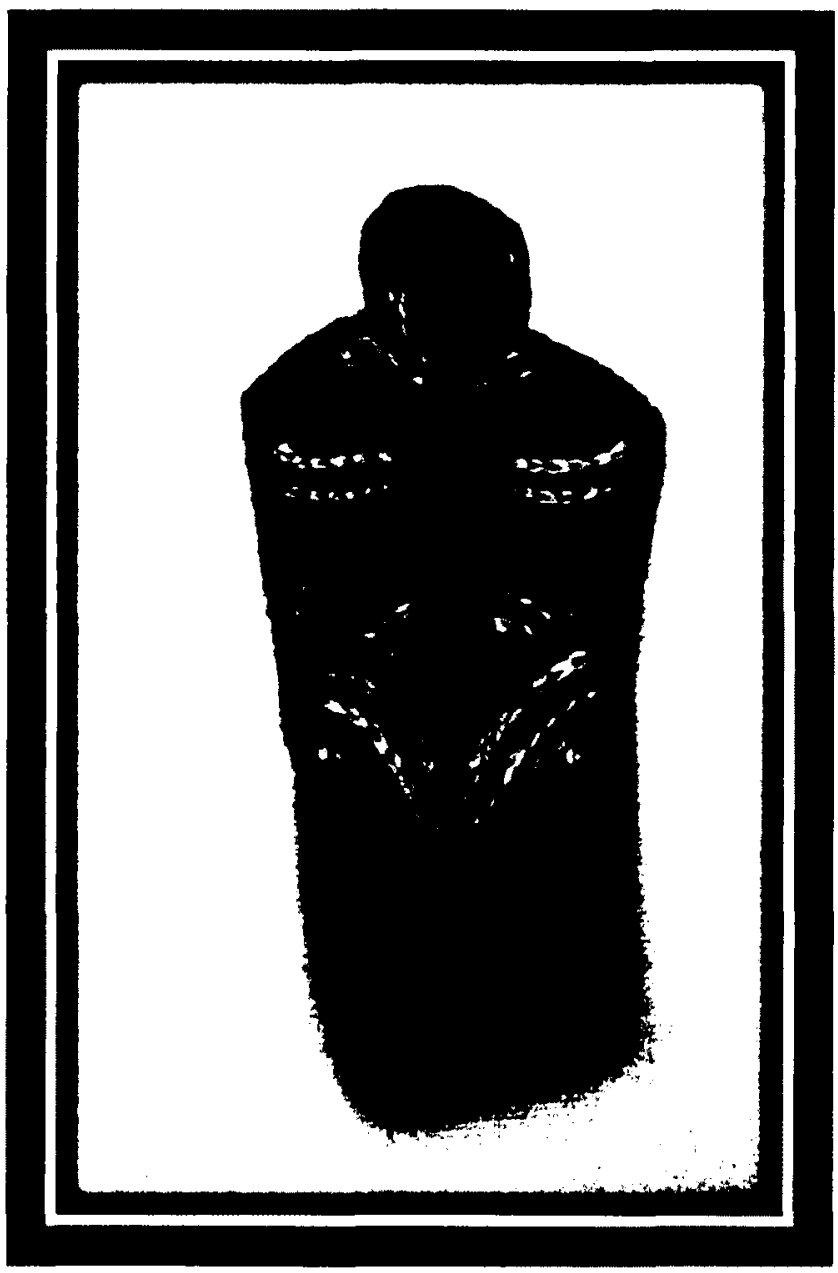

Figure 21. My sister was adopted to my grandmother because my mother was away when she had TB. My grandmother eventually adopted my sister because she was looking after her. 


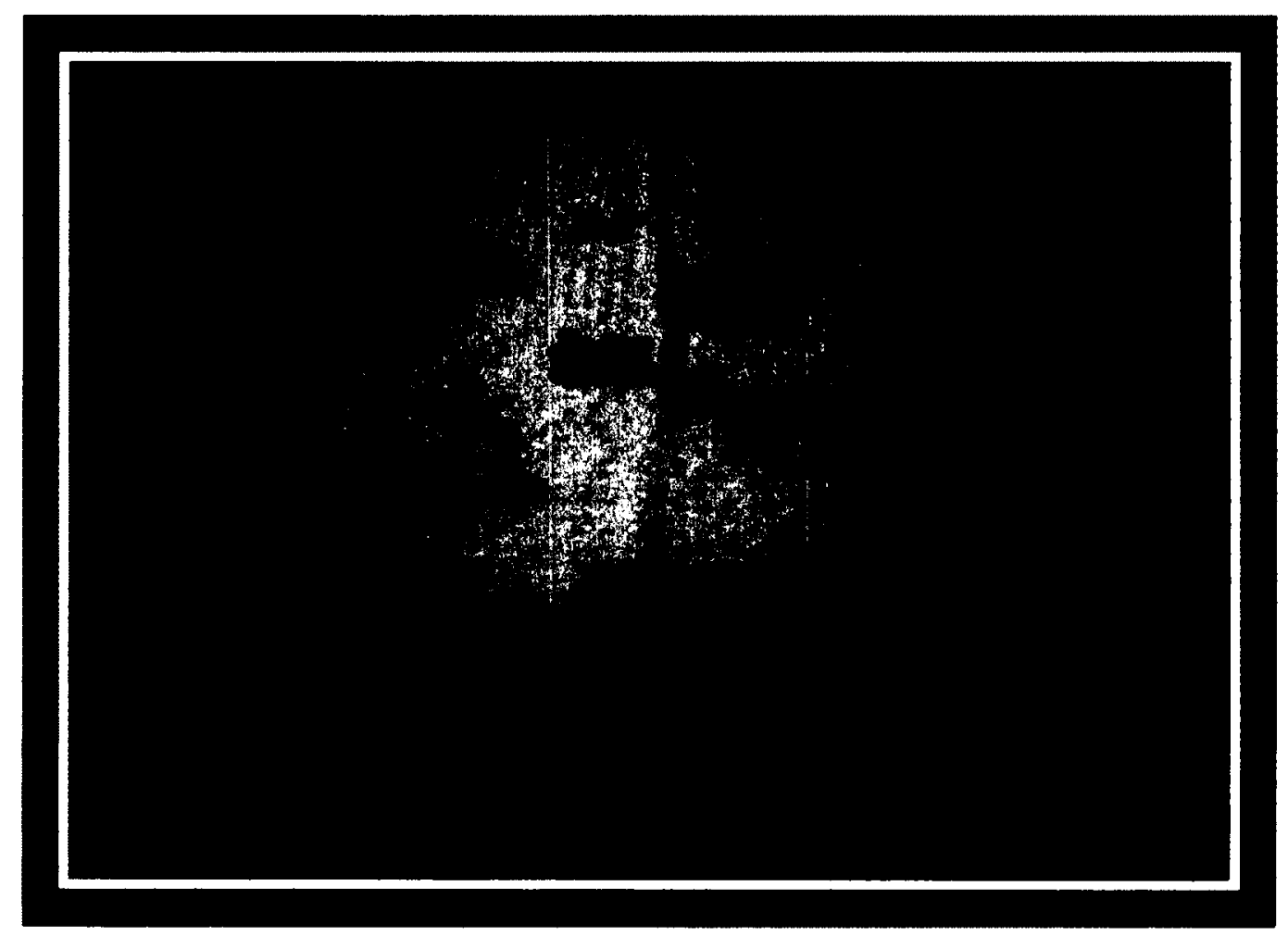

Figure 22. These are the stories from my childhood. 
Sally elaborates on her reasons for making the wall hanging and its importance. She began making the wall hanging to earn a bit of extra money. However, now it has come to represent part of her family's history.

I started working on this in maybe ' 85 . Somewhere in the' 80 s. Long time ago. Actually I started making wall hangings to make extra money. When I started telling people what it was about, recording my childhood memories, and they told me I couldn't sell them. And I asked why not? I want to make extra money that's why I started making wall hangings. But they said it belongs to the family now. It represents my family history and the story of my childhood. So I can't sell it now.

Telling her life stories feels more natural using her hands and the figures rather than reading a written story.

I don't want to write the story down on paper. I'd rather use my hands to tell the story and the figures. Because if it try to write it on the computer I wouldn't really know what to say. But when I use the figures I can tell the stories exactly the way I remember them.

The wall hanging of Sally's childhood memories are an evolving project she adds organically when she has time. She has many ideas and many more stories she wishes to share.

It's not finished. There are a lot more things that I am going to add on. The stories are from the memories of my childhood. All of them, the felt pieces, I made them by hand. The moss took the longest, maybe four weeks to finish, because of the fine stitching. I used felt and canvas and stitching to make the all pieces that tell the story.

I just add pieces to it when I have time. What I would like to add is a tepee made out of caribou skin. One of my uncles told me that. They couldn't afford to buy a tent. They had nothing so he and his wife when they were travelling they had to make do and put the pieces together of the caribou skin. From that they made a shelter for themselves! It was really dark but really cosy inside, he said. Because the fur was on. They were using what they had. I still have to put that in the story.

Sally sometimes uses the wall hanging when she is asked to attend an event or gathering to educate others about her life experiences. 
Sometimes when they ask me to tell a story at an event or gathering, I use this. That's all the pieces I have for now. Well that's all the story I have for now. It's not finished but it's the beginning anyways. I don't know what story I will work on next. It just comes to me.

\section{Back to Baker Lake}

After living at her grandparents camp for two years, Sally returned back to Baker Lake to attend school. She and her classmates were forbidden to speak Inuktitut.

All the education was in English. We weren't allowed to speak Inuktitut, not even at recess time. They wanted us to practice speaking English. Baker Lake is known as an English speaking settlement. We speak English a lot. And mixed, Inuktitut and English together.

When we were in school we were not allowed to speak Inuktitut at recess time, so we can practice to speak in English. Nothing to do with Inuktitut at all. Strictly English. Math, science, whatever, everything in English. But now they have a choice they can learn in Inuktitut or English. They have more choice now.

Now, people have more choice when it comes to learning and speaking Inuktitut. More choice than when Sally was growing up in the community.

It was not until the ' 80 s or " 90 s that the Elders started to say, "Our children are forgetting their language". Now they have a choice to learn in Inuktitut or English in school. Now they have a choice. If they want them to learn Inuktitut at kindergarten, they do now. People are taking advantage of that. And at the daycare centre too they speak a lot of Inuktitut. So that helps.

Sometimes the teenagers learn how to speak Inuktitut, and they do, but it's more like baby talk. When I went back recently, I had never heard the Elders speak English before. But they were speaking English so the children could understand them. I thought to myself, "My goodness, Elders speaking English so that the kids can understand!" It was so funny to hear. Now it's more common for people up North to be able to speak Inuktitut, but not know how to read or write syllabics. There's more Inuktitut spoken even in the workplaces, which is good. More than when I was growing up.

Other memories which are prominent in Sally's mind were they ways non-Inuit were favoured over Inuit in the community. For instance, consider the water delivery service. 
Only white people were getting water delivered to their houses. That was around '59. Water was delivered to the white people who were working in the community, like the area administrator, the catholic mission, the Anglican mission, the HBC, the RCPM, nurses and teachers. They were the first ones to get water delivered to their houses. Local people delivered the water by pulling the qamutik with a barrel, a forty-five gallon barrel filled with water. The white people would hire the local people.

Only several years later did Inuit start to get delivered to their houses as well.

Up until around " 65 we were still getting water for ourselves from the lake or collecting ice to melt. We were still getting water for ourselves from the lake with buckets. We had to walk quite far down to the lake to get water, maybe about half an hour there, half an hour back. And you are carrying the water on the way back. Until they started delivering water to the houses. Maybe around ' 66 or ' 67 did we start to get water delivered to our houses too. It took a while. That was a lot easier because you wouldn't have to go down to the lake to get water daily. If you have forty-five gallons of water, that will last you quite a bit.

\section{Moving Around the North}

Sally and her husband David lived in a few different northern communities when their children were young. David was an adult educator at the time employed by Indian and Northern Affairs. During that time Sally was occupied with raising her young family.

I lived in Arviat after Baker Lake. We moved in there '67. Then a year later we moved to Churchill, Manitoba. And then back to Arviat, and then back to Baker Lake. Our kids were really small then. We moved around with my husband work. I wasn't working at the time. I was looking after the babies.

\section{First Time Living Down South}

Sally was a teenager when she first experienced life in the south. As a sixteen year old she travelled to Brockville to receive training as a Teacher's Aide. The following year she travelled to Smith Falls for another month of Teacher's Aide training. 
I first lived down south in 1961. I went to Brockville for a month. And the following year I went to Smith Falls. I was there for teacher's assistant training. I was sixteen years old during that period. I stayed down south just for a month during the month of July. I found that I didn't mind Brockville the first time when I went there. They are really nice people living there. But, the second time I went to Smith Falls, the second summer, I felt less comfortable. The family I was staying with had kids too, they were a big family. The mother would yell at her kids. I was not used to hearing that. And me being a teenager at the time too, I thought, “My goodness, what am I coming into here?". But it was fine.

\section{Moving to Ottawa}

Sally and her husband decided to move their family to Ottawa so their children could attend high school. At the time, there was no high school in Baker Lake so children had to be sent to either Yellowknife or Iqaluit. In order to keep the family together Sally's husband got transferred to Ottawa.

We moved down to Ottawa in around 1983. We moved down when our kids were ready for high school. I told my mother and the other people that we are moving down south because there was no room for my kids at the Yellowknife high school. There was a high school in Iqaluit but we didn't want to send them to Iqaluit. So we had a chance to move down south. My husband worked for the government, INAC. We came down to Ottawa and I'm glad we did because the kids ended up with a good education and good jobs.

The other mothers in Baker Lake told me, "That's good that you have a chance to move down south with your family and your children. We can't do that, we can't go with them. When they go to school we wait for a whole year to see them." Their kids would leave for Yellowknife or Iqaluit at the end of August for the starting of school in September and not come home until the end of June. In those days they didn't have telephones, so they would write letters to stay in touch. They said to me, "If you can do that, we're really happy for you. That way you can move down and stay with your children when they go to high school. 


\section{A Sheltered Urban Existence}

Sally's life in Ottawa was focused on the raising her children and looking after her family. She had a great deal of support from her in-laws. For the first two years of living in the city, she did not go anywhere by herself.

My mother-in-law wouldn't let me go on the city bus. Every time I wanted to go out she would say, "I'll drive you there". She would say, "Don't go on the bus, I can take you." So, for two years when we moved down, I didn't go anywhere myself. Either my mother-in-law or my husband would take me places in the car. My mother-in-law would take me around herself during the day. And after work, my husband would take me to go shopping or we would go to the stores on the weekend. So, that was okay.

When she started working for ITK, she grew more familiar with public transportation and getting around the city on her own.

When I started working the reception desk at ITK in '85, I guess that's when I learned to take the bus to downtown. They would tell me how to get to work. My husband would say, "When you get to downtown that's when you get off". I wouldn't go anywhere else, but I got to know some bus routes after that, and then I was more comfortable getting around on my own. We had a car and that helps too, to get around the city. I didn't have to take the bus all the time, or depend on the bus all the time.

\section{'One of the lucky Inuit'}

Sally feels like she was one of the lucky Inuit living in Ottawa at the time. Due to her strong family support system, she did not experience many challenges.

I did not have too many challenges when I moved to Ottawa. My in-laws lived here, so I was being helped all the time. My husband would make sure to help me if I had an appointment or something. Or my mother-in-law would help me. So, I did fine here. I'd get help all the time. I guess I was one of the lucky Inuit living down here!

We never had to use many of the services from the Inuit community centres. We already a family doctor here, and we had a dentist, so I told them I don't need 
extra help finding a family doctor. I guess I was one of the lucky Inuit living in Ottawa.

Being occupied with raising her family, Sally did not experience loneliness. She was able to visit Baker Lake every other year which eased her sense of homesickness.

I was not really lonely when I moved to Ottawa. We were busy with the kids. They were going to school, and I was busy getting them ready for that.

I would go up there to Baker Lake every two years to see my family after we moved to Ottawa. So, that helped a lot in terms of homesickness.

At the time, the other Inuit Sally met was predominantly through her work at ITK.

I didn't know too many Inuit that were living down here at the time. There were not many Inuit living here at all. But I know there were some working for ITK at the time.

She also socialised with other Inuit at gatherings the growing community began to organize, such Christmas. Later on, Tungasuvvingat Inuit started in Ottawa.

There was a drop-in centre they started. They said they were going to have a Christmas get together, so we went down for that to see some Inuit. I remember it was downtown. It was before TI started. I guess they were enough Inuit by that time to get organized to get together. We went down to see that. Then after that Tungasuvvingat Inuit started.

Sally remembers missing country food when she moved to Ottawa. She would sometimes have access to country food if a friend or relative brought some down with them.

I did miss country food when I first moved down to Ottawa, but whenever we would have a chance we would get it from somebody else who had been travelling from the north. They would let us know they were coming down and where to meet them. They would have something for us.

Now Sally is able to bring back country food when she goes back to Baker Lake, and also through her son who works for First Air.

When I go back to Baker Lake every other year, I usually bring some country food down. Or if somebody comes down they would bring me some country food. 
My son can also ship some country food down by cargo, because he works at First Air in cargo. So, I can get country food if I really need it.

Sally feels sharing country food is an important part of Inuit culture. When she comes back from Baler Lake she gives country food to those in the community in need.

It's important to keep sharing. I usually share my country food when I come back from the north. I know who needs it in the community. So I would either have them here at my house to eat, we'll have caribou or fish. Food is a big part of Inuit culture. Especially sharing country food, that's a big thing with the Inuit. Sharing food, whatever you have. If they don't have it, and I know they need it, I usually just give whatever country food I have away.

It is easier to access country food now than when Sally first moved to Ottawa.

I know they can get it easier now. Like if they work at ITK or TI they can get it at work, once a month when they have feast. Or they would order it through work. It's expensive but it's good. It's easier to get country food now than it used to be.

\section{Living in Ottawa Today}

Despite having lived in Ottawa for nearly thirty years, Sally does not feel as though her sense of Inuit identity has changed. For her, being Inuk surpasses geographic boundaries or north versus south. Being Inuk is linked to her genetic heritage, and her sense of Inuit traditions, customs, and values (e.g. family bonds, helping, sharing) which are distinct from those of the dominant society.

I don't feel my identity has changed since I moved to Ottawa. I always will be an Inuk even though I live in the city. My parents are both Inuk. No matter where I am living I will still be an Inuk woman. Because I am still an Inuk even though I live in the city. Because my tradition is different than the white people. I do not know how their traditions are, or customs. My grandmother told me that your relatives will help you. Whatever I need, go to my relatives, and they are the ones who will be willing to help me out. Either clothes or food. And I do not have to replace it or return it.

Reflection back on her family's urban life, one of the things Sally regrets is not teaching her children Inuktitut fluently. She appreciates the presence of the OICC because they 
teach children to speak Inuktitut, something she wishes she had maintained with her own children.

I started talking to my children in English because my husband has a hard time speaking Inuktitut. He can never pronounce things right! So I spoke to them all in English. I wish I had taught them Inuktitut when they were young. They know a bit, but not enough to speak fluently. They can understand but they can't speak it. Which is so bad. Now I wish I had kept it. That's why OICC is really good. They learn a lot of Inuktitut. That's the way it should be. While you're young to learn Inuktitut.

From time to time Sally attends events at the OICC and TI, such as Elder nights or community feasts.

I went to one Elder gathering at the OICC last year. It was fun. Last time we got together there was Maggie and her sister Sarah, she was telling about the beadwork she did when she was down south. Beautiful work. I go to the community feast at Christmas time. They have them every month, every third Thursday at TI if they have country food they will serve it. But I don't go down unless I have to. Keep it for the people that really need it.

Sally enjoys participating in community life in Ottawa through her Elder teachings. She stared making herself available to the community around five years ago. Encouraged by her husband to do so, Sally shares her knowledge of Inuit culture with Inuit of all ages.

I like working with people, with other Elders or with children. I'm more of a social person. I get a lot of phone calls to give presentations or to open ceremonies. I started using e-mail recently. They e-mail me with a request and I follow up with them that way. I used to say no when people started calling me asking me to teach. But then my husband said, "If you can help people than why not?" He said, "You can do it." So I started to say yes when they would ask me to speak. I'm starting to get more comfortable with it all the time. I haven't been teaching as an Elder for very long. I started maybe five years ago. Not that long ago. Within the last year, I've been getting more and more phone calls to teach. I go TI or Wabano or Odawa. To do the Openings. That's what I do. I light the qulliq too.

I go to the OICC to teach little kids sometimes. They will probably give me a call again this fall or this winter and I'll probably go in to teach them again. I would ask them, what do you want me to do, talk about the language or Inuktitut teaching. They usually tell me what they have been learning. I like to know ahead 
of time what I'm supposed to be doing. Then I can prepare and get things ready. Sometimes I'll go to the school, E.B. Wilson and talk to the students. I talk to the kids about drumming. I talk about Inuit culture.

Sally passes on her knowledge of Inuit culture, for instance, of sewing traditional parkas

to Inuit in Ottawa who may not otherwise have the opportunity to learn.

I even talked to the Inuit women down here who live in Ottawa. Took my stuff, and talk to them about what I have done in the past. And I bring a wall hanging and talk about art. And clothing. Because some people live down here and because they went to school down here they don't know traditional clothing. Some of them do, but not all of them. I do traditional sewing. Mostly traditional aati or amauti we call it. I haven't done parkas yet. So they want me to come in sometime to talk to the women and teach them how to sew.

In addition to passing on her teachings to other Inuit, Sally is frequently asked to make cultural presentations to non-Inuit. She takes advantage of these opportunities to educate non-Inuit about her culture in the hopes of facilitating cross cultural understandings.

I taught for a week at Health Canada. I talked about Inuit culture and about the north. The first day I used a PowerPoint presentation to talk about the north with a map. Talking about different settlements different places. Because I'm from an inland community, and the others are from the coastal community that means they get more game like caribou, char, polar bear, and seal. But where I come from it is mostly caribou, musk ox, and fish. The second day I talked about all the traditional tools I have for teaching. Wednesday I did drumming. Thursday I talked about the language. And on Friday it was just a pot luck.

Over the years, Sally has put together a collection of 'teaching tools' to help facilitate her cultural presentations. They are a collection of cultural objects which have either been passed down to her from relatives, have been given to her as gifts, or she herself has made or bought.

I have teaching tools, like everything. I just a bought a miniature qamutik when I was up in Baker Lake last June. I buy things I see for my teaching tools, I keep adding them up. I have kayak, I have dogs, I have traditional games and tools. It's important to me to have these teaching tools because whenever I am asked to go to the school to talk to the kids, I want to have things the kids can touch. Instead of just talking verbally, they often have no idea what I'm talking about. But if 
they see these things it gives them more visual items they can see and understand. If I could educate them, or if I get my point across to them, and they learn something about the north, then I'm happy. If they don't understand they can ask questions and I just have to explain.

Sally describes herself as being 'in-between' cultures. She keeps to what she knows when it comes to her cultural teachings.

I'm in-between. I was born when traditional Inuit ways were still strong. I'm inbetween cultures, in-between worlds. I know a little bit about what life was like on the land, I don't know enough, but I'm in-between. So whatever I know I will teach. I've been told not to tell the story if you don't know it right through. Because somebody could correct you. Only tell it if you know it, only tell the whole story. Even the legends or songs. They say the legends are so important that you have to tell it all of the way through, just the way it is. Don't add anything, don't skip anything. Tell it right through.

Through her teachings and collection of cultural teaching tools Sally is able to connect with Inuit culture in Ottawa, and share her knowledge with others. Her collection, like her wall hanging, is a work in progress. She is always looking to expand the contents of her teaching 'tool box'.

I'm in-between. I know traditional stuff, not all of it, but some of it. Whenever I go back I try to pick up whatever I didn't have down here for teaching tools. Like in June, the last time I went up to Baker Lake I went to see if someone could make me a miniature qamutik for my teaching tools. And they didn't have it. So I went to Nunamiut Lodge where they usually have things to sell. The manager said he had a miniature qamutik, so I bought it.

Below, Sally shows us the teaching tools she uses when invited to speak about Inuit culture. Each photograph is accompanied by a brief description describing the teaching tool, its function, and/or where Sally acquired the object. The teaching tools are significant because, like the wall-hanging (presented earlier), they are tangible ways in which Sally connects with Inuit land and culture as an urban Inuit Elder. 


\section{Teaching Tools}
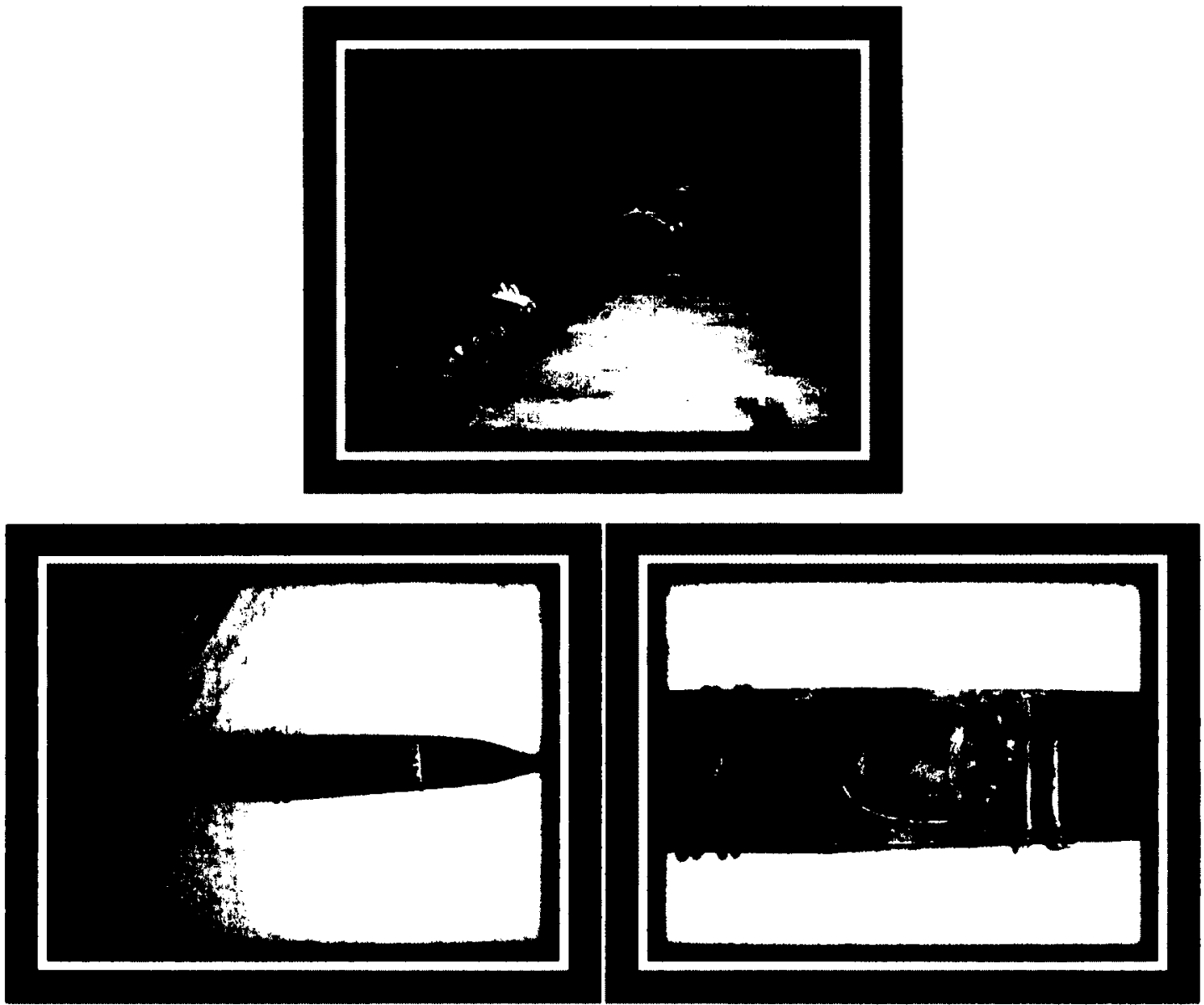

Figure 23, 24, 25. My husband bought this miniature kayak in 1965. That's when people were still living in igloos and there was an old man was selling this. It had floats, but I used to let the kids play with it in the bathtub so we lost all the little pieces! It is made of caribou skin. That old man made the frame and my mother sewed it together. The old man came to my mother with the frame and asked her if she could sew the caribou skin together for the kayak. When you use the kayak, you have to know it's tippy. My mother told me she used to sit inside or on top of the kayak when my grandfather was travelling in the lake. Even women go inside when they are long kayaks, and the children can go inside or on top. 


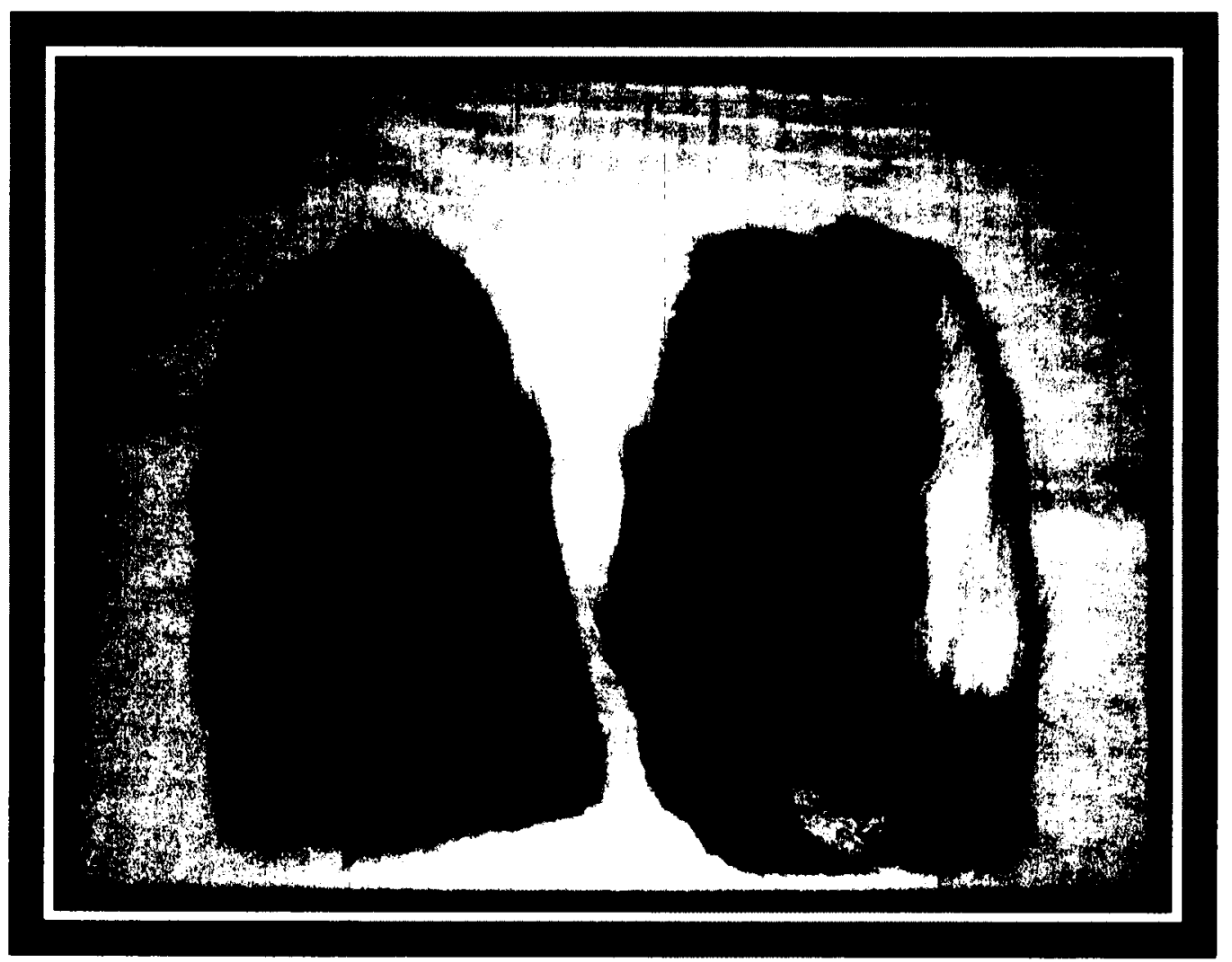

Figure 26. These are women's mitts from the front legs of a caribou. The front legs of caribou are for women. We use them to make mitts for women. And the back legs are for men, because they have wider hands than the women. A woman from Baker Lake made these mitts. 


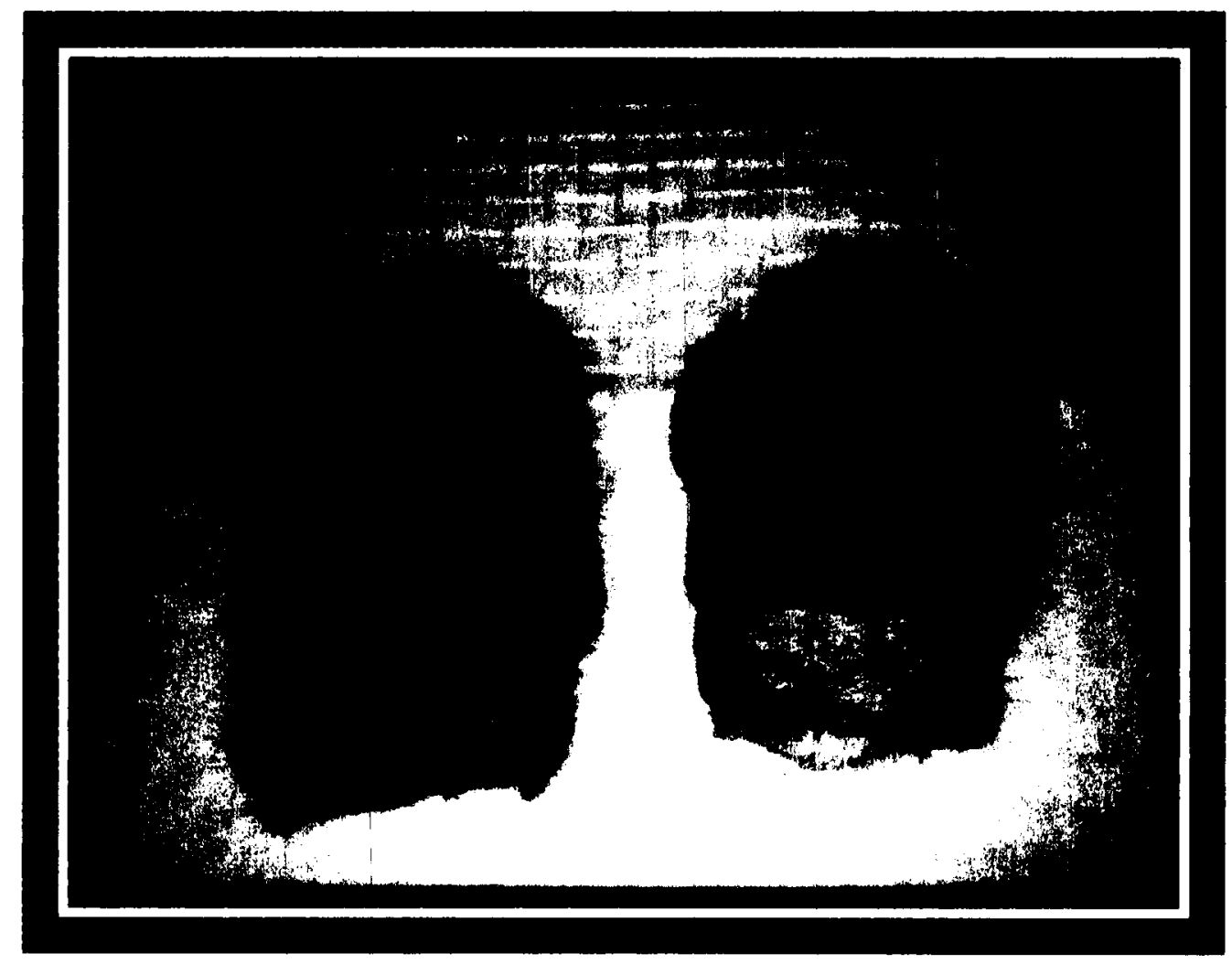

Figure 27. These are little mitts for children. Just the body parts of the caribou are used to make these mitts. That material is a baby caribou, a calf. They are really soft. And they have lining inside. The lining is just fake fur, or cotton. That's what we would use before we started to buy the store bought mitts, like leather and that sort of thing. When my mother was growing up, that's what she would use. 

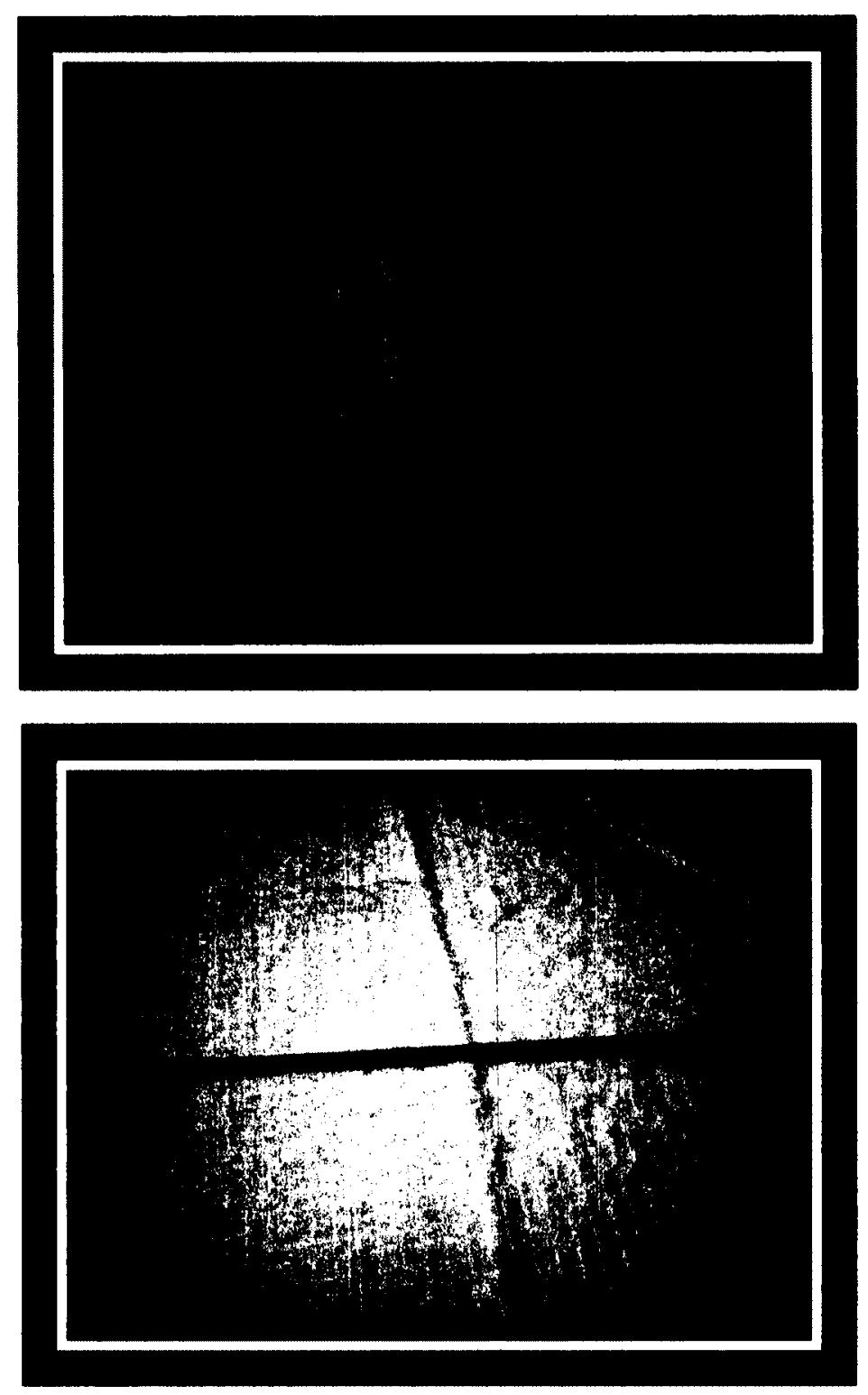

Figure 28, 29. This is called a snow tester. It is used when people are going to build an igloo. They have to check the snow to see if it too soft on the bottom or too hard. If it is too soft it tends to break or if it's too hard it tends to break too. Somebody made this snow tester. We bought it in Baker Lake. This is made of wood and antler at the end. I used to hear my step-grandfather walking around testing the snow, and he would say, "No! No!", until he found the right type of snow to make igloos. Then he would say, "That's good." If you didn't have wood it would probably be made of antler. If they go up to the tree line at Aberdeen Lake (west of Baker Lake) they can find trees. 


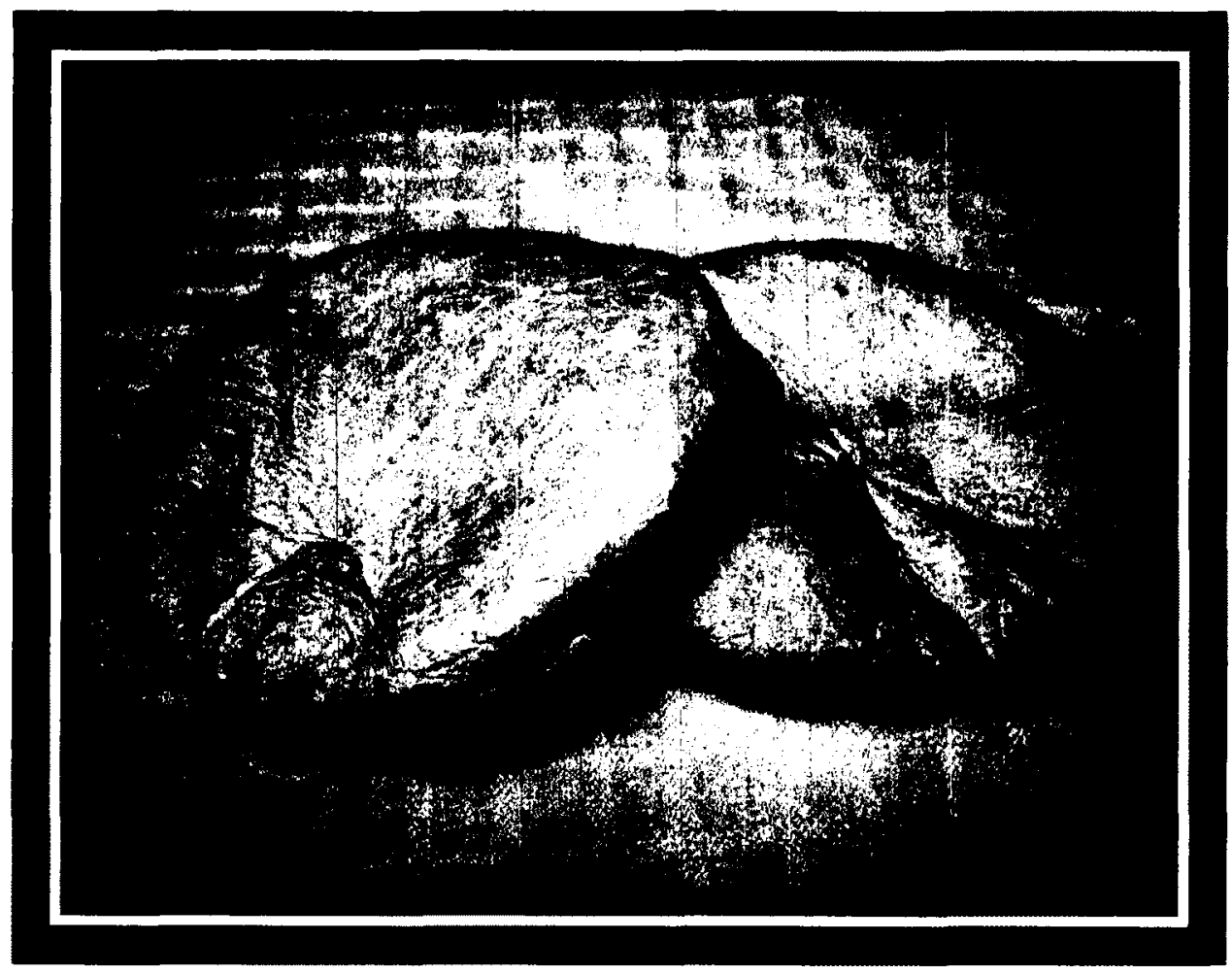

Figure 30. This is like an Inuit Frisbee. It is made of caribou skin. It is filled with sand from Baker Lake. You have partners and you throw the disc back and forth with your partner. You throw it as far as you can, and they catch it, and throw it back to you. The people standing in the middle try to catch it. It's a game. It's more of a traditional game. My mother made these two discs. 

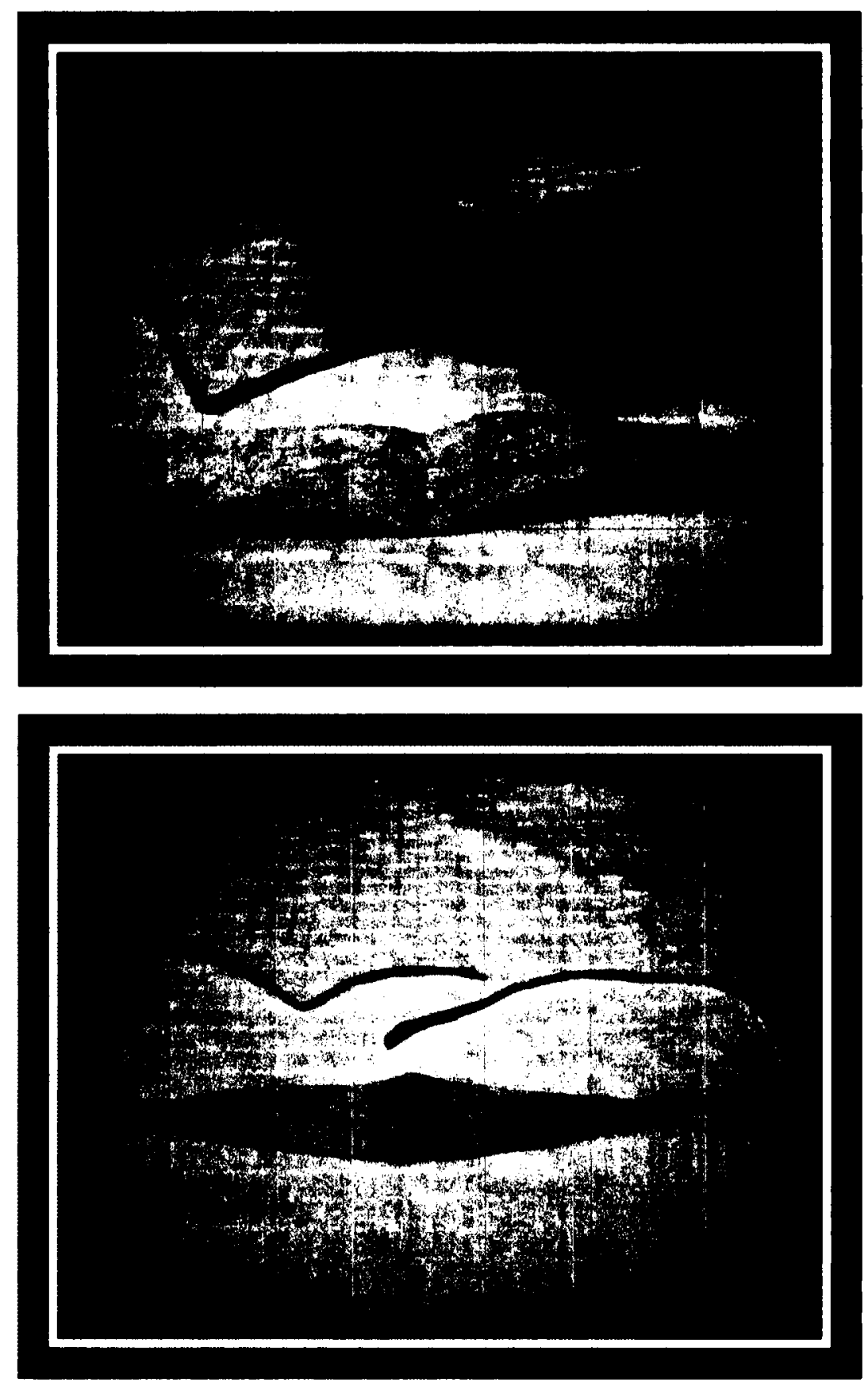

Figure 31, 32. This is a boy's sling shot. Made out of caribou skin. When the boys go down by the shore by the lake, they put the stone in the middle, and swing it to see how far they can throw. It's a game. But they can use it too if they need to hunting ptarmigan, or something. If they want to use it for hunting they can too. It's mostly a boy's game or tool. Everything is from Baker Lake. There is a heritage centre where people make things and sell them. I bought this there. 

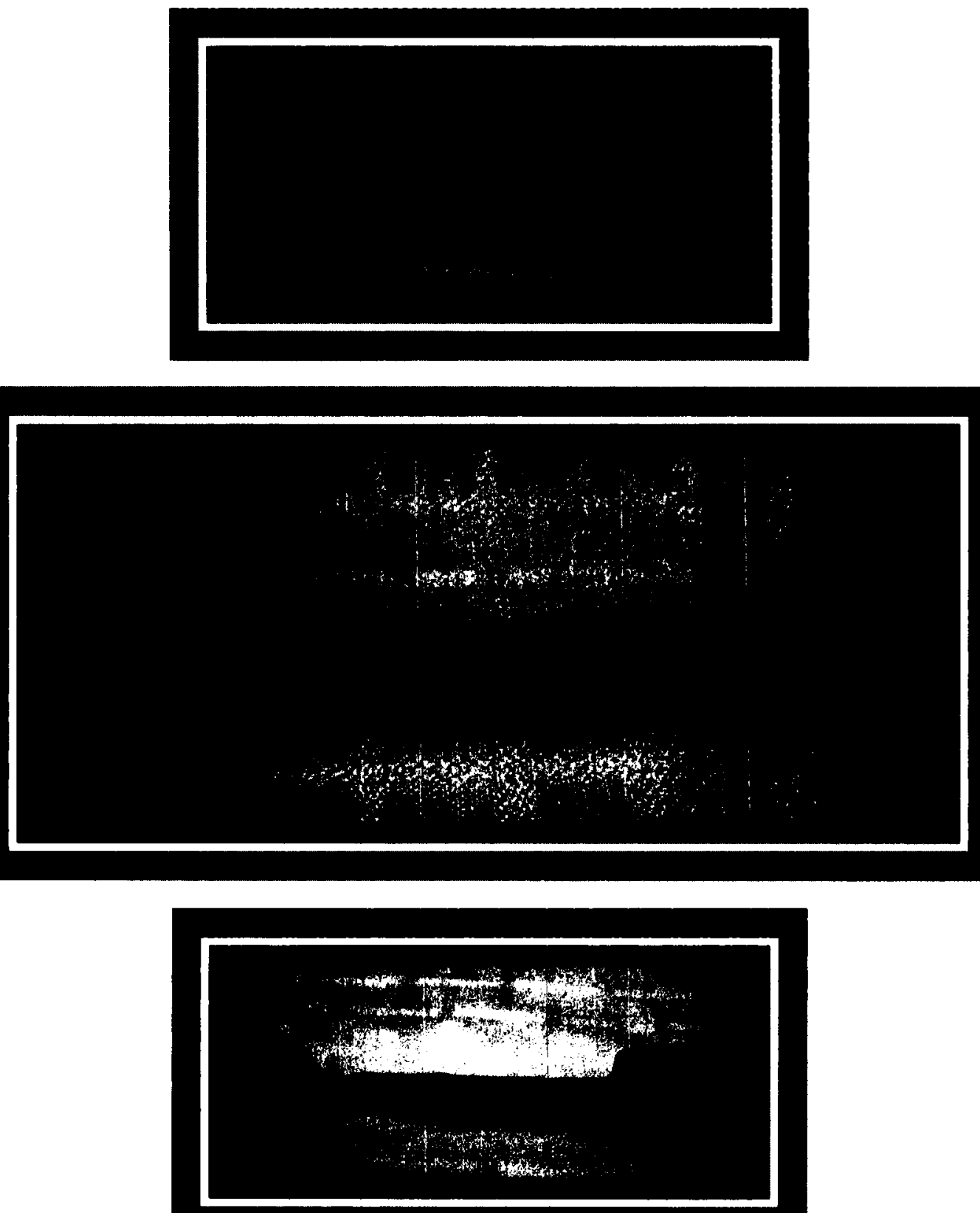

Figure 33, 34, 35. This is a needle case. You put the sewing needles in there when travelling so that way you don't lose or break them. This is made of antler and caribou. This case that was made by a man who works at the shop in Baker Lake. He made the little decorations on the case. 

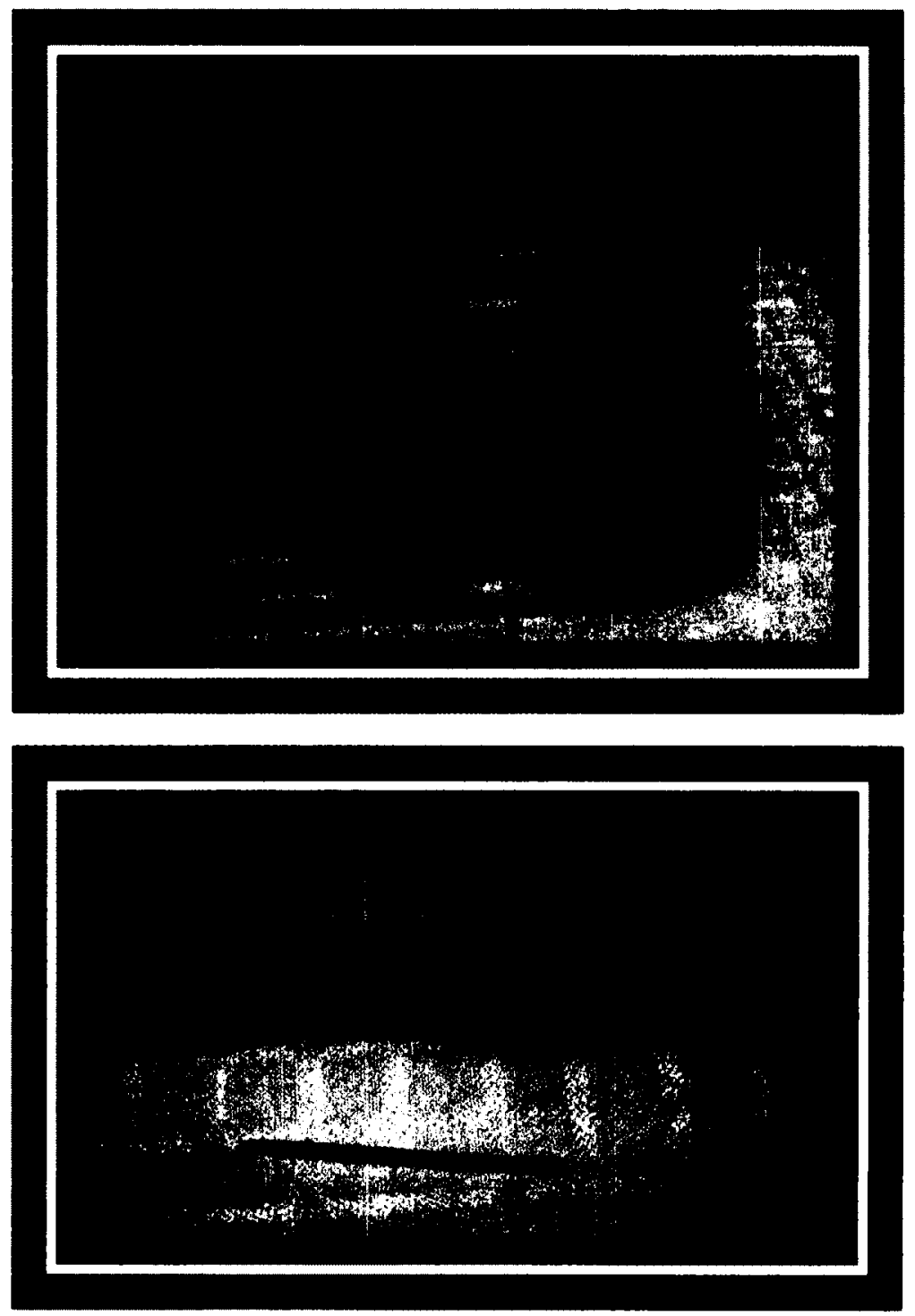

Figure 36,37 . This is another needle case. This one was made by a woman. It is made from the bone of the caribou, and you put the needle inside. It is made of bone, part of the leg of the caribou. You can see it. I guess she didn't have antler so she used bone. There was marrow inside here, and she hollowed out the marrow. 

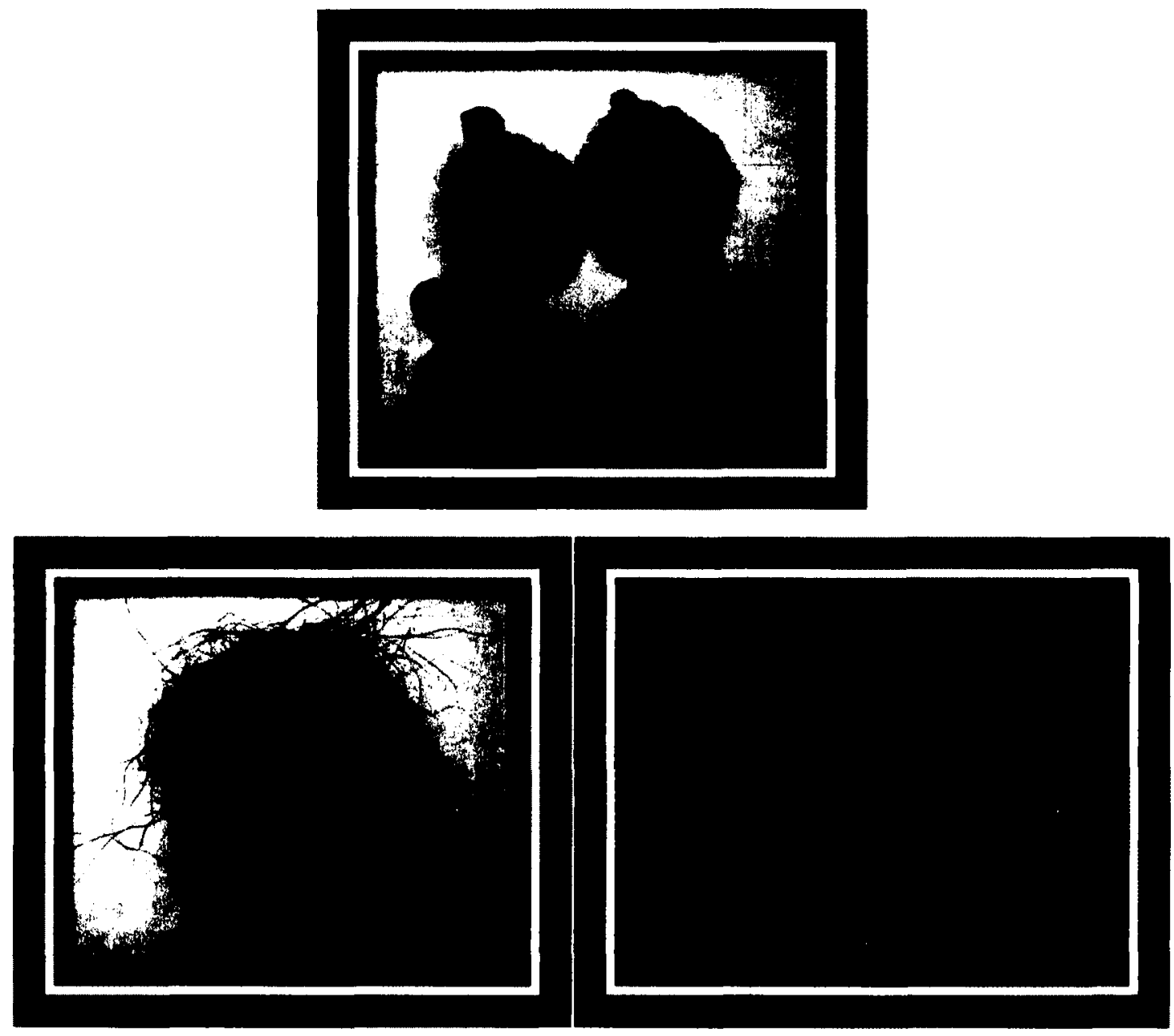

Figure 38, 39, 40. These doll heads were given to me by a lady when I lived in Arviat. It was a gift. They are decorations. There is a set of four (top photograph). She said she worked with sealskin, and used her fingers to shape it into a face. She made this one too (lower photographs). This one is made with musk ox hair. What she did was use sheep skin for the fur, the white part. Isn't she clever! She passed away just a year ago. They are decorations. I put them on the wall. 


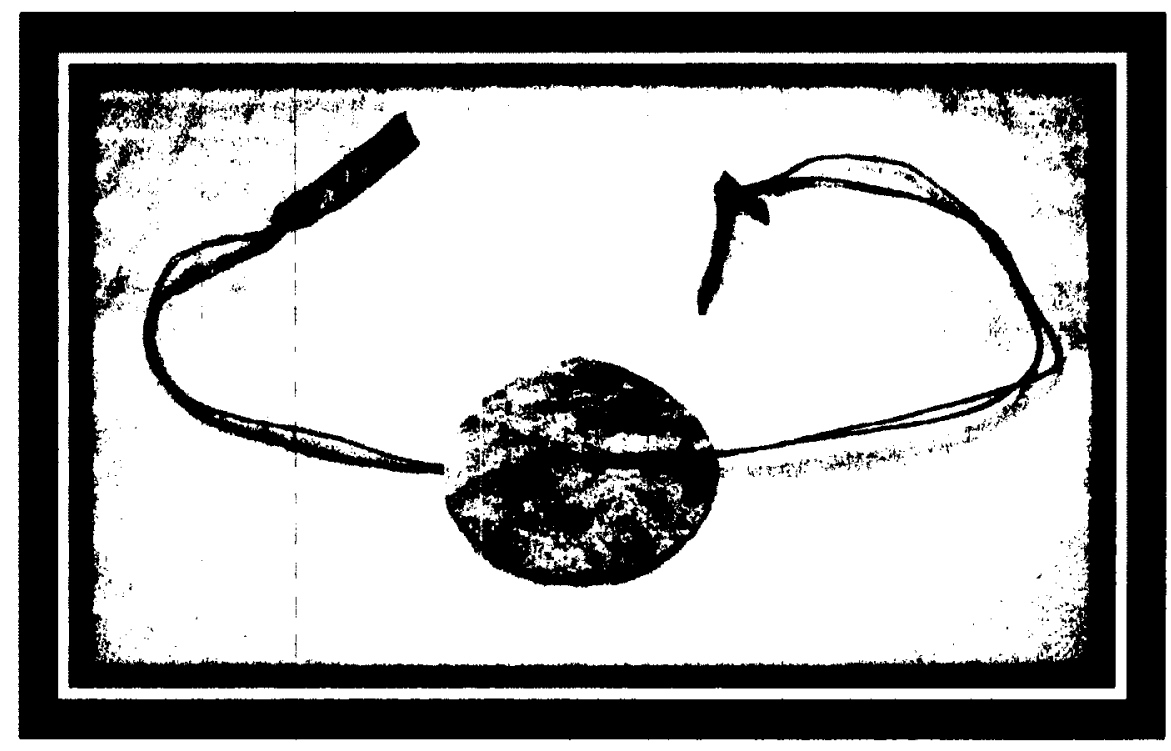

Figure 41. This is called Imigluktuq. It is a traditional toy. It is a kids game. You wet the string with your mouth. Once it's wet, you hold the ends and make it spin. It will spin and make a loud noise. It's for the kids to amuse themselves. It's made out of caribou skin and sinew. 


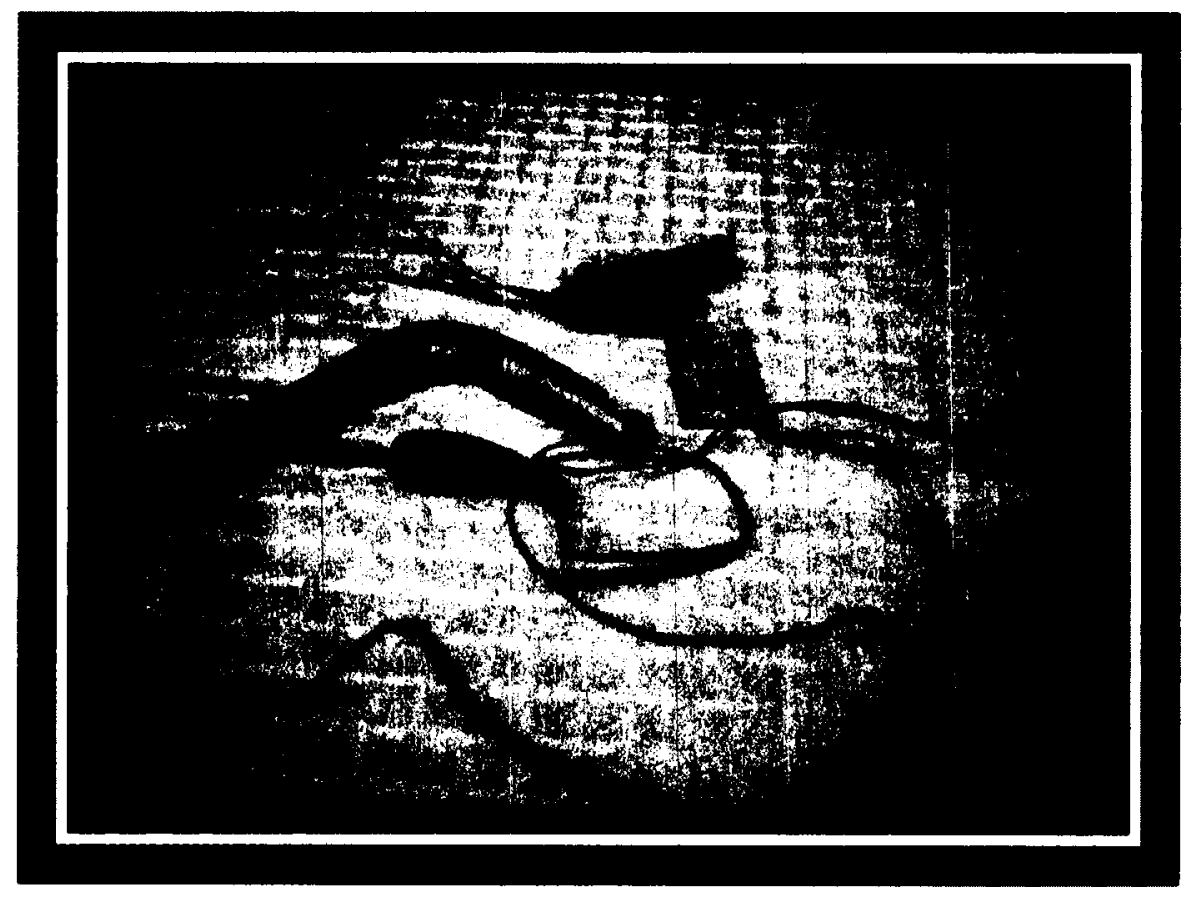

Figure 42. This was used for ice fishing. This is sinew braided together with a piece of antler and a hook used to go fishing. My cousin, Denis, and his mother made this. In the springtime what you would do is use a rope and put a hook at the end, and just throw it. Instead of a fishing rod they used a rope. 

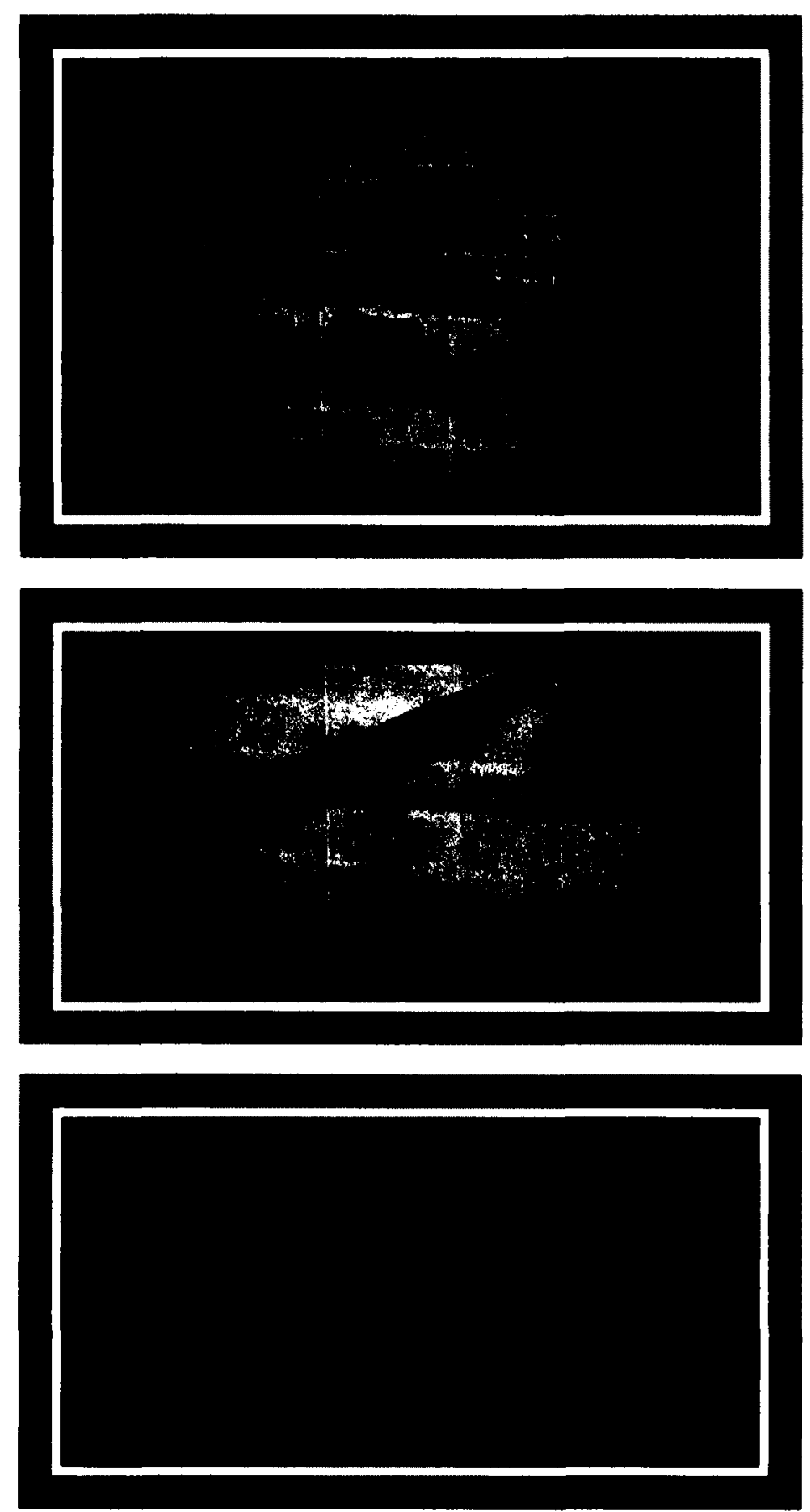

Figure 43, 44, 45. This is called stick and hole game. You have a contest to see who is going to put the stick in the hole. These are for school kids. This one (bottom photograph) is from the south. It is made from deer. The hole is very big, maybe too big. The others are from the north. They are made from caribou. 


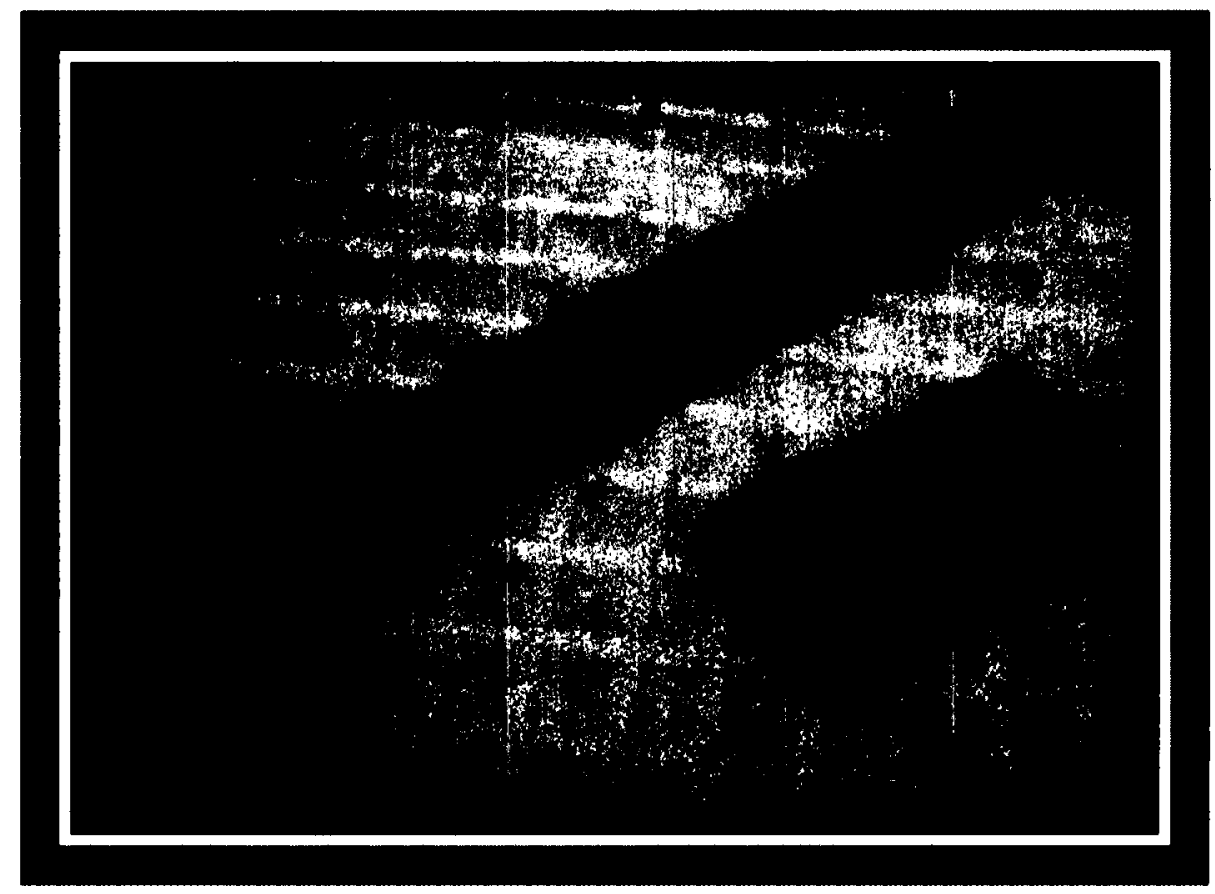

Figure 46. This is used to make fish nets. This is the needle (top) and this is the spool (bottom). You use twine to make a fish net. This was my grandfather's. It is maybe eighty or ninety years old. It is made of wood. They would have gotten driftwood from the beach or by going to Aberdeen Lake. I've never made fishing nets yet, but I have seen them being made. One day I would like to try using these tools. If I find the right things to use. 


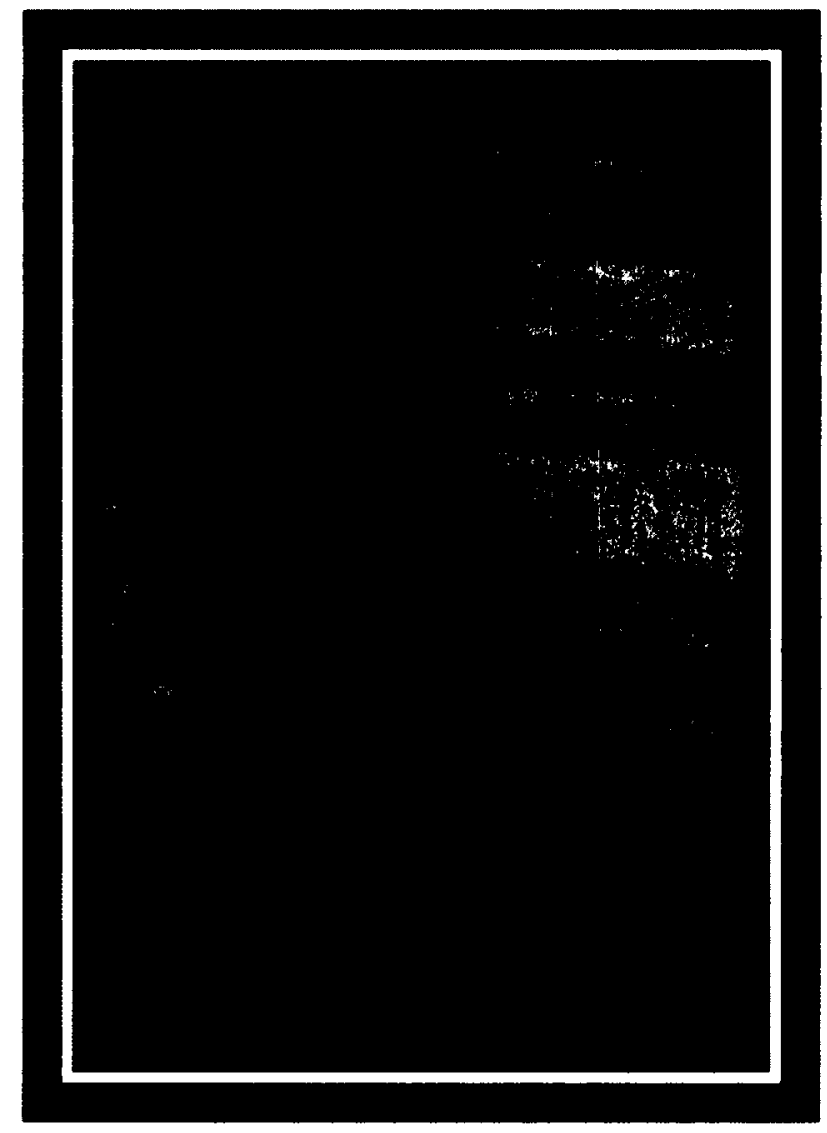

Figure 47. This tool is used to stretch out the caribou skin. You do the edges first. Once you are finished the edges, stretch the skin out lengthwise, then stretch it out the width wise until it gets soft. It's not an ulu (i.e. woman's knife). It was made from the metal from old drums. 

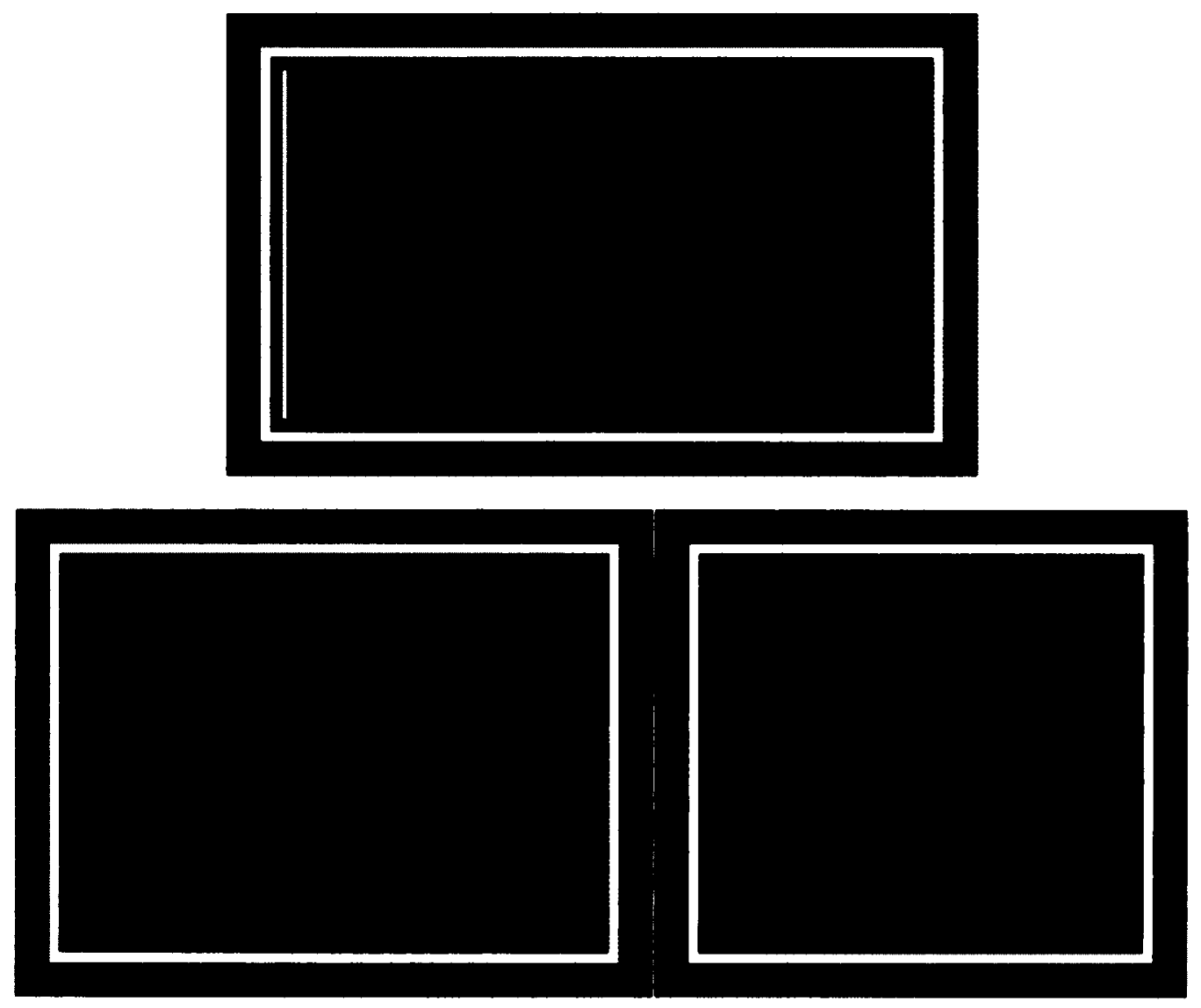

Figure 48, 49, 50. This tool is used for scrapping. It's for the last stage of working with a caribou skin. You finished stretching it, then you want to scrap it to take the dead skin off and to make it white. My grandmother made that one (top left; bottom right). It's made of antler and the blade is from an old metal drum. This one (top right; bottom left) was given to me. It's made of wood. You can see the difference. They are made to fit to the hand of the person using it. It has to fit right in your palm of your hand. Each one is custom made. 


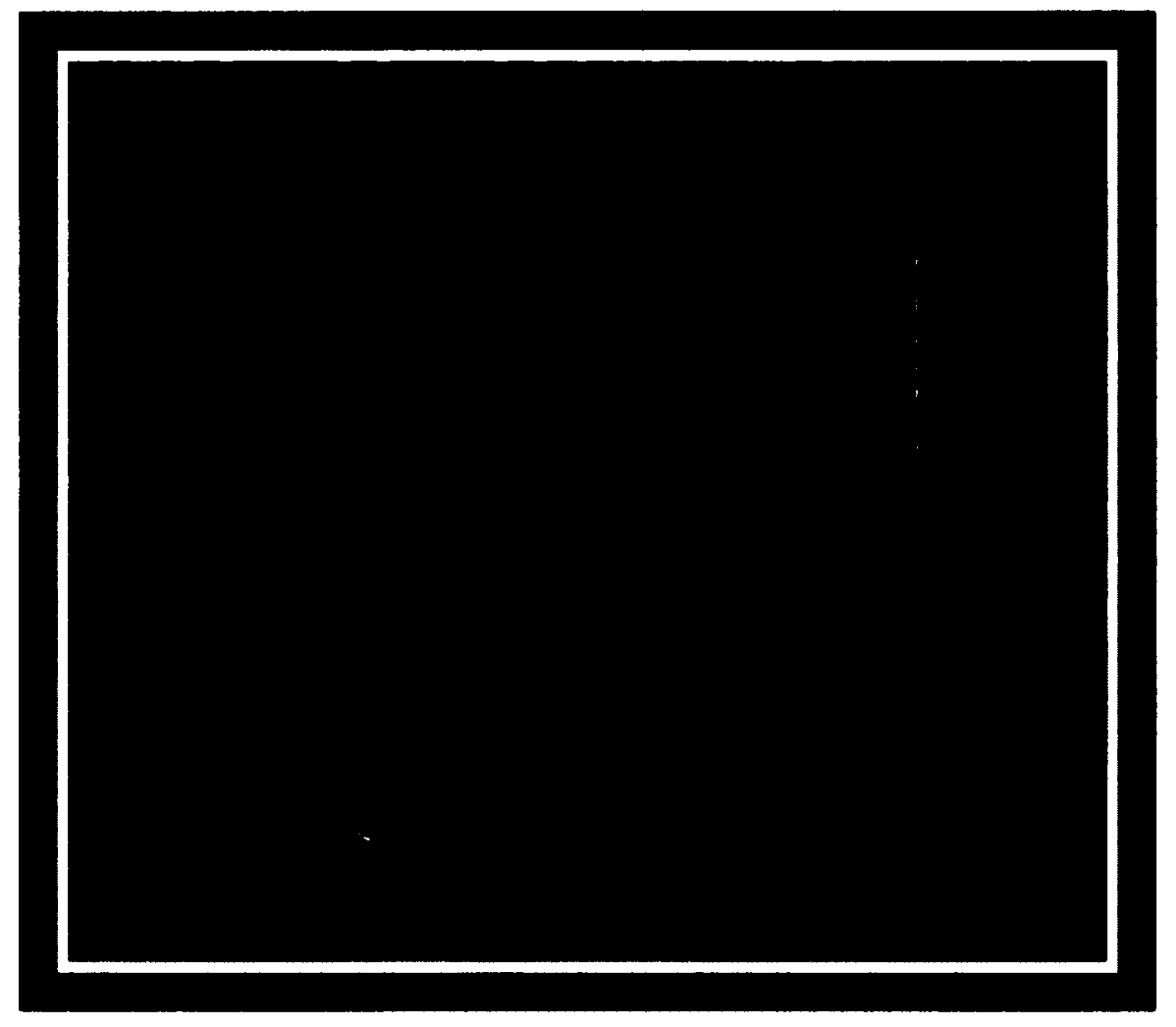

Figure 51. This is an $u l u$ (woman's knife). When you are cutting the skin we don't use scissors. This is for cutting the skin and meat. 

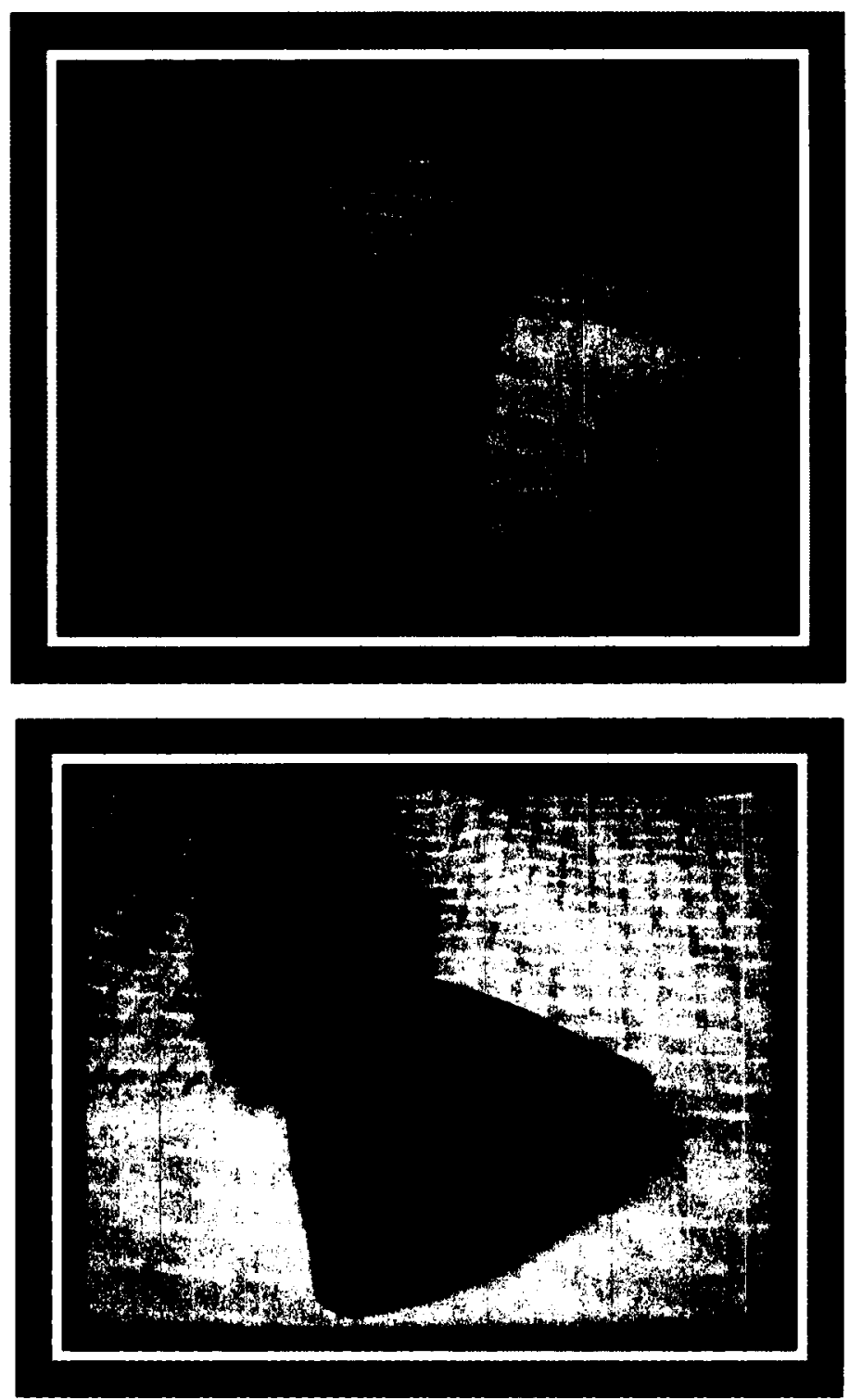

Figure 52, 53. They would use this tool to scrape the diaper. This is made from the dried hide of caribou and they took off the fur. My mother used it when the baby urinated, to take it out or to take the poop out. Take it out of the caribou skin. They would use caribou skin as a diaper. 

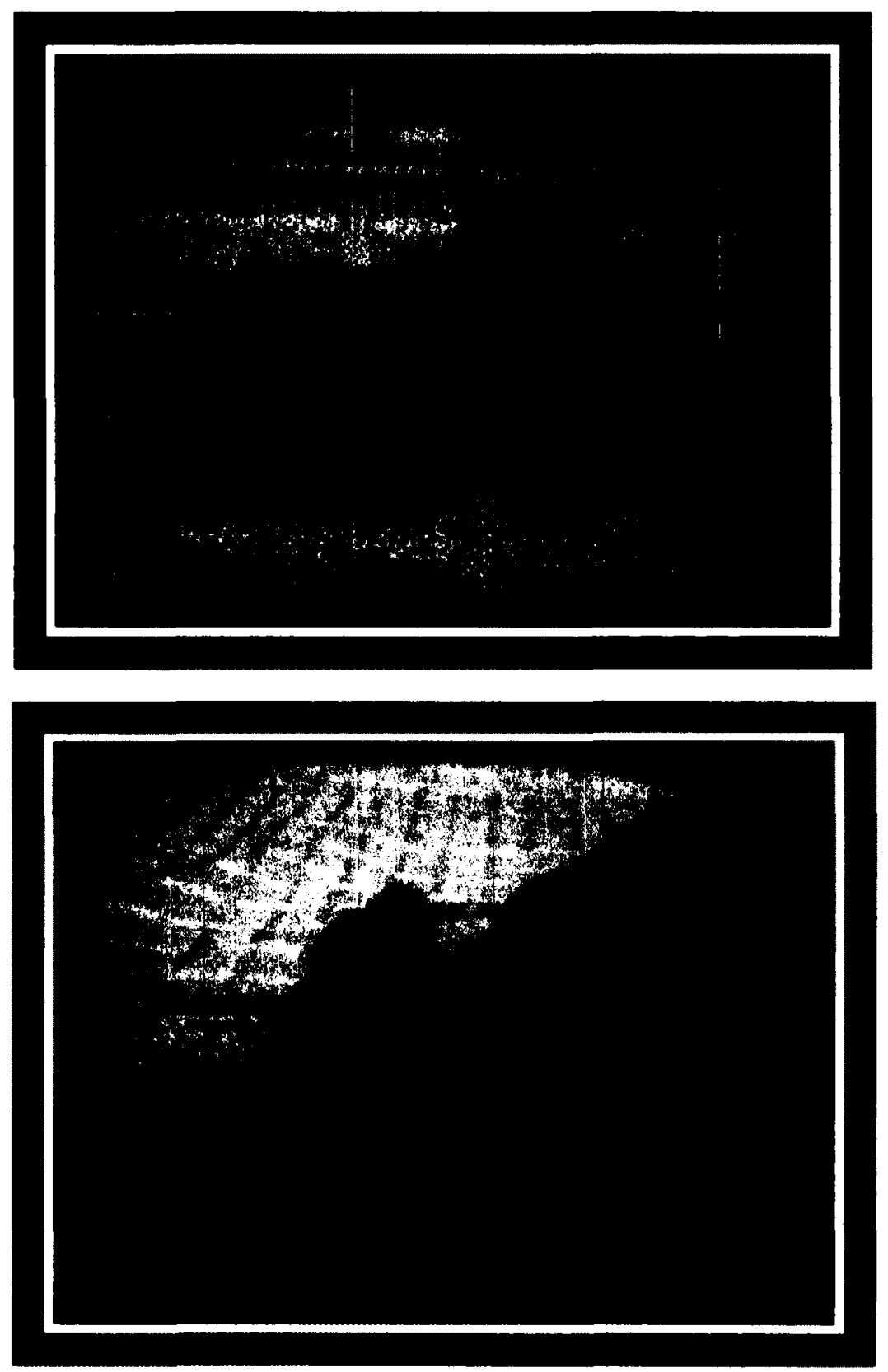

Figure 54, 55. Inuit moss candle. Moss from the tundra. You put it on a small piece of stone and it will burn like a candle. It will burn for a while because you put fat underneath and that fat will absorb into the moss like a wick. This moss was given to me by an old lady in Baker Lake and I still keep it. 

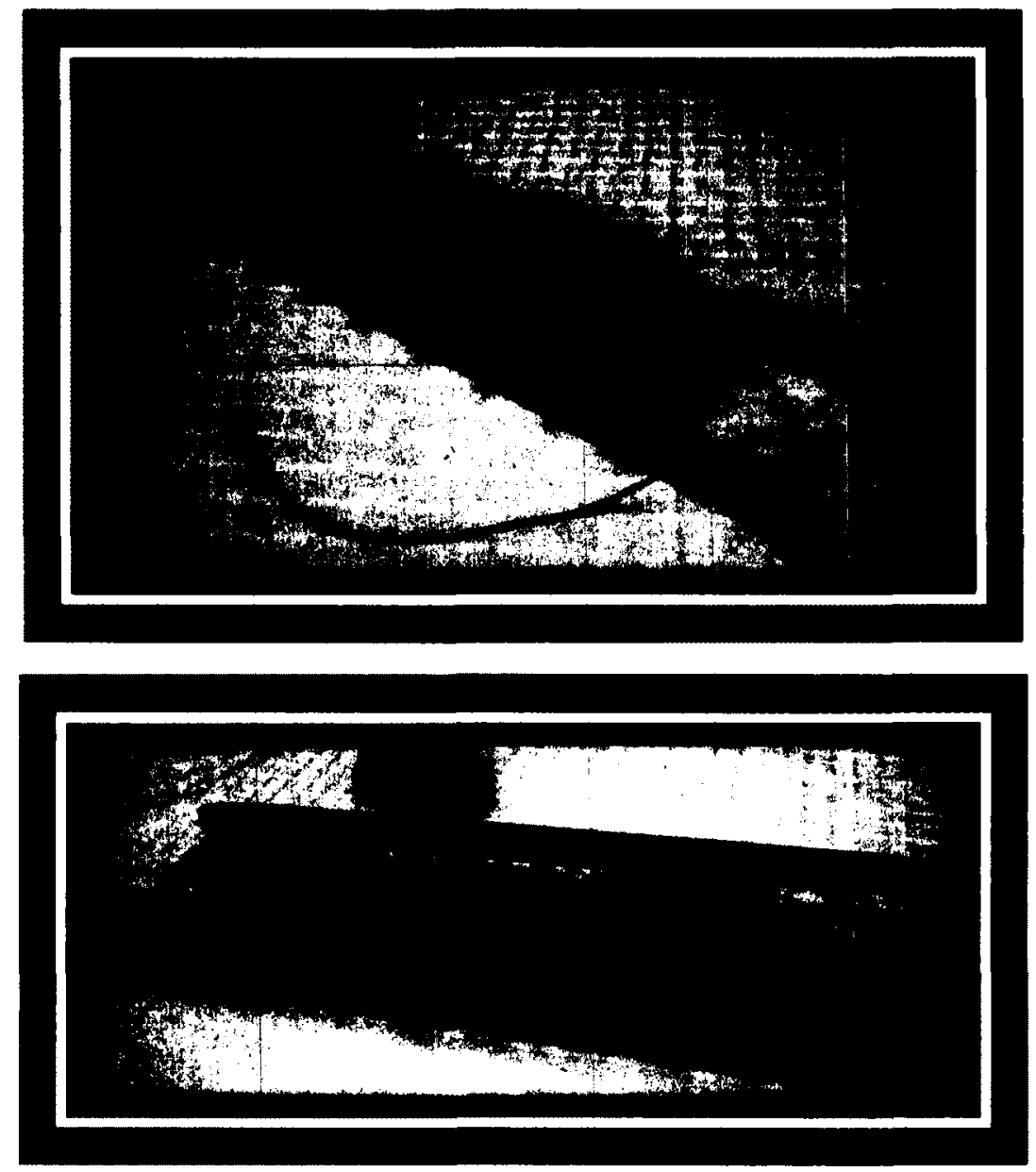

Figure 56, 57. Qamutik. I got recently. It was expensive! \$95! I got this from the hotel, Nunamiut Lodge. When you use qamutik, it's flexible. When you go on the snow it goes back and forth. Nowadays they make them higher and use runners instead of mud. In the old days they used to use natural mud from the ground and it would freeze. What you do is mix the mud, put it all along the bottom of the sleigh and once it's frozen you to smooth it out. You use polar bear or caribou skin to smooth it. Normally it would be mostly made of wood. In the old days when they didn't have wood they would use frozen fish on each side, put a skin on it, and they used that to pull things. If ever they could find antler or bone they would use it too. 


\section{Summary:}

Sally's direct knowledge and experience of the land primarily comes from the two years that she spent living at her grandparents' camp, after her father passed away and while her mother was down south being treated for tuberculosis. She credits her grandparents for teaching her about the land and the traditional Inuit way of life. She describes herself as someone that is "in-between" - she knows about Inuit culture but wants to know more. Her childhood experience has had a dramatic impact on Sally's life as an Elder. As indicated in the previous section, her wall hanging (see Figures 3-20) tells the story of how she arrived at camp, highlights some of the aspects of camp life, as well as some of the things she learned through observation and participation (e.g. how to shoot caribou). Even though Sally only lived on the land for two years, the land still has a "special" meaning for her. Before living on the land, Sally could not understand why her mother longed to live on the land instead of in the settlement of Baker Lake. However, after living with her grandparents, Sally finally understood what her mother meant. For Sally, the land is a place of belonging (e.g. "They called it our land"). The land is a source of survival (e.g. food, shelter, clothing), independence and ingenuity as Inuit derived what they needed from the land. The land is a source of knowledge to be passed between generations. The land is a source of values such as helping one another. Sally emphasized the importance of experiencing the land for oneself.

As an Ottawamiut Elder, Sally connects to the land as an Inuit cultural educator. She has a collections of teaching tools (see Figures 21-54) which have served not only to broaden her own knowledge of Inuit culture, but also that of other Inuit and non-Inuit. 


\section{Chapter Summary:}

In this chapter, we were presented with the narratives of Ovilu, Maria, and Sally, three Elders who reside in Ottawa. There narratives provide insights into the dramatic social and cultural changes experienced by Inuit during the mid-twentieth century when the federal government adopted policies which intervened into Inuit lives, the legacies of which Inuit communities in the North and South continue to struggle with today. Although their experiences are unique, and based on their individual circumstances and experiences, each Elder expressed a connection to the land that remains ever-present in their lives, even as urban Inuit. The land is important as a source of history, identity, knowledge and values which is not only significant for the Elders themselves, but also for the future generations of Inuit being raised in the South. The Elder narratives highlight the importance of 'Inuit place" in fostering connections to the land, specifically through local Inuit organizations, some of which the Elders helped to develop in the early days of their establishment. These narratives raise important questions about the connection between the land and identity for urban Inuit, as well as how urban Inuit maintain connections to the land while living outside the North. These questions are further explored in the discussion in Chapter 6.

Since these Elders have migrated to Ottawa, so too have an increasing number of younger generations of Inuit. Many leave their northern communities for the same reasons as their predecessors (i.e. education, employment, health care, following family, etc); and a growing number have been (or are being) raised in the South. These younger generations have access to programs and services that their Elders did not. This research is concerned with gaining a deeper understanding of the land for Inuit residents of 
Ottawa, and the role of urban place-making in fostering connections to land and the meanings, practices and values associated with the land. In the following chapter, we are presented with the narratives of younger generations of urban Inuit, in an effort to understand if the land continues to remain significant to these individuals. If so, how are these meanings created, and what is the role of urban place-making in fostering these connections to Inuit land and culture. 


\section{Chapter 5}

\section{Urban Inuit Perspectives on Land, Identity, and Place}

This thesis is concerned with gaining a deeper understanding of the significance of the land for Inuit residents of Ottawa, and the role of urban place-making in fostering connections to land and the meanings, practices and values associated with the land. As noted in Chapters 1 and 2, research shows a growing number of Inuit are being raised in southern urban centres. In this chapter we will examine the perceptions of younger generations of Inuit residing in Ottawa. These narratives demonstrate what the land means for younger generations of Inuit, some of whom have been raised in the South all of whom are raising children in the South. The narratives highlight the intergenerational similarities and differences with regards to relationships with the land. They also illustrate the ways in which urban Inuit connect to land and pass that knowledge on to future generations. Based on the narratives, the role of urban placemaking in fostering connections to Inuit land, culture and identity becomes evident. In addition, the narratives highlight the issue of urban Inuit rights and the equitable representation of Inuit by national level organizations, like Inuit Tapiriit Kanatami. In terms of structure, the chapter begins with a discussion of the land and the meanings of the land for younger generations of urban Inuit. This is followed by a discussion highlighting the complexities of urban Inuit identity as it is constructed in the South. The importance of community-based Inuit organizations is woven into these discussions. The chapter ends with a discussion of urban Inuit rights and representation. 


\subsection{Land}

When asked about the meaning(s) of the land participants' responses varied depending on whether or not they had direct experiences on the land in the Arctic. Those that had firsthand knowledge of the land, like the experiences documented with elders in Chapter 4, had more experiential and tactile memories associated with the land from which to draw meaning. Whereas for those participants whom had left the north as children and were raised primarily in the south, the meaning(s) of the land were constructed from a variety of indirect sources (i.e. relatives, Elders, community members, school, books, media sources, etc). In these cases, though firsthand experiential knowledge of the land may not have been present, the land was nonetheless identified as significant as a source of cultural and familial history, cultural symbols and practices, Inuit knowledge and values, country food, and language. Participants reported that these land-based elements provide the cultural base from which they are able to construct healthy Inuit identities.

For one participant whom I shall refer to as 'Cindy' 58 for reasons of confidentiality, who left her northern community at the age of six when her parents moved the family to a city in southern Canada, direct and personal memories of the land were difficult to recollect due to the young age at which she left the north. However, by listening to the stories of her mother she was impressed with the importance of the land and the role it played in her mother's life:

I totally get where the connection to the land is, and where it comes from. When my mom talks about her childhood, all of her best memories are on the land.

38 'Cindy' is an urban Inuit woman aged $35-45$. 
Traveling by dog sled, or skidoo, going from her home community to go visit relatives, and things like that. All my mom's favorite stories are the ones where she wasn't in the community. She would be out on the land, doing traditional things out on the land. (Cindy, Ottawa, 2012)

Cindy goes on to describe how memory and nostalgia associated with the land is stronger for those Inuit, like her mother, who were raised on the land. Despite living in the south of over thirty years, her mother still longs for the land, where she found a place of connection and understanding which urban living has not provided:

I think that if you've grown up on the land then you miss that. Like my mom, she's been living outside of the North for thirty-two years, and that's what she talks about. That's what she talks about missing, that feeling like she knows where she is. As opposed to living down here and feeling lost. It's funny, I think to myself, in such a big open space as she feels connected. And yet here there's more people to connect to, and yet you often don't feel connected. I think that's part of my mom's connection to the land, that connection through knowing. Knowing how to get from one place to the other. My mom still gets lost here in Ottawa. It's very difficult and different navigating the city. That's a big culture shock. The connection to the land is very important (Cindy, Ottawa, 2012)

Cindy goes on to describe how her connection to the land is distinct from her mother's, and elaborates about what meanings she draws from the land as someone who identifies as an "urban Inuk". Here we see how land values can affect behaviour:

I think for me because we left the North when I was six, I grabbed onto an urban setting. I feel really comfortable with the concrete. I don't have that same need to get out and go to the country. But I am very Inuk. I think for me, it's not so much a direct connection to land, it's what the land represents. The land is a source of values. Inuit have that sense of 'do it now', 'be in the moment' mentality. It's more about a free-flowing connection. Like for instance, 'the weather is good today, the hunting is good today, I'm going out.' Connections to the land offer an attitude towards things. Here we're really restricted in terms of our schedules. (Cindy, Ottawa, 2012) 
Cindy connects the meaning she has drawn from the land to the way Inuit lived traditionally:

Really if you think about it this way, Inuit traditionally did not live in communities. They constantly travelled. They travelled based on the weather, based on the animals' migration. Those were the predicting factors. I would rather walk than take a car or bus. In some ways I feel like that's where my connection to the land is. I love being out walking about. That I would rather walk. Enjoy the scenery rather than get there quickly. I think that's where I get are from. I can't sit still for more than 30 minutes. I think that's where I get it from, that Inuit get up and go. I think that's where my connection to the land comes from. (Cindy, Ottawa, 2012)

She continues her narrative by elaborating on her belief that connections to the land are more than physical. As an urban Inuk, understanding the role of the land in her own life has helped her adopt a philosophy which helps her cope with city living:

It's not necessarily being on the land physically, but understanding how what Inuit have learned from the land affects our lives, and recognizing what that connection is in your own life.

Western civilization is all this is your calendar. It's funny because I used to always get caught up being late and following the clock. Then I started working here (i.e. an Inuit organization). I realized that I was getting upset over nothing. In a grand scheme of things it was not important. So I took the watch off. That was about ten years ago and I haven't put one back on since.

Working here, I picked up that pattern, that philosophy that things happen and have their own natural way. You don't have to force it. And I think that point is you goes back to the land. You let external things help you plan things, not only your own internal desires. That's one of the biggest differences when people come here from the North. They have the hardest time reconciling keeping with the pace of life and scheduling in the south. Up north, if it was 24-hour daylight and your kid was playing outside at midnight, you don't get freaked out. (Cindy, Ottawa, 2012)

Cindy continues to describe how she tries to instill the importance of the land in her children, especially in terms of them knowing Inuit history and values associated with the land. However, as her children are being raised in the south, she is unsure what their 
connection to the land will be as they grow up. It is a process she is watching develop as her children grow:

It's hugely important. I get it. I understand why that connection to the land is important. I'm trying to foster that with my children. Learning about the land is definitely important in terms of history. Learning how the elders used to live on the land. It'll be interesting to see how their connection to the land develops. It's hard to know what the land will mean to them. We're just watching to see what it means as they grow up. But we're sure to provide them with a lot of examples, like that freedom and kind of letting things happen naturally. That philosophy of kind of going with the flow. (Cindy, Ottawa, 2012)

One of her children has been up north to visit with relatives while her other two children have not. The experience of visiting the north for her son left a lasting impression:

My oldest has been up north. He got to go visit my sister last year which he thoroughly loved. The first thing he said when he came back was: "Can we move there?" Up north he had a lot of freedom. For him, when he thinks about the north, that's what he thinks of. He thinks about having more freedom. He's twelve now, so we allow him to go around in our community in Ottawa, but he still has to check in every now and then. Up north, he loved was being able to go out and play without having an adult watching everything he does. So for him that's the connection he made. (Cindy, Ottawa, 2012)

While her other two children have yet to visit the north, she credits them as still developing strong connections to Inuit culture:

My younger two haven't been up north yet. What they've seen pictures. My middle child is the best performer I've got. He surprises me every time. (Cindy, Ottawa, 2012)

Another participant whom I shall refer to as 'Mary" ${ }^{59}$ described the land as a place of beginning, belonging and stewardship for Inuit:

The land is so important for Inuit. Very important. It's where life began for us. When I think of the nuna, I think of how we took care of it, how we took care of the land. There was no waste or garbage around. When I think of nuna, I think of

39 'Mary' is a pseudonym given to an urban Inuit woman aged 45-55. 
nunavinira which means, 'I used to live there' or 'It used to be my land'. (Mary, Ottawa, 2012)

For Mary, being on the land was connected to memories from childhood for which she was nostalgic. She associated the land with good mental health, quiet and cleanliness, the latter two of which can often be a challenge to find in urban settings. These memories and associations with the land helped her to deal with some of the challenges she encounters living in Ottawa:

What I miss about the land is camping. And helping my mother. I remember helping her with skinning sealskin. She would let me help a bit. Playing on the land. When I was growing up we lived in the settlements in Arctic Bay. At that time maybe for families were still living out on the land. It's so good for your mental health. You have less anger if you live on the land. You have a better mentality. It's clean, everything is natural around you. There's no noise except for the river. When I get sick of the cars and the bus sounds, I pretended it's the sound of a river. Because I'm not used to that. I'm not used to that kind of noise. (Mary, Ottawa, 2012)

The participant went on to share her most cherished childhood memory of being on the land with her family:

It was in 1963. I was five or six years old at that time. We went by dog team. I remember we went camping in May by dog team with my father's relatives. I think it's about 50 miles away from Arctic Bay. We stayed on the land until August. That is the best memory I have from my childhood. My uncle let me travel with him and his sled. We would see birds, animals like seal, wolf, and narwhal. We were there from May to August. (Mary, Ottawa, 2012)

The significance of this memory becomes clearer as Mary describes the horrific event which followed, during the autumn after the returned to Arctic Bay from their camping trip on the land. Her narrative demonstrates the traumatic impacts of the government's interference into Inuit lives: 
Then I remember that year in the Fall, like September-October time, I remember I was going home by myself and I saw these RCMP with these red suits and brown hats. I saw them, and they were killing the dogs. I remember the day they killed the dogs. It was windy and it was full of snow around. The dog was sleeping and he killed the dog. When I went home I felt so bad. I felt so bad about that dog. I love that dog. Probably it was our dog. I asked my mother why was he killing that dog. She said that they said they had rabies. In my mind even though I was six years old I thought to myself that doesn't make sense. I felt bad for that dog. (Mary, Ottawa, 2012)

The killing of the dogs had a lasting effect on her life, as she and her family lost their way of getting out on the land. Years later, while living in Yellowknife this memory would return to haunt her:

Then when I was in Yellowknife. I had a friend who liked to go camping. She expected me to know a lot about camping. But I didn't know a lot. I didn't get to learn all of that because our dogs were killed. We had no dog so we didn't go camping anymore. That was the last time I went camping, in 1963.

But I would follow my aunt when she would go term ptarmigan hunting around Arctic Bay by foot. And we would go boating but I don't remember going camping anymore. So, I didn't know about camping, I didn't know how to camp in Yellowknife. Without the dogs we didn't have a way to get out on the land. So I did not end up learning the things I could've learned out on the land.

I think what they did is a crime. It made me feel so empty. It made me feel sorry for my grandparents. Inuit did not complain they just listen to authority. Like they never said no or anything. They never complained. (Mary, Ottawa, 2012)

Now as an adult, she recognizes her desire to learn more about the land, the parts that she was deprived of as a child. Despite the events of the past, she has the sense that Inuit can reclaim and rediscover the things that were taken from them, and pass Inuit knowledge on to future generations. Mary illustrates how there are many lessons to be learned from the land: 
I lived in the settlement. That's different than people who lived on the land. I want to learn more about the land by reading books. I want to pass that knowledge onto my children, and keep it alive. We can have it back.

Children were good listeners back then. Women were leaders. They would organize the activities, and teach how to discipline the children. Inuit ways of parenting always work. We would learn to keep our land clean. Not wasting. There's a lot more to do. We can have all those values and lessons back. (Mary Ottawa, 2012)

Another participant, whom I shall refer to as 'Lucy ${ }^{60}$, who had been raised in the north and moved to Ottawa to attend university, described her connection to the land while she lived in the north as a given. That even in the community she was on ther land':

Naturally, living up north we were on our land. But I remember growing up we had a tent that I got, I was 11, and we were out by Sylvia Grinnell in Iqaluit, and it was me, my mom, and my older brother and we'd go fishing and just really good memories of that. We didn't go out hunting or anything like that we did little things like that. I missed that when I moved down. (Lucy, Ottawa, 2012)

Like other participants, she associated therapeutic properties with being on the land, experiences which she and her family try to replicate in Ottawa:

Being on the land, I think it's just like therapy. I mean, up North it is. And I think it's the same down here. It's nice to get out for picnics down here in the parks. Because you know, up north we do things like this a lot. (Urban Inuit Woman, Ottawa, 2012)

Similarly, another participant told me about a yearly camping trip her family would take each summer when she lived in the north. She has tried to go camping in the

60 'Lucy' is an Inuit woman aged 25-35. 
Ottawa area, but remarks that camping in the south isn't the same as camping in the north.

The most common association participants made with land were related to time spent on the land (i.e. hunting, fishing, gathering or camping), and to country food:

I miss country food a lot. I crave it. Store-bought food is from the farm, it doesn't smell right. I get country food from my son-in-law. And they share it at TI. Now I probably eat country food three times a month. (Mary, Ottawa, 2011)

Participants explained how consuming country food helped connect them to the land, and other values they cherished as Inuit such as sharing and gathering together. Participants were able to access country food through family members sending food to Ottawa, as well as through Inuit organizations. For instance, Inuit Tapiriit Kanatami is known for ordering country food and making available to its employees. Tungasuvvingat Inuit (TI) holds a country food feast once a month at St. Margaret's Church, in the Vanier neighbourhood of Ottawa, which is located right next to its Family Resources Centre and administrative building. For Inuit who do not have relatives or friends that are able to send them country food, having access to country food through community centres is critically important. There appears to be this understanding within the community as well, since those who do have access to country food tend not to attend these community feasts, so that those who 'really need it' get to have at least some country food. Needless to say, the monthly feasts are always very well attend, and it is not uncommon to run out of food.

Participants expressed their desire for their children to also eat country food. However, due to limited access it is often difficult to expose children to enough country 
food that eating it becomes habitual. Having limited access to country food can be a source of frustration. In addition to being associated with land and culture, country food is often perceived as healthier than store-bought foods. Despite having limited access to country foods, according to participants it is a tradition that will continue on with future generations of Inuit residing in Ottawa:

Country food was our main meal. Like narwhal, muktuk, seal. We used to eat it raw, frozen. My children ate country food when they were small. I tried to cut and serve country food for my children so they have healthy food. But they can't be reached rich seal meat now. They like caribou, boiled fish, and maybe young seal to. The food down here from the store is not that good for you. The meat has chemicals and preservatives in it. It bothers me that I cannot have country food every day. I wish you could have access to it every day. But it keeps going. Because my grandson eats country food. (Mary, Ottawa, 2011)

Younger Inuit being raised in Ottawa, in addition to being exposed to country food in the home if it is available, are exposed to country food as part of the programming at the Ottawa Inuit Children's Centre. Learning about the land and the various practices, symbol, values, and meanings associated with the land is particularly important for those Inuit being raised outside of the north. As stated by the following participant, Inuit have entered a phase in their history were generations will be born outside of the northern regions:

When I look at generational differences, everybody develops their own connection to the land. When you get to my age, we're getting into people that have been born outside of their region. So there is this growing population of people who don't have any physical connection to the north. Because they have been removed from it either by choice or by force. So I think that we're entering a different phase. But then I think of my friend, who raised her son here in Ottawa. This year for his birthday he wanted to have an 'Inuit party' with all kinds of traditional games and arts and crafts, all kinds of cultural things. And that came from her son who was born and raised here. He learned those connections here, on his own. (Cindy, Ottawa, 2011) 
It should be noted that while twelve participants were interviewed, the quotes in this section rely heavily on the responses of three participants in particular. The other participants' responses reflected similar themes as those represented in the quotes above; however, the quotes above were selected for their clarity and specificity.

\subsection{Identity}

Identity was a major theme which emerged from the interviews with younger generations of urban Inuit. Being raised outside of the north, immersed in mainstream society can present many challenges to forming an Inuit identity. For instance, Cindy explains how growing up in the Edmonton, surrounded by negative stereotypes about Inuit culture, caused her to disassociate from her Inuit heritage. Her sense of cultural shame grew so deep, she began to identify as Chinese rather Inuit:

The first place we moved to after leaving the north was Edmonton. I believe that Edmonton was an extremely racist place. We had negative experiences with the people in our neighborhood, with the kids at my school. They made comments and stuff. Some of them I still remember. I remember one day I brought a friend home from school and my mom was eating seal. My friend got freaked out and grossed out. She went back to school and told everybody how gross it was. So, being Inuk became this really negative thing for me.

Living in Alberta was negative. There was a lot of negative stereotypes there. The only Inuit I ever saw were drunks on the street. There was the perception that Inuit were so far behind, like we still lived in igloos and used dog sleds. Those are great parts of the culture and the history. But when you are living in a society where everyone has the coolest car and the newest thing, all of those other things can seem outdated. I didn't want to be connected to those stereotypes. I think maybe if we had moved anywhere else in Canada, the shame I felt might have changed. Once we left Edmonton things got better but I still had the pattern of not identifying as Inuit.

In Edmonton, there was a large Chinese community. At the time, it was really cool to be Chinese. Because they have Chinese New Year, they had Dragon dances, they had astrology and all those cool things. That's when I actually started to identify with being Chinese. (Cindy, Ottawa, 2012) 
For Cindy, not all of her negative feelings toward Inuit culture came from the racism she endured growing up in Edmonton. In hindsight, she realized that many of her negative self-perceptions about being Inuit were passed down from her mother's low self-esteem. Her mother had experienced the traumatic impacts of the government's interventionist assimilation policies. The legacy of these experiences had lasting effects, as the negative perception's Cindy's mother internalized, were later passed onto Cindy herself:

I've done a lot of retrospective thinking. My mom didn't speak English until she met my dad. She was born on the land and didn't go to school until grade four. She went for a year and then my grandparents hid her so she wouldn't have to go back to school, so she could stay home and help raise the younger children. At some point she met white traders, and got in her head that they lived a better life. From a certain point in her early development, she decided that she didn't want anything to do with Inuit culture.

If I look back to what my beginning was like and the low self-esteem I had about being Inuit, it's because basically in school she was told that 'You're a savage. You people don't even speak a real language. You don't eat real food.' Everything about her personal fundamental way of life was knocked down over and over. I can understand why her self-esteem was so low. Without her self-esteem being strong enough, she wasn't able to give that to anyone else. Not to me or my sisters.

However, receiving positive reinforcements from a high school teacher caused her to acquire more knowledge about her Inuit heritage during university:

Now I identify as an urban Inuk. But, up until I was about 18 or 19 I tried to pretend that I wasn't even Inuk. It wasn't until I was about to leave high school that I had a really awesome teacher that made me start to believe that my culture was actually an exciting culture. Growing up, there were a lot of stereotypes. So, when my teacher was so excited about my culture, it made me think maybe I should learn more about my culture. Things just kind of grew for me from there. (Cindy, Ottawa, 2012)

In university, rooming in a residence with other Inuit gave her the opportunity to learn more about her background in a safe environment with her peers. Together they started 
an 'Inuit club' and organized a trip to the Inuit Circumpolar Conference, which was a cultural experience which marked a turning point for her:

I had nothing to do with Inuit until I went University. I realized there was so much I didn't know, and I felt like I should know. My first year I lived in a residence, and three of us were Inuit. We thought, 'Wow, this is really unusual!'. So, we shared experiences. The other two came straight from the north. I helped them get adjusted to living in an urban setting.

We started an Inuit club. That first year we raised money to send to people to the International Circumpolar Conference. I was one of the lucky ones. We met Inuit from around the world. I remember one night where people were sharing their talents. There were Russian throat singers, there were drum dancers, all these people that had traditional talents. The whole time I thought to myself, I don't know any of this! That sparked my interest when I went back. When I went back I thought to myself, I want to learn more about this. I took Native Studies as a minor in University. For every project no matter what, it was I focused on Inuit. And I got really good marks. Which probably added to the positive reinforcement that I was learning something. (Cindy, Ottawa, 2012)

Being able to learn about Inuit culture in University started to fill the knowledge she felt she had, while at the same time changing some of the negative perceptions she held about Inuit culture acquired while she was growing up. Initial connections to Inuit culture fostered through academic work were strengthened while she interned at local Inuit organizations in Ottawa, Tungasuvvingat Inuit and the Ottawa Inuit Children's Centre, during the summer holidays. It was through this direct contact with Inuit organizations that she was able to participate in the community side of life with other Inuit residing in Ottawa. Upon completion of her undergraduate degree, she decided to settle in Ottawa and work at Inuit organizations. Being embedded within the urban Inuit community in Ottawa gave her the opportunity to develop her identity as a young urban Inuit woman. Without having connected with Inuit organizations in Ottawa, she admits that the path she has travelled towards a healthy sense of identity may have turned out very differently: 
When I graduated university I had a bit of cultural knowledge from the courses I took. But coming to Ottawa I realized there was a lot I didn't know. And becoming connected to the Inuit community through the Headstart program teaching young kids about Inuit culture. That really helped make connections to the culture for me. That's kind of where it started for me.

So it's been a journey and a process. I've had a chance to look back and see where the change started. You know I've gone from being in kindergarten and having a bodyguard walking me to school because I got beat up by both Inuit and the nonInuit because I did not fit in.

Had I not got connected with Headstart I don't think I would be on the same path I am now. Witnessing firsthand how Inuit culture was being fostered to young children so strongly here though OICC, that helped me realize I want connections to my culture and its helped me be stronger. Now I am much stronger and comfortable in my own skin, so I can pass that along to my kids. (Cindy, Ottawa, 2012)

Other participants remarked on how negative stereotypes about Inuit have affected their own sense of identity, and that of their children. Younger generations of Inuit, particularly those being raised in the south, face the challenge of being 'caught between two worlds'. However, as identified in the quotes below, many Inuit have started to recognize the injustices they suffered as youth, and reclaim their sense of identity by drawing upon Inuit knowledge and history:

I thought Southerners were better. We learned that in school . But they were not. At school our teachers were not nice. I felt dirty, I felt hurt. They even called us savages in books. The people in the universities call us noble savages. But it's not true. Why did they ever say that about us? It's racist. White society made them think that way. I learned that it's not true, we are not savages. But I believed that as a child. We felt unworthy. Our self esteem went away. But now I know there could be many books written about the Inuit language, about Inuit clothing like the amauti, about igloos, about qamutik, and qulliq, and traditional medicine. There is a lot of information, a lot of Inuit knowledge. Inuit can survive in a harsh land, Inuit made our own games, Inuit have good families, we invented igloos, and even know which edible plants to eat. (Mary, Ottawa, 2012) 
I made mukluks for my daughter, but she didn't want to wear them to school because she was ashamed. She had heard that the world and the government did not have respect for us as Inuit. The children can be caught between two worlds: the old world and the new world. What's most important to teach children, the first thing to teach them, is self esteem. My daughter learned to have self esteem over time. (Debra ${ }^{61}$, Ottawa, 2011)

When asked about what it means to identify as an 'urban Inuk' participants stated that it was distinct from being an Inuit born and raised in the north. Living as urban Inuit in Ottawa is often described as 'the best of both worlds'. Inuit residing in Ottawa benefit from all the opportunities which come with living in the city, while also never being far from a vibrant and social Inuit community. Furthermore, due to the size of Ottawa and the anonymity that comes with living in a city, individuals are able to choose when they want to immerse themselves in community life and when they would like to step away, which is virtually impossible to do in smaller northern communities:

Being an urban Inuk is definitely different than being an Inuit born and raised in the north. I've lived outside the north for the majority of my life. I've spent the past thirty years living in urban settings. So, that's where my comfort about being an 'urban Inuk' comes from. You know, like living in a city, being around lots of people and cars and traffic and all that sort of thing. This is what I'm used to. But, I also identify with the culture. Living in Ottawa is a nice combination of both. I can be part of the community when I want to be, but I can also step away from it when I want to. That's really important when you look at how small our community is, and how you can end up living in a fishbowl. So, for me it's really the perfect combination. For example, where I live there aren't a lot of Inuit, but it doesn't take me long to be around other Inuit. It's one of the things I really feel like I benefit being an urban Inuk. I can judge where I want to be. I am quite happy to identify as being Inuit. But I also really love being urban. So being an urban Inuk really sits well with me. In fact years ago a friend of ours made T-shirt and I still have it, and it says lifelong urban Inuk. (Cindy, Ottawa, 2012)

${ }^{61}$ 'Debra' is a pseudonym given to an Inuit woman aged 45-55. 
Living outside of the north, urban Inuit have fewer opportunities to engage in activities which can help to strengthen and reinforce their sense of Inuit identity. For instance, while eating country food may be part of everyday life in the north, access to country food in Ottawa is limited. Despite this challenge, the participants I spoke with expressed a deep sense of pride at being Inuit. Their sense of identity was not diminished because they ate country food once a month at a community feast, as opposed to once a day. For these participants, it was not the frequency of their participation in culturally significant practices which reinforced identity, but rather access and participation itself, however frequently or infrequently, that mattered. For instance, one participant spoke of her love of throat singing as being important cultural identity as an urban Inuk even though it had been five years since her last performance. She explained that for her, throat singing itself was a powerful cultural practice that is distinctly Inuit, thus her identification with throat signing reinforced her sense of identity. Participants explained that when it comes to participating in activities which reinforce their sense of Inuit identity, they "do the best they can" at making the most of opportunities which arise in the community. Participants spoke about the importance of sewing, drumming, throat signing, eating country food, wearing traditional clothes, attending community events and speaking Inuktitut:

There's definitely resurgence in our cultural pride where now it is cool to be Inuit. But there is definitely a period where it was like no way did you want to be Inuit. I identify with my culture through drum dancing and throat singing, those are core things about who I am now. My involvement in performances it all started out here at the OICC. (Cindy, Ottawa, 2012)

I have a strong sense of Inuit identity and I'm never not going to feel that way. I think I've improved a lot. When I lived in Arviat I learned how to make parkas 
and I got more into garment making. Coming down here, I've still been sewing. (Lucy, Ottawa, 2012)

As mentioned previously, speaking Inuktitut was identified as being an important, albeit contentious, aspect of identity for urban Inuit. Participants expressed their desire to keep speaking Inuktitut, and also to teach their children the language because it is a significant aspect of Inuit culture. One participant expressed worry at the decline of her fluency in Inuktitut after living in the south for ten years, as she sometimes struggles to "find the words" when conversing with other Inuit. This participant, who was pregnant at the time, expressed a great desire to teach her daughter, who will be born and raised in the south, Inuktitut: "It's important she speaks our language". The issue of how language ties into identity for urban Inuit is often complex, especially for those who left the north as young children or were born and raised in the south. Inuit Participants who were not fluent in Inuktitut often felt judged by other Inuit, despite their cultural literacy in other areas:

I think that sometimes where people get the idea that our identity as Inuit is diminished is from the loss of language. Growing up in an urban setting, I didn't need to speak Inuktitut. I didn't have anyone else to speak to besides my mom. I think that's where a lot of urban issues come from. It's not so much the cultural stuff, we can participate in all of those things. We can order the food, we can order the clothes, we can look at videos, and all that stuff. For language it's a personal thing. I think it's the language where it's the toughest link to keep. (Cindy, Ottawa, 2012)

The role of community centres plays a significant role in providing services and support for cultural activities, and though this area shall be developed further in the thesis, it bears mentioning here. Community centres are often spoken of in relation to language. The following participant, who left the north as a young child and is now 
learning Inuktitut as an adult, explained how despite her participation in language classes offered by the Ottawa Inuit Children's Center (OICC), she feels intimidated to speak in front of other fluent Inuktitut speakers for fear of being judged as not "really Inuk":

I've taken three sessions in the last five years. When I'm in the class, I get it, I understand. I get really motivated. But as soon as I'm in front of someone that speaks Inuktitut fluently, I get really shy, I'm too shy to actually use it. So that's an area where I really feel like some people judge me. They judge whether I am really Inuk, or whether they consider me to be Inuk. It's because I don't have the language. (Cindy, Ottawa, 2011)

Another participant who was learning Inuktitut as an adult expressed her desire to learn the language because she saw it as an important link to culture. She credits the language classes offered by the OICC for giving the opportunity to learn Inuktitut while residing in Ottawa. However, as in the quote above, this participant worried about embarrassing herself when speaking to fluent Inuktitut speakers:

For me, I don't speak Inuktitut. I know little bits of the language. And I've been learning more here and there. I've been taking classes and I really want to develop so I have that link to the culture and the language. That's really important. I've learned four different dialects to say 'thank you'. I've learned the proper way to say 'Iqaluit' so I'm not embarrassing myself or my family by saying it wrong. (Cindy, Ottawa, 2012)

The language classes offered to adults and children through the Ottawa Inuit Children's Centre make learning Inuktitut in Ottawa possible for both adults and children. This is particularly important for urban Inuit that do not speak Inuktitut at home:

For those that don't speak Inuktitut in the home, having Inuktitut class is an essential service in order to have the connections to the culture and language. There are kids that are adopted into non-Inuk families, and kids that are in foster care, or kids who have one Inuk parent and one non-Inuk parent. (Cindy, Ottawa, 2012) 
Despite the positives of having access to Inuktitut language classes in Ottawa, the classes are often offered in a sporadic way:

Inuktitut classes in Ottawa, they are sporadic. They depend on funding in order to be able to implement the classes. It's a major challenge. The longer and longer we go without classes in the morning more we forget. (Cindy, Ottawa, 2011)

The major barrier to local organizations offering consistent Inuktitut classes to the public is adequate and consistent funding, an important point that shall be revisited further along in thesis.

An added issue in terms of language is the matter of dialect. There are regional difference to the way Inuktitut is spoken in different regions across Canada. However, the majority of Inuit residing in Ottawa come from Nunavut, leading to the unintentional favoring of Nunavut dialects:

We have the whole added factor of dialect. I speak South Baffin. That's where my mom's family is from, that's the dialect I want to learn. I'm not opposed to learning other dialects, but my preference would be if this is how they say it in South Baffin. When you're speaking to a person from Keewatin region and they don't understand you. It's completely different. An Elder from Labrador was telling me how she could speak to someone from Russia, a Russia Yupik, but she couldn't speak to someone from Nunavut. That's the dialect difference. (Cindy, Ottawa, 2012)

As evident in the quotes above, challenges associated with being an urban Inuk, and asserting one's identity, often comes from within the community itself. Unlike northern dwelling Inuit or elders, who's "Inuitness" is never called into question, urban Inuit often feel judged, and feel the need to prove themselves to other 'real' Inuit. Urban Inuit are often criticized by elders and their northern counterparts as living in a 'different world' in the south, as having a 'different understanding of Inuit customs', as well as having 
'different manners'. In conversations with other community members, I've heard it said that urban Inuit "don't do things right, but it's not their fault. They just don't know." Judgment and rejection from one's own community can be the most difficult aspect of forming one's identity as an urban Inuk. Thus, urban Inuit often travel a more challenging path towards self-identification and self-acceptance:

I think up north they take it so much for granted. They take their identity for granted. They feel like they don't have to prove anything. They don't have to make sure that the culture is there. It's just a given.

Being an urban Inuk, probably the hardest part is the rejection from your own community, as opposed to others. That's probably been the hardest part for me. If I say something and if someone says to me, 'you're not even really Inuk'. Or when they make comments about me in Inuktitut and think I don't understand them. Who gets off making those decisions? Who decides who the real Inuk is anyway? As long as you're person than you're real.

Those are the hardest comments for me. But I'm in a totally different place now. Ten years ago I would've cried. Now I'm like who cares, get over it. If you don't like it then don't listen to me. I'm in a totally different place where I can let that go, where I wouldn't be able to do that before. Before when strangers would make comments it would affect me. But now I can let it roll off my back. Now I'm at the point where I understand that people are not just one thing. We don't identify with just one thing. It's taken me a long time to get there though. (Cindy, Ottawa, 2011)

For Cindy who was learning how to throat sing negative comments from other

Inuit undermined her desire to reclaim and learn an aspect of the culture:

For me when I was first learning what probably killed me the most was when people judge me and said you're not doing it right. Or said why you singing that you're not even saying it right. Those comments coming from other Inuit that was probably harder to take than someone on the street yelling at me, 'You dirty alcoholic'. (Cindy, Ottawa, 2012)

This was a lesson that reminds her not to do the same to the Inuit youth performance group she now works with: 
With this youth group performance group, I want them to take the reins and do their own thing. To take a traditional song and incorporate their own voice, or whatever they're into right now, and make it their own. I'm not a stickler for 'this is the way it's always been done'. I'd rather they know how traditionally it was done, and then make it their own. (Cindy, Ottawa, 2012)

In the face of scrutiny, urban Inuit living in Ottawa have the opportunity to challenge the way things have been done traditionally, draw on those traditions for cultural inspiration and grounding, and develop their own ways of doing things which are relevant to the lives they lead in the south:

Some people tell me I shouldn't drum because I'm a girl, and then other people think it's great that I'm drumming because I'm a girl. I would never say quit doing it or you're not doing it right because you're a girl. (Cindy, Ottawa, 2012)

Following a similar vein, one participant who I shall refer to as 'Carmen",62 remarked on how the cultural generalizations Inuit make about one another can serve to exclude urban Inuit and the ways they connect with the culture and their identity:

It really bothers me when people say "Inuit we do this". I disagree. I would say some Inuit or maybe most Inuit. The only thing you can say everybody does is breathe. There's definitely some generalizations that kind of identify us as a whole but I'm very careful as to recognize that we're still individuals within the community. Sometimes we pretend like the things we do are all the same for cultural reasons. That's one thing I'm being a lot more conscious of when I talk. I say that it's for my own experiences to make sure that I'm not generalizing. For instance, most Inuit do like fish. I'm one that doesn't. It doesn't make me less Inuit. So that's been an eye-opening experience for me being an urban Inuit, I try not to make generalizations. (Carmen, Ottawa, 2012)

The issue of appearance can also present a challenge to urban Inuit wanting to assert their cultural identity. Cindy explains how she sometimes catches herself stereotyping her daughter, whose father is non-Inuit. As a mother, she worries her

62 'Carmen' is an Inuit woman aged 25-35. 
daughter will come to think that she is 'less than' because she does not look like most Inuit:

I think another important thing is to stop identifying the way you look with who you are. I think that's something that in our community we need to address as well. We need to stop equating what we look like with who we are. For instance, my daughter is Inuit but she's got blonde hair and blue eyes. I catch myself calling her my 'blonde hair, blue eyed Inuit'. I find myself stereotyping her. She might be getting the message that you have to be black haired and brown skinned to be Inuit. I catch myself, and I'm really trying to stop doing that. I don't want her to think that because she has blonde hair and blue eyes she is less. Appearance goes a lot into how you identify.

I wonder if it makes her feel like less than others. I know it doesn't make her less. She eats the most country food. She knows the most Inuktitut songs. She's the most Inuk child if you want to give 'Inukness' a percentage value. It's her. And yet I'm diminishing it because she's got blonde hair and blue eyes. (Cindy, Ottawa, 2012)

Carmen emphasizes that when it comes to connecting to culture and finding one's identity it is more to find a way that works, as opposed to doing things the "right" way. This statement acknowledges how life for Inuit living in Ottawa is different than for those living in the north, and so connections to culture require a certain fluidity while not losing their significance:

When you come here to Ottawa things are a bit different. I'm able to see what my mom had to go through, I see where my kids are, and we're trying to find out what works right now. What works right now isn't necessarily what's going to work 15 years from now. It's more fluid and dynamic. (Carmen, Ottawa, 2012)

As noted in the quotes above, the process of northern and urban Inuit culture coming together is not without its challenges and negotiations. For some Inuit this highlights where the Inuit community in Ottawa is at the moment. That is, the Ottawa Inuit community is in the process of figuring out what its identity is collectively. In order 
for acceptance to prevail the following participant states the need for setting aside judgments and prejudice:

I think one of the things that Inuit community in Ottawa is trying to work out is what their identity is collectively. The majority of the abuse comes from within the community. I think of the comparison of Black-on-Black hate in the United States. They're basically fighting amongst themselves. I see that here. Like the whole, 'She speaks Inuktitut so she's a real Inuk. She doesn't speak it, so she's not really Inuk'. The biggest thing is you're from Nunavut you're from Labrador. Most people who end up in Ottawa come from Nunavut, and they have total disdain for people from Labrador. I understand that their traditions and languages are very different from other Inuit, also because of the fact they were assimilated a hell of a lot earlier than other Inuit. What I don't understand is where the hate comes from. Why people from Nunavut would hate people from Labrador. To me that doesn't make sense. Or when they say Inuit from the Western Arctic are more like First Nations and are not really Inuit. Comments like that just don't make sense. (Cindy, Ottawa, 2012)

The path towards self-acceptance can be more challenging for urban Inuit, however, as the following participant highlights below. Ottawa is a place where Inuit can plant roots, ground themselves, and find a way that works best for them:

The way I look at it now is that I have the best of both worlds. I'm comfortable. I feel like I really know my Inuit side. And I found what works best for me. And I'm comfortable. And every year I'm here the more I realize that I really grounded myself here, and I've grown from where I started from. And that's what I see my kids doing. And they'll be able to dig their roots even deeper because they started before they were even born. (Cindy, Ottawa, 2012)

The quote above also highlights the importance of imparting self esteem and a sense of culture to urban Inuit children who have been raised in the south. According to participants, Ottawa is an ideal city in which to raise children due to the programs available, such as the Head start program and kindergarten run by the Ottawa Inuit Children's Centre, and the sense of community organization present in Ottawa. By 
having access to these culturally-specific programs children being raised in Ottawa are offered a cultural base from which to build their identities and self esteem. In doing so, participants hoped this would mean their children would have an easier time finding their sense of self:

Growing up without identifying with the culture, and trying to be other things trying to pretend to be other things I don't want that for my kids. Having such a strong community base here in Ottawa I think it's giving that to them that support from the culture. (Carmen, Ottawa, 2011)

I hope that my kids don't struggle the way I did. I hope because they have strong cultural base now, they won't be finding it when they're in their 20s like me. I hope they're able to handle things and find their own way of doing things their own identity. The only reason my kids have such a strong identity with Inuit is because we have the centre. I think programs like the things that the OICC does it definitely helps, and goes the longest way into ensuring that cultural base.

I always share the story of my son, when he was in grade 1 and he got into a fight with the substitute teacher. She was talking about cultures. And she asked him, what are you? And he said, I'm Inuit. And she said, no you're not! He's the blonde one [son]. And he said, yes I am. And he and she said no you're not. I think back to me at the same age as him; there's no way in the world that I would have said, I'm Inuit! So, you know I think there are great things happening. I look at my children and how they love to do presentations. They love wearing their Inuk clothes.

My little one she loves to eat country food. She can't wait to eat it. The other day, she was all dressed up in her Inuit clothes sitting on the floor eating the country food with blood dripping down her face. That is such an urban Inuk thing to see! At school she understands when the teachers speak to her in Inuktitut, and she responds back. She likes being called her Inuk name. Those are things that I feel being here in Ottawa I've given her. (Cindy, Ottawa, 2012)

\subsubsection{Identity and Urban Inuit Rights}

For many urban Inuit the issue of rights is closely connected to those of identity and land. The following participant describes how her persistent representation of urban 
Inuit issues lead to their inclusion by Pauktuutit, the national organization which represents Inuit women across Canada:

For me urban issues are a huge part of what I identify with as an urban Inuk. Urban issues are huge part of what I think needs to be emphasized. I worked at Pauktuutit several years ago, from about 2006 two 2008. Before I worked there I know they weren't addressing any urban Inuit issues. Not at all. But I kept kind of nagging the executive director saying it's great that we're doing all of this work in the northern regions, and yes they need that representation, but I kept telling her we have the same problems here. I mean they're different, in the sense that we have a lot more support services here. We have access to more services in general here in Ottawa. But I still kept telling them urban issues we need to start addressing these things. Finally the executive director said 'okay, you have to handle the urban file then'. (Cindy, Ottawa, 2012)

Despite being beneficiaries of the Nunavut land claim agreement this participant lost their right to vote in Nunavut elections and also was not eligible to access educational dollars through Nunavut Tunngavik Incorporated (i.e. the organization responsible for implementing the Nunavut Land claims agreement) which would have assisted the funding of her postsecondary studies:

And that's when I started doing my work and realized all the land claims to have a caveat about urban Inuit. Right now ITK (i.e. Inuit Tapiriit Kanatami) represents the four regions. And in all four regions to in their land claim agreement talk about urban Inuit. The best one is definitely Labrador Inuit, they are allowed to vote. But they were the last ones to get their land claim agreement so they learn from everyone else. Labrador is the only one that's really tried to move forward and keep their membership no matter where they live.

Essentially, I have some benefits with the Nunavut land claim, being a Nunavut beneficiary. They do have provisions for urban Inuit, like I can access discounted rates on airfare to go visit home, and there's bereavement travel, and obviously getting my NTI card to prove that I'm a beneficiary of the Nunavut land claim. And I've registered my children as beneficiaries of the land claim. But I lost my right to vote, by not living in the territory. They have money they can access. They have education dollars they can access. (Cindy, Ottawa, 2012) 
There is the perception among urban Inuit that national level organizations know about their existence and their needs. However, at the moment there appears to be less time and energy focused upon addressing urban Inuit issues. The urban Inuit I spoke with understand that national level organizations which represent Inuit interests such as Inuit Tapiriit Kanatami and Pauktuutit are often stretched focusing their attentions on the four northern settlement regions. However, as urban populations of Inuit continue to grow, in some cases larger than many northern communities, they argue that their interests need to be considered equally. At the moment, in Inuit Tapiriit Kanatami deals with urban Inuit issues by supporting and referring clients to the local urban Inuit organization, Tungasuvvingat Inuit. However, it is acknowledged that this does nothing for addressing the situation of urban Inuit in other parts of Canada. For these national level organizations to be truly representative of the voice of all Inuit across Canada, the issue of urban Inuit representation needs to be more diligently addressed:

I think ITK, most of it ignores the urban area. They are a national political organization that represents mostly the arctic. They try to help urban Inuit through TI. ITK are not so involved with urban Inuit people, but they have a good reputation for representing all the Inuit politically. When they want to do something for urban Inuit in cities they support TI, because that is where most Inuit go to is TI. They have done good things for Inuit through TI. (Mary, Ottawa, 2011)

I think they should have more national representation for urban Inuit because it's going to get bigger. It gets bigger every year. Actually Ottawa Inuit community is bigger than some of the communities up north now. So I would like to see that represented as the urban Inuit community gets bigger. It should be part of that representation through let's say ITK. (Carmen, Ottawa, 2010)

I think Pauktuutit should do a lot more than what they do. Represent more Inuit women and children in urban cities, which they don't do enough. They have a 
mandate to represent every Inuk woman and child. And there was supposed to be an Inuit woman selected from each city to represent that area, but being in Ottawa we never heard anything. (Debra, Ottawa, 2010)

I think urban Inuit issues have made it onto the radar of the national organizations. How ITK deals with the whole urban Inuit in Ottawa issue, their loophole is that they support TI in doing their work. But I don't think TI should be the national voice for urban Inuit issues. I feel that way for a lot of different reasons. I think that it is I TK's responsibility if they say that they represent all Inuit across Canada. There's a large growing population here and in other cities across Canada to. (Cindy, Ottawa, 2012)

As mentioned in the quotes above, the issue of access to educational dollars is significant to urban Inuit. As urban Inuit, students are not eligible for the same funding opportunities available to Inuit residing in Nunavut ${ }^{63}$. Related to the issue of access to educational dollars, another participant explained how even though she knows her children will be denied funding from the Nunavut government because the family lives in the Ottawa, they are still required to be apply to Nunavut Tunngavik Incorporated (NTI) for funding first, get rejected, and then continue to apply for funding elsewhere:

Eventually because my children are NTI beneficiaries, they will have to apply for funding for school, and then get denied, and then apply somewhere else. Because they're not actual residents of Nunavut, they don't get to get the money from Nunavut. But they still have to apply to NTI first before they can apply for funding anywhere else. To show that they tried. It's a ridiculous system. (Cindy, Ottawa, 2012)

\subsection{Inuit-specific Community-based Services Agencies}

As mentioned in earlier sections, community centres provide culturally specific services and programs which have helped Inuit in Ottawa continue to grow and develop as a "community". In other words, they are places within the urban landscape which connect Inuit residing in Ottawa to their northern homelands, communities, and cultural

\footnotetext{
${ }^{63}$ This relates back to the experiences of Elder Ovilu Goo-Doyle and her son described in Chapter 4.
} 
practices. The services provided by community centres are not only critical for newcomers to help them adjust to life in Ottawa, but also provide a place where social and cultural connections can be made. The following participants describes how programs and services at The Ottawa Inuit Children's Centre (OICC) and Tungasuvvingat Inuit help them to build social networks, as well as provide them with a space where they feel at home and grounded despite living in a large city.

I think the biggest thing is that sense of community. I think what the O ICC does is give that sense of community within such a large urban setting like Ottawa. It's quite easy to get lost in Ottawa. Having a place that you can be grounded, where you can feel at home is hugely important. (Cindy, Ottawa, 2011)

TI is important because it's a place where you can share your life with people, we can eat country food together, meet there. (Mary, Ottawa, 2012)

Participants emphasized the role community centres play not only in their lives in Ottawa, but those of their children who are being raised in the south. The following participants describe how the Headstart program and kindergarten at the OICC are helping to teach Inuit youth about Inuit culture and language:

Organizations like the OICC are important because they teach the children Inuit ways and they teach them how to be proud of themselves. My granddaughter is at the OICC kindergarten. She's learning how to sing in Inuktitut. I'm happy she's learning how to eat country food too. It's helping her a little. It's helping her learn her Inuit culture. She's learning throat singing, games, drumming. It's good. It's better than nothing. (Mary, Ottawa, 2012)

I think programs like the things that the OICC does it definitely helps, and goes the longest way into ensuring that cultural base. It's a matter of being able to have a place for the children to come and be able to pick up and learn those different cultural and language skills. (Cindy, Ottawa, 2012) 
My daughter attends OICC kindergarten. It was important for me to send her there as opposed to a public school, because she has her friends, and they have really good resources, and they offer more than a public school. It just seem like a natural choice to keep her there, since she was already there for the Headstart program. She's learning Inuktitut. It's nice that she's connected to our culture. (Lucy, Ottawa, 2012)

Key to developing community is participation. The following participant described how her work as an Inuktitut teacher and literacy coordinator were not only important for her as a source of employment, but as a way of connecting and contributing to the community. In this role she felt like she was actively passing on Inuit knowledge and culture to younger generations of urban Inuit:

I worked at the OICC as the literacy coordinator. I also used to teach Inuktitut to children on the weekends. We would have cultural teaching as well. We would do drumming, have Inuit games. The children need to taste, touch, hear, and do it in order to learn about the culture. We would teach them how to make igloos. We would do arts and crafts for literacy on Inuit day. Like we would make little qamutik out of paper, with little dogs on strings. We would teach culture and literacy. We teach them their numbers and letters in Inuktitut. We don't have much time so we couldn't do more. But they need to learn the basic words. It's very important not to forget our language. It's very important for urban Inuit children. (Mary, Ottawa, 2012)

Although Ottawa is fortunate to have numerous programs and services available for Inuit residents, the organizations are often stretched in terms of staff and funding. For instance, the participant quoted above, who was performing an incredibly important job providing literacy support to urban Inuit youth, has been waiting for funding to come through in order to renew her contract. Until then, the programming has been put on hold until an adequate source of funding can be found. Another important dimension is staff burnout. Service agencies in Ottawa provide for a large and growing population of 
residents, and are typically understaffed and overworked, as emphasized by the following participant:

The OICC tries to provide families with the services they need, while working within our funding limitations. That's always the biggest problem. It's the funding. Or the actual physical manpower. I can only spread myself so far. I've done many jobs here at this community center, and I'm quite happy to do so. But I know at some point, I will get fatigued at some point. (Cindy, Ottawa, 2012)

Despite the challenges faced by community centres in Ottawa related to adequate funding, consistent programming, and staff exhaustion, participants were well aware that the situation in Ottawa was still far more favourable than that in other Canadian cities. Some participants lived in other cities before settling in Ottawa, and noted that their experience in Ottawa has been far more positive, hence their desire to settle and raise their families here:

There were no Inuit organizations in Yellowknife, and my experience living there was very different. Here my experience has been more rich. Here we get together, we do things together. (Mary, Ottawa, 2012)

Ottawa is the only place that has services like the OICC. I know in Montréal they're really trying to beef up their services through the Aboriginal friendship center. (Lucy, Ottawa, 2012)

When asked about the future for the Inuit community in Ottawa, the following participant was inspired to talk about one of her colleagues to whom I will give the pseudonym 'Martha'. According to the participant, her friend 'Martha', who is now a well-known community leader traveled a challenging path to find and define her Inuit identity. As an Inuk person born and raised in the south she went through a period of denying her background, opting to identify as First Nation when she was growing up rather than Inuit. However, through her association with Inuit community centres she was able to learn 
about her background and form her identity as an urban Inuk and community leader. The participant credits the community centres for providing the cultural base which made her friend's transformation possible:

I think it will just keep going. There's a lot more educated urban Inuit who still have the connection to the home communities and land and everything. But they are still finding their way here. Like I look to Martha. Martha was born and raised here in Ottawa. She's always been an urban Inuk. And she's pretty much taken the same path as I have. Where she disassociated from the culture, then she came back to it, and now she's a throat singer and performer. And she gives cultural presentations to school aged children. Without a place like this like the OICC, she would never have found this path. It's hugely key to have a place like this that provides that cultural base. (Cindy, Ottawa, 2012)

This research seeks to gain a deeper understanding of the significance of the land to Inuit residents of Ottawa, and the role of urban place-making in facilitating connections to Inuit lands and culture. This chapter presented the narratives of younger generations of urban Inuit residing in Ottawa. The narratives demonstrate that the land continues to be of significance in terms of a source of history, identity, knowledge, practice and values to the participants. The participants expressed a desire for their children, whom they are raising outside of the North, to also develop relationships to Inuit lands and culture, although how this shall manifest in the future remains to be seen. One way in which connections to the land are currently being fostered outside the home, is through the programs and services provided by local Inuit organizations. The narratives also highlight the complexities and heterogeneity of Inuit identities as they are constructed in the urban environments. The narratives suggest younger generations have a more challenging time asserting their Inuit identities in comparison to their northern counterparts. Lastly, the narratives highlight the crucial matter of urban Inuit rights, as 
well equitable representation by national level organizations like Inuit Tapiriit Kanatami and Pauktuutit. These themes shall be further developed and explored in the following chapter. 


\section{Chapter 6}

\section{Synthesis: Thematic Analysis and Discussion}

In this chapter I will provide an analysis of the major themes distilled from the rich participant narratives presented in Chapters 4 and 5. Specifically, this chapter highlights the participants' perspectives regarding the land, its varied meanings and significance, and the role urban place-making plays in fostering linkages to the land within urban environments.

Before beginning the thematic analysis, however, it is important to contextualize the narratives. Nearly all of the participants in the study originated from different northern communities. Relevant to establishing context is Massey's (1994) concept of progressive sense of place, as sites where multiple histories, mobilities and identities interact to create place that is dynamic and reflects the unique character of the individuals which come together to create said place. The diversity and dynamic nature of place as described above is particularly relevant when characterising the Ottawamiut community. For instance, if we consider the Elder narratives as described in Chapter 4, each originated from a distinct community in the Eastern Arctic: Ovilu was born in and raised in Cape Dorset, Nunavut; Maria is originally from Nain, Labrador; and Sally is from Baker Lake, Nunavut. Based on my exposure to local community organizations in Ottawa, which corroborates with the findings of Patrick and Tomiak, (2008), Ottawa attracts Inuit from all over the Arctic; however, most typically Inuit from communities located in the Eastern Arctic (e.g. Nunavut, Nunavik or Northern Québec, Nunatsiavut or 
Labrador). Significantly, each of these Elders brings with them their own unique experiences which have been shaped by the characteristics of, not only their region, but also by the particular histories and local culture of their respective communities.

The narratives show how the personal experiences and knowledge of the participants have had subsequent effects which have influenced their urban experiences. For example, consider the regional diversity of Inuktitut spoken in the Arctic. Each Elder in this study speaks a dialect of Inuktitut specific to their region, and represents a form of cultural knowledge that they bring with them to Ottawa. However, within Ottawa, only certain dialects of Inuktitut are favoured (e.g. Nunavut dialect over Nunatsiavut dialect) due in large part to the make-up of the local population. As a result, only the most common dialect of Inuktitut is taught in the language programming offered by the Ottawa Inuit Children's Centre. This directly impacts the urban experiences of Inuit like Maria, for instance, who speaks a dialect common in Nain but not commonly spoken outside of her region. Thus, Maria's ability to converse with other Inuit is more limited. Furthermore, her grandchildren who are being raised in Ottawa are learning a dialect of Inuktitut that she herself is not fluent in. Another example would be that of Ovilu who was born and raised in Cape Dorset, Nunavut. As explained in her narrative, it was Ovilu's art work that first brought her south to exhibit her work at the 1967 Expo held in Montréal (see Chapter 4). Later, her artwork helped to secure her employment with Canadian Arctic Producers (CAP) which brought her to Ottawa. Ovilu did not happen to pick up the art of Inuit print-making by accident, however. Print-making and sculpture are a large part of the local culture and economy in Cape Dorset, for which the community is world-renowned. The skills and knowledge she was able to acquire in Cape 
Dorset, greatly influenced her later success in Ottawa. Similar to Lee (2003) and the Yu'pik women involved in the Indigenous marketplace in Anchorage, Alaska, Ovilu also experienced both cultural, social and economic benefits through her creation of Inuit art and participation in the Inuit art world. Furthermore, as stated by Patrick and Tomiak (2008) there are a growing number of Inuit who are being raised in the south, possessing their own unique urban experiences that, as this thesis demonstrates in Chapter 5, can share commonalities with the experiences of older generations, but can also be quite distinct. Thus, it is important to be mindful of context when considering the narratives, and its potential influence on the urban experiences of the participants, given the regional diversity of Inuit who live in Ottawa.

Given the diversity of Ottawamiut, it raises the question: What is the foundation or common ground that draws urban Inuit together? As this chapter will show, in this thesis I argue that the underlying unifying force which draws Inuit residing in Ottawa together is the land, and the meanings, cultural knowledge and practice, and values it represents. It is well-documented that the land has provided the foundation upon which Inuit history, knowledge and identity is based (Mannik, 1998; Bennett and Rowley, 2004; ITK, 2004; Price, 2008) as discussed in Chapter 2. While there may local and regional distinctness (e.g. geography, colonial histories and legacies, local economies, regional dialects), the land and the sense of collective identity, which results from land-based cultural knowledge and practice act to unify Ottawamiut as a group.

As is discussed in Chapter 1, the collective agency of Inuit has enabled them to advocate for their rights. Based on the narratives, and of particular interest to this thesis, the collective power of Inuit over time in Ottawa, has led to the establishment of local 
Inuit organizations which provide much needed programs and services to Ottawamiut. This thesis argues that local Inuit organizations are more than just places where Inuit can go to receive services; in this chapter I will show that these places transform abstract, urban space into 'Inuit place'. This speaks to some of the literature in Chapter 2, section 2.4., namely the work of Fogel-Chance (1993), Lee (2003), Kishigami (2008), Olofsson (2004),and Tomiak and Patrick (2008; 2010). These studies show how urban space can be transformed into Inuit place through strategies employed, for example, in households, at Indigenous marketplaces, and community centres. However, none of these studies explicitly examine the relationship between these urban place-making efforts and the land, as this thesis demonstrates.

I argue that in Ottawa, urban Inuit places - that is, places of cultural safety and inclusion - are key to fostering linkages to the land. Linkages to the land are facilitated largely through the programs and services, previously described in Chapters 4 and 5, that local Inuit organizations, like Tungasuvvingat Inuit and the Ottawa Inuit Children's Centre provide to the community, as well as the sense of community these centres foster. As we shall see in the thematic analysis below, these linkages extend connections to land and Inuit cultural knowledge and practice which surpass supposed geographic boundaries of North and South, or urban and rural. I will demonstrate how connections to the land are recreated within urban space in meaningful ways, which not only unify Ottawamiut but also fortify their sense of collective identity. That is, similar to Patrick and Tomiak (2008), this research found that where community members originate from seems less important as compared to the act of their coming together as Inuit, with shared histories, cultural knowledge and practices, which I argue are inextricably connected to the land. 
This thesis also demonstrates the inter-generational significance of the land to Ottawamiut who are raising families in the city. Urban place-making efforts are especially significant to youth being raised in Ottawa who have no direct experience or knowledge of the northern communities from which their families originate. For these cases, in particular, having access to Inuit-specific programs and services through local Inuit organizations is instrumental in facilitating the formation of positive cultural identities. According to the Royal Commission on Aboriginal Peoples (1996) in order for Indigenous people to live successfully in cities there is a need to support the elements that they consider to be an integral part of their cultural identities. This thesis argues that for the Ottawamiut participants of this study, having access to programs and services within urban space that connect Inuit to the land-that is, to the meanings, cultural knowledge and practices associated with the land-supports both successful urban Inuit lives and strengthens Inuit cultural identity. These findings extend research by Olofsson (2004) and Tomiak and Patrick $(2008,2010)$ which show the importance of urban Inuit and Indigenous community centres in urban centres like Montréal and Ottawa, respectively, in helping creating a sense of community in urban centres, and also in enabling younger generations of Inuit to gain the knowledge and skills necessary to legitimate their identity claims. However, unlike the studies above, this thesis makes explicit the connection between land-based knowledge, practice, and ethics and the programs and services offered by local Inuit organizations. The greatest strength of local organizations is how they ground themselves in knowledge, practice and ethics that are rooted in Inuit world views which, as demonstrated in this thesis, are rooted in land. 
This section has so far presented a discussion on the importance of context when considering the Ottawamiut narratives documented in Chapters 4 and 5, especially as this relates to the regional diversity and particular urban experiences of the participants. This section also foreshadows the main arguments of this thesis which are further demonstrated below. That is, that the the land—and the meanings associated with it—is the primary force that unifies the diverse Inuit participants in this study, providing the sense of a common ground for those living in the city. For the participants, connections to the land are largely facilitated through local Inuit organizations, which operate to transform abstract, urban space into Inuit place through the land-based programs and services they provide, and the sense of community they foster. Lastly, that the land continues to be of inter-generational significance to urban Inuit youth, and that urban place-making efforts, such as local Inuit organizations, are key to the transmission of land-based knowledge, practice and ethics to younger generations. The next section explores the reasons why Ottawa is an attractive place for Inuit to settle, historically, and today.

\subsection{Why Ottawa?}

My research shows that there are several key reasons why Inuit have, and still choose to, settle in Ottawa. For instance, as described in Chapters 4 and 5, the prospect of finding better employment opportunities, to further education or training not available in the North, and to follow a family member. These reasons for migration corroborate the motivations documented in the literature (Kishigami, 1999; 2002; Patrick and Tomiak, 2008), while also extending these findings to show what makes Ottawa a unique destination as compared to any other southern Canadian city. 
In Ottawa, greater employment opportunities are linked to both the to the rise of Inuit political organizations during the 1970s and 1980s. Inuit Tapiriit Kanatami (ITK), the organization that is mandated to represent the national voice of Inuit across Canada, was founded during the early 1970 s and initially established its headquarters in Edmonton. However, in 1972 ITK moved its offices to Ottawa, in order to facilitate its access to the federal government and strengthen lobbying power and visibility (INAC, 2008). Headquartering its offices in Ottawa led to the creation of jobs ideally suited for Inuit candidates. Later, in 1984, ITK established Pauktuutit in Ottawa, to be the national organization representing the interests of Inuit women across Canada, thereby leading to more employment positions for Inuit. In addition to the rise of national level organizations, as the grassroots movement started in Ottawa during the 1980s, finding work at local organizations like Tungasuvvingat Inuit, also became a source of employment. On the surface, the impact of these jobs may seem minimal, as there were only a limited number of positions available. However, at the time Inuit faced a great deal of racism and discrimination from non-Inuit when seeking employment. Therefore, working with Inuit organizations was often the only jobs Ottawamiut could find. Each of the Elders have at one time or another relied on local or national level Inuit organizations for employment. Over time, these local and national Inuit organizations have grown and other Indigenous organizations have been established, such as: Inuit Tapiriit Kanatami, Nunavut Tunngavik Incorporated, Pauktutiit Women's Association, and Inuit Circumpolar Council-Canada. In addition, Ottawa is home to Inuit-specific communitybased service agencies such as Tungasuvvingat Inuit and Ottawa Inuit Children's Centre, as well as other organizations which provide programs and services to Inuit (e.g. Nunavut 
Sivuniksavut Program, Inuit Art Foundation, Larga Baffin Home, Wabano Centre for Aboriginal Health, Inuit Non-profit Housing Corporation, Gignul Non-profit Housing Corporation). These organizations continue to be an important source of employment for Ottawamiut. Today, jobs at ITK, Pauktuutit, Tungasuvvingat Inuit, the OICC, and other Indigenous organizations are highly sought after. Part of the reason is that Inuit in Ottawa continue to face racism and discrimination. In addition to highlighting Inuit organizations as a place to work, participants also spoke about feeling more at ease when working at Inuit organizations because there is an inherent understanding of Inuit values built into the very structure of these organizations. However, jobs at Inuit organizations are not necessarily secure as they largely depend on stable sources of funding. Thus, while there are more jobs potentially available to Inuit living Ottawa compared to the opportunities available in a remote northern community, it can be difficult for Inuit to secure a position.

The narratives highlight education as another reason for migrating and settling in Ottawa. During the 1960s and the early 1970 s, few northern communities had facilities for secondary and vocational education, requiring students to travel from smaller, remote communities to larger communities like Iqaluit or Yellowknife (INAC, 2008). Postsecondary studies required even greater relocations to cities like Montréal and Ottawa where college and university facilities were available. In addition, as an alternative to formal education, and in an effort to improve Inuit employment rates, the Department of Indian Affairs sponsored on-the-job management training in community and business administration for Inuit through several government agencies and organizations (e.g. Inuit Tapiriit Kanatami, Makivik Corporation, the Federation des Cooperatives du Nouveau Québec, the Canadian Armed Forces, Employment and Immigration Canada, and the 
Vocational Training Section of Indian and Northern Affairs Canada) in urban centres (INAC, 2008). For example, as discussed in Ovilu's narrative in particular, during the 1980s, Ottawa drew Inuit students due to the programs and services offered by the federally-funded Vocational Training Section which provided support to Inuit students by funding counsellors, orientations, boarding homes, tutors and the Inuit House drop-in centre. Interestingly, the Inuit House drop-in centre later developed in what is now, Tungasuvvingat Inuit, one of the key local Inuit organizations that this thesis argues creates Inuit place in Ottawa, and fosters meaningful connections to the land for Ottawamiut.

Over time, as Inuit began to migrate to Ottawa in greater numbers, in search of employment and education, the population of Inuit in Ottawa seemed to reach a 'critical mass'. Once this critical mass was established, it has meant that there have been a significant number of people to organize and to create the institutional spaces serving Inuit in Ottawa. Ovilu's narrative, in particular, highlights the significance of critical mass in the formation of social networks and early grassroots community-building efforts, specifically with regards to Inuit House. The establishment of this forerunner to Tungasuvvingat Inuit (TI, the current Inuit community center) was a unifying force for Inuit residing in Ottawa during the eighties. Although Inuit House was only meant to be used by students who were in Ottawa to attend government-sponsored educational and training programs, it acted as a social and cultural hub that drew together the small yet growing number of Inuit living in Ottawa. At the time, no Inuit-specific social or cultural programming was available; however, Inuit House gave people the opportunity to gather, socialize, speak their own language, and build social networks, which helped ease the 
culture shock that often came with southern life. When the federal funding for Inuit House was cancelled, Ovilu recognized that there was still a need for an Inuit drop-in centre in Ottawa, particularly because she noticed that there were growing numbers of Inuit like herself settling there. The leadership and commitment she and others like her displayed had a dramatic impact on the grassroots movement and mobilization of Inuit in Ottawa. What began as Inuit House over time has developed into Inuit-specific community centre, $\mathrm{TI}$, which provides a wide range of programs and services to Ottawamiut. As more Inuit migrated to Ottawa, a true sense of community began to develop, largely centred around the programs and services provided by $\mathrm{TI}$, and later the Ottawa Inuit Children's Centre (OICC), an Inuit educational centre that split from TI in 2005. Similar to work discussed in Chapter 2 by Lobo (2002), Patrick and Tomiak (2008, 2010), Watson (2010), Howard, (2010) and Manitowabi (2010), this thesis demonstrates the importance of urban Indigenous gathering places and organizations for social networks. This thesis shows how in Ottawa the presence of grassroots Inuit organizations has not only shaped the Ottawamiut community, but has also acted as a significant draw for Inuit migrants seeking support, while attempting to navigate an unfamiliar urban setting.

In summary, Ottawa has been an ideal location for early migrants due to the employment and educational opportunities available in the city, as well as the rise of national level organizations in the 1970 s and 1980 s that were headquartered in Ottawa. Over time, as greater numbers of Inuit moved to Ottawa, thus creating a critical mass, Inuit residents began to organize and mobilize to advocate for the needs and concerns of their growing community, and build broader social networks. The grassroots movement 
that began in the 1980s set the foundation for the development of the local Inuit organizations which are most active in Ottawa today, namely TI and the OICC, which are unique to Ottawa. While urban Inuit have made attempts to organize in other southern urban centres, such as Montréal, Winnipeg and Edmonton, as discussed in Chapter 1, the level of support Inuit residents of Ottawa receive from local Inuit organizations is, to date, unmatched as compared to these other cities. Local Inuit organizations in Ottawa provide social and culturally-specific programs and services, as well as employment opportunities, which continues to make Ottawa an attractive place for Inuit to settle. All of these reasons have contributed to Ottawa developing into what Patrick and Tomiak (2010) refer to as a social hub for Inuit, and as a centre the largest population of Inuit living outside of the Inuit homeland regions of Canada.

The previous section has discussed the unique characteristics that make Ottawa an attractive place for Inuit to settle. The next sections discuss the major themes that emerged from the richness of the Ottawamiut narratives presented in Chapters 4 and 5. I begin with a discussion of the significance of the land and its various meanings.

\subsection{Meanings of the Land}

This thesis aims to gain a deeper understanding of the significance of the land to Ottawamiut. However, in order to understand this significance, it is important to begin by exploring the various meanings associated with the concept of land. The narratives support the description of nuna as defined in Chapter 2, and further our understanding of this description by providing more personal insights which reveal the depth of meaning of nuna for the participants. We'll remember that Inuit conceptions of the land or nuna 
tend to encompass meanings which are far more complex than a simple reference to physical land, and which overall need to be seen as a holistic, all-encompassing concept that relates living things in a web of interconnections to their environment (Wenzel, 2004; Jessen Williamson 2006:19; Nuttall 1992).

In this thesis, all of the participants maintained that the land was significant to their lives in one form or another. In the case of the Elders, reflecting on the meanings of the land connected them to their childhood memories and a time before government interference into Inuit lives (see Chapter 1). This was a time when Inuit still lived largely independent way of life based around seasonal hunting and gathering activities. The land was a place of belonging, the basis of the Inuit way of life, and a source of values that organized Inuit social life. The land is a source of elaborate knowledge and practice, which have shaped Inuit society and culture. Life on the land has led to Inuit knowledge and expertise related to navigation, hunting, gathering, seasonal migration patterns of animals, shelter construction, clothing, food preparation, medicinal and edible plants, among others. Before Inuit moved to settlements, the land was not only a source of sustenance and subsistence, the land was home. That sense of belonging inspired stewardships and land-based values and ethics which dictated respect for the land, and the animals upon which Inuit have been dependent for their livelihoods. In addition, the land is associated with strong Inuit values such as family togetherness, sharing and stewardship. Both Inuit ethics and values are often rooted in spirituality that connects the physical and metaphysical world in a close-knit web of cause and effect. This relationship with the land and mode of Inuit conduct, or customary law, is known in Inuktitut as maligait: 
Maligait are rules that govern Inuit and their relationships within the metaphysical world. Respecting maligait is a requirement that flows from traditional Inuit spirituality, which recognizes the constant presence of spirits and respects the authority of spirits to challenge Inuit physical survival. Spiritual authority exists within an intrinsic spiritual network of relationships that guide Inuit existence, which included Inuit, the land, weather, and the animals. Therefore, any individual who disrespects maligait affects the spiritual balance of these relationships, challenging individual and community well-being. (Price, 2008: 131)

In this way, we see how connections to the land extend far beyond the physical. The allencompassing nature of the land was further elaborated in quote cited by Ovilu in Chapter 4 (p. 104). The quote demonstrates the strength of its presence for Inuit migrants who live at great distances from the land. As Ovilu noted, upon arrival in Ottawa she "missed the Arctic very much", including the "smell of the ocean, the mountains, and the country food..." and her family. As she stated, after forty-six years she is "still very connected to the north" and her connection to Inuit and Inuit culture "will never stop". The land is "serenity" and well-being (i.e. "You feel good when you are on the land") and Ovilu "will always go back even just for a visit."

This description of the land includes physical, emotional, and psychological aspects. Ovilu's associations with the land incorporate sensory appeals to sights and smells as well as connections to family, to Inuit, and to Inuit culture as a whole. The meaning of the land surpasses the physical and moves into the realm of health and wellbeing as she describes her longing for the land while living in Ottawa. In contrast, being on the land is associated with good health and well-being. The land is also a source of Inuit history and ancestry.

Based on the narratives in Chapter 5, it is clear that the younger generations of Inuit participants also believe that the land is significant to their urban lives. Those 
participants who had memories of the land and of being on the land, for instance, traveling, camping, hunting and gathering, etc, expressed longing that was comparable to the longing expressed by the Elders. In this case, the land is similarly described as a place of belonging for Inuit, a source of values and ethics, a source of cultural knowledge, and also highlighted as important to health and well-being.

The participants who had little memory of the land because they were too young when their parents migrated South, did not tend to express the same visceral connections to the land as the Elders. A lack of longing or direct experience of the land did not, however, mean these participants saw the land as less important to Inuit. However, making connections to the land for urban Inuit like Cindy, can be a complicated and challenging path. Cindy's life experience, as it is detailed in Chapter 5, illustrates the inter-generational impacts of colonialism. Her mother was taken from the land to attend school in the settlement. This act of intervention not only interrupted the transmission of land-based knowledge to her from her family, it had the subsequent impact of robbing her of the knowledge that she would have otherwise passed onto to her children. Furthermore, in school Cindy's mother learned to be ashamed of her Inuit culture. Later in life she married a White man and moved out of the North, so that she could distance herself from Inuit culture, and instead identify with the dominant society. So, while Cindy's direct knowledge of the land is limited because she grew up mostly in southern Canadian cities, her understanding of what the land represents and its significance to her sense of identity are strong. For Cindy, the land is an important source of history, values, knowledge and identity. These connections to the land and what it represents in her life surpass geographic boundaries of North and South, or urban and rural. The land and its 
meaning are embedded in her sense of Inuit identity. The story does not end there. Cindy, like the other participants, believed that passing on knowledge about the land to younger generations was extremely important for Inuit

The narratives of the participants are significant because they demonstrate the complex nature of connections to the land and how these connections are facilitated and expressed. Rather than be extinguished, these connections remained when the participants migrated to the city, which counters arguments to the contrary in much of the literature on colonial and post-colonial discourses (e.g. Jacobs, 1996 ; Peters, 1996; 1998, 2000, 2002; Todd, 2001; Newhouse and Peters, 2003; Wilson and Peters, 2005; see Chapter 2). As this literature shows, colonial and post-colonial discourses generally assumed that being Indigenous and "Urban" are mutually exclusive and that Indigenous connections to their homelands are maintained by residence in those homelands. Contrary to this, like the studies above, this thesis shows that Ottawamiut hold onto their connections to the land and the varied meanings it brings to their lives. I argue that the support provided by local Inuit organizations in Ottawa enables participants to pass on land-based knowledge and practice to younger generations in ways that would not otherwise be possible, thereby contributing to the continued significance of the land for these younger generations of urban Inuit.

As discussed in Chapter 5, the significance of the land continues to be important to younger generations of Inuit, many of whom are raising their children in Ottawa. Many urban Inuit children have not experienced the North or visited their parents or grandparents who live in northern communities. And yet, the land is so central to Inuit 
history, cultural knowledge and values, that their parents believe providing them with knowledge about the land is significant for the reasons detailed in the section above.

This discussion raises an important question: How do Inuit in Ottawa connect to the land within urban settings? The narratives revealed various ways that the participants create connections to the land while living at a great distance from the North and these connections are explored in the next section.

\subsection{The Land and Symbols}

Inuit residing in Ottawa, much like other Indigenous people living in cities (Todd, 2001; Howard and Proulx, 2010), anchor themselves to an abstract, largely symbolic sense of the land. Through this, they thereby link themselves to traditions and place despite the fact that they may occupy materially 'de-territorialized' zones. As my research has shown, the active, collective and cultural memory (Assman, 2010, 2011) of land and efforts to revive and sustain it, grounds Indigenous peoples in cities differently, yet actively, despite lived dislocations and disjunctures (Clifford, 2001: 481). Thus, for urban Inuit migrants, the relevance of cultural and collective memory belongs to the construction of the future (Hage, 2010). That is, cultural memory, rather than being relegated to the past, plays a key role in how the urban Inuit participants create links to land and culture which support their urban lives and futures (Olick, Vinitzky, and Levy, 2011).

As I will demonstrate below, the participants make symbolic connections to the land through their familial and ancestral histories, Inuit knowledge, cultural practices, country food, language and identity. All of these connections to the land are largely 
facilitated and supported by the programs and services provided by local Inuit organizations in Ottawa. The active memory of land strongly influences the social and cultural programming offered by local Inuit organizations. These local organizations, in turn, serve as places where Inuit may engage in land-based knowledge and practice, which extends land meanings and culture into urban space. This is accomplished through the programs and services provided by Inuit 'community centres', for example, through language programming, community feasts, Elder storytelling events, and more (see

Chapters 4 and 5). All of these act work together to transform abstract urban space, into Inuit place. This transformation of abstract space into Inuit place extends meanings of the land. Most significantly, is the transmission of knowledge to the wider community and younger generations.

\subsection{The Land and History}

The narratives reveal that for the participants, as a symbol, the land can represent many things, each of which possesses particular significance and meaning. For instance, as widely stated in the narratives, the land itself is a symbol that connects the participants to their personal, familial and cultural histories. These histories provide participants with a sense of who they are as individuals and as a cultural group (Radstone and Schwarz, 2010). The land is a symbol which represents the Inuit way of life before contact with non-Inuit and the colonization of the Arctic, when Inuit lived in close relationship with the land. The Elder narratives in particular, demonstrated how this time before contact represented a time of independence and self-sufficiency for Inuit. The narratives demonstrate how the land and its connection to the Inuit way of life continue to be a source of pride and strength for the participants. Knowing how their ancestors lived, 
whether sixty years ago or centuries ago, served to remind them of the strength, resilience and innovation of their people.

Connected to the idea of the land as a source of history, is the notion of the land as a symbol of change - social, cultural, economic and environmental. Having lived as land-based people for centuries (see Chapter 1), the notion of change is nothing new for Inuit. In fact, living in close relationship with the seasons, the migrations patterns of animals, the seasonality of plants, etc, has not only shaped how Inuit perceive change (i.e. as a part of life) but also influenced the strategies they employ in order to deal with change. Thus, the land is also symbolic of the adaptive capacity of Inuit, their resilience, and their perseverance and persistence over time in the face of various types of social, cultural, economic and environmental change. For urban Inuit, being able to draw upon these Inuit perspectives of resilience and adaptive capacity in the face of change, is a coping strategy that provides strength to migrants who often experience culture shock and other challenges adjusting to the realities urban life, as documented in Chapters 4 and 5 .

Other urban Indigenous groups are asserting their historic connections to land and drawing upon these connections, as Brock Pitawanakwat explains:

Nishnaabeg oral history describes a long western migration from the salt water to the Great Lakes and beyond. As our people moved, we renewed our relationship to the land to create a new bond between the people and the environment. This relationship between the peoples and their natural landscape is at the core of Indigenous epistemologies. Honouring our ancestors means that we carry our language and customs with us wherever we go. As urban Nishnaabeg, our ancestral legacy is to reconnect with the natural landscape and live honorably and sustainably - wherever we reside. (Pitawanakwat, 2008: 171)

Parallels can be draw between the migration experience of the Nishnaabeg and that of Inuit. Inuit have a long history of migration which speaks to their dispersal throughout 
the circumpolar Arctic (i.e. Canada, United States of America, Russia and Greenland). Over eight thousand years ago, Inuit ancestors migrated across the Bering Land Bridge and into Alaska and later Canada (2004). Like for the Nishnaabeg, migration is a foundational aspect of Inuit history and culture. And like the Nishnaabeg, Inuit adapted to the landscape and carried various forms of cultural knowledge and practice with them. For urban Inuit, drawing upon this history is an important source of strength and identity. Most importantly, and as discussed in detail in Chapter 2, the quote above demonstrates that urban Indigenous relationships to the land are complex, and that the notion of "urban" and "Indigenous" as being mutually exclusive is strongly contested by many urban Indigenous peoples who assert their links to their lands and culture, as discussed in Chapter 2 (RCAP, 1996; Jacobs, 1996 ; Peters, 1996; 1998, 2000, 2002; Lobo, 2002; Newhouse and Peters, 2003; Wilson and Peters, 2005).

\subsection{The Land and Inuit Knowledge}

Participants also make symbolic connections to the land through Inuit knowledge or Inuit Qaujimajatuqangit (IQ), a concept which is defined in Chapter 2. In the broadest sense, the land represents Inuit knowledge because the land is the primary basis and source of IQ. The narratives support the view that many Inuit have, that in order to overcome colonial legacies, Inuit ontologies and epistemologies (i.e. Inuit ways of being, knowing and doing) need to be privileged over Western knowledge systems. This assertion is echoed by Price (2008: 129) who reiterates "[...] Inuit must look back to Inuit knowledge systems in order to imagine a time where Inuit are able to rise above colonial chaos. Inuit must remember the lessons that come from interacting with the land" (Price, 2008: 129). While Inuit knowledge can be shared in the home as a strategy to maintain 
links to Inuit cultural knowledge and practice in the city, similar to work by FogelChance (1993), the narratives show the greater influence and significant role urban Inuit places, such as local Inuit organizations, play in facilitating both the transfer and creation of IQ within Ottawa, primarily through the programs, services and social networks that they provide. In the next section, I will show examples of how meaningful connections to land and Inuit knowledge are being made, specifically, through the learning and performance of significant cultural practices.

\subsection{The Land and Cultural Practices}

Symbolic connections to the land can also be made through various forms of cultural knowledge and practice. Based on the narratives, it is evident that acquiring cultural knowledge and participating in cultural practice are important ways for Ottawamiut to connect to the land. For instance, consider how Elders work as Cultural Educators both in and outside the Ottawa Inuit community. Through storytelling Elders are able to pass on social and cultural knowledge (Bennett and Rowley, 2004). Storytelling is an important aspect of Inuit history and culture as Inuit were an oral cultural before missionaries introduced syllabics to the North (ITK, 2007). In Ottawa, the tradition of storytelling is being upheld and is an integral way that knowledge is passed between generations. For example, consider Sally's use of her wall-hanging and teaching tools to convey specific aspects of her own life experiences and Inuit culture.

Consider, first, Sally's wall-hanging. The example of the Sally's wall-hanging is useful to illustrate how she creates symbolic connections to the land through storytelling. While she did not speak about this explicitly, Baker Lake is renowned for its wall- 
hangings which are considered to be a part of the local art culture ${ }^{64}$. The wall-hanging is an important symbol, not only of Sally's connection to the local art culture in Baker Lake, but also in terms of the land-based stories it tells. The significance of these stories cannot be underestimated as they represent a reflection of the Elders knowledge and experience of the land, but also significantly, what knowledge is then passed to younger generations, who may or may not have directly experienced their northern homelands.

Not only does the wall-hanging tell a variety of stories taken from Sally's childhood spent at her grandparents' camp, it does so through symbols which create direct links to the land, and land experiences and knowledge. These symbols were not chosen by accident, but rather were deliberately selected by Sally due to their personal and cultural significance. For instance, the symbols she chose tell the story of her arrival at camp, the first time she shot a caribou, the importance of keeping busy at camp, etc. Sally chose certain symbols to tell her story, no doubt symbols which influenced her as a child and continue to hold relevance for her as an Elder. For example, the canvas tents her grandparents lived in which were very different than the clapboard houses she was used to in the settlement. Or the quarmak they made of ice when there was not enough snow to build an igloo. The details of her grandmother's and her aunt's amauti, their traditional Inuit clothing. The camp fire which she associated with preparing tea and food, and keeping busy from dawn until dusk, a work ethic instilled in her by watching her grandmother. The time her uncle took her caribou hunting and the time he taught her how to set up a fox trap which resulted in Sally catching her first fox. Thus, the use of symbols within the wall-hanging to tell stories of personal and cultural significance is not

\footnotetext{
${ }^{64} \mathrm{http}: /$ www.bakerlakearts.com/
} 
only a way for Sally to connect with the land and reflect on her own life experiences, it is a means of passing on such knowledge to future generations, as well as to educate others (i.e. non-Inuit) about Inuit culture.

Similarly, symbols were also important in terms of Sally's teaching tools. By collecting symbols which she believes are representative of Inuit culture, she has not only empowered herself, she educates others about Inuit culture. This is particularly significant for Sally, who describes herself as: "in-between [...]in- cultures, in-between worlds". Sally's self-description as being 'in-between' is a direct result of her life in the settlement and the Western, southern-style education she received there. However, rather than be victimized by this colonial legacy she has chosen to build on what she knows and shares her knowledge with others. As part of her 'teaching tool box', Sally has chosen to include what are to her, iconic symbols and representations of Inuit culture. For example: miniature caribou skin kayaks; caribou skin mitts; tools; games; dolls; uluit (women's knives); and qamutik (see Figures 21-54). She is always looking to add to her collection. Thus, for Sally, passing on Inuit knowledge through these symbolic representations is not only an important way of connecting to the land, it has facilitated her own learning, and allowed her to connect with others in meaningful ways.

Other participants noted connecting to the land and Inuit culture through sewing, drumming and throat singing. These are cultural practices that the participants either brought with them from the North, for instance like Mary and Sally who sew traditional clothing, or were skills that they learned in Ottawa. For instance, Cindy learned how to throat-sing and drum dance in Ottawa, and doing so served to strengthen her Inuit identity. The impact of throat singing and drum dancing has not only had a positive 
influence of Cindy's sense of identity, but had also influenced younger generations whom she leads in a youth drumming group which perform in Ottawa and other communities. The narratives elaborate upon the research conducted by Anderson (2000), Lee (2003), Wilson and Peters (2005), Patrick et al., (2008, 2013), and Watson (2010), which demonstrates how participation in cultural practices enable urban Indigenous people to make place for themselves in cities that foster connections to other Indigenous people from their group (i.e. the collective) and to the land.

This section discussed how participants made connections to the land through various cultural practices such as storytelling, sewing, throat singing and drumming. The next section will discuss another significant way participants connected to the land, that is, through the preparation, distribution and consumption of country food.

\subsection{The Land and Country Food}

Based on the narratives it is clear that country foods are an important symbol which connect participants to the land. As discussed in Chapter 2, the land is a symbol and source of physical, social and cultural nourishment through the hunting, gathering, preparation, and consumption of country foods. Country foods can be defined as consisting of specific compositions of local products gathered and prepared in certain ways that are thereby meant to fulfill the nutritional and cultural needs of the population (Kuhnlein and Chan, 2000). Country foods include all of the food species that are available to a particular culture from natural resources and the accepted patterns for their use within that culture (ibid.). Furthermore, the term country food incorporates an understanding of the socio-cultural meanings given to these foods. Inuit country foods 
include marine and land mammals, fish, plants, berries, and waterfowl/seabirds harvested from local stocks. Inuit communities are widely recognised as having mixed, subsistencebased economies in which harvesting country food for primarily domestic consumption plays a significant role in their food security (Usher et al., 2003) as well as the nutritional, social, economic, and spiritual well-being of Inuit communities (Thompson, 2005). Certain benefits are repeatedly emphasized in surveys regarding attitudes to traditional foods, such as: well-being, health, leisure, closeness to nature, spirituality, sharing, community spirit, pride and self-respect, economy, and the education of children (Arctic Monitoring Assessment Program, 2003: 75). Thus, we see how country foods have the ability to impact the physical, psychological, social and even spiritual health and well-being of Inuit.

Based on the narratives, it is clear that country foods remain of great significance to urban Inuit. Participants expressed deep physical, psychological and social connections to country food. I argue that as a symbol country food connects Inuit to the land both directly and indirectly. Direct physical connections are made via the preparation, distribution and consumption of country foods. Consuming country foods can also have direct health benefits, as studies have shown that many country foods are excellent sources of vitamin C, omega fatty acids, vitamin A, D,and E, as well as iron, zinc, selenium, copper, magnesium and manganese (CACAR, 2003).

Research has shown that for northern-dwelling Inuit, country foods serve as a focus for cultural and social activities that help to maintain the social bonds with groups through sharing and feasting, thereby creating indirect links to land which benefit health and wellbeing (AMAP, 2003:75). Thus, the harvesting, preparation, distribution and 
consumption of country foods tend to be inseparable from Inuit social systems (Usher et al., 2003). Similarly for urban Inuit, I argue that significant indirect links to land are made through sharing and feasting, which strengthen social bonds and networks within urban settings.

In contrast, while country foods offer many benefits to Inuit health and wellbeing, their restriction can also be a source of both physical and psychological strain. Participants often expressed their desire for country foods as cravings and longing. Over time, access to country food in Ottawa has improved, primarily due to improved freezer storage in airplanes, and social networks. Country food can be accessed through friends and relatives however, the costs associated with shipping foods, or delivering them in person, is prohibitive.

Local organizations, in particular, have sought to make country food more accessible to the Ottawamiut community. For instance, local Inuit organizations like Tungasuvvingat Inuit and the Ottawa Inuit Children's Centre have tried to fill the country food gap by supplying country food to the community through community feasts. For instance, consider the seal feast described in Chapter 3 , as well as the country food which was supplied during Inuit Day. In addition, every third Thursday of the month, TI organizes a community feast which serves country food shipped in from various arctic communities. The staff of TI come together to prepare and serve food to Inuit community. The event is held at St. Margaret's Church, located in Vanier, next door to the Family Resources Centre. The community feast is always well attended, with usually 100 or sometimes more community members participating. The community feast provides the opportunity for Inuit in Ottawa to gather, an aspect of Inuit culture that is 
highly valued, while also being able to share country food which is not easily accessible to many community members.

While access to country food has improved over time, it is in no way as available in Ottawa as it is in the North. Having inadequate access to country food continues to be a source of physical and emotional strain, and while it is not a focus of this study, may impact the overall health and well-being of urban Inuit. For instance, studies have shown that reduced country food consumption in northern Inuit and Indigenous communities has been associated with obesity, dental carries, anaemia, immune depression, and diabetes (Szarthmary et al., 1987; Thouez et al., 1989; CACAR, 2003). For urban Inuit, who have even more restricted access to country foods than their northern counterparts, the risks to physical, psychological and socio-cultural health and well-being may be serious, and warrants further study.

The relationship between food, memory and culture are well-understood (e.g. Sutton, 2001; Korsmeyer, 2005; Counihan and Van Esterik, 2008). For migrants, the connection between food and memory can often be visceral and even painful as they may experience home-sickness and culture shock, as demonstrated in the narratives.

However, connections to food and culture can also provide the basis for home and community building, as is the case with local Inuit organizations in Ottawa. For example, the monthly community feast described above acts as not only means of physical nourishment, but creates an opportunity for social engagement for the community members who participate, thus strengthening social networks, that this thesis demonstrates is key to the success of Inuit migrants residing in Ottawa. The narratives 
support the idea that just as food provides the basis of homely practices within the private sphere, it also can provide the basis of home-building in the public sphere, in particular, in the way it creates communality for migrants who often long for their native foods (Hage, 2010).

The narratives support the notion that country foods (i.e. local or traditional foods) can serve to connect migrants to land, while also strengthening social networks when foods are shared communally. Similarly, Watson shows how urban Ainu living in Tokyo, Japan gather at a local Ainu-run restaurant to not only partake in traditional foods but also socialize with other members of the community without fear of outside interference. Similar findings have been reported by Greenop (2009) for urban Aborigines living in Brisbane, Australia.

This section has shown the importance of country foods as a means of connecting urban Inuit to the land, and also as a means of fostering social networks when it is shared communally. In Ottawa, local Inuit organizations play a significant role in distributing country foods in the community. While access to country food has improved in Ottawa over time, its availability in the city remains poor as compared to in northern communities. The next section discusses the importance of Inuktitut in fostering connections to land.

\subsection{The Land and Language}

Language is an important symbol of Inuit knowledge and speaking Inuktitut is a highly regarded way of connecting with Inuit culture and identity. However, language is also a problematic area as many generations of Inuit have lost their ability to speak 
Inuktitut due to the government's suppression of Inuktitut in day and residential school programs, as discussed in Chapters 1, 2, 4 and 5.

However, the government's attempts to assimilate Inuit through education has had dramatic impacts upon subsequent generations, the legacies of which are still being experienced. The inter-generational impacts of Inuktitut suppression in day and residential schools are vast and rippling. For instance, consider Cindy's situation. Her mother attended school in the settlement where she was forbidden to speak Inuktitut. The Elder narratives also confirm this suppression of language and the often brutal physical and emotional consequences that resulted if the students did not comply. As a result, Cindy's mother learned to be ashamed of her language and subsequently did not teach Cindy to speak Inuktitut. Now, as an adult Cindy is reclaiming her links to language by attending classes held at the OICC. Furthermore, her children attend the cultural programs offered at the OICC (e.g. Headstart program) where they are being taught to speak Inuktitut. Due to the programs and services offered by local Inuit organizations like the OICC, Inuit residing in the city are able to reclaim the aspects of their identity and counteract colonial legacies.

The issue of language is particularly significant for Inuit being raised outside the North. There are also a growing number of Inuit who are born and raised in the southern cities (i.e. the children of migrants), as well as those that have been adopted into southern families (Patrick and Tomiak, 2008). In some cases, children are being raised households where there are no Inuktitut speakers. Thus, for individuals who do not have the opportunity to learn to speak Inuktitut in the home, having access to cultural 
programming through Inuit organizations is critical in order for younger generations of urban Inuit to have fluency in Inuktitut.

Language, in particular, was highlighted as having special significance in terms of both legitimizing the identity claims of urban Inuit, but also their acceptance by other Inuit, a finding supported by Patrick and Tomiak (2008). Unlike Cindy who grew up without access to Inuktitut classes, in Ottawa, Inuit children have access to Inuit-specific educational programming through the Ottawa Inuit Children's Centre (OICC). In 2010, the OICC began Ontario's first Inuit Kindergarten program in partnership with the Ottawa-Carleton District School Board (OCDSB). The pilot program is the first of its kind in any southern Canadian city and focuses on teaching children about Inuit identity, culture and values. There are fifteen students, aged 4 to 5 , who attend the full day program. In the classroom there are two teachers, one from the OCDSB and an OICC Inuit cultural teacher. In addition, the OICC run other programs, such as the Sivummut Head Start program for children from 18 months old to six years old. The Sivummut Head Start Program is part of the Aboriginal Head Start Initiative administered and funded by the Public Health Agency of Canada (PHAC). The intention behind this program is to assist in creating a beneficial and supportive learning environment for Aboriginal, preschool aged children and their families that is culturally appropriate, and to give children an educational 'head start'. In terms of language and cultural literacy, the programs offered by the OICC were highlighted by the participants as invaluable to the cultural education of their children, which would have been impossible to access in any other southern Canadian city. In addition to creating links to the land, as this thesis shows, recent research by Patrick et al., (2013) that shows Inuit-centred literacy activities can be 
a driving force for family literacy policy, linking people to urban Inuit educational centres, such as the OICC, and to their urban and Arctic Inuit families and homelands.

This section discusses how participants create connections to the land through language, and demonstrate the significant role local Inuit organizations play in providing cultural and language programming that is, to this day, unique to Ottawa. The next section highlights the important connection between land and identity.

\subsection{The Land and Identity}

Based on the narratives it is evident that the issue of Inuit identity as it relates to the land is complex. As discussed in Chapters 1 and 2, government intervention into Inuit lives during the mid-twentieth century-namely through the creation of northern settlements and the implementation of Westernized day and residential school programs - altered the historical relationship Inuit possessed with the land to thousands of years. This removal from the land, combined with the assimilation philosophies perpetuated in schools, not only interrupted the transmission of land-based knowledge between generations, but also served to sabotage Inuit identity. The narratives describe the intergenerational consequences of subjugating Inuit culture and identity to that of southern Canadian society, for example, the tendency of some Inuit to dissociate from their culture. However, significantly, the narratives also show the efforts of Inuit to reclaim not only their links to land and land-based knowledge, but also their sense of Inuit identity.

The narratives demonstrate that links between the land and identity are created in various complex ways; for example, through memory, language, country food, cultural 
knowledge and practices, and self-identification. I argue that, in Ottawa, local Inuit organizations play a key role in providing culturally-specific programs that not only create links to land and land-based knowledge, but also serve to fortify Inuit identity. These findings support the work of Patrick and Tomiak (2008) that shows local Inuit organizations, through their programs and services, provide younger generations of Inuit being raised in Ottawa, in particular, the skills and knowledge needed to legitimate their identity claims.

The narratives provide further insights into the complex nature of Inuit identity and how it is conceived of within urban contexts, and extends previous work done by Patrick and Tomiak (2009) for Ottawamiut, and work by Kishigami (2002) relating to Inuit residing in Montréal. The narratives strongly echo the sentiments of Newhouse (2010: 33), who maintains that his '[...] life in the city has not made [him] less of an Aboriginal person. It has made [him] a different Aboriginal person". This perspective asserts that urban Indigenous experiences do not lessen Indigeneity but rather adds to it.

Specifically, the narratives show a distinction between the identity construction processes experienced by Inuit who were raised in the North (e.g. Elders) and those primarily raised in the South. For instance, let us consider the Elders in the study. Despite living in the south for decades, none of the Elders doubted their sense of Inuit identity, nor did they believe their identity had changed over time. They identified as 'Inuit', rather than 'urban Inuit', and saw no distinction between themselves and their northern counterparts. Living in the South was overwhelmingly acknowledged as being a distinct experience from life in northern communities; however, such differences were not viewed to impact their sense of Inuit identity. For the Elders, their sense of identity was 
rooted in being raised in the North (in other words, "I am Inuit because I come from 'such-and-such' community), in their lineage (in other words, 'I am Inuit because I have Inuit parents'), and in the distinctness of Inuit culture and values as compared to those of mainstream society. It is clear that Elders draw upon cultural memory (Assman, 2010, 2011; as discussed in Chapter 2) to construct their sense of identity. In terms of identity construction, cultural memory preserves the store of knowledge from which a group derives an awareness of its unity and peculiarity (Assmann, 2011). As shown in the narratives, the objective manifestations of cultural memory are defined through a kind of identificatory determination in a positive ("We are this") or in a negative ("That is our opposite") sense (ibid.). This definition is useful in the way that it highlights the push and pull, the negotiation, that exists within a cultural group that is in the process of defining itself, as are urban Inuit living in Ottawa.

In contrast, the process of identity construction is not as straightforward for participants who were raised, either fully or partially, in the South. For instance, some participants had no direct knowledge of, or contact with, northern communities; some were of mixed parentage (i.e. did not possess the physical characteristics commonly associated with 'looking Inuit'); and were raised in a 'multi-ethnic' urban setting strongly influenced by mainstream culture and values. For these individuals, being Inuit was not necessarily a given, but rather linked to a process of becoming. These findings are supported by work by Hall (1990: 225) who states that cultural identities are a matter of 'becoming' as well as 'being'; they have history, and like everything historical they undergo transformation. Based on the narratives, participants that were primarily raised outside the North viewed their process of 'becoming' Inuit as far more challenging than 
for their northern counterparts. Participants perceived that northern Inuit take their claims of cultural identity for granted. Also, participants felt like they were constantly being compared to northern Inuit; that is, northern Inuit were the standard against which southern Inuit were measured. Connected to the idea of 'urban' Inuk is the idea of 'real' Inuk. For Inuit in the Arctic, an authentic or 'real Inuk' possesses the cultural and linguistic knowledge necessary to pursue a traditional way of life based on traditional harvesting practices (Patrick, et al, 2010: 71). For Inuit raised in urban settings 'northern' practices and knowledge are desirable forms of cultural capital that validate identity claims (ibid.:80). Thus, as southern-dwelling Inuit, the participants believed they had to work to develop their sense of Inuit identity in order to prove themselves as worthy of belonging. For instance, participants in this study described how eating country food, sewing, drumming, throat signing, among others, were ways in which they learned about and connected with Inuit culture.

The process of 'becoming' is further complicated by the fact that these individuals live immersed in mainstream society which does not reflect Inuit culture or values, and in fact is often hostile towards them (see Patrick et al., 2010 for similar reports). In addition, despite their efforts to 'belong', urban Inuit often experience judgement by Elders and/or recent migrants.

All of these factors contribute to the formation of a distinct 'urban Inuk' identity that is perceived as a distinct experience as compared to being a 'northern Inuk'. Here, as in work by Flynn (2010), the 'urban' in 'urban Inuit' reflects the significance of urban as an identity marker as defined by the people themselves. By identifying as urban, these individuals are giving voice to their particular experiences, while also asserting their 
claims to Inuit culture and identity. Participants who identified as urban Inuit see themselves as being comfortable within urban environments, while also feeling connected to Inuit culture. They see themselves as having 'the best of both worlds' and the freedom to 'find out what works for them' in terms of incorporating Inuit culture into their urban lives. As Inuit living in Ottawa, participants felt like they belonged to a legitimate and established southern Inuit community that is diverse and distinct. Local Inuit organizations are credited with facilitating community development in Ottawa, and for providing vital services, without which many participants assert their process of 'becoming' Inuit would not have been possible, findings which extend previous work by Patrick and Tomiak (2009).

These findings support other research that asserts that the notions of transformation and continuity are central to the identity experience of urban Indigenous people; however, transformation is often perceived as oppositional to tradition (Howard and Proulx, 2010). Rather than be oppositional to tradition, as we have seen in this thesis, change or transformation may be perceived as grounded in continuity. Similarly, tradition is central to processes of 'becoming' for Indigenous people in cities. That is, perceptions of the past are themselves an important dynamic in emerging identities (Howard and Proulx, 2010: 11) particularly for younger generations being raised in urban settings. Some Indigenous people bring relatively complete forms of specific cultural knowledge and practice with them when they move to cities, like the Elders in this study (ibid.). Those traditions are then subject to the creative, tactical, and strategic ways in which Indigenous cultures are being produced and performed in cities. As demonstrated by the Inuit participants in this thesis who were raised in the south, 'becoming' Inuit can be a 
process involving multiple pathways that are distinctly urban. Thus, this research supports work by (Patrick et al., 2010: 81) that states rather than doing things 'wrong', urban Inuit are enriching what it means to be Inuit.

Patrick et al. (2010) point out that understanding the tensions which exist between community members is particularly relevant to understandings of community building:

While there might be a noticeable tension between Northern- and Southern-born Inuit, based on their geographic, historical, and cultural positioning, there are nevertheless community-based processes that unify Inuit as a recognizable, important force in the urban Aboriginal landscape. Tensions between desired forms of symbolic capital that Northern-raised Inuit possess (linguistic and cultural knowledge that could define "authentic Inuitness") versus that of Southern-raised Inuit (the language, literacy, and social capital necessary for urban life) might create a boundary between community members, but the boundary is fluid and becomes more salient at certain times than others (2010: 72).

Despite the diversity and complexity of the community, urban Inuit have unified and mobilized for particular social and community services (Patrick et al., 2010: 72). This research argues that connections to the land and land-based knowledge and practice provide common ground which draws Inuit living in Ottawa together, in ways that overcome differences, and act as a unifying force. Based on the narratives, it is evident that Inuit specific community based service agencies, such as the Ottawa Inuit Children's Centre and Tungasuvvingat Inuit, enable Inuit residents of Ottawa to re-territorialize their links to land, culture, and identity through urban place-making efforts which transform urban space into 'Inuit place'. These safe cultural places within the city come to represent an extension of Inuit lands and the cultural meanings, knowledge, and practices associated with the land. Furthermore, community centres provide urban Inuit with the cultural knowledge and support necessary to develop positive identities. Through Inuit 
community centres urban Inuit are able to acquire valuable social and cultural capital which validate their identity claims, while also finding a community to belong to.

For Inuit living in Ottawa, connections between the land and Inuit culture are largely facilitated through local Inuit organizations. The significance of these urban places and their role in facilitating connections to Inuit land will be further examined in the following section.

\subsection{The Land and Local Inuit Organizations}

Based on the narratives, for Ottawamiut, urban place-making is key to creating connections to Inuit land and land-based knowledge and cultural practices. Connections to land and culture are in large part facilitated through the programs and services provided by Inuit-specific community-based service agencies (or 'community centres'). This thesis argues that these 'Inuit places', that is, safe places of cultural inclusion, come to represent an extension of the land within urban space, and the cultural meanings, knowledge, and practices associated with it.

The notion of safe space/place is significant to urban Indigenous people who are often subjected to racism and discrimination (Peters, 2012). The narratives in this study reveal that the participants often deal with racism and discrimination as part of their urban experiences, and thus, as argued by this thesis, having access to safe places of cultural inclusion are key to their participation in culturally significant practices which reinforce links to land, without fear of judgement.

Connections to Inuit lands and culture are created in various ways through the diverse programs and services offered by community centres. For instance, direct 
connections to land are made through the consumption of country foods provided by community centres; through the facilitation of Inuktitut language classes; through cultural programs which connect Elders with youth; through the performance of cultural practices such as, throat signing, drumming, carving, sewing, among others.

While creating links to land and culture is important to the success of the wider Ottawamiut community, it is of particular significance for urban Inuit who have little or no direct knowledge of the North. Whereas, for instance, an Elder may recall the first time they tasted seal meat as being during a camping trip on the land, for an urban Inuit youth chances are they were exposed to country food at a community centre (e.g. at school or a community event). Many participants feel that by settling in Ottawa they have provided their children with the best opportunities to learn about Inuit culture outside the North.

In addition, Inuit specific community-based service agencies are credited for building social networks which help to create a sense of a legitimate and functional 'urban Inuit community' in Ottawa, a finding that agrees with work by Patrick et al., (2010). In Ottawa, the centrality of identity-based institutions in constructing 'community' for urban Inuit cannot be overstated (Patrick et al, 2010), particularly for the ways they foster links to land create Inuit place within an urban setting (this thesis). This contrasts to the perspective that "there really is no such thing as an urban Aboriginal community" (Hasselmann, 2001: 20), a misconception which often arises from the difficulty in defining in a fixed way the nature of urban Indigenous communities which tend to exists as a fluid, non-geographically bounded entities (Lobo, 2001). 
Similar to friendship centres which have met the cultural, social, and recreational needs of urban Aboriginal peoples (RCAP, 1996, vol. 4: 565), this thesis demonstrates that local Inuit organizations in Ottawa have acted to establish an urban Inuit presence in a culturally diverse urban centre, while also acting as a mechanism for community building through the delivery of a variety of programs and services. Similarly, Patrick (2010) states the 'community' has no precise geographic location, but rather is visible as a social network in which community-based service agencies and the programs and services they provide, act as key nodes.

\subsection{The Evolution of 'Inuit places' in Ottawa}

The oral histories presented in this thesis provide unique and detailed insights into the evolution of the Ottawa Inuit community and of 'Inuit place' over time. As told in the Elders narratives, the Inuit community in Ottawa started out with very humble beginnings, as a handful of Inuit informally gathering in each others' homes. However, over the last few decades, Ottawa Inuit community has grown and the services provided by local Inuit organizations has expanded, making it easier for migrants access services to ease their transition to urban life.

When community centres first began in Ottawa, their focus was on helping newcomers adjust to life in the city through the delivery of services related primarily to housing, employment, and education, while also trying to help build social connections between Inuit living outside of the north. As the urban Inuit community in Ottawa has evolved, so too has the role of community centres. Today, Inuit community centres in 
Ottawa still provide essential services to newcomers, but have moved far beyond, in order to meet the social and cultural needs of the community.

Just as the construction of an Inuit 'community' in Ottawa is fluid, so too is the construction of 'Inuit places'. Like Massey (1994), this thesis adopts a progressive understanding of place-making, and argues that local Inuit organizations in Ottawa are 'Inuit places' which are open, hybrid, and porous, and are the product of multiple mobilities, identities, and intersecting histories, especially given the diversity of the Inuit population in Ottawa.

However, the social construction of place does not necessarily put it at odds with notions of groundedness and rootedness (Tuan, 1974; Relph, 1976), as is often argued (Hubbard et al., 2004; Hubbard et al., 2008). Inuit community centres are able to be fluid, while at the same time providing community members with a sense of belonging, attachment, and meaning which they themselves identify as beneficial to their urban lives. For instance, participants noted it was easy to feel lost, disconnected, and extremely lonely in Ottawa, especially when arriving from smaller northern communities. For many urban indigenous peoples, cultural and social isolation (e.g. the culture shock the participants cited as an early challenge) can often occur when individuals move from small communities where almost every face is known to the relative anonymity of the city (RCAP, 1996; Newhouse and Peters, 2003; Lawrence, 2004; Pittawanakwat, 2008). Urban alienation is magnified for urban Indigenous peoples who live in cities where they do not have the opportunity to participate in cultural and social events (ibid). Participants often described Inuit community centres as their 'home away from home'. For migrants, building a sense of community is crucial to developing a sense of belonging in their new homes (Hage, 
2010). Often identified as key to building community is the establishment of shared space, where one recognizes people as "one's own" and where one feels recognized by them as such (ibid.).

Through this transformation of abstract urban space into the felt experience of place (Tuan, 1977), Inuit residents living in Ottawa actively make place for themselves, their families and their community, which improves the quality of their lives in the city. For instance, participants who had lived in other southern Canadian cities before settling in Ottawa, remarked how their experiences were far richer in Ottawa, due in large part to the sense of community local Inuit organizations facilitate through the programs and services they provide. This sense of community and access to Inuit specific programs and services greatly influenced their reasons for choosing to settle in Ottawa as opposed to another urban centre, in order to raise their families. Through their associations with local Inuit organizations, Ottawa in a larger sense begins to feel like home. Community-based service agencies, such as Tungasuvvingat Inuit and the Ottawa Inuit Children's Centre, were identified as significant places for creating connections to Inuit lands and culture.

This argument is supported by the work of Patrick and Tomiak (2008) which demonstrates for Inuit living in Ottawa, "Inuitness" is re-territorialized through spaces and processes that symbolically, if not physically, connect urban Inuit to home communities and Inuit Nunaat. The urban Inuit spaces that are created and used as sites in this process are of particular importance. National organizations like Inuit Tapiriit Kanatami and Pauktuutit Inuit Women of Canada, as well as local organizations such as Tungasuvvingat Inuit, and the Ottawa Inuit Children's Centre, foster a growing sense of collectivity in Ottawa by acting as central nodes in these urban networks. They produce a 
sense of locality that explicitly includes the Inuit Nunaat, rendering migrants "rooted" in more than one society.

Similarly, other urban Indigenous groups in Canada have been actively promoting the creation of their own institutions such as Friendship Centres, as well as cultural activities such as round dances, powwows, and pipe and sweat lodge ceremonies (RCAP, 1996; Anderson, 2000; Newhouse and Peters, 2003; Lawrence, 2004; Warry, 2007; Pittawanakwat, 2008; Simpson, 2008).

The narratives presented in this study challenge discourses which assert connections to land are reserved for Indigenous people who live 'on the land' in rural or reserve communities (see Chapter 2). Discourses regarding Indigenous connections to land tend to have a traditional resonance which promotes particular forms of identity, agency, and solidarity. 'Authentic' Indigenous people have been perceived individually and collectively in the imaginations of dominant societies as natural, unchanging, spiritual beings who belong outside the modern colonial project of 'the city' (Jacobs, 1996). This static perception of Indigenous cultures is not only entrenched in dichotomies that oppose Indigenous and urban, the holders of these perceptive uncritically accept a hierarchal arrangement of Indigenous culture on a rural to urban lineal decline (Howard and Proulx, 2010).

Such perceptions contextualise the presence of Indigenous people in cities in terms of cultural loss or between-two-worlds syndrome which claim that constant interaction with non-Indigenous culture and lack of access to land, elders, Indigenous languages, and ceremonies are assumed characteristics of urban Indigenous life. This 
type of discourse, what Newhouse (2010: 35) calls a "study in lack", dominated the historical literature on urban Indigenous people. Newhouse notes until fairly recently, through the work of Indigenous and like-minded scholars, has the urban environment begun to be characterised in positive terms. This emerging area of scholarship demonstrates that urban experiences have not resulted in a loss of Indigeneity, but rather represent an addition to it.

In the case of land, when one looks beyond the restrictive boundaries predicated by highly politicised binaries, it becomes apparent that rather than be seen as extinguished, Indigenous connections to land need to be seen as complex in urban settings (Howard and Proulx, 2010; emphasis added). That is, rather than contributing to the essentialism which helped exclude Indigenous presence in cities, urban Indigenous relationships to land and culture have been shown to contribute to health and well-being of their communities and to the 'alternative futures' they aspire to achieve (RCAP, 1996).

This research contributes to a growing, body of literature which demonstrates many Indigenous people residing in cities actively make urban space their place; placemaking which allows for both the transformation and continuation of relationships to the land (Fogel-Chance, 1993; Lee, 2003; Wilson and Peters, 2005; Watson, 2010).

The narratives demonstrate that the land continues to be of significance to urban Inuit and this significance is passed on to younger generations of Inuit being raised in Ottawa. This chapter illustrates the significance of the land is a symbol with various physical, social, cultural and psychological meanings. The participants connected to the land primarily through memory, storytelling, country food, cultural practices and 
language. For urban Inuit, having the opportunity to acquire land-based cultural knowledge and practices helps to provide them with the skills and knowledge which can be used to legitimize their identity claims. In Ottawa, connections to the land are largely facilitated through local Inuit organization, like Tungasuvvingat Inuit and the Ottawa Inuit Children's Centre. These centres facilitate the creation of 'Inuit place' out of abstract urban space. These 'Inuit places', that is, safe places of cultural inclusion, come to represent extensions of the land within urban space, and the cultural meanings, knowledge, and practices associated with it.

\subsection{Land and Urban Inuit Rights}

Connected to issues of land and identity for Ottawamiut, is the matter of urban Inuit rights. The issue of urban Inuit rights and representation by national level Inuit organizations featured as an underlying tension throughout this work. Based on the narratives, it is evident that the process of identity formation (i.e. the process of 'becoming' and 'being') for urban Inuit is often complex and can be challenging to negotiate within multi-ethic, urban environments; nevertheless, one of the primary ways urban Inuit connected to land and Inuit culture was through self-identification. Despite their strong sense of Inuit identities, however, the participants reported being marginalized, particularly by national level Inuit organizations, such as Inuit Tapiriit Kanatami, which is mandated to represent all Inuit residing in Canada, yet which tends to overlook urban Inuit issues and concerns. The participants also expressed frustration at being unjustly excluded by northern governments, that restrict their access to educational funding, and extinguish their ability to vote in northern elections. 
While the participants believed national level Inuit organization are aware of the situations being faced by urban Inuit residing in southern Canadian cities, they do not feel represented by them. This perspective is consistent with findings of the Urban Aboriginal Task Force (2007) which found that even though national level Aboriginal organizations are headquartered in Ottawa, they are often not perceived to represent the interests of local Aboriginal communities. Unfortunately, this lack of consideration by national level Inuit organizations sends negative messages to urban Inuit regarding their identities. In other words, urban Inuit often feel their voices are not being heard by national level organizations because they are not perceived as 'real Inuit' as compared to their northern counterparts. As discussed earlier, this is similar to the alienation many urban Inuit feel as compared to their Elders or recent migrants from the North, who are perceived as having the skills and knowledge to validate their identity claims. Whether consciously or unconsciously, by not giving equal voice to urban Inuit rights and issues, national level organizations are reinforcing colonial notions of what qualifies as Inuit space and place in Canada (e.g. Indigenous and urban are mutually exclusive). By remaining solely focused on the North, they not only restrict Inuit identities, but they ignore the contemporary realities of thousands of Inuit residing in southern, urban centres. Whether intentional or not, the lack of consideration to the representation of urban Inuit issues on the part of national level Inuit organization leaves ample room for misunderstanding and mistrust to grow.

In Ottawa, national level organizations (like Inuit Tapiriit Kanatami and Pauktuutit Inuit Women of Canada) are able to claim support toward urban Inuit through their association with community-based organizations like Tungasuvvingat Inuit (TI) and 
the Ottawa Inuit Children's Centre (OICC). For instance, in the case of ITK, it is understood that they support urban Inuit issues indirectly through their association with Tungasuvvingat Inuit ${ }^{65}$ (i.e. participation on the Board of Directors). This tendency to default responsibilities onto local level Inuit organizations appears to be indicative of the current level of engagement and involvement of national level organizations with regards to urban Inuit issues. However, this tendency is not only problematic, it is ineffective. First, local Inuit organizations in Ottawa have a good grasp of the interests of local people; however, this does little to speak of the situation of Inuit living in other cities across Canada (e.g. Montréal, Winnipeg, Edmonton, St. John's, etc). Given the previous discussion on the complexity of urban Inuit communities, it cannot be assumed that Inuit communities in other Canadian cities will have the same needs and interests as Inuit living in Ottawa. Second, local level organizations lack the visibility and advocacy power of national level organizations. This therefore begs the question: Whose responsibility is it to represent the interests of urban Inuit across Canada, if not national level Inuit organizations, such as ITK and Pauktuutit? Does the responsibility of representation fall solely on the shoulders of local Inuit organizations which currently operate under strained conditions (i.e. under-funded and under-staffed)?

The issue of representation is a matter currently being grappled with by national level organizations, but to date such considerations have resulted in no tangible actions or solutions. For instance, consider the following statement given NTI President, Jim Lyall, who asserts that in order for ITK to maintain its strength in the future, it must begin to respect the voices of urban Inuit:

\footnotetext{
${ }^{65}$ In researching this topic, I became confronted with the tendency of national level organizations (e.g. ITK, Pauktuutit, NTI, Makavik) to defer inquiries regarding urban Inuit to local level Inuit organizations.
} 
Currently the national Inuit representational landscape includes ITK, ICC-Canada, the National Inuit Youth Council ${ }^{66}$, and Pauktuutit Inuit Women of Canada. In the next 40 years, our population will grow considerably and there will be more and more urban Inuit whose voices must be respected. [...]If we are not diligent in representing all of our Beneficiaries, there will be those people that seek alternatives to the current models. We must do everything we can to protect the concept of one national voice for Canadian Inuit, always ensuring that our representation is an unbroken chain from Inuit communities to ITK and ICCCanada. If we do not protect this model, our representational role can be questioned. ${ }^{67}$ (emphasis added; )

As implied the quote above, this research asks when will ITK expand its concept of 'Inuit homeland' to meet the contemporary situation of Inuit living outside of the North? When will national organizations like ITK, which arguably has to greatest advocacy power to lobby in support of Inuit issues, add southern urban communities to the tally of Inuit communities they claim to represent?

In fairness, it is acknowledged that ITK has the great task of representing pressing issues including the assertion of Canadian sovereignty in the North and control over the North West Passage and "Inuit waterways", climate change and degradation, threats to animal (and human) populations in the north, chronic housing shortages, substance abuse, and social and educational problems, to name but a few - thus, it is understandable that resources for urban Inuit are limited (Patrick and Tomiak, 2008: 9). However, despite acknowledging "that this is an area that is growing and that needs more attention" (Patrick and Tomiak, 2008: 9) there remains a serious gap between such statements and

\footnotetext{
67 'What is the role of ITK in the post land claims era and what are the challenges that lie ahead?'. Accessed April 23, 2012 (http://www.tunngavik.com/?s=urban+lnuit)

${ }^{68}$ Quote given by Mary Simon President of Inuit Tapiriit Kanatami, originally cited in Patrick and Tomiak, 2008
} 
meaningful action. According to recent statistics, over a quarter of the Inuit population of Canada now reside in cities, with population numbers increasing with every passing year (Statistics Canada, 2006). If this is true, the matter of urban Inuit presentation will become more difficult to ignore.

The issue of urban Inuit representation is further complicated by the current political and economic climate in Canada. The Canadian federal budget for fiscal year 2012-2013 was presented to the Canadian House of Commons by Finance Minister Jim Flaherty on 29 March 2012. The austerity budget outlined several cutbacks which will impact Aboriginal and Inuit organizations, in some cases severely. For instance, in the case of the National Aboriginal health Organization (NAHO), the government cut all of its $\$ 5$ million of federal funding, resulting in the closure of NAHO scheduled for June $30^{\text {th }}, 2012$. NAHO has been operating for 12 years with the mandate to work to advance the health of First Nations, Métis and Inuit people in Canada. Inuit Tuttarvingat is the separate branch dedicated to addressing the specific health needs of Inuit. NAHO has produced more than $\$ 60$ million in information on First Nations, Métis and Inuit health, including reports, databases, journals and video footage, with an estimated 2,000 to 3,000 health documents available on its website. The organization also produced what Simon Brascoupé, NAHO's chief executive officer, calls "groundbreaking" research and reports on health in the Arctic, such as the impact of overcrowded housing on children's health and a smoking cessation program. NAHO is currently looking for partners in academia 
or elsewhere to assist in the preservation of its vast repository of Indigenous-specific health information ${ }^{69}$.

These were not the only budgetary cuts to negatively impact Inuit health programs and research. Health Canada cut Inuit Tapiriit Kanatami's health budget by $40 \%$. This translates into a loss of $\$ 1.5$ million dollars a year, for the next two years. President of ITK, Mary Simon, described the reductions in funding as 'unconscionable' stating that:

The cuts to Health Canada will have an impact on ITK's ability to effectively represent . [...] These cutbacks to ITK's health capacity will severely reduce the ability of Inuit to participate, even in a modest way, in the development of policies and programs aimed at combating enormous health challenges experienced so graphically in Inuit regions, communities and families. [...]This is particularly unfortunate in light of the attention given by Canadian courts in recent years as to the duty of the Crown to consult closely with Aboriginal peoples and to seek to accommodate our Aboriginal rights and interests ${ }^{70}$

Similar budget cutbacks fell upon Pauktuutit Inuit Women of Canada, as they were notified that the First Nations and Inuit Health Branch of Health Canada (with whom they have partnered with over the past three decades) would no longer support the organization's Inuit-specific health projects ${ }^{71}$.

Budget restraints will not only reduce the capacity of these national level organization (i.e. loss of funding, reduced staff), but under increased strain, these organizations are potentially even less likely to begin addressing the issues of urban Inuit

\footnotetext{
69 "National Aboriginal Health Organization's funding cut" . Accesssed April 23, 2012. http://www.cbc.ca/news/canada/north/story/2012/04/09/north-naho-funding-cut.html

70 "Inuit Describe Health Canada Cuts as Unconscionable". Accessed April 23, 2012. http://www.itk.ca/media-release/inuit-describe-health-canada-cuts-unconscionable

71 "Funding for Pauktuutit's National Inuit Health Projects Eliminated". Accesssed April 23, 2012. http://pauktuutit.ca/index.php/funding-for-pauktuutits-national-inuit-health-projects-eliminated
} 
in any meaningful way. Without additional support the issues of Inuit residing in cities will continue to be marginalized as compared to their northern counterparts.

In summary, based on the narratives presented in this thesis, it is clear that not only is the land significant to Ottawamiut, but connections to the land are complex. Elders and younger generations of Inuit alike highlight the importance of the land as a means of history, knowledge, values, cultural practices, language, country food and identity. Within urban environments connections to the land and the various meanings, knowledge and cultural practices associated with it, are fostered through urban placemaking efforts. That is, local Inuit service agencies enable Ottawamiut to re-territorialize their links to land, culture and identity. Ottawa remains unique in terms of the cultural programs and services available to urban Inuit through local service agencies. The significance of local Inuit organizations goes beyond the programs and services they provide; they are also play a critical role in representing and addressing the issues of urban Inuit which are largely unaddressed by national level organizations like Inuit Tapiriit Kanatami. However, given the current economic climate in Canada, and the drastic cuts that other Indigenous organizations have been subjected to recently, the stability and viability of these local organizations is in no way guaranteed. 


\section{Chapter 7}

\section{Summary and Conclusion}

\subsection{Summary and Conclusion}

According to the 2006 Canadian Census, $22 \%$ of Inuit lived outside of Inuit homeland regions, representing an increase of approximately $60 \%$ from a decade earlier. Inuit living in urban areas represent approximately $17 \%$ of the total Inuit population in Canada, and this proportion is expected to grow. In the Census, Ottawa was reported to have the largest population of Inuit residents with 725 individuals. However, according to Inuit-specific community-based service agencies, the actual population of Inuit residents is likely closer to 2000 individuals based on their interactions with the community.

Whether northern- or urban-dwelling, Inuit possess strong physical, sociocultural, and spiritual connections to the land. These connections are rooted in the history of Inuit as Arctic peoples who have hunted, travelled, and lived in close relationship with the land for millennia. However, unlike the other urban Indigenous people, who are able to move between their city and urban residences with relative ease, Inuit living in the south have greater geographic and economic hurdles to overcome in order to visit their northern communities.

This research asks: (1) what is the significance of 'nuna' (the land) to Inuit residents of Ottawa?; (2) what role does urban place-making play in fostering connections to the land, and the cultural meanings, practices, values associated with the land?; and (3) what role have local and national Inuit organizations, including political 
and community-based institutions, played in fostering Inuit connections to land and cultural identities?

To date, this thesis represents the only body of work which examines the significance of the land to urban Inuit as a central focus, revealing in-depth, intergenerational narratives and analysis. Based on the rich, insightful and compelling narratives presented in this thesis, I argue and demonstrate that:

(1) the land or nuna plays a significant role in the lives of Ottawamiut participants in this study;

(2) the land continues to be of significance for Ottawamiut between generations (i.e. the inter-generational significance of the land);

(3) urban place-making efforts are key to fostering meaningful connections to the land within this urban setting; and

(4) local Inuit organizations, in particular, facilitate connections to the land, thereby transforming abstract urban space into Inuit place-that is, safe places of cultural inclusion - where Ottawamiut are able to engage with land-based cultural knowledge and practices in ways that are both beneficial and relevant to their urban lives.

(5) furthermore, local Inuit organizations play a key role in representing the rights and issues of urban Inuit, which are in large part ignored by national Inuit organizations.

I demonstrate that Ottawa Inuit are a diverse group, who are drawn to Ottawa for a variety of reasons ( e.g. following a friend or relative, to seek better education and employment, drawn by growing Inuit community and services provided by location of 
local and national Inuit organizations), in addition to there being an increasing number of Inuit residents being born and raised in the city.

I argue that the common ground which draws this diverse and growing population of individuals together is their deep rooted connections to the land, a connection that is part of the collective, cultural memory and identity of Inuit whether northern or southerndwelling.

I show that for Ottawamiut, symbolic connections to the land are made through the transfer of Inuit knowledge, cultural practices, country food, language, and identity. Critical to all of these is the ability to gather and share. In Ottawa, local Inuit organizations, through the culturally-specific programs and services that they provide, not only serve to build community, but also, as this thesis shows, foster connections to the land that extend its meanings, practices and values, in ways that are relevant to the urban lives of the participants. These organizations enable Ottawamiut who use their services to 're-territorialize' their links to land, culture, and identity through urban place-making efforts which transform abstract urban space into 'Inuit place'. This network of 'Inuit places', that is, safe places of cultural inclusion, come to represent extensions of the land within urban space, and the cultural meanings, knowledge, and practices associated with it. For urban Inuit who have been raised in the south, this social and cultural capital helps to legitimate their identity claims. In addition, local Inuit organizations are credited with building social networks which help to create a sense of a legitimate and functional urban Inuit community in Ottawa. 
Through the richness of the narratives, I also demonstrate in this thesis the evolution of Inuit places in Ottawa, thereby providing insights into how and why the Ottawamiut community has been able to flourish over time, as compared to other Inuit populations in other southern Canadian cities (e.g. Montréal, Winnipeg, Edmonton). In Ottawa, the development of local Inuit organizations was strongly dependent upon critical mass, grassroots leadership, sources of funding, and community engagement. These insights may provide useful information that can be used for the establishment of local Inuit organizations in other southern Canadian cities.

Based on the narratives presented in this thesis, it is evident that the value of local Inuit organizations in Ottawa cannot be overstated for the support that they provide in terms of community building and culturally-specific programs and services. Within these Inuit places, residents are able to build social networks and engage in land-based cultural knowledge and practices which enable them to make meaningful connections to the land that are both beneficial and relevant to their urban lives. However, a lack of adequate and consistent funding remains a major obstacle to the consistent delivery of programs and services which meet the specific needs of the Ottawamiut community. Similarly, inadequate funding presents a major obstacle to the establishment of viable Inuit-specific community-based service agencies in other Canadian cities (e.g. in Montréal, Winnipeg, Edmonton). Without consistent and adequate funding local Inuit organizations in Ottawa will continue to operate under strain, and be limited in the types of programs and services that they provide to the community.

This thesis also identifies many of the needs and concerns of urban Inuit living in Ottawa, which tend to be poorly understood in researcher and underrepresented in the 
literature pertaining to urban Indigenous experiences. In particular, this thesis shows the importance of urban Inuit rights and representation, and their struggle to gain visibility and recognition by national Inuit organizations. Local Inuit organizations play an important advocacy role in representing the issues of urban Inuit which are largely ignored by more national level Inuit organizations. This thesis raises important questions about, if and how, national Inuit organizations plan to address the needs of urban Inuit, as their populations in southern cities continues to grow. This thesis argues that there is a larger role to play for national level Inuit organizations, like ITK, who are mandated to represent the interests of all Inuit residing in Canada. Support and lobbying power of national level Inuit organizations like ITK could not only aid in the establishment community-based Inuit organizations across Canada, but could also support their longterm viability in an increasingly uncertain economic climate. However, without this type of action urban Inuit risk remaining largely invisible and marginalized as compared to their northern counterparts.

While it is well-known in the literature pertaining to urban Indigenous experiences, that being 'urban' and Indigenous were often purported as mutually exclusive (see Chapter 2; McClintock, 1995; Jacobs, 1996 ; Peters, 1996; 1998, 2000, 2002; Todd, 2001; Newhouse and Peters, 2003; Das Gupta, 2007), this thesis contributes to a growing body of literature which demonstrates that urban Indigenous connections to the land are complex and poorly understood in research. By showing how Ottawamiut participants create links to the land through their engagement with Inuit knowledge, cultural practices, country foods, language and identity-links which are largely facilitated by local Inuit organizations--this research furthers understandings of how 
urban Inuit 'make place' for themselves in Ottawa in ways that extend land meanings, thereby transcending supposed geographic boundaries of North and South, and/or urban and rural.

\subsection{Future Directions}

Research which examines the experiences of urban Inuit is an emerging area of study which will only increase in relevance as various push-pull factors (see Chapter 1) continue to influence Inuit to migrate South. Thus, this represents an opportunity for researchers and community members to collaborate together on issues that are of mutual interest and benefit. This research opens the door to many possibilities. As discussed in Chapter 3, there are certain silences present in this work. For instance, the lack of male participants in this study. Understanding if and how Ottawamiut males connect to the land would add richness to this area of research. Of particular interest, would be investigating why there is an apparent under-representation of Inuit men and local Inuit organizations, both as service providers and as clients. Is there something about these places that exclude male presence? Or is building social networks and community viewed as more of a female role? How do men make contributions to the wider community?

Also as discussed in Chapter 3, is the fact that not all Inuit residents of Ottawa make use of the programs and services offered by local Inuit organizations. As Tomiak (2011) notes, while on the surface access to services for urban Indigenous peoples may seem readily available in cities, in reality, many experience social and geographic realities that limit their access to culturally relevant services. Although figuring out how to access these individuals would be a challenge, it would be interesting to see how their 
urban lives fare as compared to Ottawamiut who do access services. Does accessing services make them more or less vulnerable? Are there individuals that have more economic and social stability and therefore do not feel the need to access services, as was suggested in Elder Sally's narrative? Or perhaps there are individuals who are more vulnerable, such as homeless Inuit, who for whatever reason are not able to make use of services? What more can be done by local Inuit organizations to reach the wider community and further develop social networks?

This research presents a case study of Inuit living in Ottawa. However, as stated in the thesis, there are urban Inuit communities being established in Montréal, Winnipeg, Edmonton, Yellowknife and St. John's. It would be interesting to examine the urban place-making efforts of Inuit in these other cities and see how this compares with the situation of Ottawamiut. This research shows why Inuit community building and urban place-making efforts have been successful in Ottawa, which leads to the questions of why local Inuit institutions in other cities have not experienced similar successes. Case studies in other cities, based on the oral history narrative approach employed in this study, may reveal the answer to these questions.

The further documentation of urban Elder life histories in Ottawa remains a worth-while collaboration which could benefit the community, and enrich current understandings of urban Inuit experiences - in particular, by including other regional perspectives, such as Elder narratives from Nunavik, and the Inuvialuit region.

Continuing to understand the inter-generational significance of the land, for instance, to Inuit children who are being raised in Ottawa, will highlight how 
relationships to the land change over time, and thereby enrich Inuit conceptualizations of 'nuna'.

In addition, as southern urban Inuit communities become more established across Canada, the matter of urban Inuit representation and rights warrants further attention.

Other areas of research which could be developed include: Inuit homelessness, housing issues, food security, urban Inuit identity and community development. Gaining these perspectives will contribute to fuller understandings of urban Inuit experiences. 


\section{References}

Agnew, John A. 1987. Place and politics: the geographical mediation of state and society. Boston: Allen \& Unwin.

Agnew, John A., and Duncan, James S. 1989. The Power of place : bringing together geographical and sociological imaginations. Boston: Unwin Hyman.

Ajunnginiq Centre. 2008. Homelessness and housing realities for Inuit: background for discussion. National Aboriginal Health Organization.

AMAP, 2003. AMAP Assessment 2002: Human Health in the Arctic, Arctic Monitoring and Assessment Programme (AMAP), Oslo, Norway.

Andersen, C., \& Denis, C. (2003). Urban native and the nation: Before and after the Royal Commission on Aboriginal Peoples. Canadian Review of Sociology and Anthropology, 40 (4), 373-390.

Anderson, B. 2008. For Space: Doreen Massey. In: Bird, Jon. 1993. Mapping the futures : local cultures, global change. London ; New York: Routledge. Pgs: 225-233.

Anderson, K. 2000. A recognition of being reconstructing native womanhood. Toronto [Ont.]: Sumach Press.

Anderson, $\mathrm{K}$ and Jacobs, J. From urban Aborigines to Aboriginality and the city: one path through the history of Australian cultural geography. Australian Geographical Studies, 35(1): 12-22.

Assmann, J. 2010. Communicative and cultural memory. In: Erll, A., and Niinning, A.

(Eds).2010. A Companion to Cultural Memory Studies. De Gruyter: Berlin, New York. Pgs: 108-118.

Assmann, J. 2011. From Moses and the Egyptians: the memory of Egypt in western monotheism and "Collective Memory and Cultural Identity." In: Olick, J.K., Vinitzky-Seroussi, V., and Levy, D. (Eds) 2011. The Collective Memory Reader. Oxford University Press: Oxford, New York. Pgs.: 497.

Backhouse, C. 1999. Colour-coded: A legal history of racism in Canada, 1900-1950.

Toronto:University of Toronto Press.

Beilin, R. 2005. Photo-elicitation and the agricultural landscape: 'seeing' and 'telling' about farming, community and place. Visual Studies, 20 (1): 56-68. 
Bennett, J., and Rowley, S (eds). 2004. Uqalurait: An Oral History of Nunavut. Québec: McGill-Queen's University Press.

Berkes, Fikret, and Arctic Institute of North America. 2005. Breaking ice : renewable resource and ocean management in the Canadian north. Vol. 7. Calgary: University of Calgary Press.

Bielawski, E. 2003. Rogue Diamonds: Northern Riches on Dene Land. Seattle: University of Washington Press.

Biernacki, P., and D. Waldorf. 1981. Snowball sampling: Problems and techniques of chain referral sampling. Sociological Methods Research, 10: 141-163.

Bjerregaard. P., Young, T.K., Dewailly, E., Ebbesson, S. V. 2004. Review Article:

Indigenous health in the Arctic: an overview of the circumpolar Inuit population. Scandinavian Journal of Public Health. 32 (5): 390-395.

Borré, K. 1994. The healing power of the seal: the meaning of Inuit health practice and belief. Arctic Anthropology 31(1): 1-15.

Boult, D. A. 2004. Hunger in the Arctic: Food (In)security in the Arctic. Ajunnginiq Centre. National Aboriginal Health Organization. (http://www.naho.ca/inuit/english/documents/FoodSecurityPaper_final.pdf)

Bradshaw, M and Stratford, E. 2005. Qualitative research design and rigour. In: Hay, I. (ed). 2005. Qualitative Methods in Human Geography. Oxford University Press, Melbourne. Second edition. Pgs: 67-75.

Brooks, C., Poudrier, J and Thomas-MacLean, R. 2008. Creating collaborative visions with Aboriginal women: a photovoice project. In: Liamputtong, P (ed). Doing CrossCultural Research: Ethical and Methodological Perspectives. Springer.

Bryman, Alan, and Burgess, Robert G. 1994. Analyzing qualitative data. London; New York: Routledge.

CACAR, 2003. Contaminant Levels, Trends and Effects in the Biological Environment. Edited by A. Fisk, K. Hobbs, and D. Muir. Ottawa: Department of Indian and Affairs and Northern Development.

Campbell, H. 2001. Urban Inuit artists, Inuit Art Quarterly, 16(2): 4-10. 
Canadian Institutes of Health Research, Natural Sciences and Engineering Research Council of Canada, and Social Sciences and Humanities Research Council of Canada, Tri-Council Policy Statement: Ethical Conduct for Research Involving Humans, December 2010.

Carpenter, M. Urban Inuit. Inuktitut, 76: 62-69.

Chaumel, G. The Aboriginal community of Montréal. Rencontre, 14(4): 10-12.

Clifford, J. 2001. Indigenous articulations. The Contemporary Pacific, 13(2): 468-490.

Counihan, C., and Van Esterik, P. 2008. Food and Culture: A Reader. Routledge: New York.

Cresswell, Tim. 2004. Place : a short introduction. Malden, MA: Blackwell Pub.

Damas, D. 2002. Arctic Migrants/Arctic Villagers: The Transformations of Inuit Settlement in the Central Artic. McGill-Queen's University Press, Montréal, Kingston. Pp 277.

Das Gupta, T., James, C.E., Maaka, CA., Galabuzi, G.E., Andersen, C. (eds). 2007. Race and racialization. Toronto: Canadian Scholar's Press.

Denzin, N.K., Lincoln, Y.S., and Tuhiwai-Smith, L. 2008. The Handbook of Critical and Indigenous Methodologies. Los Angeles: Sage.

Donaldson, SG. 2007. The role of local renewable resources in the health and well-being of Inuit living in Cape Dorset, Nunavut, Canada. Ph.D. Thesis. Carleton University, Ottawa, Ontario, Canada.

Dirlik, A. The past as a legacy and project: postcolonial crticisms on the perspective of Indigenous historicism. American Indian Culture and Research Journal, 20(2): 1-31.

Dowling, R. 2005. Power, subjectivity, and ethics in qualitative research. In: Hay, I. (ed). Qualitative Methods in Human Geography. Oxford University Press, Melbourne. Second edition. Pgs: 19-28.

Dunn, K. 2005. Interviewing. In: Hay, I. (ed). Qualitative Methods in Human Geography. Oxford University Press, Melbourne. Second edition. Pgs: 79-103.

England, K. 1994. Getting Personal: Reflexivity, Positionality and Feminist Research. The Professional Geographer, 46(1): 80-89. 
Erll, A., and Niinning, A. (Eds). A Companion to Cultural Memory Studies. De Gruyter: Berlin, New York. Pgs.: 441.

Fixico, D.L. 2000. The Urban Indian Experince in America. Albuquerque: University of New Mexico Press.

Flax, J. 1992. The end of innocence. In: Butler, L., and Scott, J.W. (eds). 1992. Feminists Theorize the Political. New York: Routledge.

Flynn, L. 2010. Plains Indians Ways to Inter-tribal Cultural Healing in Vancouver. In:

Howard, H. and Proulx, C. (eds) 2011. Aboriginal peoples in Canadian cities : transformations and continuities. Waterloo, Ont: Wilfrid Laurier University Press. Pg: 249.

Fogel-Chance, N. 1993. Living in both worlds: 'modernity' and 'tradition' among North Slope Inupiaq women in Anchorage. Arctic Anthropology, 30: 94-108.

Freeman, M.M.F. 1993. The International Whaling Commission, small-type whaling, and coming to terms with subsistence. Human Organization 52: 243-251.

Frideres, J.S. 1998. Aboriginal Peoples in Canada: Contemporary Conflicts. Fifth edition. Scarborough: Prentice Hall and Bacon Canada.

Gill, L. 1995. From the Reserve to the City: Amerindian Women in Québec Urban Centres. Ottawa, Status of Women Canada.

Goldie, Terry. 1989. Fear and temptation: the image of the indigene in Canadian, Australian, and New Zealand literatures. McGill-Queen's University Press: Kingston.

Government of Canada. 2005. Tri-Council Policy Statement: Ethical Conduct for

Research Involving Humans. Panel on research Ethics. (http://pre.ethics.gc.ca/eng/policy-politique/tcps-eptc/)

Greenop, K. 2009. Place Meaning, Attachment and Identity in Indigenous Inala,

Queensland. Conference paper, Australian Institute of Aboriginal and Torres Strait Islander Studies Conference, Canberra, 2009.

Grygier, P.S. 1994. A Long Way from Home: the Tuberculosis Epidemic Among the Inuit. Montréal: McGill-Queen's University Press. 
Hage, G. 2010. Migration, food, memory, food and home-building. Chapter 28 in: Radstone, S., and Schwarz, B. 2010. Memory: Histories, Theories, Debates. Fordham University Press: New York. Pgs. 561.

Hall, S. 1990. Cultural Identity and Diaspora. In: Rutherford, J. (ed). 1990. Identity: Community,

Culture, and Difference. London: Lawrence \& Wishart. Pgs.:222-237.

Hall, R. 2012. Diamond mining in Canada's Northwest Territories: a colonial continuity. Antipode. Early View. doi: $10.1111 / \mathrm{j} .1467-8330.2012 .01012 . x$

Hanselmann, C. 2001. Urban Aboriginal People in Western Canada: Realities and Policies. Calgary, Canada West Foundation.

Haraway, D. 1991. Simians, Cyborgs and Women: The Reinvention of Nature, New York: Routledge, and London: Free Association Books.

Harvey, D. 1993. From space to place and back again. In: Bird, Jon. 1993. Mapping the futures : local cultures, global change. London ; New York: Routledge. Pgs: 3-29.

Hay, I. (ed). 2005. Qualitative Methods in Human Geography. Oxford University Press, Melbourne. Second edition.

Helin, C. 2006. Dances with Dependency: Indigenous Success through Self-Reliance. Vancouver: Orca Spirit Publishing and Communications.

Howard, H. and Proulx, C. (eds) 2011. Aboriginal peoples in Canadian cities : transformations and continuities. Waterloo, Ont: Wilfrid Laurier University Press.

Howard, H. And Proulx, C. 2010. Transformations and Continuities: An Introduction. In: Howard, H. and Proulx, C. (eds) 2011. Aboriginal peoples in Canadian cities : transformations and continuities. Waterloo, Ont: Wilfrid Laurier University Press. Pg. 1

Howard, H. 2010. The Friendship Centre: Native People and the Organizations of Community in Cities. In: Howard, H. and Proulx, C. (eds) 2011. Aboriginal peoples in Canadian cities : transformations and continuities. Waterloo, Ont: Wilfrid Laurier University Press. Pg: 87. 
Howitt, R. and Stevens, S. (2005). Cross-cultural research : Ethics, methods, and relationships. In Hay, I. (ed). Qualitative Methods in Human Geography. Oxford University Press, Melbourne. Second edition. Pgs: 30-50

Hubbard, P., Kitchin, R.M. and Valentine, G., (eds). 2004. Key Contemporary Thinkers on Space and Place. London: Sage.

Hubbard, Phil, Kitchin, Rob, and Valentine, Gill. 2008. Key texts in human geography. Los Angeles: Sage.

Indian and Northern Affairs. 2008. Canada's Relationship with Inuit: A History of Policy and Program Development. Inuit Relations Secretariat: Ottawa.

Inuit Tapiriit Kanatami. 2004.5000 Years of Inuit History and Heritage. Ottawa, On. http://www.itk.ca/publications

Inuit Tapiriit Kanatami. 2007. Inuit Statistical Profile. Ottawa, Ontario.

Inuit Tapiriit Kanatami and Inuit Circumpolar Conference. 2007. Building Inuit Nunaat: The

Inuit Action Plan. Ottawa, Ontario.

Inuit Tapiriit Kanatami and Nunavut Research Institute. 2007. Negotiating Research Relationships with Inuit Communities: A Guide for Researchers. Pp 38.

Jacobs, J.M. 1996. Edge of Empire: Postcolonialism and the City. London: Routledge. Jones, A., and Jenkins, K. 2008. Rethinking collaboration: working with the indigenecolonizer hyphen. In: Denzin, N.K., Lincoln, Y.S., and Tuhiwai-Smith, L. 2008. The Handbook of Critical and Indigenous Methodologies. Los Angeles: Sage. Pg: 471-486.

Kishigami, N. 1999. Why do Inuit move to Montréal? A research Note on Urban Inuit. Etudes/Inuit/Studies, 23(1-2):221-227.

Kishigami, N. 2002. Inuit identities in Montréal, Canada. Etudes / Inuit / Studies. Vol. 26(1):183-191.

Knotsch, C and Akalehiywot, M. 2008. Housing as a determinant of health: annotated 
bibliography. Inuit Tuttarvingat. National Aboriginal Health Organization. (http://www.naho.ca/inuit/e/whatsnew/documents/2009FinalAnnotatedBibliograp hy.pdf)

Kovach, M.R. 2009. Indigenous Methodologies: Characteristics, Conversations and

Contexts. Toronto: University of Toronto Press.

Korsmeyer, C. (Ed). 2005. The Taste Culture Reader: Experiencing Food and Drink. Berg: Oxford, New York.

Krupnik, I., and Jolly, D (eds). 2002. The Earth is Faster Now: Indigenous Observations of Arctic Environmental Change. Vol. Fairbanks, Alaska: Arctic Research Consortium of the United States.

Kuhnlein, H.V., and Chan, H.M. 2000. Environment and contaminants in traditional food systems of northern indigenous peoples. Annual Review of Nutrition 20, 595-626.

Kulchyski, Peter K., and Tester, Frank J. 2007. Kiumajut (talking back) : game management and Inuit rights, 1900-70. Vancouver: UBC Press.

Kushwaha, A. 2007. Monitoring environmental change using Inuit Qaujimajatuqangit in Cape Dorset, Nunavut. Unpublished MA Thesis. Carleton University: Ottawa.

Lawrence, B. 2004. "Real" Indians and Others: Mixed-blood Urban Native Peoples and Indigenous Nationhood. Lincoln: University of Nebraska Press.

Lee, M. 2002. "How will I sew my baskets?": women vendors, market art, and incipient political activism in Anchorage, Alaska. American Indian Quarterly, 27(3-4): 583-593.

Lobo S. and Peters, K. (eds). 2001. American Indians and the Urban Experience. Lanham, Md.: Altamira Press.

Lobo, S. 2001. Is urban a person or a place? Characteristics of urban Indian country. In:

Lobo S. and Peters, K. (eds). 2001. American Indians and the Urban Experience. Lanham, Md.: Altamira Press. Pg.: 73-94.

Lobo, S. 2002. Urban Voices: The Bay Area American Indian Community. Tucson: The University of Arizona Press.

Manitowabi, D. 2010. Neoliberaism and the urban Aboriginal experience. In: Howard, H. and 
Proulx, C. (eds) 2011. Aboriginal peoples in Canadian cities : transformations and continuities. Waterloo, Ont: Wilfrid Laurier University Press.. Pgs."109-122.

Mannik, Hattie. (Ed). 1998. Inuit Nunamiut = Inland Inuit .Friesen Corporation:

Manitoba.

Mansvelt, J and Berg, L.D. 2005. Writing qualitative geographies, constructing geographical knowledges. Hay, I. (ed). Qualitative Methods in Human Geography. Oxford University Press, Melbourne. Second edition. Pgs: 248-264.

Massey, Doreen B. 2005. For space. London; Thousand Oaks, Calif.: Sage.

Massey, Doreen B. 1994. Space, place, and gender. Minneapolis: University of Minnesota Press.

Massey, Doreen B., and Jess, P. M. 1995. A Place in the world? places, cultures and globalization. Vol. 4. Oxford: Open University.

McClintock, Anne. 1995. Imperial leather : race, gender, and sexuality in the colonial contest. New York: Routledge.

McElroy, A. 2008. Nunavut Generations: Change and Continuity in Canadian Inuit Communities. Long Grove: Waveland Press.

McGhee, Robert, and Canadian Museum of Civilization. 2001; 1996. Ancient people of the Arctic. Pbk ed. Vancouver, BC: UBC Press.

Michael Q. P. 1990. Qualitative Evaluation and Research Methods : Newbury Park, CA: Sage Publications.

Miller, J.R. 2004. Lethal Legacy: Current Native Controversies in Canada. McClelland and Stewart. Pgs. 299.

Minch, K., Saudny, H., Lennie, C., Wood, M., Williamson-Bathory, L., Cao, Z., Egeland, G.M. 2011. Inuit housing and homelessness: results fron the International Polar Year Inuit Health Survey 2007-2088. International Journal of Circumpolar Health. 70 (5): 520-531.

Moller, H. 2010. Tuberculosis and colonialism: current tales about tuberculosis and colonialism in Nunavut. Journal de la santé autochtone. Janvier. National Aboriginal Health Organization. 
Morgan, D.L.2008. The SAGE Encyclopedia of Qualitative Research Methods. SAGE · Publications. Pp. 816-817.

Mullings, B. 1999. Insider or outsider, both or neither: some dilemmas of interviewing in a cross-cultural setting. Geoforum, 337-350.

Newhouse, D., and Peters, E. 2003. Not Strangers in These Parts: Urban Aboriginal Peoples. Ottawa: Policy Research Initiative.

Newhouse, D. 2010. Urban Life: Reflections of a Middle-Class Indian. In: Howard, H. and Proulx, C. (eds) 2011. Aboriginal peoples in Canadian cities : transformations and continuities. Waterloo, Ont: Wilfrid Laurier University Press. Pg.: 23.

Nuttall, Mark. 1992. Arctic homeland; kinship, community and development in northwest Greenland. London: Belhaven.

Olick, J.K., Vinitzky-Seroussi, V., and Levy, D. (Eds) 2011. The Collective Memory Reader. Oxford University Press: Oxford, New York. Pgs.: 497.

Olofsson, E. 2004. In Search of a Fulfilling Identity in a Modern World: Narrative of Indigenous Identities in Sweden and Canada. PhD dissertation, Uppsala University: Uppsala.

Oswalt, Wendell H. 1979. Eskimos and explorers. Novato, Calif.: Chandler \& Sharp. Ottawa Inuit Children's Centre. 2009. Nipivut, 'Our Voice': A Community Needs Assessment for Inuit Families in Ottawa. Final Report. Pp. 96.

Patrick, D and Tomiak, J.A. 2008. Language, culture and community among Inuit in Ottawa. Etudes/Inuit/Studies, 32(1): 55-72.

Patrick, D., Budach, G., and Muckpaloo, I. 2013. Multiliteracies and family language policy in an urban Inuit community. Language Policy, (12): 47-62.

Patrick, D., Tomiak, J.A., Brown, L., Langille, H., and Vieru, M. 2010. "Regaining the childhood I should have had" The Transformations of Inuit Idenities, Institutions, and Community in Ottawa. In: Howard, H. And Proulx, G. (eds). Aboriginal Peoples in Canadian Cities: Transformations and Continuities. Pg: 69-85. 
Patrick, D. Chapter Two: Inuitness and Territoriality in Canada. In: (In press) Forte, M.C. (Ed.). Who Is An Indian? Race, Place, and the Politics of Indigeneity in the Americas. University of Toronto Press.

Peters, E. J. 1996. Urban and Aboriginal: an impossible contradiction? In: Caulfield, J and Peake, L (Eds). City Lives and City Forms: Critical Research and Canadian Urbanism. Toronto: University of Toronto Press. Pg: 47-62.

Peter, E.J. 1997. 'Challenging the geographies of 'Indianess': The Batchewan Case'. Urban Geography, 18(1): 56-62.

Peters, E.J. 1998. Subversive spaces: First Nations women and the city. Environment and Planning D: Society and Space, 16: 665-685.

Peters, E.J. 2000. Aboriginal people and Canadian geography: a review of the recent literature. The Canadian Geographer, 44(1): 44-55.

Peters, E. 2004. Suzanne MacKenzie Memorial Lecture: Conceptually unclad: feminist geography and Aboriginal peoples. Canadian Geographer, 48(3): 251 -

Peters, E., and Laford, C. "I Basically Mostly Stick with my Own Kind": First Nations appropriation of Urban Space in Saskatoon, Saskatchewan. In: Peters, E.J. and Andersen, C. (eds.), Forthcoming, March 2012. Indigenous in the City: Contemporary Identities and Cultural Innovation. Vancouver: UBC Press.

Pitawanakwat. B. 2008. Bimaadziwin Oodenaag: a pathway to urban Nishnaabeg resurgence. Chapter 10 in: Simpson, L. (ed). 2008. Lighting the Eight Fire: The Liberation, Resurgence, and Protections of Indigenous Nations. Arbeiter Ring Publishing: Winnipeg. Pgs.: 161-173.

Poirier S, Brooke L. Inuit perceptions of contaminants and environmental knowledge in Salluit, Nunavik. 2000. Arctic Anthropology 37(2):78-91.

Price, J. 2008. Living Inuit governance in Nunavut. Chapter 7 in: Simpson, L. (ed). 2008.

Lighting the Eight Fire: The Liberation, Resurgence, and Protections of Indigenous Nations. Arbeiter Ring Publishing: Winnipeg. Pgs.: 127-138.

Radstone, S., and Schwarz, B. 2010. Memory: Histories, Theories, Debates. Fordham University Press: New York. Pgs. 561. 
Razack, 2007. When place becomes race. In: Das Gupta, T., James, C.E., Maaka, CA., Galabuzi, G.E., Andersen, C. (eds). 2007. Race and racialization. Toronto: Canadian Scholar's Press. Pg: 74-82.

Relph, E. C. 1976. Place and placelessness. Vol. 1. London: Pion.

Riewe, R., and Oakes, J. 2006. Climate Change: Linking Traditional and Scientific Knowledge. Aboriginal Issues Press: University of Manitoba.

Robinson, G.M. 1998. Methods and Techniques in Human Geography. John Wiley and Sons.

Rose, G. 1997. Situating knowledges: positionality, reflexivities, and other tactics. Progress in Human Geography, 21(3): 305-320.

Royal Commission Report on Aboriginal Peoples. 1996. (http://www.aincinac.gc.ca/ap/rrc-eng.asp)

Seamon, D and Sowers, J. 2008. Place and placelessness: Edward Relph. In: Bird, Jon. 1993. Mapping the futures : local cultures, global change. London ; New York: Routledge. Pgs: 44-51.

Simpson, L. (ed). 2008. Lighting the Eight Fire: The Liberation, Resurgence, and Protections of Indigenous Nations. Arbeiter Ring Publishing: Winnipeg. Pgs.232.

Szathmary, EJE, Ritenbaugh, C, Goodby, CSM. 1987. Dietary change and plasma glucose levels in an Amerindian population undergoing cultural transition. Social Science and Medicine 24(10):791-804.

Smith, D. (1993). The emergence of "Eskimo Status": An Examination of the Eskimo Disk List System and its social consequences, 1925-1970. In N. Dyck \& J. Waldram (Eds.), Anthropology, Public Policy, and Native Peoples in Canada (pp. 41-74). Montréal: McGill-Queens University Press.

Spradley, J.P. 1980. Participant Observation. New York: Holt, Rinehart and Winston.

Statistics Canada. 2006a. Aboriginal Peoples in Canada in 2006: Inuit, Metis, and First Nations, 2006 Census: Findings. (http://www12.statcan.ca/english/census06/analysis/aboriginal/surpass.cfm)

Statistics Canada. 2006b. Aboriginal Statistics Profile.

(http:/www12.statcan.ca/english/census06/analysis/aboriginal/inuit.cfm) 
Statistics Canada. 2006c. Aboriginal Peoples in Canada in 2006: Inuit, Metis, and First Nations, 2006 Census: Inuit population in urban centres has grown. (http://www12.statcan.ca/english/census06/analysis/aboriginal/inuit.cfm)

Statistics Canada (2008). Aboriginal Peoples in Canada in 2006: Inuit, Métis and First Nations, 2006 Census (Catalogue no. 97-558-XIE). Ottawa: Statistics Canada.

Steckley, J. 2008. White lies about the Inuit. Peterborough, Ont: Broadview Press. Pg. 168.

Stellick, P. March 2008. Personal communication.

Sutton, D. 2001. Remembrance of repasts: An anthology of Food and Memory. Berg: Oxford.

Suzuki, David, and Knudtson, Peter. 1992. Wisdom of the elders : honoring sacred native visions of nature. New York: Bantam Books.

Tester, F.J., and Kulchyski, P. 1994. Tammarniit (Mistakes):Inuit Relocation in the Eastern Arctic, 1939-63. Vancouver: UBC Press.

Tester, F.J. and Irniq. 2008. Inuit Qaujimajatuqangit: Social history, politics, and the practice of resistance. Arctic, 60 (1): 48-61.

Tesch R. 1990. Qualitative research: analysis types and software tools. New York: Falmer.

Thompson, Paul. (2000). Voice of the Past, The: Oral History. Oxford University Press.

Thompson, S. 2005. Aboriginal Arctic food security in a toxic world. In: Berkes, F, Huebert, R, Fast, H, Manseau, M, and Diduck, A (editors). Breaking ice: renewable resource and ocean management in the Canadian north. Vol. 7. Calgary: University of Calgary Press

Thouez, JP, Rannou, A, and Foggin, P. 1989. The other face of development: Native population, health status, and indicators of malnutrition-the case of the Cree and Inuit of Northern Québec. Social Science and Medicine 29(8): 965-74. 
Tobias, J. 1983. 'Protection, civilization, assimilation: an outline of Canada's Indian policy', in: Getty, A. And Lussier, A. (Eds) As Long as the Sun Shines and the Water Flows: A Reader in Canadian Native Studies. University of British Columbia Press, Vancouver, BC.

Todd, R. 2001. Between the land and the city: Aboriginal agency, culture and governance in urban areas. The London Journal of Canadian Studies, 16: 48-66.

Tomiak, J.A. 2011. Indigenous self-determination, neo-liberalism, and the right to the city: rescaling Aboriginal governance in Ottawa and Winnipeg. Unpublished $\mathrm{PhD}$ Thesis. Carleton University: Ottawa.

Tomiak, J.A. and Patrick, D. 2010. Transnational migration and indigeneity in Canada: a case study of urban Inuit. In: Forte, M.C (ed). 2010. Indigenous Cosmopolitans: Transnational and Transcultural Indigeneity in the Twenty-First Century. Pg: 127.

Tsetta S, Gibson G, McDevitt L and Plotner S (2005) Telling a story of change the Dene way: Indicators for monitoring in diamond impacted communities. Pimatisiwin: $A$ Journal of Aboriginal and Indigenous Community Health 3(1):59-69.

Tuan, Yi-fu. 1977. Space and place : the perspective of experience. Minneapolis: University of Minnesota Press.

Tuan, Yi-fu. 1974. Topophilia: a study of environmental perception, attitudes, and values. Englewood Cliffs, N.J.: Prentice-Hall.

Tuhiwai-Smith, L. 2007. Imperialism, history, writing and theory. In: Das Gupta, T., James, C.E., Maaka, CA., Galabuzi, G.E., Andersen, C. (eds). 2007. Race and racialization. Toronto: Canadian Scholar's Press. Pg: 328-338.

University of Victoria. Faculty of Human and Social Development. 2003. Protocols and Principles for Conducting Research in an Indigenous Context. (http://www.hsd.uvic.ca/policies/documents/igovprotocol.pdf)

Usher, P.J. 2000. Traditional ecological knowledge in environmental assessment and management. Arctic 53(2): 183-193.

Usher, P., Duhaine, G and Searles, E. 2003. The household as an economic unit in Arctic Aboriginal communities, and its measurement by means of a comprehensive survey. Social Indicator Research 61: 175-202. 
Warry, W. 2007. Ending Denial: Understanding Aboriginal Issues. Toronto: University of Toronto Press.

Wachowich, Nancy, et al. 1999. Saqiyuq : stories from the lives of three Inuit women. Montréal: McGill-Queen's University Press.

Watson, M. 2010. Diasporic Indigeneity: place and the articulation of Ainu identity in Tokyo, Japan. Environment and Planning A, 42: 268-284

Wenzel GW. 2004. From TEK to IQ: Inuit Qaujimajatuqangit and Inuit cultural ecology. Arctic Anthropology. 41(2): 238-250.

Wilson, K., and Peters, E.J. 2005. "You can make a place for it": remapping urban First Nations spaces of identity. Environment and Planning D: Society and Space, 23: 395-413.

\section{Websites:}

Baker Lake Arts: www.bakerlakearts.com

Edmonton Inuit Cultural Society: http://www.edmontoninuit.ca

Gignul Non Profit Housing Corporation: www.gignulhousing.org

Inuit Art Foundation: www.inuit art.org

Inuit Tapiriit Kanatami: www.itk.ca

ITK Website. About ITK. Accessed September $26^{\text {th }}, 2012$. https://www.itk.ca/about-itk Inuit Tuttarvingat: $\mathrm{http}: / / \mathrm{www} \cdot$ naho.ca/inuit

Inuit Tuttarvingat. Overview of Inuit health: access to health care. Accessed September $26^{\text {th }}$ 2012. http://www.naho.ca/inuit/overview-of-inuit-health/access-to-health-care

Inuit Tuttarvingat. Overview of Inuit health: education. Accessed September $26^{\text {th }} 2012$. http://www.naho.ca/inuit/overview-of-inuit-health/education

Inuit Tuttarvingat. Overview of Inuit health: income. Accessed September $26^{\text {th }}, 2012$ http://www.naho.ca/inuit/overview-of-inuit-health/income

Larga Baffin Home: www.largaweb.com 
Makivik Corporation: www.makivik.org

Manitoba Urban Inuit Association: http://www.manitobainuit.ca/en

National Association of Friendship Centres: www.nafc.ca

National Aboriginal Health Organization: www.naho.ca

Native Friendship Centre of Montréal: $\mathrm{nfcm}$. org

Nunavut Sivuniksavut: www.nstraining.ca

Nunavut Tunngavik Incorporated: www.tunngavik.com

Ottawa Inuit Children's Centre: www.ottawainuitchildrens.com

Pauktuutit Inuit Women of Canada: www.pauktuutit.ca

The Wabano Centre for Aboriginal Health: www.wabano.com

Tungasuvvingat Inuit: www.tungasuvvingatinuit.ca

Statistics Canada: http://www.statcan.gc.ca

St John's Native Friendship Centre: http://www.sjnfc.com

\section{Videos:}

Qallunajatut (Urban Inuk). [Montréal] : Igloolik Isuma Productions, 2005. 


\title{
Appendix A
}

\section{Ethics Clearance Form}

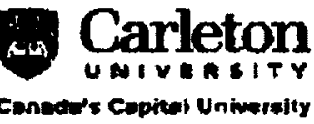

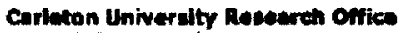 \\ Rustit: Ellins Exated \\ yth roor ory b. (ating \\ 112 s ciolone my lorve \\ Dilawe on Kis swe conse. \\ Tel: $5(3-500-2 a 12$ \\ fex: bis $5 \% 0252$
}

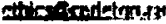

\section{Ethics Cloarance Form}

This in to cartify that twe Carlulon Universilty Research Ethics Ponrd hes axominud the applicolion lor othical rilarrensen. The REg found the rescorch project to meat appropriate ethical standorda as

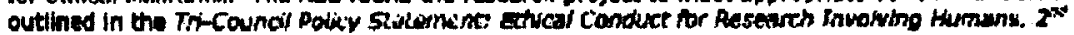

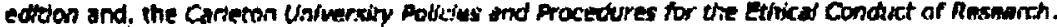

i Now ctevranee

X Remewal of oridind charaho

Orfolnal date of clearance: 7 April 2010

Dote of renewps 11 Mer 2012

Rowarehur Milte kuthweh

sxexus

Supervisor

runding status

Project numbe

Tilis of project

Mh.D. Eludent, Eeography and Rovironment-l fudius

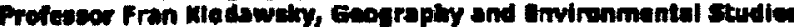

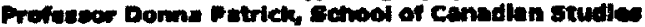

Non-tunded

$11-1482$

The alynitiennes of the land end urban plece-maling tro Iauk ling in

Ottawa, Grterlo, cannde

Clarrance expins: 31 Mrov 2013

Al reasurchers are gowerned by the following cenditans:

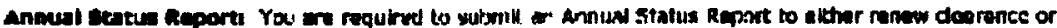

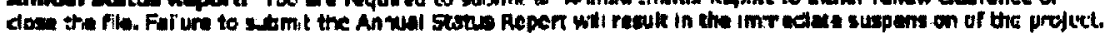

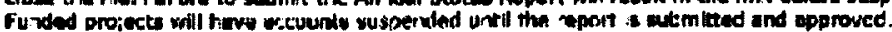

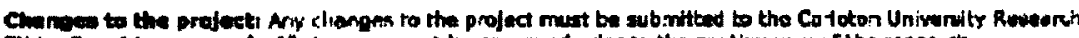

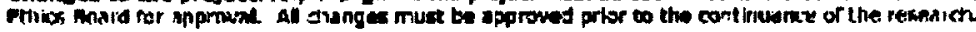

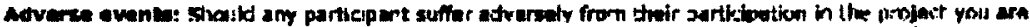

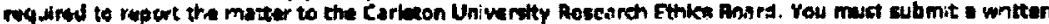

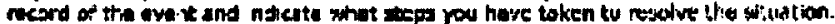

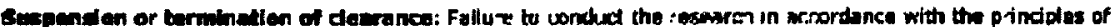

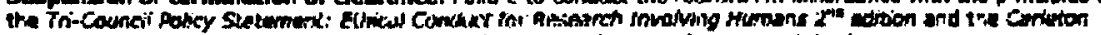

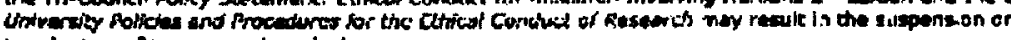
terminat on of tרe reses ch prejext.

Antonio R. Gualtiari, Chair

Carteton Uhlversity Research Ehics Rond 


\section{Appendix B}

\section{Consent Forms}

\section{Participant Consent Agreement for Project Entitled: "Ottawamiut: The Significance of the Land and Urban place-making for Inuit Living in Ottawa, Ontario.}

Anita Kushwaha, M.A., Ph.D. Candidate, Department of Geography and Environmental Studies, Carleton University, Ottawa, Ontario. E-mail:akushwah@connect.carleton.ca

\section{Introduction}

The purpose of this informed consent agreement is to inform you about this project and to ensure your rights and confidentiality.

\section{Project Summary}

My name is Anita Kushwaha. I am a third year doctoral student in the Department of Geography and Environmental Studies at Carleton University. As part of my doctoral work, I am interested in working with Inuit who have migrated from northern communities to live in the Ottawa area. The project I am proposing seeks to understand how changing relationships to the land impacts the everyday lives of Inuit living in Ottawa, Ontario. This research involves talking in-depth about reasons why Inuit migrate to southern cities, what challenges they face when they are transitioning to city life, and how they connect to Inuit culture while living in Ottawa. It is my hope that this research will help to shed light on the under-represented issues of Inuit living in urban areas, and that this deeper understanding will be used to better support their needs and concerns.

\section{Informed Consent Agreement}

I would like to invite you to participate in the project. Your participation in this project is completely voluntary. It is estimated that the interview will take roughly 1-2 hours at a location that is convenient to you. The interview will be conducted in English or Inuktitut, which ever language you prefer. If you would like to conduct the interview in Inuktitut, I will arrange for an interpreter to be present to translate our conversation. It is likely that we will need to have more than one interview session in order to have the time to talk about various topics. You have the freedom to determine how many sessions you want to participate in. There is no foreseen risk to you in participating in this study. You do not have to answer any questions which make you uncomfortable. If at anytime during the course of the interview you feel uncomfortable and wish to stop, let me know and we will end the interview immediately. If you chose to withdraw from the study, you may decide what is to be done with the data you have provided (i.e. destroy data or give permission to use data). 
This research will be conducted with your best interests in mind. Your name and information will be kept confidential. The interviews will be identified by date and time. The name of the participant will be kept in a separate notebook. Notebooks and tape recordings will be under lock and key at all times at my personal residence. The only people that will have access to the interviews will be me and my supervisors, Dr. Fran Klodawsky and Dr. Donna Patrick.

When the research project is completed, I will be presenting my findings to all participants in a summary report that shall be delivered to your place of residence.

If you have any concerns please do not hesitate to contact me by telephone at (613) 2302031, or by e-mail at akushwah@connect.carleton.ca. If you have further concerns you may contact: Dr. Fran Klodawsky, Associate Professor, Department of Geography and Environmental Studies, Carleton University, Ottawa, Ontario. Tel: (613) 520-2600, ext.: 8689. E-mail: fklodaws@connect.carleton.ca; or Dr. Donna Patrick, Professor, Department of Canadian Studies, Carleton University, Ottawa, Ontario. Tel: (613) 5202600 ext.: 8070. E-mail: donna_patrick@carleton.ca; or Professor Antonio Gualtieri, Chair, The Carleton University Research Ethics Committee, Office of Research Services, Carleton University, 1125 Colonel By Drive, Ottawa, Ontario, K1S 5B6. Tel: (613) 5202517. E-mail: ethics@carleton.ca.

\section{Informed Consent}

By signing below, you are acknowledging that you have been informed about this study and agree to participate.

I, wish to participate in this study.

(please print your name here)

Participant Signature Date

Do you wish your name to be listed in the acknowledgement section of the final report? Yes No Signature Date 
Key-informant Consent Agreement for Project Entitled: "Ottawamiut: The Significance of the Land and Urban place-making for Inuit Living in Ottawa, Ontario".

Anita Kushwaha, M.A., Ph.D. Candidate, Department of Geography and Environmental Studies, Carleton University, Ottawa, Ontario. E-mail: akushwah@connect.carleton.ca

\section{Introduction}

The purpose of this informed consent agreement is to inform you about this project and to ensure your rights and confidentiality.

\section{Project Summary}

My name is Anita Kushwaha. I am a third year doctoral student in the Department of Geography and Environmental Studies at Carleton University. As part of my doctoral work, I am interested in working with Inuit who have migrated from northern communities to live in the Ottawa area. The project I am proposing seeks to understand how changing relationships to the land impacts the everyday lives of Inuit living in Ottawa, Ontario. This research involves talking in-depth about reasons why Inuit migrate to southern cities, what challenges they face when they are transitioning to city life, and how they connect to Inuit culture while living in Ottawa. Another important dimension of this work relates to how urban Inuit concerns and needs are considered and represented by government and Inuit organizations. It is my hope that this research will help to shed light on the under-represented issues of Inuit living in urban areas, and that this deeper understanding will be used to better support their needs and concerns.

\section{Informed Consent Agreement}

I would like to invite you to participate in the project. Your participation in this project is completely voluntary. It is estimated that the interview will take roughly 1 hour at a location that is convenient to you. The interview will be conducted in English. There is no foreseen risk to you in participating in this study. You do not have to answer any questions which make you uncomfortable. If at anytime during the course of the interview you feel uncomfortable and wish to stop, let me know and we will end the interview immediately. If you chose to withdraw from the study, you may decide what is to be done with the data you have provided (i.e. destroy data or give permission to use data).

This research will be conducted with your best interests in mind. Your name and information will be kept confidential. The interviews will be identified by date and time only. The name of the participant will be kept in a separate notebook. Notebooks and tape recordings will be under lock and key at all times at my personal residence. The only 
people that will have access to the interviews will be me and my supervisors, Dr. Fran Klodawsky and Dr. Donna Patrick.

When the research project is completed, I will be presenting my findings to all participants in a summary report that shall be delivered to you.

If you have any concerns please do not hesitate to contact me by telephone at (613) , or by e-mail at akushwah@connect.carleton.ca. If you have further concerns you may contact: Dr. Fran Klodawsky, Associate Professor, Department of Geography and Environmental Studies, Carleton University, Ottawa, Ontario. Tel: (613) 520-2600, ext.: 8689. E-mail: fklodaws@connect.carleton.ca; or Dr. Donna Patrick, Professor, Department of Canadian Studies, Carleton University, Ottawa, Ontario. Tel: (613) 5202600 ext.: 8070. E-mail: donna_patrick@carleton.ca; or Professor Antonio Gualtieri, Chair, The Carleton University Research Ethics CommitteeThe Carleton University Research Ethics Committee, Office of Research Services, 511A Tory Building, 1125 Colonel By Drive, Ottawa, Ontario, K1S 5B6. Tel: (613) 520-2517.

\section{Informed Consent}

By signing below, you are acknowledging that you have been informed about this study and agree to participate.

$\mathrm{I}$ wish to participate in this study.

(please print your name here)

Participant Signature Date

Do you wish your name to be listed in the acknowledgement section of the final report?

Yes No Signature

Date 
Appendix C

List of Elder Participants

Table 1. List of Elder participants.

\begin{tabular}{lllll}
\hline Name & Sex & Age & Location of interview & Date \\
\hline & & & & \\
& & & & \\
$\begin{array}{l}\text { Ovilu } \\
\text { Goo-Doyle }\end{array}$ & F & $55-65$ & $\begin{array}{l}\text { Participant's home } \\
\text { (5 sessions) }\end{array}$ & $\begin{array}{l}\text { Jan 2011- } \\
\text { March 2011 }\end{array}$ \\
& & & & \\
\hline
\end{tabular}




\section{Appendix D}

\section{Guiding Questions for Oral Histories}

\section{Research Question 1) How do relationships to the land change for Inuit living in Ottawa, Ontario?}

Theme: Understanding urban migration and transition

Q: What northern community did you live in before moving to Ottawa?

Q: Why did you decide to move to Ottawa? How long have you lived in Ottawa?

Q: What were some of the greatest changes/challenges you had to face when you moved to Ottawa? How did you overcome these challenges?

Q: If you could compare them, what would be some of the some of the greatest differences between the environment in the north and the environment in Ottawa? Is your connection to the northern environment different than your connection to an urban environment like in Ottawa? If so, how?

Q: If you could compare them, what would be some of the greatest differences between your everyday life and experiences in the north and those in Ottawa?

Q: How did you connect to the land (nuna) when you lived in the arctic? Was this important to you? If so, why?

Q: What do you think it means to be an "urban Inuk"? Is being an urban Inuk different than being an Inuk from the north? Do you consider yourself to be an urban Inuk? 
Research Question 2) How do Ottawamiut connect to the land, and the practices, values, and meanings associated with the land while living in the city?

Theme: Examining meanings and connections to the land (nuna) in an urban context

Q: What does the land (nuna) mean to you? (e.g. physically, socially, culturally, spiritually significant?)

Q: Has the meaning of the land (nuna) changed for you now that you live in Ottawa? If so, how?

Q: Do you find ways of connecting to the land (nuna) and Inuit culture while living in Ottawa? How?

Q: Is maintaining a connection to the land (nuna) and Inuit culture important to you? Why or why not?

Q: How has living in Ottawa impacted your access to country food? How do you acquire country food? How often to do consume country food?

Theme: Examining social connections in both northern and urban contexts

Q: Are you able to visit your northern community? If so, how often do you visit, and for how long? How do you connect to the land when you visit your northern community? If not, what barriers prevent you from travelling north?

Q: How do you stay connected to your family and friends up north while living in Ottawa? 
Q: How do you stay connected to your family and friends that live in Ottawa?

Research Question 3) What role does urban place-making play in facilitating connections to the land for Ottawamuit?

Theme: Examining the significance of Inuit places and implications for health and wellbeing

Q: Are there places in Ottawa which help you connect to the land (nuna) and Inuit culture in Ottawa? If so, what/where are these places?

Q: How do these places help you connect to the land and Inuit culture in Ottawa? Are they important to you? Why? Are they important to your sense of health and well-being?

Q: Do you use services provided by Inuit and Aboriginal organizations in Ottawa? Which organizations?

Q: What programs, services, and events do you utilize most often? Are they important to you? Why? Are they important to your sense of health and well-being?

Q: Are there other services you would want provided?

Q: Has living in Ottawa had a positive or negative impact on your health and well-being? 
Appendix E

List of Participants from the Ottawa Inuit Community.

Table 2. List of participants from Ottawa Inuit community.

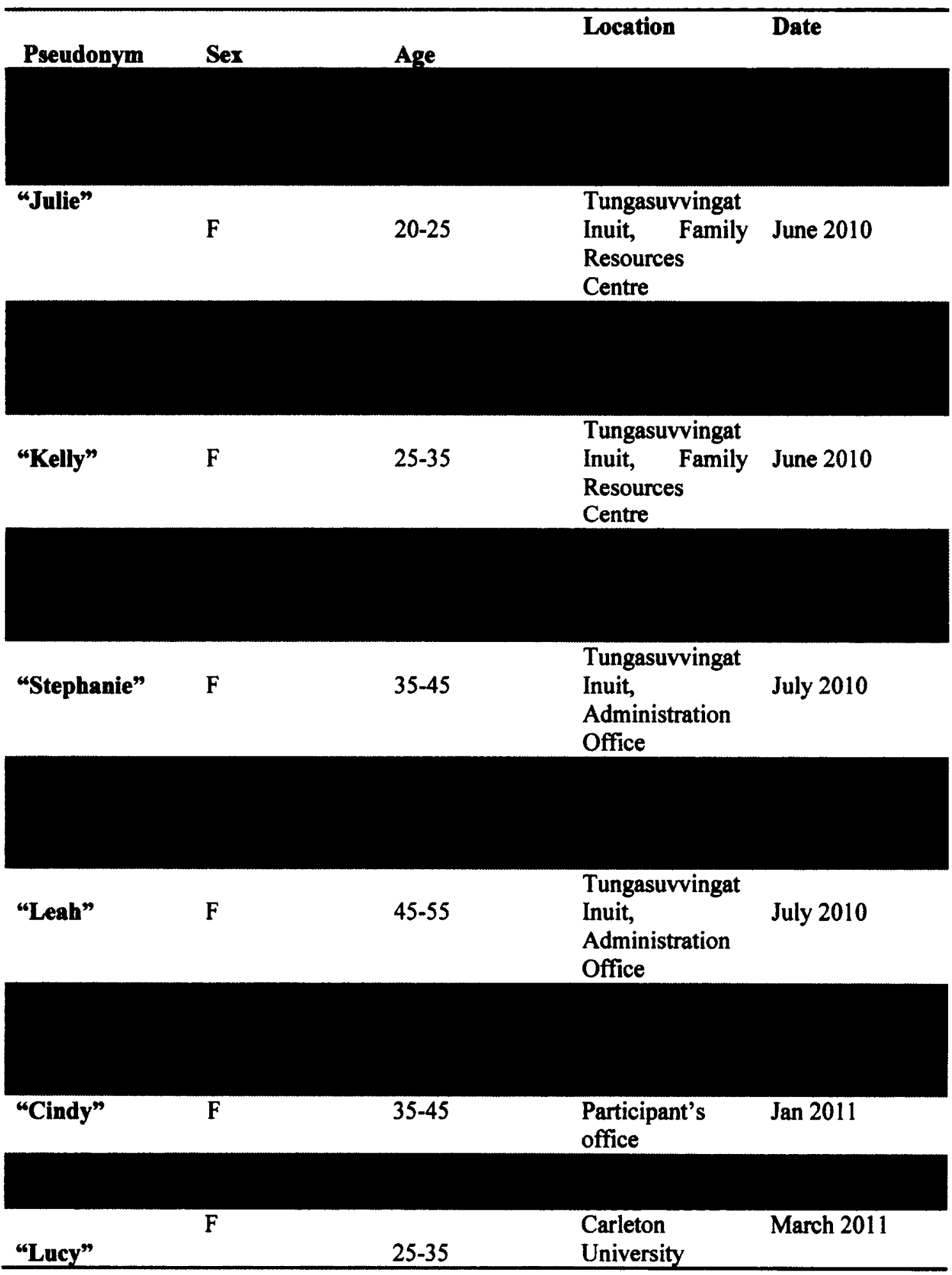




\section{Appendix F}

List of Key Informants from Government and Inuit Organizations

Table 3. List of key Informants from government and Inuit organizations.

\begin{tabular}{|c|c|c|c|}
\hline Name & Organization & $\begin{array}{l}\text { Location of } \\
\text { Interview }\end{array}$ & Date \\
\hline Sarah Cox & $\begin{array}{l}\text { Director of } \\
\text { Communications and } \\
\text { Outreach, Inuit Relations } \\
\text { Secretariat }\end{array}$ & $\begin{array}{l}\text { Inuit } \\
\text { Relations } \\
(\mathrm{X} 2)\end{array}$ & $\begin{array}{l}\text { July 2010; } \\
\text { Jan } 2011\end{array}$ \\
\hline Marc Maracle & $\begin{array}{lr}\text { Ottawa } & \text { Aboriginal } \\
\text { Coalition, } & \text { Aboriginal } \\
\text { Non-profit Housing Corp. }\end{array}$ & Telephone interview & July 2010 \\
\hline Mary Hutton & $\begin{array}{l}\text { Pre- and post natal care } \\
\text { program, Tungasuvvingat } \\
\text { Inuit, Family Resources } \\
\text { Centre }\end{array}$ & $\begin{array}{l}\text { Tungasurvingat Inuit, } \\
\text { Family Resources } \\
\text { Centre }\end{array}$ & June 2010 \\
\hline
\end{tabular}




\section{Appendix G}

\section{Interview Guide for Key Informants}

Q: What is your mandate in relation to "urban" Inuit? If urban Inuit issues are not a part of your mandate, would this be a possibility for the future? If urban Inuit issues are part of your mandate, is this considered a longstanding commitment?

Q: Does your (organization or department) view the issues of urban Inuit as a priority? Why or why not?

- If so, how are priorities relating to urban Inuit issues set? Are urban Inuit community members consulted? If so, what steps are involved in the consultation process?

Q: From your perspective, what are some of the key issues and concerns of Inuit living in Ottawa?

Q: Does your (organization or department) provide funding to community-based Inuit organizations in Ottawa?

- If so, how are funding priorities set? Are organizations consulted regarding their specific program and service needs? Is funding considered a longstanding commitment?

- If not, is this a possibility for the future?

Q: From your perspective, what efforts could your (organization or department) make in order to better support the growing needs of community-based Inuit organizations in Ottawa?

Q: Are urban Inuit issues represented in an equal manner, in comparison to their northern counterparts? Why or why not?

Q: Are urban Inuit issues represented in an equal manner, in comparison to other urban indigenous groups? Why or why not? 